\title{
An Engineer's Guide to Public Engagement in Renewable Energy Projects
}

by

Nathalin Moy

A thesis submitted to the Faculty of Graduate and Postdoctoral Affairs in partial fulfillment of the requirements for the degree of

\author{
Master of Arts \\ in \\ Sustainable Energy Policy
}

Carleton University

Ottawa, Ontario

(C) 2019, Nathalin Moy 


\begin{abstract}
This thesis examines the public engagement process for renewable energy projects, focusing on the extent to which public engagement factors into the technical design of the projects. This interdisciplinary research features a two-part literature review, summarizing the key academic literature on public engagement and engineering design, respectively. The resulting insights are distilled into eight guidelines directed to engineers looking or needing to incorporate public engagement into their design processes for renewable energy projects. A case study of the renewable energy landscape in Eastern Ontario under the Green Energy Act tests the validity and applicability of the guidelines. The analysis is based on consultation reports from eight solar and wind projects, supplemented by eight interviews with renewable energy stakeholders in the same geographical area. This research has implications for renewable energy projects, for policymakers, and for the engineering profession, particularly in the context of current initiatives to improve public engagement processes.
\end{abstract}




\section{Acknowledgements}

- Dr. Alex Mallett for teaching me the ropes of social science research

- Dr. Craig Merrett, P.Eng. for keeping me grounded in my engineering roots

- The interviewees for lending their time and expertise

- NEB Mod for the opportunity to see firsthand what the federal government is doing on public engagement

- Yogatown Ottawa for giving me a reason to leave my computer at least once a week

- My friends and family, both in Ottawa and Toronto, for helping me put things in perspective and keeping me from going insane

- Funding from the Ontario Graduate Scholarship and the School of Public Policy and Administration (note to the Tri-Agency: get on that multidisciplinary research funding!) 


\section{Table of Contents}

Abstract........................................................................................................................... ii

Acknowledgements .............................................................................................................. iii

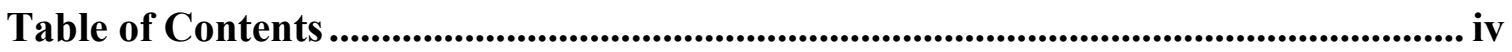

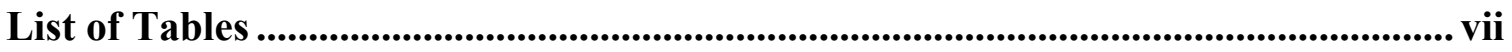

List of Figures.............................................................................................................................. viii

List of Acronyms ....................................................................................................................... ix

1 Introduction................................................................................................................ 1

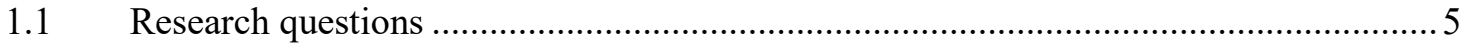

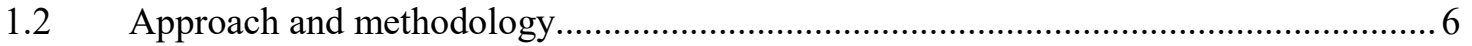

1.3 The policy cycle and the engineering design cycle - a primer ..................................... 8

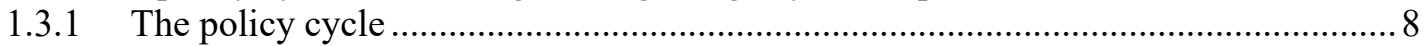

1.3.2 The engineering design cycle ......................................................................... 10

1.3.3 Comparing the two cycles .................................................................................. 12

2 Public Engagement - Literature Review ........................................................... 14

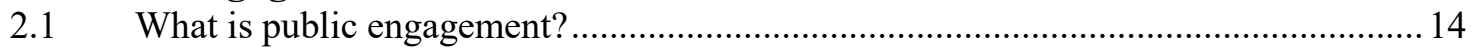

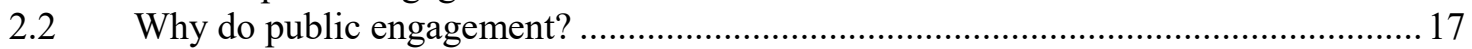

2.3 What is 'effective' and 'meaningful' engagement? ................................................. 19

2.4 Why are current engagement practices not effective/meaningful?............................22

2.4.1 The public as uninformed - the information-deficit model ..................................23

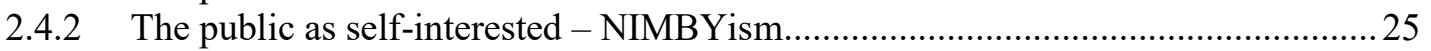

2.5 What factors are necessary for effective/meaningful engagement? ...........................27

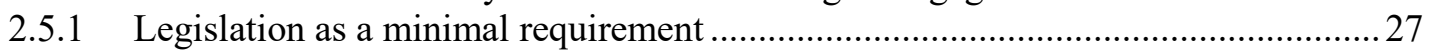

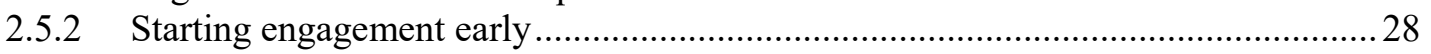

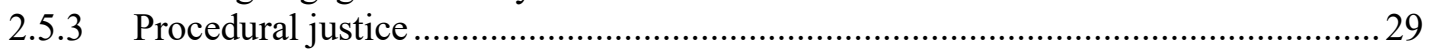

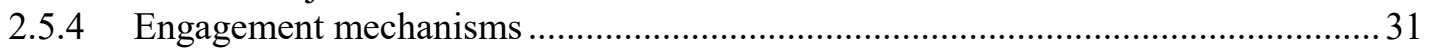

3 Engineering Design - Theory, Practice, and Education........................................... 36

$3.1 \quad$ Academic analysis of the engineering design process................................................36

3.2 Considering non-technical factors .......................................................................... 39

3.2.1 Considering the environment .......................................................................... 40

3.2.2 Considering sustainability ……………………………………………….... 42

3.2.3 Considering human behaviour ………………………....................................... 44

3.2.4 Insights from the various non-technical factors .........................................................4

3.3 Professional Engineering and the public ……………..........................................4

3.3.1 Professional practice and ethics ........................................................................4

3.3.2 Consulting engineering ……………………………................................... 50

3.3.3 Public involvement.........................................................................................52

3.4 Integrating public engagement into the design process .............................................5

3.4.1 The human-centred design process ……………………………………………....5

3.4.2 Developing the skills required for public engagement.............................................59

3.5 Examples of public engagement in engineering design pedagogy ................................60

3.5.1 Examples of student-directed community-engaged learning ......................................62

3.5.2 Examples of humanitarian engineering in community-engaged learning..................63 
3.5.3 Lessons learned from community-engaged learning..........................................6 65

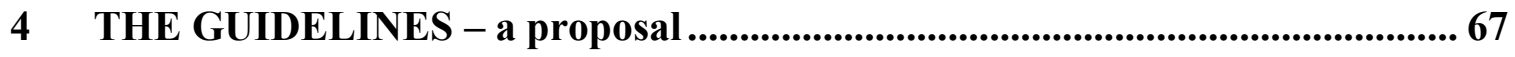

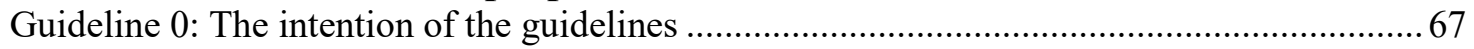

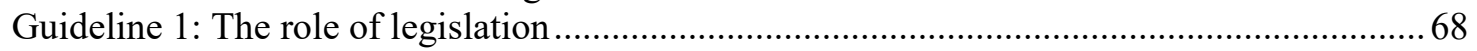

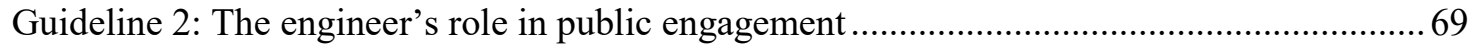

Guideline 3: The fundamental principles of effective public engagement ................................70

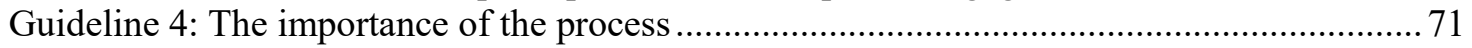

Guideline 5: The opportunities for public input to feed into design........................................ 72

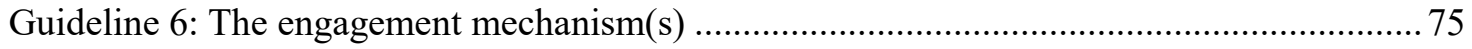

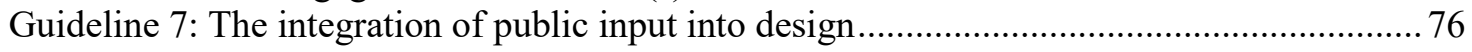

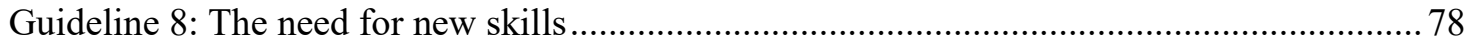

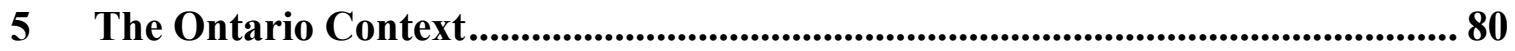

$5.1 \quad$ Regulatory Framework

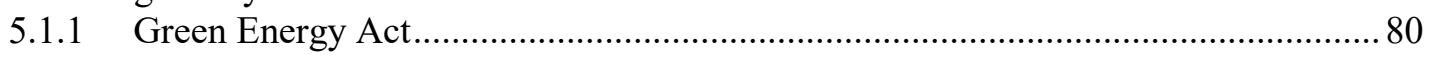

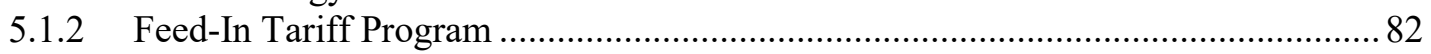

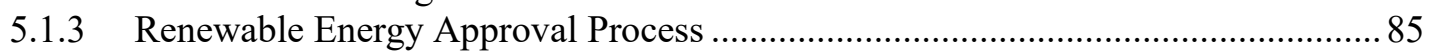

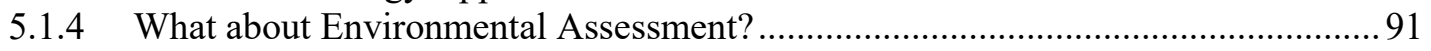

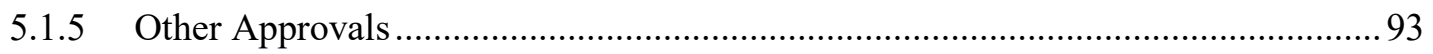

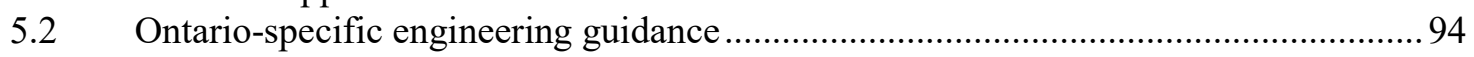

5.2.1 Professional Engineers Ontario (PEO) ............................................................ 94

5.2.2 Ontario Society of Professional Engineers (OSPE) …........................................ 97

6 The Case Study................................................................................................................ 99

6.1 A history of renewable energy development in the case study area .......................... 100

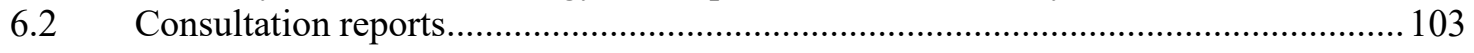

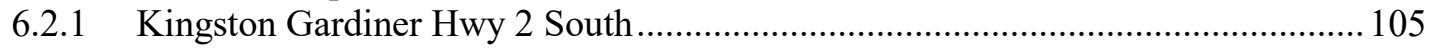

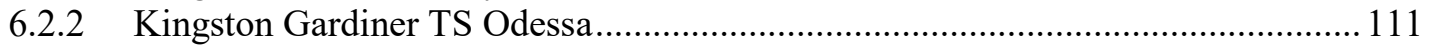

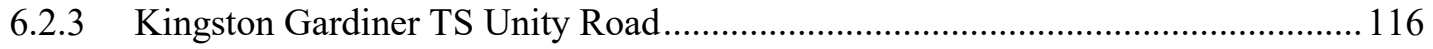

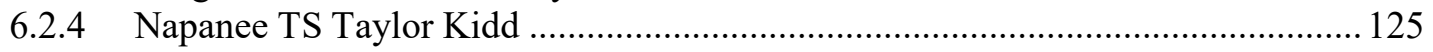

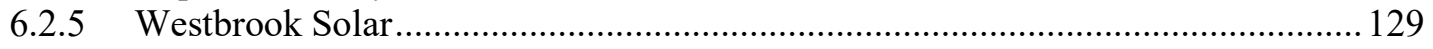

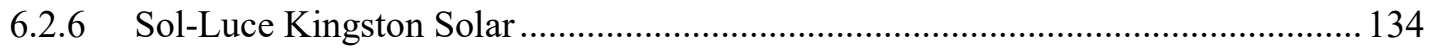

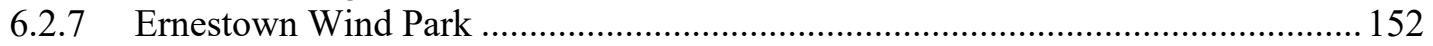

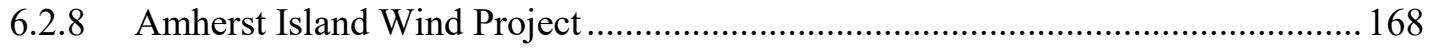

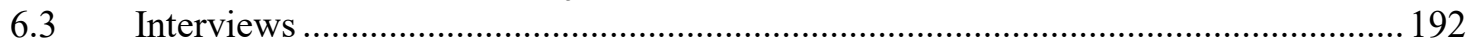

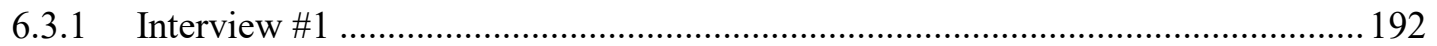

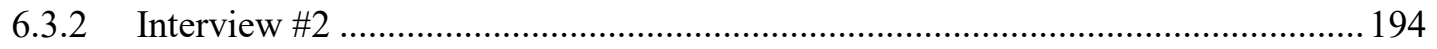

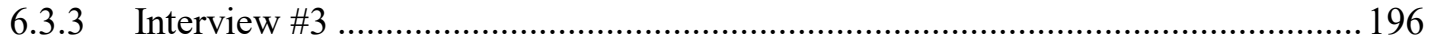

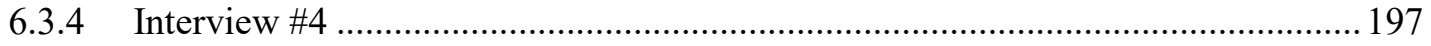

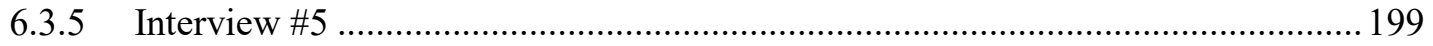

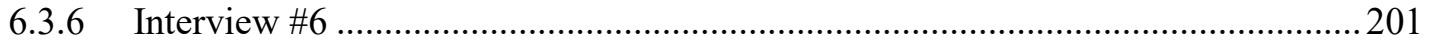

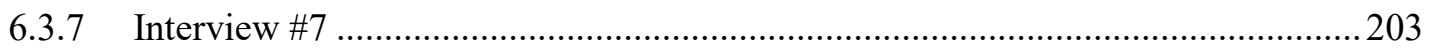

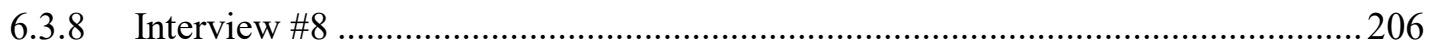

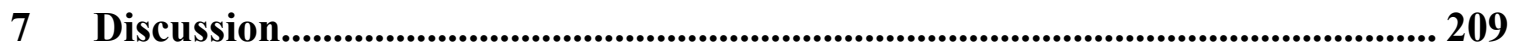

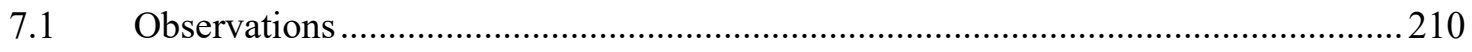

7.2 Discussion of the projects in the context of the guidelines in Chapter 4 …............... 211

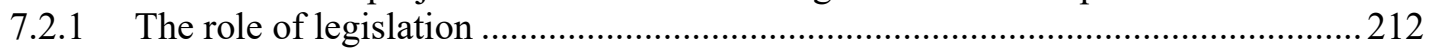

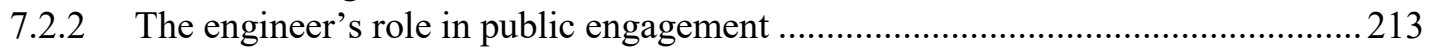

7.2.3 The fundamental principles of effective public engagement ..............................215

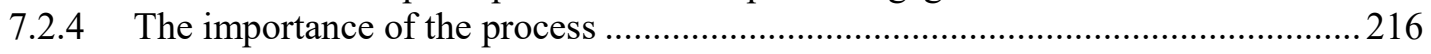




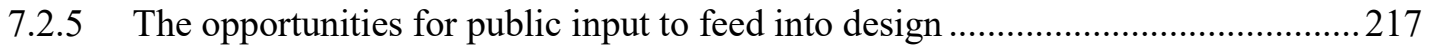

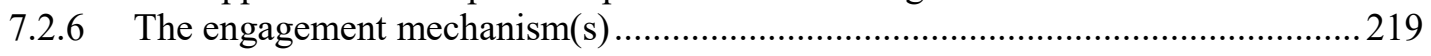

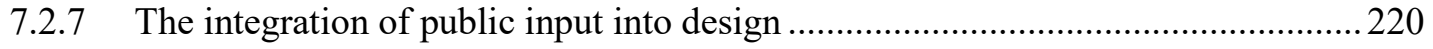

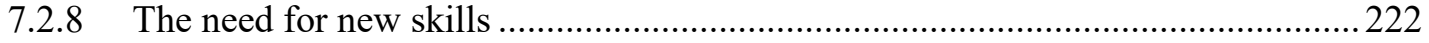

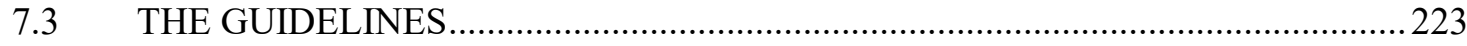

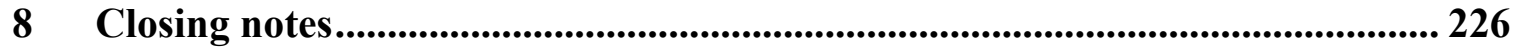

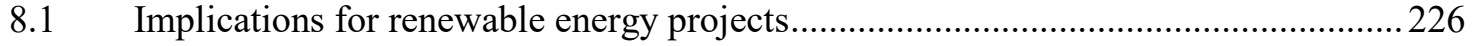

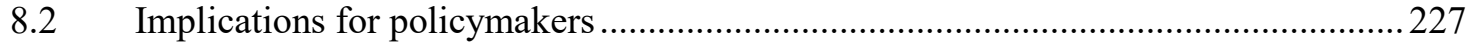

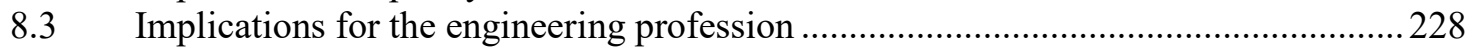

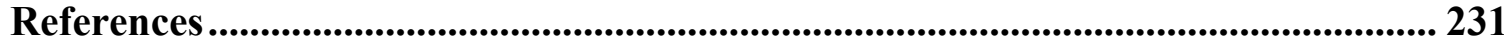

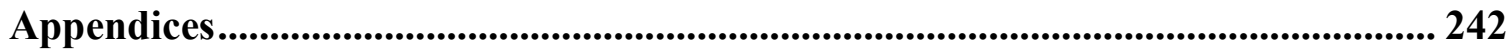

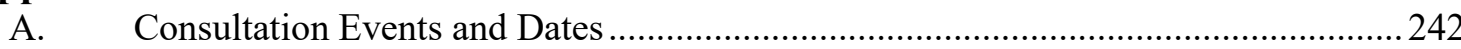

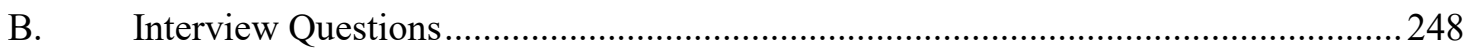

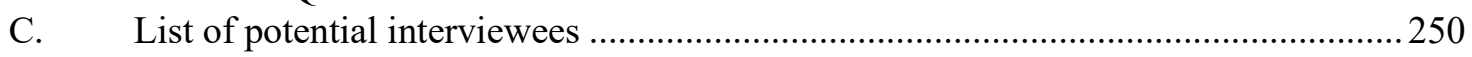




\section{List of Tables}

Table 1: Comparison of definitions of public engagement 17

Table 2: Key Engagement Mechanisms. Adapted from (Rowe \& Frewer, 2005, pp. 276-

277) 32

Table 3: Hwy 2 South Public Comments and Responses (pp. 9-10) .............................. 110

Table 4: Odessa Public Comments and Responses (pp. 17-18)..................................... 115

Table 5: Unity Road Public Comments and Responses (pp. 14-19)............................... 120

Table 6: Taylor Kidd Public Comments and Responses (p. 16)..................................... 129

Table 7: Westbrook Public Meeting \#1 Comments and Responses (p. 16).................... 131

Table 8: Westbrook Public Meeting \#2 Comments and Responses (p. 17).................... 133

Table 9: Sol-Luce First Public Meeting Comments and Responses (pp. 1-3)............... 139

Table 10: Sol-Luce Interim Community Session Comments and Responses (pp. 3-4).. 143

Table 11: Sol-Luce Final Public Meeting Comments and Responses (pp. 4-8)............. 146

Table 12: Ernestown Community Outreach Events (pp. 8-9)....................................... 157

Table 13: Ernestown Public Comments and Responses (pp. 16-22) .............................. 161

Table 14: Amherst Island Public Comments and Responses (pp. 5.9-5.23)................... 179 


\section{List of Figures}

Figure 1: The Policy Cycle, Adapted from $(\mathrm{Pal}, 2014)$................................................. 9

Figure 2: The Engineering Design Cycle, Adapted from (Earle, 2005) .......................... 11

Figure 3: The three types of public engagement (Rowe \& Frewer, 2005, p. 255) .......... 15

Figure 4: The cycle of NIMBYism (Devine-Wright, 2011, p. 23) …………………..... 25

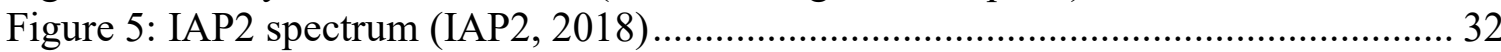

Figure 6: Matrix of Public Participation Techniques (CEAA, 2008, pp. A-2) …………. 33

Figure 7: Contents of the Public Engagement Plan (CEAA, 2008, pp. 4-6) ………….... 35

Figure 8: Engineering design process model (Atman, et al., 2007, p. 366) ..................... 37

Figure 9: Scope of life cycle assessment of a product or process (Rosen, 2012, p. 2281) 41

Figure 10: CSE as an integrating force for design (Militello, Dominguez, Lintern, \&

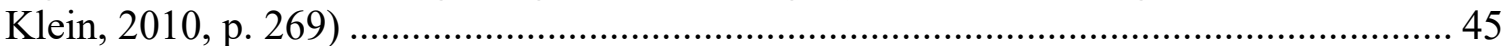

Figure 11: Conceptual model: human-centred design process (Bielefeldt \& Lima, 2019, p.

4) 56

Figure 12: Overview of the principal elements of the REA application process (Ontario

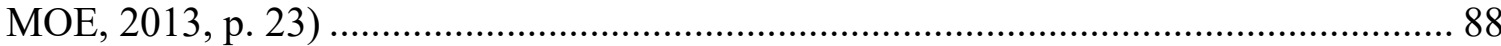

Figure 13: Map of renewable energy projects in the Kingston area ................................ 99

Figure 14: Consultation Report Publication Timeline .................................................... 104

Figure 15: Hwy 2 South public consultation timeline ................................................ 106

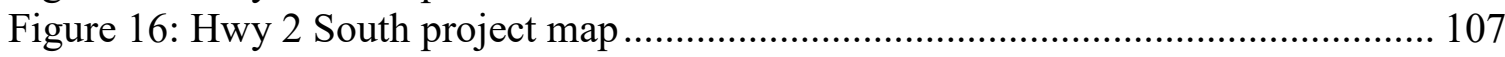

Figure 17: Odessa public consultation timeline........................................................ 112

Figure 18: Odessa project map …………………….............................................. 113

Figure 19: Unity Road public consultation timeline.................................................. 117

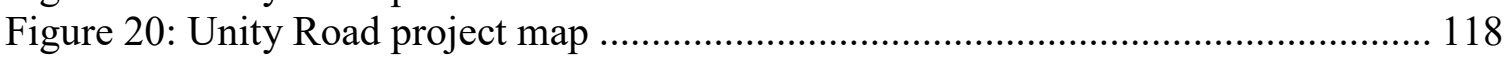

Figure 21: Taylor Kidd public consultation timeline............................................... 126

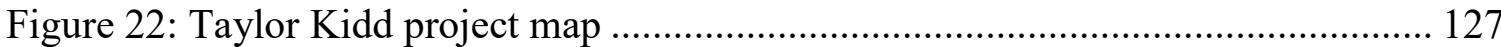

Figure 23: Westbrook public consultation timeline......................................................... 129

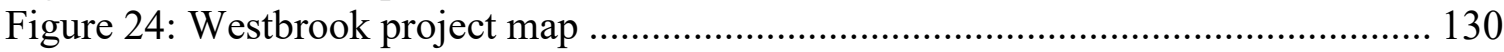

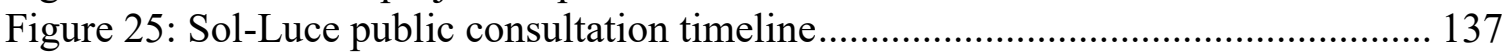

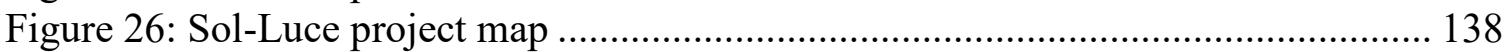

Figure 27: Ernestown public consultation timeline .................................................... 154

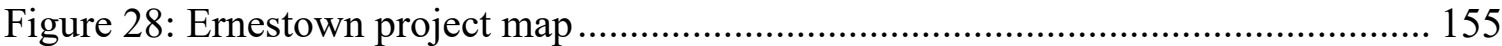

Figure 29: Ernestown 2010 Meetings Questionnaire Responses.................................. 156

Figure 30: Ernestown 2012 Meetings Questionnaire Responses.................................... 159

Figure 31: Amherst Island public consultation timeline................................................ 171

Figure 32: Amherst Island project map ................................................................ 172 


\section{List of Acronyms}

\begin{tabular}{|c|c|}
\hline ABET & (American) Accreditation Board for Engineering and Technology \\
\hline ASCE & American Society of Civil Engineers \\
\hline ASEE & American Society for Engineering Education \\
\hline ASME & American Society of Mechanical Engineers \\
\hline $\mathrm{B} 2 \mathrm{P}$ & Bridges to Prosperity \\
\hline CAIRDE & Community Awareness Initiatives Responsibly Directed by Engineers \\
\hline CanSIA & Canadian Solar Industries Association \\
\hline CanWEA & Canadian Wind Energy Association \\
\hline CCA & Connection Cost Agreement \\
\hline CDTII & Community Driven Technology Innovation and Investment \\
\hline CEAA & Canadian Environmental Assessment Act (or Agency) \\
\hline CEAB & Canadian Engineering Accreditation Board \\
\hline CERP & Clean Energy Resources and Projects \\
\hline CEPA & Canadian Environmental Protection Act \\
\hline CIA & Connection Impact Assessment \\
\hline CLC & Community Liaison Committee \\
\hline CNWA & Canadian Navigable Waters Act \\
\hline COMFIT & Community Feed-In Tariff \\
\hline CoMoDe & $\begin{array}{l}\text { Collaborative Model for capturing and representing the engineering } \\
\text { Design process }\end{array}$ \\
\hline CSE & Cognitive Systems Engineering \\
\hline CSPS & Canada School of Public Service \\
\hline DfE & Design for the Environment \\
\hline $\mathrm{DSC}$ & Distribution System Code \\
\hline EA & Environmental Assessment \\
\hline EIS & Environmental Impact Study \\
\hline ENGO & Environmental Non-Governmental Organization \\
\hline EPD & Environmental Product Declaration \\
\hline EPICS & Engineering Projects in Community Service \\
\hline ERR & Environmental and Regulatory Reviews \\
\hline ESA & Endangered Species Act \\
\hline ESET & Energy Systems Engineering Technician \\
\hline EWB & Engineers Without Borders \\
\hline FAQs & Frequently Asked Questions \\
\hline FIT & Feed-In Tariff \\
\hline GEA & Green Energy Act \\
\hline GLP & Government Liaison Program \\
\hline HONI & Hydro One Networks Inc. \\
\hline IA & Impact Assessment \\
\hline IAIA & International Association for Impact Assessments \\
\hline IAP2 & International Association for Public Participation \\
\hline IBA & Important Bird Areas \\
\hline ICE & Idea-Configuration-Evaluation Model \\
\hline
\end{tabular}




$\begin{array}{ll}\text { IESO } & \text { Independent Electricity System Operator } \\ \text { km } & \text { Kilometre(s) } \\ \text { kV } & \text { Kilovolt(s) } \\ \text { kW } & \text { Kilowatt(s) } \\ \text { LCA } & \text { Life Cycle Assessment } \\ \text { LDC } & \text { Local Distribution Company } \\ \text { Learn4PE } & \text { Learning Together for Better Public Engagement } \\ \text { LEED } & \text { Leadership in Energy and Environmental Design } \\ \text { LRP } & \text { Large Renewable Procurement } \\ \text { m } & \text { Metre(s) } \\ \text { MNR } & \text { (Ontario) Ministry of Natural Resources } \\ \text { MOE } & \text { (Ontario) Ministry of Environment } \\ \text { MPAC } & \text { Municipal Property Assessment Corporation } \\ \text { MTO } & \text { (Ontario) Ministry of Transportation } \\ \text { MW } & \text { Megawatt(s) } \\ \text { NEB } & \text { National Energy Board } \\ \text { NGO } & \text { Non-Governmental Organization } \\ \text { NHA } & \text { Natural Heritage Assessment } \\ \text { NIMBY } & \text { Not In My Back Yard } \\ \text { NRCan } & \text { Natural Resources Canada } \\ \text { OEB } & \text { Ontario Energy Board } \\ \text { OPA } & \text { Ontario Power Authority } \\ \text { OSPE } & \text { Ontario Society of Professional Engineers } \\ \text { PCF } & \text { Pan-Canadian Framework on Clean Growth and Climate Change } \\ \text { PDR } & \text { Project Description Report } \\ \text { PEO } & \text { Professional Engineers Ontario } \\ \text { PLC } & \text { Public Liaison Committee } \\ \text { ProCEED } & \text { Program for Civic Engagement in Engineering Design } \\ \text { PUC } & \text { Projects in Underserved Communities } \\ \text { PV } & \text { Photovoltaic } \\ \text { REA } & \text { Renewable Energy Approval } \\ \text { REDI } & \text { Renewable Energy Deployment Initiative } \\ \text { RFP } & \text { Request for Proposal } \\ \text { SAR } & \text { Species at Risk } \\ \text { SEA } & \text { Strategic Environmental Assessment } \\ \text { STS } & \text { Science and Technology Studies } \\ \text { TMX } & \text { Trans Mountain Pipeline Expansion } \\ \text { WCED } & \text { World Commission on Environment and Development } \\ \text { WGC } & \text { Wintergreen Renewable Energy Co-op } \\ & \end{array}$




\section{Introduction}

As Canada transitions to a low-carbon energy system, renewable electricity generation is becoming increasingly common. Wind and solar energy are the fastest growing sources of electricity in Canada; over the past ten years, wind capacity has grown at an average of 1000 megawatts (MW) per year, and solar capacity has grown at an average of $500 \mathrm{MW}$ per year (NRCan, 2018). As both wind and solar projects have visual impacts on the communities in which they are located, residents potentially affected want to have a say in the projects developing near them. Typically, they have an opportunity to do so during the public engagement process that occurs in the early stages of project development (Barnett, Burningham, Walker, \& Cass, 2012).

Public engagement has jumped into the spotlight lately as a key area that requires improvement, not only at the project level, but also at the broader process level. As part of the federal review of environmental and regulatory processes in Canada, expert panels reviewing both the environmental assessment (EA) process and the National Energy Board (NEB) heard that many participants were dissatisfied with the way that project proponents and regulatory agencies conduct public engagement. A quotation from the expert panel report, Building Common Ground: A New Vision for Impact Assessment in Canada (2017), summarizes the main concerns that were expressed:

In large measure, the Panel heard that public participation opportunities in current assessment processes are unsatisfactory. The greatest disillusionment and frustration was not being able to have an impact on the outcome. Neither proponents nor governments were viewed as actively considering and applying the information gleaned through public participation; this in turn led many participants to see 
decisions as foregone conclusions and participation in these processes as futile (p. 36).

Similar concerns were expressed about the NEB, as written in the expert panel report on NEB Modernization, Forward, Together - Enabling Canada's Clean, Safe and Secure Energy Future (2017):

We heard from Canadians who were barred from simply sending the $N E B$ a letter about a project under consideration, because they didn't have official standing to do so. We heard from Canadians who received funding as official intervenors, but had to choose between procuring legal advice and scientific study. We heard from parties to NEB hearings who felt that the entire system was one of "people vs. suits" and that the "suits" have outsize influence and resources. Overall we heard from people across the country who feel as though the NEB does not listen to their concerns, and, indeed, has no process by which to do so (p. 14).

Common to these two quotations is a perception that public input into assessment and regulatory processes falls on deaf ears. As a result, those who participate in such processes feel that their efforts are a waste of time and energy. In response to these concerns, the federal government is currently revamping the legislative requirements for public engagement as part of the Environmental and Regulatory Reviews (ERR). This review process includes the revision of four existing Acts: the Canadian Environmental Assessment Act (CEAA), the National Energy Board Act (NEB Act), the Canadian Navigable Waters Act (CNWA), and the Fisheries Act (ERR, 2019). The proposed impact assessment (IA) process, which would replace the existing EA process, features provisions for more openness, transparency, and public participation throughout the assessment process. Specifically, the responsibilities of both the project proponent and the proposed revamped Impact Assessment Agency would be increased; the proponent 
would be required to undertake an early planning and engagement phase, after which the Agency would be required to provide the proponent with a Public Engagement Plan and an Indigenous Engagement Plan. These plans would be developed and customized for each project in collaboration with relevant stakeholders; they would outline the engagement approach and tools to be used for public and Indigenous engagement respectively during the IA process. The proposed legislation would apply to projects under federal jurisdiction, designated in the Physical Activities Regulations, also known as the Project List (Discussion Paper on Information Requirements and Time Management Regulatory Proposal, 2019).

Most renewable energy projects recently developed or currently under development do not meet the thresholds on the Project List, and as such fall under provincial jurisdiction. Regardless of whether federal or provincial rules apply, in the absence of stringent legislative requirements regarding public engagement, many project proponents conduct public engagement as a best practice, considering it "necessary if not essential... a core part of being a responsible developer” (Barnett, Burningham, Walker, \& Cass, 2012, p. 40). However, as the EA Expert Panel heard, simply conducting the engagement is not enough; participants want to see their input reflected in project outcomes. For public input to be reflected in the design of renewable energy projects, those facilitating the engagement need to pass on this input to the engineers responsible for the technical design, who must then consider the input and incorporate it into the project design as appropriate. 
Engineers have historically regarded public engagement as a low priority, having been trained to build their design criteria around cost, scope, and time (Morrissey, 2015). As such, they may be reluctant to allow public input to change their design requirements. To minimize opportunities for public input, engineers may influence the design of the engagement process so that its primary goals are to educate the public and minimize opposition rather than actively solicit input and feedback (Cass \& Walker, 2009). Alternatively, engineers may not be involved in the public engagement process at all. Either case can lead to ineffective engagement processes and dissatisfied communities, which can hinder or even halt project progress.

As an example, on August 31, 2018, construction of the Trans Mountain Pipeline Expansion Project (TMX) was indefinitely put on hold when the Federal Court of Appeal ruled that Indigenous consultation was inadequate. While feedback pertinent to the technical design was provided during the initial Indigenous consultation process, it was simply collected and passed on to decision makers at the NEB. For example, the Coldwater First Nation in British Columbia proposed an alternate route for the pipeline that would address certain issues they had. In response, the NEB could have asked Trans Mountain to reroute the pipeline; however, the federal government had already decided that the NEB would not be revisiting its findings. Federal government representatives repeatedly told this to the First Nations groups participating in the consultation. As such, the input from Coldwater First Nation was never considered in the technical design of the project, which goes against the Supreme Court's requirement that "consultation includes approaching talks in good faith with the view of substantially addressing concerns" (Bakx \& Seskus, 2018). 
A substantial body of academic research has determined the fundamental principles of effective public engagement, with a particular focus on renewable energy projects. As this research is mostly in the social sciences, where the research gap occurs is connecting this work with the technical design of a project. As discussed earlier, the public wants to see their input reflected in project outcomes; for renewable energy projects, this is ultimately demonstrated through technical design decisions and features. Bridging the gap between public engagement and engineering design requires the former to become an inherent part of the latter; however, how to do so is not clear. Since engineers typically work directly with a proponent (or client, or stakeholder), there is minimal guidance for engineers on how additional public engagement, particularly early in the project, may influence their design process. This thesis takes the unique step of integrating the public engagement process with the engineering design process, and ultimately providing guidelines on how public engagement could be considered and conducted in the engineering design of renewable energy projects.

\subsection{Research questions}

This thesis examines the public engagement process for renewable energy projects, particularly wind and solar, with a focus on the extent to which public engagement factors into the technical design of the projects. While this research is situated in the Canadian context, and specifically in Ontario, its findings can potentially be applied to other jurisdictions. Acknowledging that Indigenous engagement requires significantly more and different efforts, demonstrated by the federal government's plan to provide 
project proponents a separate Indigenous Engagement Plan (ERR, 2019), those dimensions are considered outside the scope of this thesis.

This thesis aims to provide insights into the following questions:

- To what extent does public engagement factor into the engineering design of a renewable energy project?

- To what extent might the consideration of public engagement change the engineering design process?

The resulting insights are presented as practical, applicable guidelines for engineers looking or needing to incorporate public engagement into their design processes for renewable energy projects. These guidelines can also be useful for policymakers as they try to better integrate technical experts within larger policy processes.

\subsection{Approach and methodology}

This thesis is interdisciplinary as it draws from research in both the social sciences and engineering, and insights are gathered from considering both disciplines together. To do this, the literature from each discipline is summarized individually (resulting in a longer than usual literature review for a master's thesis), followed by the guidelines that draw from connections between the disciplines while considering the differences between them. A case study of the area surrounding Kingston, Ontario helps to refine the guidelines to better consider current practice. The interdisciplinarity of this research is then exploited as the implications for each discipline are discussed in turn. 
The remainder of the thesis is structured as follows:

- Chapter 2 summarizes some of the key academic literature on public engagement in renewable energy projects. While this literature review is not intended to be restricted to any discipline, most of the research on this topic comes from the social sciences, including public policy.

- Chapter 3 summarizes some of the key academic literature on the engineering design process, as well as professional engineering practice and ethics guidance as it relates to consideration of the public. The chapter also features innovative examples of public engagement in engineering design pedagogy.

- Chapter 4 features a preliminary proposal of the guidelines, based on the research presented in the previous two chapters. The guidelines are directed to engineers looking or needing to incorporate public engagement into their design processes for renewable energy projects.

- Chapter 5 provides the provincial context for the case study, including the regulatory framework for renewable energy in Ontario (focusing on the mandated public engagement requirements), and related engineering guidance provided by provincial professional engineering organizations.

- Chapter 6 presents the case study featuring eight wind and solar projects in the area surrounding Kingston, Ontario. This component of the research also contributes to a separate but related ongoing project, entitled "Under Whose Authority? Re-examining interactions within renewable energy projects and processes in Eastern Ontario" (CUREB clearance \#109229). The chapter includes 
a historical overview of renewable energy development in the case study area, the consultation reports documenting the projects and their associated public engagement processes, and interviews with renewable energy stakeholders in the area, adding a supplementary, experiential dimension to the research.

- Chapter 7 is a discussion of the case study in the context of the guidelines as they were proposed in Chapter 4. Based on the discussion, the guidelines are refined and restated.

- Chapter 8 concludes the thesis with the implications of this research for energy projects, policymakers, and the engineering profession.

\subsection{The policy cycle and the engineering design cycle - a primer}

This section describes the policy cycle and the engineering design cycle (in theory), as taught in various courses at Carleton University. These cycles describe the problemsolving processes used by policymakers and engineers respectively. While these may seem like vastly different procedures, there are parallels between them. A comparison of the cycles illustrates the knowledge gap that this thesis aims to fill.

\subsubsection{The policy cycle}

Introduced in Carleton's graduate course PADM 5121: Policy Analysis, The Practical Art of Change, Leslie Pal's presentation of the policy cycle features six steps. Often the last step leads back to the first, where the evaluation of a policy results in defining a new emerging problem. The steps are illustrated in Figure 1. 


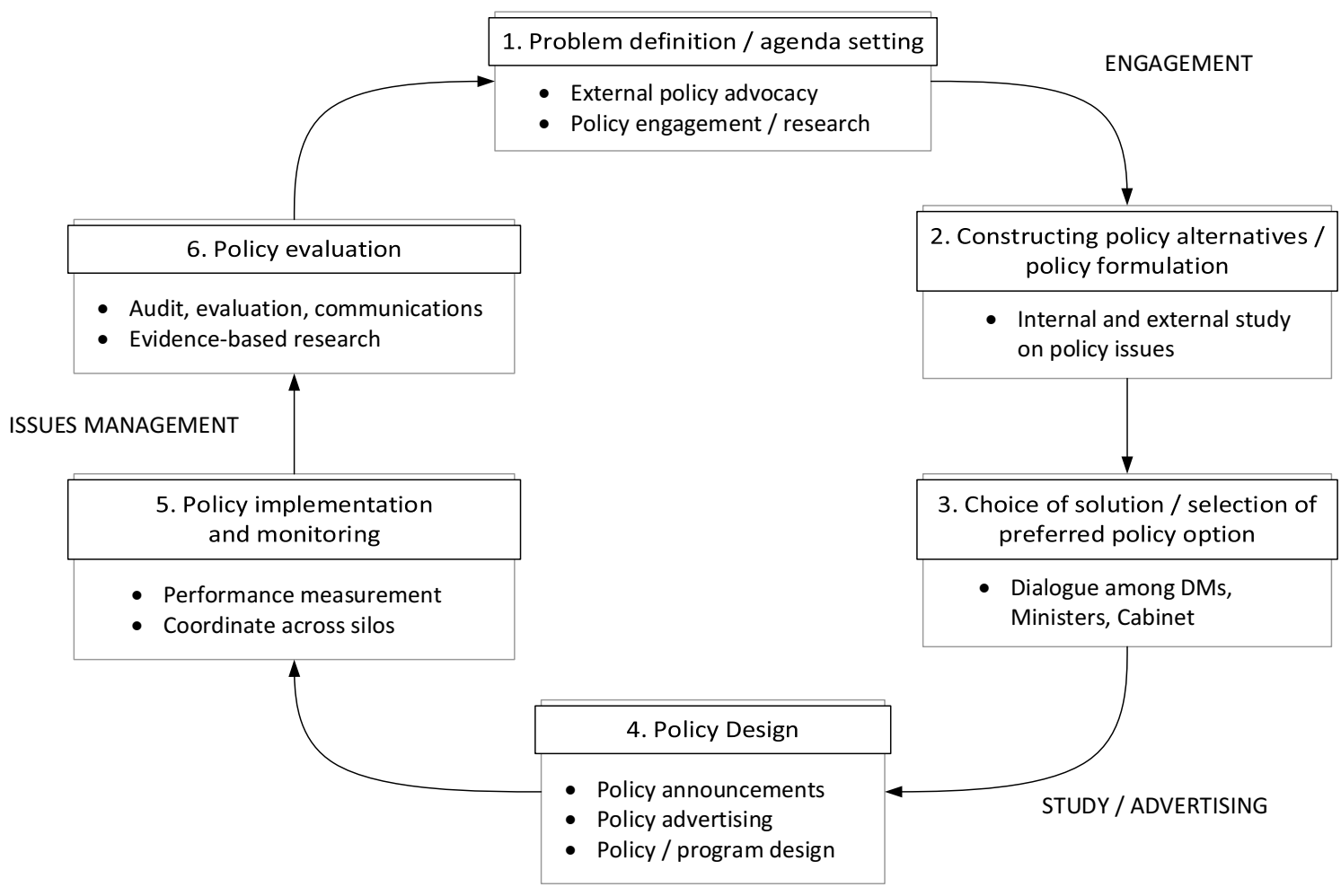

Figure 1: The Policy Cycle, Adapted from (Pal, 2014)

As an example of the policy cycle in action, consider Canadian climate change policy.

The problem was that the federal government wanted to incentivize individuals and businesses to reduce their greenhouse gas emissions. The government initiated a public engagement campaign in which the Minister of Environment and Climate Change toured the country and hosted town halls to hear Canadians' ideas about how to tackle climate change. The policy alternatives fell into four broad categories: carbon pricing, greenhouse gas mitigation, climate change adaptation, and fostering a low-carbon economy. The government ultimately chose to combine those four alternatives, which together formed the pillars of the Pan-Canadian Framework on Clean Growth and Climate Change (PCF). The first of those pillars is carbon pricing, which required many considerations in order to design effectively; the government could have chosen between 
carbon taxes and cap-and-trade, but ultimately decided on a flexible approach that allowed each province to design its own carbon pricing scheme. Since the PCF's launch in December 2016, the government has published two annual reports documenting the progress on implementation. However, given the time lag between implementation of policies and subsequent changes in behaviour, evaluation of the PCF's impact on greenhouse gas emissions is not possible at the time of writing (Pan-Canadian Framework on Clean Growth and Climate Change, 2019).

Note that public engagement is explicitly situated between steps 1 and 2 of the policy cycle; the significance and implications of this are discussed in Section 1.3.3.

\subsubsection{The engineering design cycle}

Introduced in Carleton's undergraduate course MAAE 2001: Engineering Graphical Design, the engineering design cycle also features six steps. There is often an internal loop between steps 3 to 5 , which are repeated as an iterative process. In some cases, the loop closes between steps 6 and 1, hence the dashed line. The steps are illustrated in Figure 2, with adaptations from other models of the engineering design cycle.

As a simple example of the engineering design cycle in action, consider the design of a connection between two buildings across a university campus road. The problem is that students would like to go from one building to another without being exposed to outdoor elements. The stakeholders include (but are not limited to) students, faculty, administrative staff, facilities staff, and visitors. Considerations for design requirements would include (but are not limited to) safety, cost, accessibility, construction logistics, 


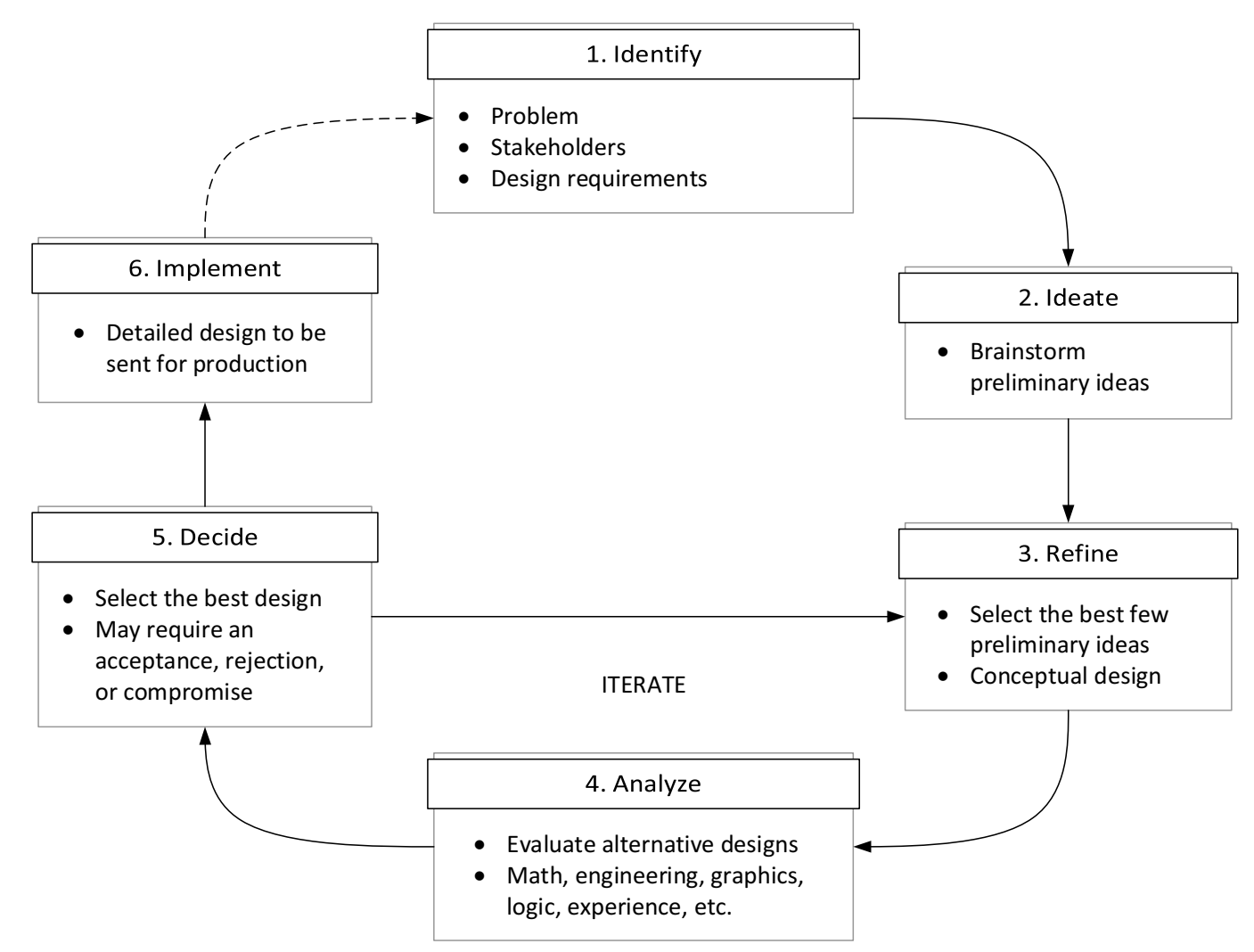

Figure 2: The Engineering Design Cycle, Adapted from (Earle, 2005)

ability to withstand weight, ability to accommodate masses of people, and ability to withstand extreme weather. Preliminary ideas for a connection mode include (but are not limited to) a bridge, a tunnel, and a zip line. In this case, the bridge and the tunnel make more sense than a zip line, as judged against the design requirements. An engineer would quantitatively assess the potential for a bridge and a tunnel, using a variety of methods as appropriate. If one alternative appears better than the other, then that one is chosen.

However, if quantitative measures of the designs are equal, then an engineer may choose the bridge over the tunnel because it would likely be easier and faster to construct. Once the decision has been finalized, the bridge would undergo a detailed design phase (choosing dimensions and materials, designing parts) before being constructed. 
Note that step 1 involves the identification of stakeholders, but there is no mention of engaging with them as that is not always necessary. In the above example, the engineer does not need to consult everyone who will be crossing the bridge before designing the bridge. Modifications of the engineering design cycle do include stakeholder engagement more explicitly; these are described in Section 3.4.

\subsubsection{Comparing the two cycles}

Despite coming from different disciplines, the policy cycle and the engineering design cycle are quite similar. Both start with identifying the problem to be solved, whether that is a policy problem or an engineering problem. Once the problem is defined, the next step is to brainstorm possible solutions. Where at this point in the policy cycle one solution is chosen, engineering design allows for the preliminary (conceptual) development of multiple options before deciding on one to pursue. Then in both cases, the chosen solution is implemented.

Where the cycles diverge is in what happens after implementation. In policy, the roll out of a policy is evaluated, often leading to the identification of emerging problems that can be addressed through another iteration of the policy cycle. In engineering design, it is assumed that all issues with the design are ironed out through iteration of the middle phases of the cycle before implementation occurs. This assumption could be reflective of the comparative ease of rolling back a policy versus retracting a design that is already produced; of course, some policies are easier to amend than others. However, there are cases when the implementation of a design leads to discovering new problems; for 
example, updates to software typically address bugs that were found in the previous version, or malfunctioning hardware leads to product recalls.

As illustrated above, public engagement has a more formalized position in the policy cycle than in the engineering design cycle. Public engagement typically happens in the early stages of the policy cycle, when policymakers conduct research to learn as much about the problem as they possibly can. This is also where policy actors, lobbyists, social movements, and other stakeholders focus their efforts in trying to influence decision makers to take stances that align with their values. These actors know that once policymakers have made decisions and settled on a policy option, the chance of changing their minds is unlikely (Pal, 2014).

In most renewable energy projects, engineers work directly with and are accountable to a project proponent (or client, or stakeholder). While the public (interested parties, external stakeholders) also plays a significant role, engineers do not typically engage with the public. Engineers have historically regarded engagement as a low priority and thus do not have the desire, resources, or skills to engage with the public (Morrissey, 2015). The responsibility for conducting public engagement often falls on the proponent and thus is not reflected in the engineering design process. However, the input gathered from public engagement could influence the technical design; as such, there is value in explicitly incorporating public engagement into the engineering design process. This thesis aims to demonstrate how the public engagement and engineering design processes can be made more cohesive. 


\section{Public Engagement - Literature Review}

This chapter summarizes some of the key academic literature on public engagement in renewable energy projects: first, defining important terms relating to public engagement; second, providing the rationales for conducting public engagement; third, outlining some of the issues with current engagement practices; and fourth, determining the factors that contribute to effective and meaningful public engagement processes. While this literature review is not intended to be restricted to any discipline, most of the research on this topic comes from the social sciences, including public policy.

\subsection{What is public engagement?}

Terms such as 'engagement', 'consultation', 'involvement', and 'participation' are often used interchangeably, without any universal agreement on the specific definitions of these and related terms. For standardization and consistency, this thesis will refer to the commonly cited definitions (Devine-Wright, 2011; Barnett, Burningham, Walker, \& Cass, 2012) given by Rowe and Frewer (2005) as described below. These definitions were chosen as they provided the clearest distinctions between the different terms.

Public engagement is considered the broadest term, which collectively includes three distinct concepts: public communication, public consultation, and public participation. The difference between these is the nature of the flow of information between participants (the public) and the project proponent. 
- Public communication is characterized by a one-way flow of information from the proponent to the public. Public feedback is not required or specifically sought. An example would be a notice published in a newspaper informing the public of a proposed project.

- Public consultation is also characterized by a one-way flow of information, but from the public to the proponent, in response to a process initiated by the proponent. No formal dialogue exists between individual members of the public and the proponent. An example would be a discussion paper that the government posts to ask for input; the government has no intention of responding individually to every person or organization that provides comments.

- By contrast, public participation is characterized by a two-way exchange of information between the proponent and the public. There is some degree of dialogue and negotiation that takes place which serves to transform opinions of both the proponent and the public (Rowe \& Frewer, 2005).

The three different flows of information are summarized in Figure 3.

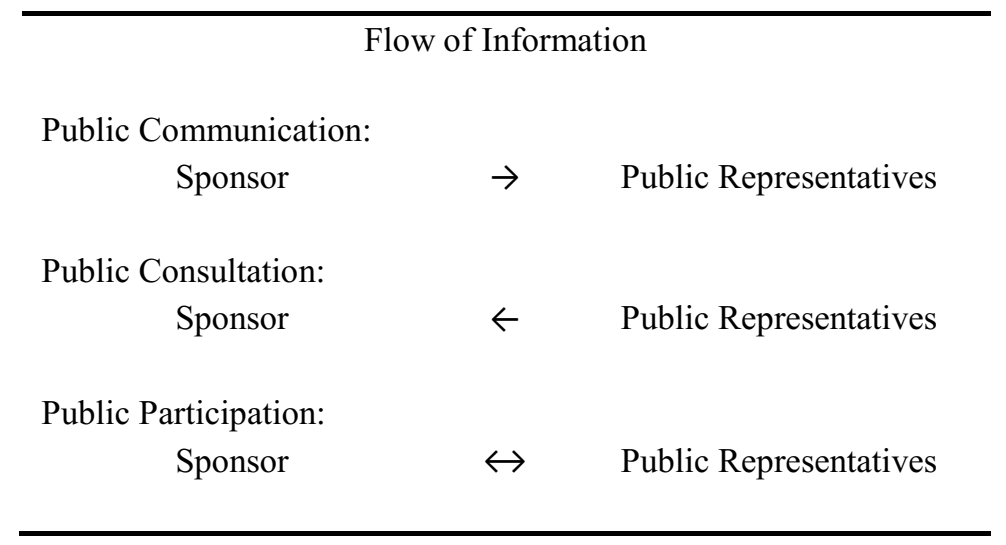

Figure 3: The three types of public engagement (Rowe \& Frewer, 2005, p. 255) 
To illustrate how these terms may have different definitions, consider the definitions provided in the Canadian Environmental Assessment Agency (CEAA)'s Public Participation Guide (2008). These definitions are consistent with the resources provided by the International Association for Public Participation (IAP2), which have been adopted around the world.

In the Guide, the public includes all members of the civic population, including Indigenous peoples. Anyone who may have an interest to protect [the environment], a stake in an issue, or knowledge to contribute in a public participation process is considered an interested party. Public participation is considered the broadest term, and is defined as "any process that involves public input in decision making" (CEAA, 2008, pp. 1-2). Public participation includes the flow of information in both directions between the proponent and the public.

- Public notice is CEAA's term for one-way information flow from the proponent to the public. The objective is "to provide information to the public and to raise awareness of the project or process so the public is informed" (CEAA, 2008, pp. $1-3)$.

- Public consultation is CEAA's term for two-way dialogue between the proponent and the public. It is considered a type of public participation that "includes an active approach to providing the public with opportunities to express their knowledge and views on aspects of the EA" (CEAA, 2008, pp. 1-5).

In comparison to the definitions given by Rowe and Frewer, the CEAA definitions are problematic for two reasons. First, there is no definition provided for 'public 
engagement', even though the government uses the term. For example, the Government of Canada's Environmental and Regulatory Reviews website features a list of “engagement opportunities" (ERR, 2019). Second, CEAA's definition of consultation includes both of what Rowe and Frewer describe as 'consultation' and 'participation', implying (incorrectly) that soliciting feedback without necessarily responding to it is equivalent to having a two-way dialogue (see Table 1). In order to critically analyze the nature of engagement processes, that distinction needs to be made.

Table 1: Comparison of definitions of public engagement

\begin{tabular}{|l|l|l|}
\hline Definition & (Rowe \& Frewer, 2005) & (CEAA, 2008) \\
\hline $\begin{array}{l}\text { Broad term describing any process involving public } \\
\text { input in decision-making }\end{array}$ & Public engagement & $\begin{array}{l}\text { Public } \\
\text { participation }\end{array}$ \\
\hline $\begin{array}{l}\text { One-way flow of information from proponent to public } \\
\text { One-way flow of information from public to proponent } \\
\text { (in response to a proponent-led initiative) }\end{array}$ & Public communication & Public notice \\
\hline $\begin{array}{l}\text { Two-way flow of information between public and } \\
\text { proponent; active dialogue }\end{array}$ & Public participation & $\begin{array}{l}\text { Public } \\
\text { consultation }\end{array}$ \\
\hline
\end{tabular}

\subsection{Why do public engagement?}

Regardless of the form, public engagement has become a necessary part of renewable energy projects. Explicit requirements for engagement during the project siting process have grown with the popularity of renewable energy (Barnett, Burningham, Walker, \& Cass, 2012). For example, Ontario’s Renewable Energy Approvals (REA) Technical Guide mandates public consultation (as defined by CEAA) and describes it as "a critical component of the REA process allowing for a two-way exchange of information... Consultation should educate and inform local communities about the project... to help ensure that concerns are identified early and addressed where possible" (Ontario MOE, 
2013, p. 54). While the regulatory framework serves as a direct imperative, project proponents also generally agree that public engagement is necessary and reasonable, and not a waste of time (Barnett, Burningham, Walker, \& Cass, 2012).

The rationales for engagement are categorized into three types: normative, instrumental, and substantive. A quotation from Stirling's chapter in Science and Citizen:

Globalization and the Challenge of Engagement (2005) describes the differences between these:

Under a normative view, public engagement is just the right thing to do. From an instrumental perspective, [public engagement] is a better way to achieve particular ends. In substantive terms, [public engagement] leads to better ends (Barnett, Burningham, Walker, \& Cass, 2012, p. 38).

These rationales are reflected in interviews conducted by Barnett et al. (2012) with various stakeholders in the renewable energy field. Supporting the normative rationale that engagement is necessary, one consultant described engagement as "expected" and "part of due process", while a manufacturer described it as "absolutely vital”. Supporting the instrumental rationale that public engagement is about the process, one developer expressed how conducting engagement, even when the public appears disinterested, can provide evidence of accountability, while another interviewee expressed that "if you try and squirrel something through quietly, then you are likely to get a backlash of opposition because they think you've got something to hide”. Finally, supporting the substantive rationale that public engagement leads to better ends, interviewees defined good outcomes as "relating to the defusing of public objections and getting planning permissions"; according to a developer and consultant, achieving these was strongly 
related to "a huge amount of public engagement at the right time" (Barnett, Burningham, Walker, \& Cass, 2012, pp. 40-41). As these interviews demonstrate, these rationales are not necessarily mutually exclusive; in fact, all of them in combination or independently provide reason to conduct public engagement.

\subsection{What is 'effective' and 'meaningful' engagement?}

As established in the introduction, conducting engagement is important, but how the engagement is conducted is equally important. Engagement processes are often described as needing to be 'effective', but again, there are many different definitions of 'effectiveness'. The various definitions all allude to two main ideas: the fairness of the process, and the competence / efficiency of the process in achieving its intended purpose (Rowe \& Frewer, 2005).

The idea of fairness concerns the perceptions of participants in the engagement process and/or the wider public. The process would be considered fair if participants believe that it was conducted honestly, with serious intent to collect the views of an appropriate sample of the affected population, and to address any concerns brought forward. Engagement processes are not intrinsically fair or unfair, but become so through the intentions of those involved in the process and how those intentions are acted upon. For example, if a proponent holds a tokenistic public meeting, the meeting is not intrinsically unfair, but appears so due to the behaviour of facilitators or the misalignment between participants' expectations for two-way dialogue and the one-way communication that results. Concepts related to fairness include public acceptability, equity, democracy, 
representativeness, transparency, and influence (Rowe \& Frewer, 2005). The idea of procedural justice, described in Section 2.5.3, is based on this idea of fairness.

The idea of competence / efficiency refers to the appropriate elicitation, transfer, or combination of public and/or proponent views. A competent / efficient process would maximize the relevant information (knowledge and/or opinions) from the maximum number of relevant sources and transfer this information efficiently to the appropriate receivers. For example, in public communication, competence / efficiency means that the proponent gathers all the relevant information, presents it in an accessible format, and delivers it with minimal information loss to as much of the affected public as possible; the recipients must then read and understand the information. Competence / efficiency may be compromised when the information provided is incomplete, irrelevant, or incorrect, when information is lost or distorted during transfer, or when information is misinterpreted or heard selectively by receivers (Rowe \& Frewer, 2005). For example, in public consultation, if public input is illegible or overly opinionated, the proponent may ignore this information.

Government documents are more likely to use the term 'meaningful' to describe engagement processes. The term alludes to many of the same ideas encompassed in 'effectiveness': having the potential to influence decisions, providing inclusive and accessible opportunities for engagement, and providing the capacity required for active participation (Expert Panel: Review of EA Processes, 2017). The ERR (2019) website defines 'meaningful public participation' as follows: 
Meaningful public participation means that members of the public who want to engage in public consultations have an opportunity to do so. It means that they have access to the information they need to take part in an informed way, and that their perspectives inform and influence decisions. Meaningful public participation means that consultation processes are open, transparent and inclusive and that they occur in a timely manner.

The ERR (2019) website also lists the Government of Canada's principles for meaningful public participation, which are summarized below:

- [Public engagement] starts early and continues throughout each step of the impact assessment process;

- It is supported with funding through the Participant Funding Program;

- It is inclusive and transparent, and information is available to the public;

- It is designed to increase the knowledge of participants and the government, and build relationships;

- It is designed to prioritize the participation of those who are most affected by the proposed project, while also ensuring that members of the public have an opportunity to share their views;

- Its methods are flexible, innovative and consider the context of the project and legislated timelines;

- It influences decision-making and participants see how their input was considered; and

- It continually adapts and improves. 
Given that participants have expressed an inability to influence project outcomes, a lack of feedback mechanisms to identify how input was considered, and a lack of in-person two-way dialogue (Expert Panel: Review of EA Processes, 2017), current engagement practices cannot be considered effective or meaningful. The next section explores some of the key theories explaining this lack of effectiveness.

\subsection{Why are current engagement practices not effective/meaningful?}

As the public's expectation for engagement rises, the processes to enable effective engagement have not kept up. This is one of the motivations for modernizing the NEB, as described in the Expert Panel Report (2017):

At the NEB's inception in 1959, public engagement in government decision-making was largely limited to elections, and there was no expectation that the public would have direct, ongoing involvement in any government business of any significance. Since that time, public attitudes in this regard have changed drastically, and the NEB is now behind the times (p. 14).

With the various uncertainties inherent in developing a renewable energy project, for example, environmental risks, climate impacts, and effects on the electricity market, there are usually multiple external stakeholders with different opinions and priorities for decision-makers to consider (Cuppen, Bosch-Rekveldt, Pikaar, \& Mehos, 2016). Even within the population of 'the public', different social groups may have different opinions, making it difficult to generalize the public as a single stakeholder (Walker, Cass, Burningham, \& Barnett, 2010). Engagement provides an opportunity to bring those differing opinions forward, with the potential to influence decisions surrounding the project. As such, effective and meaningful engagement implies that there needs to be an 
element of flexibility in the process; however, there is a tendency to overestimate collective agreement on policy goals and means, based on the incorrect assumption that the public is a homogenous body (Cuppen, Bosch-Rekveldt, Pikaar, \& Mehos, 2016; Walker, Cass, Burningham, \& Barnett, 2010). This assumption results in public engagement being approached as a rather structured process, where objectives are clear and undisputed from the beginning, and procedures are designed to meet those objectives. This phenomenon is called the "engineer's and planner's fallacy" and is linked to two common preconceptions of public opposition towards a project: people oppose because they are uninformed, and people oppose because they are self-interested (Cuppen, BoschRekveldt, Pikaar, \& Mehos, 2016).

\subsubsection{The public as uninformed - the information-deficit model}

Project proponents often enter engagement having a preconceived notion of their audience, which influences how the engagement process is conducted (Walker, Cass, Burningham, \& Barnett, 2010). The first preconception of public opposition towards a project is that people oppose because they are uninformed. This preconception leads to the information-deficit model, which assumes that by providing correct and balanced information, people will be persuaded to support what is being proposed (Cass \& Walker, 2009). Proponents believe that if the public has the 'correct' information about the project, understands the benefits of the project, and understands how risks are covered, then based on rational reasoning, they will support the project (Cuppen, Bosch-Rekveldt, Pikaar, \& Mehos, 2016; Simis, Madden, Cacciatore, \& Yeo, 2016). In addition, proponents often do not want to deal with the emotions associated with opposition, as 
they are seen as irrational in the context of a structured decision-making process (Cass \& Walker, 2009). As such, public engagement is designed to limit the emotive response, and efforts are focused on providing information and reducing concerns (Cass \& Walker, 2009; Barnett, Burningham, Walker, \& Cass, 2012).

The information-deficit model has been observed and critiqued across a diversity of policy and innovation contexts (Cass \& Walker, 2009). It has been highly criticized for "being overly simplistic and inaccurately characterizing the relationship between knowledge, attitudes, beliefs, and behaviours" (Suldovsky, 2017). In the renewable energy context, the information-deficit model results in proponents ignoring the importance of values, particularly those associated with place-attachment to the location of a proposed project (Bidwell, 2013; Carlisle, Kane, Solan, \& Joe, 2014). Nearby residents may have an established sense of place-based identity, and thus perceive a potential project as an 'invasion' and a threat to the place; however, these views are "seen by planning officers as both impossible and inappropriate to bring into decision-making processes" (Cass \& Walker, 2009, p. 64). Perhaps more importantly, the informationdeficit model has been shown not to hold; for example, despite the scientific consensus on anthropogenic climate change and the widespread communication of the science, there are many in the 'public' who continue to believe that the Earth's climate is not warming. Alternatively, if the Earth's climate is indeed warming, these people believe that human activity is not the primary cause (McDivitt, 2016). To quote David Maggs, an author and researcher at the University of Toronto, "the best evidence that the information-deficit model doesn't work is that we have 40 years of evidence that it doesn't work but we keep using it!"' (Robinson, 2019). 


\subsubsection{The public as self-interested - NIMBYism}

The second preconception of public opposition towards a project is that people oppose because they are self-interested. This preconception is commonly known as NIMBYism, which stands for Not In My Back Yard. NIMBYism is used "to describe opponents of new developments who recognize that a facility is needed but are opposed to its siting within their locality" (Burningham, 2000, p. 56). Research shows that NIMBYism implicitly influences how decision makers think about and undertake public engagement; for example, a senior government politician in the United Kingdom called for 'Age of Stupid' awards to be given to those who oppose wind farms (Devine-Wright, 2011). Proponents believe that people oppose a project because they value the aesthetics, quietness, and/or safety of their neighbourhood over the collective need for a clean and secure energy supply (Cuppen, Bosch-Rekveldt, Pikaar, \& Mehos, 2016). This belief leads to a perpetual, self-fulfilling cycle of NIMBYism, as illustrated in Figure 4.

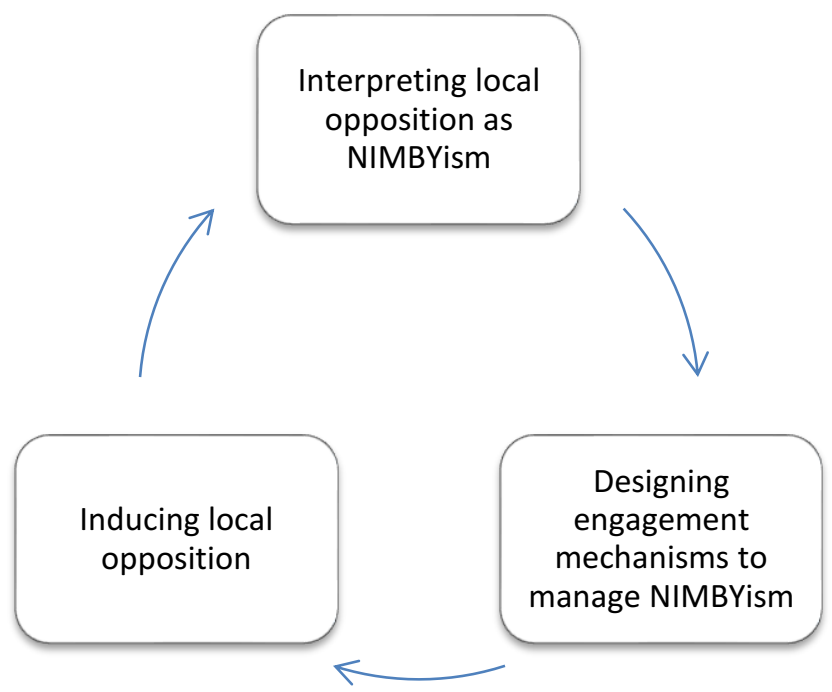

Figure 4: The cycle of NIMBYism (Devine-Wright, 2011, p. 23) 
Local opposition is interpreted as NIMBYism, then engagement is designed to limit NIMBY responses (for example, by limiting opportunities to participate, focusing on information provision, and addressing self-interested concerns), but this leads to more local opposition (for example, towards the limited opportunities to participate and invalidation of emotional response), which is then interpreted as NIMBYism, and so on (Devine-Wright, 2011).

Despite the prevalence of NIMBYism as a way of thinking about public opposition, academic social scientists critique it as an inadequate and unfair explanation (DevineWright, 2011; Burningham, 2000). The term itself is seen as "unhelpful and misleading, and as misrepresenting the genuine motivations of some of not most objectors" (Cass \& Walker, 2009, p. 63). In addition, the term is used to discredit objectors, as DevineWright (2011) describes:

The NIMBY label is a succinct way of pejoratively describing local opposition to unwanted land uses, attributing hostility to the ignorance, irrationality, or prejudice of members of the public. NIMBYism blames technology controversies upon local objectors; homogenizes and simplifies their arguments; and counterbalances an often poorly defined 'national interest' in developing large-scale infrastructure against 'local concerns' (pp. 21-22).

Not only is NIMBYism theoretically inadequate, but it hinders the facilitation of a constructive engagement process (Fisher \& Brown, 2009). The cycle of NIMBYism described in Figure 4 "does not provide a suitable social context for the rapid [energy] transformation [required]"; Devine-Wright (2011) proposes breaking out of the cycle with a process that promotes more active public engagement, requiring "a two-way process of participation that... enables a dialogue between different values" (p. 23). 


\subsection{What factors are necessary for effective/meaningful engagement?}

From the literature, four factors were identified as necessary for effective and meaningful engagement: going above legislative requirements, starting engagement early in the project development process, ensuring engagement processes are fair and just, and choosing the appropriate engagement mechanism.

\subsubsection{Legislation as a minimal requirement}

The first factor necessary for effective and meaningful engagement is going above legislative requirements. Particularly in Ontario, there is a heavy reliance on procedural compliance for renewable energy projects. Such procedures are usually dictated in legislation for an EA process (the case is slightly different in Ontario; see Chapter 5). The project proponent is required to hold a public forum and present the potential environmental impacts of a proposed project. While the intention is to allow for public comments and feedback, research has shown that this is typically not the case. Rather, the flow of information is generally one-directional, and this minimal interaction tends to lead to dissatisfied community members and public opposition (Jami \& Walsh, 2017).

There are two ways to address the issue of procedural reliance resulting in suboptimal outcomes. First, legislation can be improved to raise the minimally required standards, an approach the federal government is currently taking (ERR, 2019). Ideally, the new standards would be such that participants have what they consider to be fair opportunities to participate so long as the mandated process is followed. Projects that cannot demonstrate having met the new standards will ultimately not receive government 
approval to proceed. Second, proponents can take the initiative to go above and beyond legislative requirements. While governments focus on improving their EA legislation, proponents can be proactive and incorporate some of the latest research findings and best practices into their own engagement processes. Doing so helps to build a strong reputation for valuing public input in project decisions, which can only help the proponent in the long run.

\subsubsection{Starting engagement early}

The second factor necessary for effective and meaningful engagement is starting engagement early in the project development process. Academics and governments generally agree that early engagement is a determinant of effective processes. Cuppen et al. (2016) suggest initiating engagement before value-based decisions are made, "involving external stakeholders in dialogue on underlying assumptions, values, and agenda setting", in contrast to current practice when external stakeholders are only involved "in the implementation phase, when many (value-based) choices have already been made and participation pertains to narrow, predefined issues" (p. 1349). The United Kingdom Office of the Deputy Prime Minister's planning statement for renewables suggests initiating "active consultation and discussion with local communities at an early stage in the planning process, and before any planning application is submitted" (Barnett, Burningham, Walker, \& Cass, 2012, p. 37). While early engagement takes more time, money, and energy up front, it can result in multiple benefits, including increased proponent credibility, avoidance of unforeseen problems, lower overall project costs, fewer delays, and less uncertainty throughout the process. By flagging and responding to 
issues early in the development process, the chances of appeals and lawsuits afterwards are lessened if not minimized. Most importantly, early engagement provides the opportunity to develop a better, socially desirable project (Cuppen, Bosch-Rekveldt, Pikaar, \& Mehos, 2016; Barnett, Burningham, Walker, \& Cass, 2012).

In practice, determining when exactly to begin the engagement process is not so simple. Proponents would find it unwise and counterproductive to publicize an idea for a project so early in the planning process that it may drastically change later or never come to fruition (Barnett, Burningham, Walker, \& Cass, 2012). In addition, in the case of a competitive market such as Ontario's, a proponent might not want to let competitors hear of their plans before they are solidified (Fast, et al., 2016). Rather, the proponent would want to engage after they have made initial decisions, when they have enough information to make a strong presentation and address any concerns or criticism that may arise in response; this is known as the "decide - announce - defend" model (Bell, Gray, \& Haggett, 2005). As such, the focus on information provision seems to constrain how early proponents are willing to undertake engagement (Barnett, Burningham, Walker, \& Cass, 2012).

\subsubsection{Procedural justice}

The third factor necessary for effective and meaningful engagement is ensuring engagement processes are fair and just. Ontario is home to nearly $40 \%$ of Canada's total installed wind capacity (CanWEA, 2019), as well as multiple groups and organizations that oppose wind energy (Jami \& Walsh, 2017). A major factor in the development of this opposition is the technocratic siting processes that came out of Ontario's Green 
Energy Act (GEA) and Feed-In Tariff (FIT) program; a study from Western University found that opposition to local developments was "highly conflated with a lack of procedural justice" (Walker \& Baxter, 2017, p. 160).

Procedural justice refers to the decision-making process and whether it is perceived to be fair and equitable. There are six principles of procedural justice (Gross, 2007, p. 2730):

- full participation in the process,

- the ability to express opinions freely and to be heard,

- being treated with respect,

- being given adequate information,

- the impartiality of the decision maker, and

- decisions that are responsive to information and that are correctable in the face of new information.

In the context of renewable energy, procedural justice focuses on the public engagement process and the conditions of that engagement. Processes are considered just and fair if meetings are accessible, decision makers recognize the legitimate contributions of participants, and public input has influence on final decisions (Walker \& Baxter, 2017).

Research finds that fairness of process may be more important than fairness in outcomes, because fair processes are more likely to lead to fair outcomes, particularly when it is uncertain what a fair outcome looks like (Gross, 2007). In Nova Scotia, the Community Feed-In Tariff (COMFIT) program requires that wind developments are owned by the public; proponents are required to prove public engagement and support. The resulting 
collaborative and participatory approach resulted in greater satisfaction and much less opposition to wind development compared to Ontario. However, in both provinces, residents felt they had little control of the outcomes (Walker \& Baxter, 2017). This example demonstrates that participants who feel that they have been treated fairly throughout the public engagement process are more likely to accept the decisions resulting from the process. This example also demonstrates the 'fair process effect', in which people have been shown to accept negative outcomes if they perceive fairness in the decision-making process (Gross, 2007).

The lesson to be learned from comparing the two provinces is that emphasis should be placed on the process rather than solely the outcome. In some cases, deliberation and negotiation among stakeholders can lead to consensus, but often that is not possible, particularly when deeply rooted values are at play. Instead, it would make more sense to aim for 'agnostic pluralism', which focuses on the settlement of differences. The process must provide opportunities for opposing positions to be aired and recognized as legitimate, or else these views may develop into antagonistic protest. In the end, while there may be dissatisfaction over the outcome, the process will have greater legitimacy if all voices are heard (Fisher \& Brown, 2009).

\subsubsection{Engagement mechanisms}

The fourth factor necessary for effective and meaningful engagement is choosing the appropriate engagement mechanism(s). Engagement mechanisms are the tools, processes, techniques, or instruments used to enable engagement. The number and variety of mechanisms to choose from are large and growing. Table 2 shows key engagement 
mechanisms categorized by type of engagement: communication, consultation, and

participation.

Table 2: Key Engagement Mechanisms. Adapted from (Rowe \& Frewer, 2005, pp. 276-277)

\begin{tabular}{|c|c|c|}
\hline Communication & Consultation & Participation \\
\hline $\begin{array}{ll}\text { - } & \text { Cable TV (not interactive) } \\
\text { - } & \text { Drop-in centres (open house, } \\
\text { one-stop shop, exhibitions) } \\
\text { - } & \text { Hotline } \\
\text { - } & \text { Information broadcasts } \\
\text { ("publicity" via TV, } \\
\text { newsletters, and/or radio) } \\
\text { - Internet information } \\
\text { ("computer-based) } \\
\text { - Public hearings / inquiries } \\
\text { - } \quad \text { Public meeting (with } \\
\text { question and answer session) }\end{array}$ & $\begin{array}{ll}\text { - } & \text { Citizens' panel - group-based } \\
\text { - } & \text { Consultation document } \\
\text { - } & \text { Electronic consultation } \\
& \text { (“interactive Web site") } \\
\text { - } & \text { Focus group } \\
\text { - } & \text { Open space } \\
\text { - } & \text { Opinion poll } \\
\text { - } & \text { Referendum } \\
\text { - } & \text { Study circle } \\
\text { - } & \text { Survey } \\
\text { - } & \text { Telepolling / televoting }\end{array}$ & $\begin{array}{ll}\text { - } & \text { Action planning } \\
\text { - } & \text { Corkshop } \\
\text { - } & \text { Consensus' jury } \\
\text { - } & \text { Deliberative opinion poll } \\
\text { - } & \text { Negotiated rulemaking } \\
\text { - } & \text { Planning cell } \\
\text { - } & \text { Task force } \\
\text { - } & \text { Town meeting (with } \\
& \text { voting) }\end{array}$ \\
\hline
\end{tabular}

A common typology for mechanisms is based on the IAP2 spectrum shown in Figure 5.

INCREASING IMPACT ON THE DECISION

\begin{tabular}{|c|c|c|c|c|c|}
\hline & INFORM & CONSULT & INVOLVE & COLLABORATE & EMPOWER \\
\hline 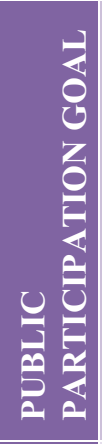 & $\begin{array}{l}\text { To provide the } \\
\text { public with } \\
\text { balanced and } \\
\text { objective } \\
\text { information to } \\
\text { assist them in } \\
\text { understanding } \\
\text { the problem, } \\
\text { alternatives, } \\
\text { opportunities } \\
\text { and/or solutions. }\end{array}$ & $\begin{array}{l}\text { To obtain public } \\
\text { feedback on } \\
\text { analysis, } \\
\text { alternatives } \\
\text { and/or } \\
\text { decisions. }\end{array}$ & $\begin{array}{l}\text { To work directly } \\
\text { with the public } \\
\text { throughout the } \\
\text { process to ensure } \\
\text { that public } \\
\text { concerns and } \\
\text { aspirations are } \\
\text { consistently } \\
\text { understood and } \\
\text { considered. }\end{array}$ & $\begin{array}{l}\text { To partner with the } \\
\text { public in each } \\
\text { aspect of the } \\
\text { decision including } \\
\text { the development of } \\
\text { alternatives and the } \\
\text { identification of } \\
\text { the preferred } \\
\text { solution. }\end{array}$ & $\begin{array}{l}\text { To place final } \\
\text { decision } \\
\text { making in the } \\
\text { hands of the } \\
\text { public. }\end{array}$ \\
\hline 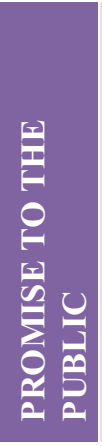 & $\begin{array}{l}\text { We will keep } \\
\text { you informed. }\end{array}$ & $\begin{array}{l}\text { We will keep } \\
\text { you informed, } \\
\text { listen to and } \\
\text { acknowledge } \\
\text { concerns and } \\
\text { aspirations, and } \\
\text { provide } \\
\text { feedback on } \\
\text { how public } \\
\text { input influenced } \\
\text { the decision. }\end{array}$ & $\begin{array}{l}\text { We will work with } \\
\text { you to ensure that } \\
\text { your concerns and } \\
\text { aspirations are } \\
\text { directly reflected } \\
\text { in the alternatives } \\
\text { developed and } \\
\text { provide feedback } \\
\text { on how public } \\
\text { input influenced } \\
\text { the decision. }\end{array}$ & $\begin{array}{l}\text { We will look to } \\
\text { you for advice and } \\
\text { innovation in } \\
\text { formulating } \\
\text { solutions and } \\
\text { incorporate your } \\
\text { advice and } \\
\text { recommendations } \\
\text { into the decisions } \\
\text { to the maximum } \\
\text { extent possible. }\end{array}$ & $\begin{array}{l}\text { We will } \\
\text { implement } \\
\text { what you } \\
\text { decide. }\end{array}$ \\
\hline
\end{tabular}

Figure 5: IAP2 spectrum (IAP2, 2018) 
The spectrum is based on Arnstein's ladder of participation (1969), and features five different levels of public engagement in the decision-making process: inform, consult, involve, collaborate, and empower (Jami \& Walsh, 2017). Each level has a corresponding increase in the opportunity for public input to influence decisions. The CEAA Public Participation Guide (2008) provides a matrix (reproduced in Figure 6) of different mechanisms organized by these different levels of engagement.

\begin{tabular}{|c|c|c|c|c|}
\hline Activity/Technique & Inform & Consult & Involve & Collaborate \\
\hline \multicolumn{5}{|l|}{ Information } \\
\hline Advertising & $\mathrm{X}$ & & & \\
\hline Briefings / Presentations & $\mathrm{X}$ & & & \\
\hline Central Information Contact & $\mathrm{X}$ & & & \\
\hline Community Fairs / Events & $\mathrm{X}$ & & & \\
\hline E-mail & $\mathrm{X}$ & & & \\
\hline Field Offices & $\mathrm{X}$ & $\mathrm{X}$ & & \\
\hline Information Centres / Repositories & $\mathrm{X}$ & & & \\
\hline Information Kiosks / Exhibits / Displays & $\mathrm{X}$ & & & \\
\hline Open Houses & $\mathrm{X}$ & $\mathrm{X}$ & & \\
\hline Print and Electronic Media & $\mathrm{X}$ & & & \\
\hline Print Materials / Mail Outs & $\mathrm{X}$ & & & \\
\hline Response Summaries & $\mathrm{X}$ & $\mathrm{X}$ & & \\
\hline Site Tours / Field Trips & $\mathrm{X}$ & $\mathrm{X}$ & & \\
\hline Symposiums / Expert Panels & $\mathrm{X}$ & $\mathrm{X}$ & & \\
\hline Telephone Hotlines & $\mathrm{X}$ & $\mathrm{X}$ & & \\
\hline Web Sites and Other Internet Tools & $\mathrm{X}$ & $\mathrm{X}$ & & \\
\hline \multicolumn{5}{|l|}{ Consultation } \\
\hline Coffee Parties & $\mathrm{X}$ & $\mathrm{X}$ & & \\
\hline Comment Forms & & $\mathrm{X}$ & & \\
\hline Focus Groups & & $\mathrm{X}$ & & \\
\hline Interviews & & $\mathrm{X}$ & $\mathrm{X}$ & \\
\hline Public Meetings & $\mathrm{X}$ & $\mathrm{X}$ & & \\
\hline Surveys & & $\mathrm{X}$ & & \\
\hline Town Meetings & $\mathrm{X}$ & $\mathrm{X}$ & $\mathrm{X}$ & \\
\hline \multicolumn{5}{|l|}{ Involvement } \\
\hline Charettes & & & $X$ & $\mathrm{X}$ \\
\hline Roundtables & & & $\mathrm{X}$ & \\
\hline Small Group Meetings & & & $\mathrm{X}$ & \\
\hline Workshops & & & $\mathrm{X}$ & $\mathrm{X}$ \\
\hline \multicolumn{5}{|l|}{ Collaboration } \\
\hline Advisory Groups & & $\mathrm{X}$ & $\mathrm{X}$ & $\mathrm{X}$ \\
\hline Consensus-Building Techniques & & & $X$ & $\mathrm{X}$ \\
\hline Study Circles & & $\mathrm{X}$ & $\mathrm{X}$ & $\mathrm{X}$ \\
\hline Task Forces & & & $X$ & $X$ \\
\hline
\end{tabular}

Figure 6: Matrix of Public Participation Techniques (CEAA, 2008, pp. A-2) 
With the focus on information provision, current practices are typically situated in the 'inform’ and 'consult' categories (Expert Panel: Review of EA Processes, 2017). Engagement 'best practice' has moved towards the exhibition format (Information Kiosks / Exhibits / Displays classified under Information in Figure 6), where information and visual material is on display or handed out, and representatives of the proponent or their consultants are available to answer questions from the public one-on-one (Cass \& Walker, 2009; Fast, et al., 2016). Research shows that proponents prefer the exhibition format because it "lends itself more successfully to the provision of information, a measured exchanged of views, and the attenuation of concern and conflict" (Barnett, Burningham, Walker, \& Cass, 2012, p. 44). By contrast, proponents find public meetings (classified under Consultation in Figure 6) to be problematic because they "invite or encourage unmanageable confrontation and often denigrate into personal attacks" and are generally "unhelpful and unpleasant". As a developer described, "We go out and we turn up at the meeting and there's generally forty or fifty people there ready to shout at you..." (Barnett, Burningham, Walker, \& Cass, 2012, pp. 44-45). Other common choices include focus groups, which can be beneficial because they "enable access to the views of the broader community: "the mildly interested but not vociferous either for or against"' (also known as the 'silent majority'), and the Internet, which can provide information while "filtering out some unwanted contact and phone calls" (Barnett, Burningham, Walker, \& Cass, 2012, p. 45; Walker, Cass, Burningham, \& Barnett, 2010).

Proponents can choose which engagement mechanisms to use, and it is evident they do so strategically. The freedom of choice allows them to target their audience and influence the nature of the engagement. For example, by choosing the exhibition format and thus 
engaging with community members one-on-one, proponents provide a platform for less extreme views to be voiced, while limiting emotive responses and defusing antagonism and conflict (Barnett, Burningham, Walker, \& Cass, 2012; Cass \& Walker, 2009). As the effectiveness of public engagement depends on the mechanism chosen and how it is applied, the context for engagement should also be considered in choosing which mechanism(s) to use. Factors to consider include the potential participants, the requirements for engagement, and the objectives of engagement (Rowe \& Frewer, 2005). The CEAA Public Participation Guide (2008) includes a chapter on planning for public engagement, which helps the proponent to develop a strategy and choose engagement mechanisms specific to the project undergoing the EA process. Figure 7 outlines the contents of a public engagement plan, as suggested in the Guide.

Your plan should detail the following information:

- clear scope, objectives and rationale for the public participation process;

$\square$ plain language project description;

$\square$ responsible authority and proponent contact information;

$\square$ description of any other parallel consultation processes and coordination requirements;

$\square$ potential issues and challenges, and how they may be addressed;

$\square$ key interested parties to involve;

- level of public participation for each objective and phase of the EA;

$\square$ detailed plans for implementing each public participation activity, including logistics, information and communication requirements;

$\square$ time lines for participation activities, including significant milestones;

$\square$ financial and human resource requirements;

$\square$ procedures for documentation;

$\square$ procedures for providing feedback to participants;

$\square$ indicators and procedures for evaluating the process; and

$\square$ any other information necessary to ensure adequacy of the public participation process.

Figure 7: Contents of the Public Engagement Plan (CEAA, 2008, pp. 4-6) 


\section{Engineering Design - Theory, Practice, and Education}

To build on the introduction of the engineering design cycle provided in Section 1.3.2, this chapter summarizes some of the key academic literature on the engineering design process; first, providing examples of different models of the process; second, describing how non-technical factors can influence the design process; third, outlining professional engineering practice and ethics guidance as it relates to the public; and fourth, describing how public engagement can be situated within the engineering design process. The chapter ends with examples of public engagement in engineering design pedagogy; the many examples published in engineering education research indicate that the future of the profession will be better equipped to consider and conduct public engagement in engineering design.

\subsection{Academic analysis of the engineering design process}

Recall that the engineering design cycle describes the process engineers use to solve problems. The six-step cycle represents a typical pedagogical model used to introduce the design process to engineering students. Atman et al. (2007) referred to seven commonly used engineering design textbooks to develop the generalized design process they used for coding their study, shown in Figure 8. This generalized model is meant to be widely applicable; however, depending on the engineering discipline and the context of the design, the process may look slightly different (Gonnet, Henning, \& Leone, 2007). 


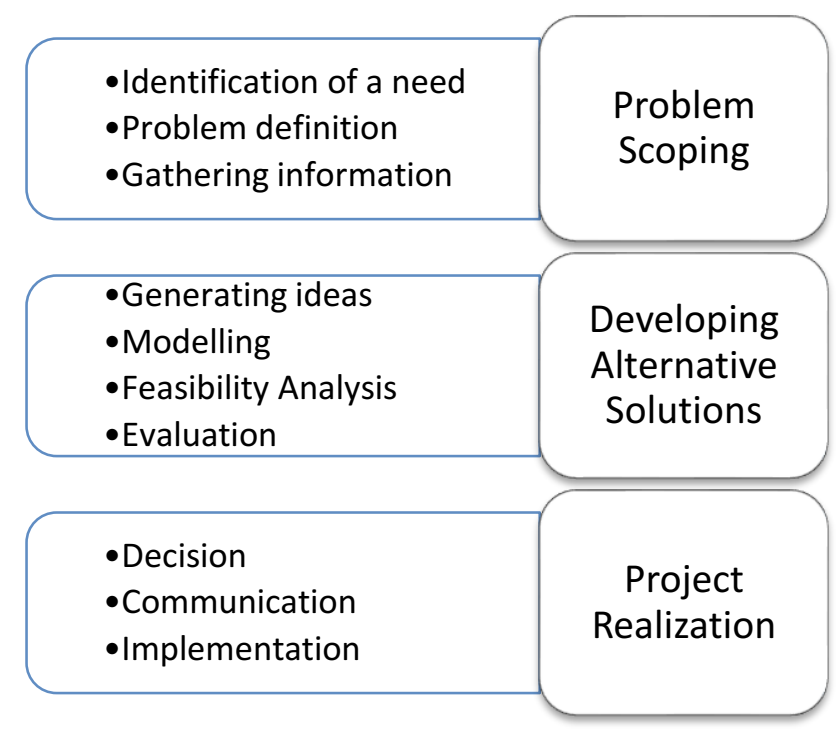

Figure 8: Engineering design process model (Atman, et al., 2007, p. 366)

Research in design theory offers many theories, models, and methods of the engineering design process. Some are conceptual while some are mathematical; some are descriptive while others are prescriptive; some are process-centred while others are product-centred; some encompass the entire process while others focus on specific parts of the process. A few examples of common models include the waterfall model from software engineering, the $\mathrm{V}$-model from systems engineering, brainstorming for ideation, functional decomposition for conceptual design, and Pugh's method for concept selection. While many models, including these, are introduced in engineering design pedagogy, most of them are not widely used in industry, at least not explicitly (Weisbrod \& Kroll, 2018).

To determine the applicability of the engineering design process as taught to students, Atman et al. (2007) conducted a study comparing engineering students with practitioners. They asked first-year undergraduate students, fourth-year undergraduate students, and 
practising engineers to design a playground. Participants were asked to think aloud so that their process could be captured and coded. The results showed that while students tended to follow the six-step process sequentially and linearly, practitioners followed a "cascade" pattern, transitioning through the different stages to gather information and clarify the problem scope throughout the process. Practitioners also spent more time overall scoping the problem, gathering more information and considering broader aspects of design. The data from the study provides rich insight into some of the complexities of engineering design that are not reflected in the simple pedagogical models.

To more accurately reflect professional engineering design practice, research focus has turned towards developing less theoretical, more practical models. These models attempt to capture the dynamic nature of the design process. For example, Weisbrod and Kroll (2018) propose the idea-configuration-evaluation (ICE) model for conceptual design, which employs "solution-problem coevolution"; the design task and requirements are gradually refined during conceptual design. As another example, Gonnet et al. (2007) propose the Collaborative Model for capturing and representing the engineering Design process (CoMoDe), which aims to explicitly capture aspects of the process: the activities performed, the underlying rationale for decisions, when the activities were done, and who executed the activities. As a third example, Cash et al. (2015) conduct a multi-scale analysis of the engineering design process based on Activity Theory, which reveals a complex fabric of embedded processes at macro-, meso-, and micro- scales.

There are a few common insights that emerge from the various new models. First, the engineering design process is iterative; the problem definition and solution coevolve as 
more information emerges (Weisbrod \& Kroll, 2018; Cash, Hicks, \& Culley, 2015). Second, there is a clear focus on the end product; by contrast, there is little evidence of people or process management (Cash, Hicks, \& Culley, 2015). If explicit representation of the process exists in documentation, it tends to be "scattered around technical domains and improperly categorized" (Gonnet, Henning, \& Leone, 2007, p. 882). Third, engineering design needs to be approached as a sociotechnical system; during the design process, human experts collaborate with each other and with computational tools (Cash, Hicks, \& Culley, 2015; Gonnet, Henning, \& Leone, 2007). In addition, often the end product cannot be designed in isolation, rather, it has to fit within a broader societal context (Atman, et al., 2007). These insights have implications for how non-technical factors may be considered in engineering design, as explained in the following section.

\subsection{Considering non-technical factors}

Referred to in Atman et al.'s study as “broader aspects of design”, non-technical considerations are equally important in engineering design. In the study where participants were asked to design a playground, compared to students, practitioners asked more questions about issues such as legal liability, maintenance concerns, and neighbourhood opinions (Atman, et al., 2007).

This section discusses three factors traditionally considered as non-technical that are commonly considered in engineering design: the environment, sustainability, and human behaviour. From these, some insights are drawn that can be applied to public engagement. 


\subsubsection{Considering the environment}

One of the most common non-technical factors considered in engineering design is the environment, particularly as climate change becomes an increasingly prevalent issue. Professional practice guidelines have been recently updated to reflect that engineers have a professional duty to protect the environment (Andrews, Shaw, \& McPhee, 2019). In September 2016, Engineers Canada published the National Guideline on Sustainable Development and Environmental Stewardship for Professional Engineers (2016). This document contains ten guidelines that are intended to be complementary to the professional Code of Ethics (more on this in Section 3.3.1).

As part of their duty to protect the environment, engineers are advised to know and consider the environmental laws relevant to their project. In Canada, these include the Canadian Environmental Protection Act (CEPA), the Fisheries Act (being revised as part of the ERR), the CEAA (also being revised as part of the ERR), and the Environmental Enforcement Act (Andrews, Shaw, \& McPhee, 2019; ERR, 2019). In most infrastructure and energy projects, consideration of the environment is mandated through the EA process, which focuses on mitigating adverse impacts. However, there are often additional incentives to develop environmentally friendly designs, such as third-party certification and improved energy efficiency. Protecting the environment and achieving complementary goals requires integrating environmental considerations early in the engineering design process (Burke, Parrish, \& El Asmar, 2018; O'Reilly, et al., 2016). In fact, the National Guideline states that engineers "should establish... criteria for 
environmental stewardship at the earliest possible stage in projects" (Engineers Canada, 2016).

One way to integrate environmental considerations into the engineering design process is through a life cycle assessment (LCA), which assesses the environmental aspects and potential impacts associated with a product from cradle to grave (Burke, Parrish, \& El Asmar, 2018). The scope of an LCA encompasses everything from material extraction to disposal, as illustrated in Figure 9.

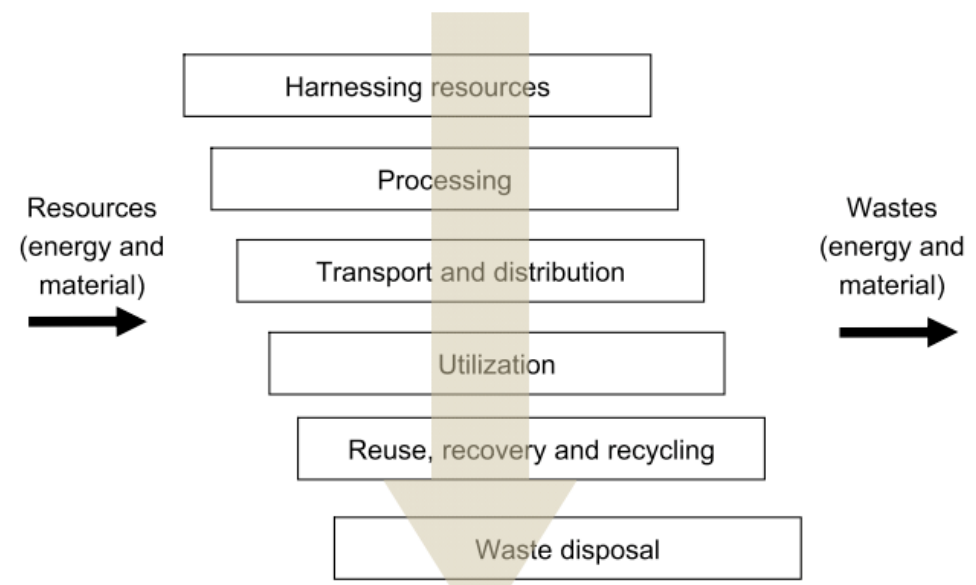

Figure 9: Scope of life cycle assessment of a product or process (Rosen, 2012, p. 2281)

LCAs are often used as part of a Design for the Environment (DfE) approach, which aims to reduce the environmental impact of products and services along their life cycle (Gagnon, Leduc, \& Savard, 2012). Engineers are encouraged to adopt LCA and other objective tools to thoroughly analyze their designs and control potential hazards to the environment (Andrews, Shaw, \& McPhee, 2019). However, despite being an important tool to inform decision making, LCAs tend to be underutilized due to lack of demand from clients. In addition, there are few effective tools available to assist in the use of 
LCA to inform design; the tools developed in academia often do not directly address designers' needs and other factors specific to industry (Burke, Parrish, \& El Asmar, 2018).

Another way to integrate environmental considerations into engineering design is through Environmental Product Declarations (EPDs), which describe the lifecycle impacts of a material. EPDs are typically used in building design, and their use is rewarded by green building certification systems such as the Leadership in Energy and Environmental Design (LEED) rating system. EPDs are a relatively new source of information widely used in the architecture, engineering, and construction industry; as such, it is unclear how EPDs will be used and the extent to which they will influence building design. In a survey of early adopters of EPDs, more than half perceived value in reviewing EPDs early. EPDs considered early informed decisions allowing for better design, and helped determine the environmental impact or sustainability of the building being designed. When considered later, EPDs were not as useful as designers had more difficulty using and accounting for them. Most respondents also believed that EPDs added value to the building design process, as they made the analysis stage easier and helped to educate both the design team and the building owner. Conversely, EPDs can present a risk of information overload, and could be ignored as a result (Burke, Parrish, \& El Asmar, 2018).

\subsubsection{Considering sustainability}

A related non-technical factor considered in engineering design is sustainability. The idea stems from sustainable development, defined as "development that meets the needs of the 
present without compromising the ability of future generations to meet their own needs" (WCED, 1987). For engineers, sustainability requires four key components: sustainable resources, sustainable processes, increased efficiency, and reduced environmental impact. These requirements are not necessarily independent; in fact, they overlap with each other (Rosen, 2012). For example, while automobile engine efficiency has improved by 30 percent over the past 25 years, drivers are buying larger, more wasteful vehicles, thus increasing environmental impact. In this case, simply improving efficiency is insufficient; engineers also need to rethink and reorganize the energy system (Andrews, Shaw, \& McPhee, 2019).

The four components listed above make fulfilling other aspects of sustainability more tractable. These other aspects include social, political and economic considerations, including but not limited to affordability, equity, increasing demand, community engagement, land use, aesthetics, human behaviour, and population growth (Rosen, 2012). The multidisciplinary nature of sustainability has given rise to sustainable engineering as a new emerging discipline (Gagnon, Leduc, \& Savard, 2012; Rosen, 2012). Sustainable engineering projects aim to "maximize positive contributions to the well-being of individuals and simultaneously preserve the sound functioning of ecosystems and social systems" (Gagnon, Leduc, \& Savard, 2012, p. 50). Researchers have developed new frameworks for sustainable engineering design, as sustainability is not simply an add-on criterion, but needs to be considered early and throughout all stages of the design process (Lindow, Woll, \& Stark, 2012; Gagnon, Leduc, \& Savard, 2012). In comparison to conventional design, sustainable engineering design is more resourceintensive, as it requires collaboration between disciplines, engagement with the end users, 
consideration of knowledge and issues outside engineering, creativity to develop radical solutions, and more and/or different tools to assess the quality of the design from different lenses (environmental, economic, social, political) (Gagnon, Leduc, \& Savard, 2012; Rosen, 2012).

\subsubsection{Considering human behaviour}

Another non-technical factor considered in engineering design is human behaviour. The consideration of human behaviour is important in the context of sociotechnical systems, involving collaboration between humans as well as human-technology interactions. The field of cognitive systems engineering (CSE) is a specialization within human factors and ergonomics that addresses the "need to design systems within which people can interact effectively"; CSE is an approach to design that integrates the "knowledge of how people think and act in the context of their work environment" (Militello, Dominguez, Lintern, \& Klein, 2010, p. 261). Typically, CSE is conducted independently from design; however, it is likely to make a more valuable contribution if considered from the outset and integrated throughout the design process. Militello et al. propose a framework which positions CSE as the integrating force for design, at the center of a cyclical design process which continuously evolves as new information emerges and engineers reevaluate their understanding of the problem and how well they are addressing it (see Figure 10). The framework offers "a perspective from which to view the environment in which the eventual solution will be implemented, taking into account worker needs, expertise, cognitive demands, constraints, goals, and key aspects of work that should be supported” (Militello, Dominguez, Lintern, \& Klein, 2010, p. 269). 


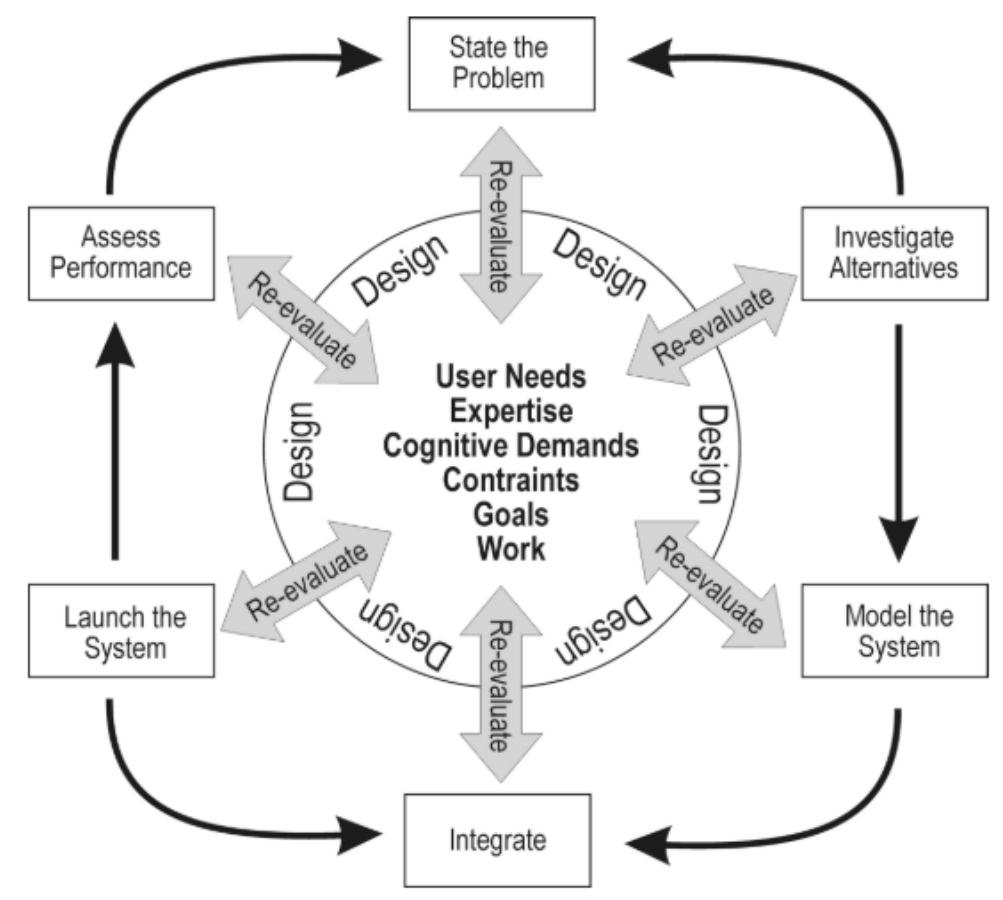

Figure 10: CSE as an integrating force for design

(Militello, Dominguez, Lintern, \& Klein, 2010, p. 269)

Current challenges facing the integration of CSE include collaboration between CSE experts and the larger engineering community, and justification of CSE's value as it is difficult to quantify and articulate (Militello, Dominguez, Lintern, \& Klein, 2010).

\subsubsection{Insights from the various non-technical factors}

There are a few common insights that can be drawn from analyzing how various nontechnical factors such as environment, sustainability, and human behaviour are considered in engineering design. First, these factors are best considered early in the design process; if considered too late, their potential added value to the design is limited (O'Reilly, et al., 2016; Burke, Parrish, \& El Asmar, 2018). Second, these factors are 
typically considered independently of design instead of being integrated into the design process, which also limits their potential added value to the design (Gagnon, Leduc, \& Savard, 2012; Militello, Dominguez, Lintern, \& Klein, 2010). Third, these factors influence the entire design process, not just one stage of design or the end result; if they are to be prioritized as a major objective of the design, the structure of the design process may need to be overhauled completely (Gagnon, Leduc, \& Savard, 2012; O'Reilly, et al., 2016; Militello, Dominguez, Lintern, \& Klein, 2010).

In addition, the consideration of non-technical factors has implications for design evaluation, as the quality of the design needs to be assessed against additional and/or different criteria. Traditionally, project managers were actively incentivized to deliver on the 'iron triangle' of cost, scope, and time; however, these three criteria alone are no longer sufficient (Morrissey, 2015). Solutions that are more environmentally-conscious, sustainable, or user-friendly may cost more and take longer to come to fruition, due to the extra work and resources required to meet these additional criteria (Gagnon, Leduc, \& Savard, 2012). These solutions may also differ significantly from those that would be generated under traditional criteria.

For example, O'Reilly et al. (2016) propose a design methodology for vehicles which has the minimization of life cycle energy, or total cumulative energy demand, as its primary goal. This differs from the traditional design approach which aims to minimize energy demand only while the vehicle is in use. In applying the new methodology to designing a car roof panel, simulation results showed that the results differed when optimizing for life cycle energy versus use-phase energy. When only use-phase energy is optimized, the 
results tended to a solution with minimum mass (as expected); both face sheets would be made completely from carbon fibre, and the core would be a mix of mostly light foam with some stiffer heavier foam. When life cycle energy is optimized, the results tended towards a heavier panel; the face sheets would be made from a mix of glass fibre and carbon fibre, and the core would be similar to before. A reallocation of space helps to reduce overall energy demand. This simple example illustrates how gains in one part of the design can be offset in another; minimizing mass counterintuitively led to a suboptimal result in terms of life cycle energy consumption. By prioritizing environmental considerations, trade-offs occur on different design features (O'Reilly, et al., 2016). In short, what may be considered the "best" or "optimal" design under traditional criteria may not remain so when non-technical factors are considered.

\subsection{Professional Engineering and the public}

In some cases, particularly when alternative designs are technologically equivalent, the optimal design is chosen based on an ethical judgement. This section discusses professional practice and ethics guidance as it relates to the engineering profession's relationship with the public. The Code of Ethics and its application in ethical problem solving have implications for public engagement. As engineers are typically hired as consultants on renewable energy projects, the second part of this section focuses on practice and ethics issues specific to consulting engineers. The final part of this section describes the minimal guidance that exists on public involvement in engineering projects. 


\subsubsection{Professional practice and ethics}

The Engineers Canada Code of Ethics is the set of underlying principles which forms the basis and framework for responsible professional engineering practice in Canada. The Code is based on "broad principles of integrity, truth, honesty, and trustworthiness, respect for human life and welfare, fairness, openness, competence, and accountability" (Engineers Canada, 2016). The national Code is a model for those published by provincial/territorial professional engineering associations; the latter have legal significance and are usually parts of engineering acts and regulations (Andrews, Shaw, \& McPhee, 2019), for example, the Professional Engineers Act in Ontario (Government of Ontario, 2018).

The first line of the Code says that engineers "shall hold paramount the safety, health, and welfare of the public, environment and workplace". This duty to society is the most important principle of the profession; as elaborated in the guideline for the Code, "all other requirements of the Code are subordinate if protection of public safety, the environment, or other substantive public interests are involved" (Engineers Canada, 2016). Engineers have a duty of care to anyone who may suffer from the harmful effects of their design, even if the harm occurs years later, for example, as a result of air or water pollution. Designing for safety involves following design codes, standards, and accepted best practices; being aware of safety regulations; and making formal hazard analyses and risk assessments (Andrews, Shaw, \& McPhee, 2019).

Under the Code, engineers "shall act with integrity, equity, fairness, courtesy, and good faith towards clients, colleagues, and others". The national guide states that this 
requirement extends to include an obligation to the public, and applies to public statements, including in a non-technical forum. In particular, engineers need to "present issues fairly, accurately, and with appropriate disclaimers, and to avoid personal, political, and other non-technical biases" (Engineers Canada, 2016). This is obviously applicable to engineers in a public engagement setting, if they are to interact directly (or indirectly) with members of the public.

In the case of an ethical dilemma, the primary textbook on Canadian engineering practice and ethics, written by Andrews et al., suggests that engineers can apply the design process to engineering problems. While the process appears quite formal, experienced practitioners can recognize patterns and select appropriate solutions quickly and intuitively. The book suggests a six-step process based on the standard design cycle (Andrews, Shaw, \& McPhee, 2019):

1. Recognize the problem and gather information. Ethical problems and usually vague and difficult to recognize. If the information shows a clear and present danger, act immediately; otherwise, wait until all relevant information is gathered.

2. Define the ethical problem: what exactly is wrong? Often, what first appeared to be an ethical problem was simply a rumour, a misunderstanding, or a disagreement; in this case, action may be unnecessary or obvious.

3. Generate alternative solutions. Try to avoid an ethical dilemma with only two equally undesirable courses of action; creative thinking usually yields a third, better option. 
4. Evaluate alternative solutions according to legal compliance, alignment with ethical theories, and an assessment of fairness.

5. Decide on a solution and optimize it. Usually one solution appears best, but see if it can be improved upon. In difficult cases, there may not be a superior solution, in which case iterate the process.

6. Implement the solution. In most cases, quick and decisive action is advised, especially if someone's health, safety, or reputation is at stake.

As alluded to in step 4, a solution to an ethical problem needs to be both 'right' (in agreement with ethical theories) and fair, which combined, result in justice. The predominant theory used to justify ethical decisions in engineering is Mill's utilitarianism, according to which the best solution produces the maximum benefit for the greatest number of people. Other ethical theories which may be more appropriate in certain circumstances are Kant's formalism (duty ethics), Locke's rights ethics, and Aristotle's virtue ethics. In addition, there are four categories of justice to consider: procedural justice (fairness in decision making), corrective justice (fairness in rectifying wrongs), distributive justice (fairness in social benefits), and political justice (fairness in political rights) (Andrews, Shaw, \& McPhee, 2019). While fairness and justice are mentioned in the Code of Ethics, their consideration is not confined to ethical dilemmas; they are also fundamental to effective public engagement as explained in Chapter 2.

\subsubsection{Consulting engineering}

The Code of Ethics also applies to consulting engineers, whose role is to advise a client (individual or company) on a project that requires specialized engineering knowledge. 
Consulting work often involves diverse tasks, including providing engineering design advice, conducting feasibility studies, and managing projects. In the case of project management, the client requires the consultant's advice to confirm that a contractor's work is being performed properly. This creates a three-way relationship between the client, the contractor, and the consultant. These roles are defined as follows:

- The client owns the project and may or may not have technical engineering knowledge.

- The contractor could be the designer, builder, or developer; they are skilled in the activity but may or may not be a licensed professional.

- The consultant is a professional engineer who guides and protects the interests of the client by giving technical advice and helping the project to progress quickly, safely, honestly, and fairly.

The nature of the client-consultant relationship depends on the knowledge, skills, and personalities of the people involved, but all client-consultant relationships fall along a spectrum. At one end is the 'independent' model, in which the client delegates decisionmaking power to the consultant. This model is not ideal because the client has essentially given up the ability to make decisions regarding the project. At the other end is the 'agent' model, in which the consultant takes direct orders from the client. This model is also not ideal because the client does not make full use of the consultant's knowledge. In the middle of the spectrum is the 'balanced' model, in which the client and consultant treat each other as equals. The consultant provides advice and evaluates the risks and 
benefits of various alternatives, and the client makes decisions based on this information (Andrews, Shaw, \& McPhee, 2019).

With respect to consulting, the Code of Ethics states that engineers "shall act as faithful agents of their clients... with objectivity, fairness, and justice to all parties". This involves maintaining confidentiality (unless public safety is at risk) and avoiding conflict of interest situations. In addition, the Code states that engineers "shall present clearly to... clients the possible consequences of engineering decisions" and "inform clients... of societal and environmental consequences". These responsibilities relate to upholding the safety, health, and welfare of the public (Engineers Canada, 2016).

Additional ethical considerations arise when consulting in foreign countries, especially developing countries with lower standards than Canada. Andrews et al. (2019) provide the following guidance based on nine 'culture-transcending' norms: avoid exploitation, avoid paternalism, avoid bribery, respect human rights, respect cultural norms and laws, promote the country's welfare, protect health and safety, protect the environment, and promote the society's legitimate institutions. This guidance should not be confined to foreign consulting, as it is also applicable within Canada, given its cultural and economic diversity. For example, it would apply in Indigenous communities, or to a lesser extent, in the case when a consulting engineer is working in a community different from their own.

\subsubsection{Public involvement}

As mentioned in Chapter 1, there is minimal guidance for engineers on public engagement. The guidance that exists comes from the American Society of Civil 
Engineers (ASCE). Its policy statement on public involvement in the decision-making process acknowledges that public involvement in engineering projects is necessary to ensure that a wide variety of viewpoints have been addressed (ASCE, 2019).

In alignment with current engagement practices and expectations of engineers, the policy statement focuses on providing information to the public. The statement suggests that raising public awareness of the long-term effects of engineering projects on public health, safety, and welfare "is critical for making informed decisions", and that engineers' analysis of a proposed project's costs, benefits, and impacts will "serve to educate the general public and assist public officials in making better informed decisions on engineering projects". In terms of delivering this information, the most practical guidance comes from the final paragraph of the statement:

\section{Civil engineers are encouraged to participate in and seek appropriate public involvement through: public meetings and social media information programs; presentations and discussions of viable alternatives [to a project] including the engineering, environmental, social and economic impacts [of a project]; explanations of the impact of decisions made; and active participation in elected or appointed legislative or regulatory bodies of government (ASCE, 2019).}

However, the statement does not elaborate on how to deliver a presentation, facilitate a discussion, or provide an explanation, other than "to effectively communicate using language that is easily understood by the public, which allows for meaningful dialogue" (ASCE, 2019). Note that 'effective' and 'meaningful' are not defined in the statement, and cannot be assumed to have the same intentions as in Section 2.3. 
As with other professional engineering guidance, the statement does not describe how public engagement, and specifically public input, may influence the design process. The challenge of integrating public engagement into engineering design has been better addressed by innovations in engineering education, as described in the next two sections.

\subsection{Integrating public engagement into the design process}

An engineer's responsibility to protect the public's safety, health, and welfare does not imply that the public has to be involved in the design process. When the public does become involved, for example, as occupants of a new building, they often bring in new criteria for evaluating the design (Atman, et al., 2007). Morrissey (2015) suggests that the list of traditional criteria (cost, scope, and time) needs an update to include people, especially affected stakeholders. They inevitably become evaluators of the design, as they will either use it or be near it long after the design process is complete (Eseonu \& Cortes, 2018). For renewable energy projects, affected stakeholders include local community members ("the public"); it is important that they are regarded as stakeholders in the design, and that they are given opportunities to provide input early and throughout the design process.

As with the other non-technical factors, involving the public necessitates a departure from traditional engineering design. Engineers have historically regarded public engagement as a low priority (Morrissey, 2015); prioritizing public engagement implies that the design process needs to be modified. However, to modify the design process by sticking public engagement into any stage or between stages of the standard engineering 
design cycle is insufficient. Militello et al. (2010) caution against attempting to communicate CSE's value by fitting it into an oversimplified, pedagogical description of the engineering design process; the sequential, stepwise presentation of the process does not accurately reflect reality, and it implies that "one ought to be able to point to one or more blocks in the model and describe how CSE will improve that part of the design process" (Militello, Dominguez, Lintern, \& Klein, 2010, p. 266). Like CSE and sustainability, public engagement can be part of every stage of the process and/or restructure the process entirely; in Gagnon et al.'s table of tools for sustainable design processes, stakeholder engagement is not explicitly listed because "depending on the strategies adopted for participation, stakeholders can be involved in a more or less extensive level in creativity, analysis, and synthesis activities” (Gagnon, Leduc, \& Savard, 2012, p. 58).

\subsubsection{The human-centred design process}

An existing framework integrating public engagement into engineering design is the human-centred design process, which is often used to frame service-learning or community-engaged learning in engineering design courses (more on this in Section 3.5). As implied by the name, human-centred design "puts the people who are the users/community members at the heart of the process, engaging them throughout all phases" (Bielefeldt \& Lima, 2019, p. 3). As shown in Figure 11, community members (C) are "at the table" working alongside engineers (E), policymakers (P), and natural and/or social scientists (S), and community expertise is valued in all phases of design. 


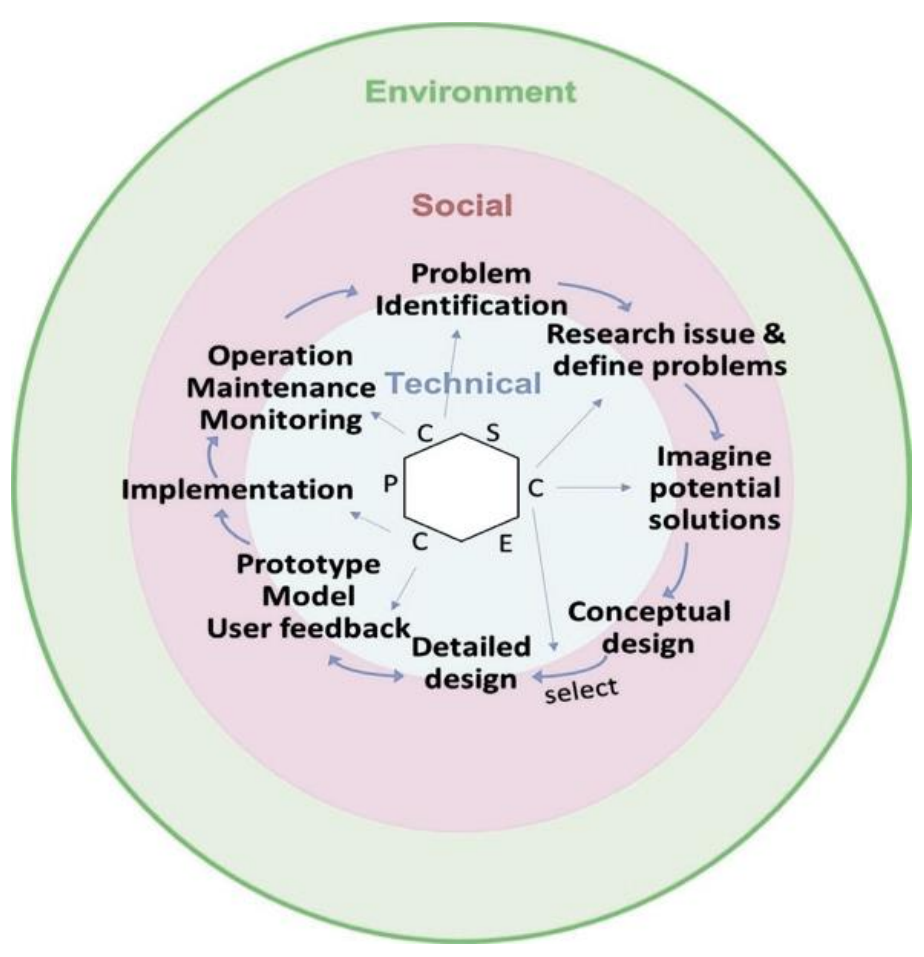

Figure 11: Conceptual model: human-centred design process (Bielefeldt \& Lima, 2019, p. 4)

Despite the caution given above about fitting public engagement into a pedagogical model of the design process, the human-centred design process is framed as an adaptation of the standard design cycle since it is often presented in a pedagogical context to undergraduate engineering students (Bielefeldt \& Lima, 2019). The process is outlined below; for consistency, the names of the stages are adapted from the engineering design cycle introduced in Section 1.3.2:

1. Problem definition: An individual or the community collectively identify a problem or situation they believe engineers might be able to contribute to solving or improving. Problem definition should not be externally imposed, in order to develop an equal partnership between the engineers and the community (Bielefeldt \& Lima, 2019). In addition, allowing the community to identify the 
problem ensures that the problem being addressed is one that the community wants addressed (Gilbert, Held, Ellzey, Bailey, \& Young, 2015).

2. Research: Gain a thorough understanding of the issue, not only the technical aspects, but also the larger context, including historical, social, political, environmental, and economic considerations. This involves talking with and listening to the community (Bielefeldt \& Lima, 2019). Having a broad understanding of the issue ensures that the technical design is coupled with social and political changes that have a positive effect on the community (Harsh, et al., 2017).

3. Ideation: Collaborate with a broad array of stakeholders to brainstorm potential solutions. Engineers can bring examples of solutions that have worked in similar situations, but they should also invite ideas from the other stakeholders. Doing so reinforces the equal partnership developed in the problem definition stage and acknowledges the value of community expertise that may not be technical (Bielefeldt \& Lima, 2019; Eseonu \& Cortes, 2018; Wallen \& Pandit, 2009).

4. Refining and design selection: Collaborate with community members to evaluate the range of ideas under the set of local constraints and criteria. Narrow in on a subset of potentially feasible and appropriate solutions to develop into conceptual designs. Since criteria can be subjective, community members should contribute to the design and ultimately select the 'optimal' design, according to their criteria. This stage may be challenging as different groups within the community may have different perspectives on what is optimal (Bielefeldt \& Lima, 2019). 
5. Detailed design: This technical phase is mostly handled by engineers. Where appropriate, prototypes are developed for community members to test; feedback should be incorporated into the design in an iterative process (Bielefeldt \& Lima, 2019). Engineers need to be transparent with the community explaining what they are doing and why; stakeholders are interested in the process as well as the final product (Cardenas, 2013).

6. Implementation: Where manufacturing is involved, this is often 'detached' from users and communities. However, if building in the area, community members can be involved, either directly working on the project, or indirectly providing services to workers. Examples of service-learning projects where community members have been involved in implementation include constructing a school playground, building a Bridges to Prosperity (B2P) bridge, and building a Habitat for Humanity home. Involvement in this phase helps the community gain a sense of ownership of the project, thus contributing to its long-term sustainability (Bielefeldt \& Lima, 2019).

While the human-centred design process is to be lauded for its extensive community engagement, it tends to stretch timelines beyond what is initially allocated. The extended time is required to build the reciprocal partnerships that enable genuine collaboration. The asset-based model of collaboration is ideal here as it identifies and leverages the strengths of the different stakeholders engaged in the design. For example, in a university-community partnership, the university would bring discipline-specific knowledge and monetary resources, while the community would bring communityspecific knowledge and capacity resources. In addition, this model of collaboration 
allows each stakeholder to learn from and teach something to the other (Bielefeldt \& Lima, 2019).

\subsubsection{Developing the skills required for public engagement}

To maximize the value of the community engagement central to the human-centred design process, engineers require skills beyond the standard technical skillset. Most engineers are not formally prepared to engage with communities; the emotional dimensions required, such as humility, empathy, and patience, are not present in typical engineering courses. Harsh et al. (2017) tested the idea of a co-curricular two-day intensive workshop for engineering students (mostly graduate and upper-year undergraduate) on community engagement. Based on literature at the intersection of science and technology studies (STS) and development studies, they developed a curriculum with three major learning outcomes:

1. Looking beyond technology: understanding the broader context (historical, social, political) surrounding engineering problems;

2. Listening to and learning from communities: addressing personal biases and developing a sense of humility in order to learn from others rather than impose upon them; and

3. Empowering communities: accounting for issues of justice (power balances and equity), building skills and social capital in the community, and planning for longterm relationships with the community. 
The workshop featured experiential learning through a case study, a guest speaker with experience in community engagement, and a group project where participants developed community engagement plans. While the short timeframe for the workshop limited the scope of what could be accomplished, the workshop served as an introduction and exposed participants to the additional considerations that are required when engaging communities. The short timeframe also ironically highlighted that engagement takes time, often longer than expected. One proposed method to overcome this limitation was to pair the workshop with an engineering course that involves engaging with a community (Harsh, et al., 2017); examples of such courses are provided in the next section.

\subsection{Examples of public engagement in engineering design pedagogy}

Many initiatives to introduce engineering students to community engagement have been integrated into engineering design courses spanning all disciplines and all years of undergraduate engineering education. These initiatives are typically framed as servicelearning or community-engaged learning, in which students collaborate with communities to address a problem that could be framed as an engineering problem with an engineering solution (Bielefeldt \& Lima, 2019). Students are provided with an opportunity to apply the engineering design process in a real-world context. Not only do these initiatives force students to develop the skills required to engage with communities, but students complete the course having a deeper appreciation for the importance of civic engagement and using their skills to give back to the community (Eseonu \& Cortes, 2018; Wallen \& Pandit, 2009). 
These initiatives satisfy engineering education accreditation requirements that include non-technical considerations, including graduate attributes related to "communication, ethics and equity, and impact of technology on society that involve engaging stakeholders and understanding users of technology". For example, the Accreditation Board for Engineering and Technology (ABET) in the United States requires engineers to "acquire the broad education necessary to understand the impact of engineering solutions in a global, economic, environmental, and social context", while the Canadian Engineering Accreditation Board (CEAB) requires that engineers possess "an ability to design solutions... that meet specified needs with appropriate attention to... economic, environmental, cultural and societal considerations" (Harsh, et al., 2017, p. 1155; Engineers Canada, 2016).

Research in engineering education provides many examples of courses and institutions that have implemented community-engaged learning in engineering design. Perhaps the most well-known example is the Engineering Projects in Community Service (EPICS) program at Purdue University, which brings together students from first-year to fourthyear, from different disciplines including outside of engineering, to work together on addressing community issues using human-centred design. Past projects include hands-on exhibits for science museums, custom toys for children with accessibility needs, and software for elementary schools, non-profits, and public agencies (Harsh, et al., 2017; Cardenas, 2013). The following subsections showcase examples of community-engaged learning that are student-directed, or humanitarian engineering efforts, respectively. 


\subsubsection{Examples of student-directed community-engaged learning}

One of the longer-standing examples of community-engaged learning in engineering design is the Program for Civic Engagement in Engineering Design (ProCEED) at the University of Michigan. The program is part of the school's mechanical engineering capstone design course. Presented at the American Society for Engineering Education (ASEE) Conference in 2000, it was unique for its time in that students were responsible for seeking community contacts and project proposals. The project aspect of the program was supplemented by lectures on technical communication, ethics, environmental concerns, and the role of the engineer in serving society. Students found the communication material particularly useful as they found that they needed to explain what engineering practice was and what they could offer to the communities they interacted with (Stott, Schultz, Brei, Hoffman, \& Markus, 2000).

Since then, other programs have been developed that require students to seek out communities and projects. For example, the Community Awareness Initiatives Responsibly Directed by Engineers (CAIRDE, an Irish word meaning "friends") program at the National University of Ireland is part of a third-year course in Engineering and Society. Students self-select and self-direct a six-month community project which applies their engineering knowledge and skillset; produces a tool, outcome, or design that meets a need in the community; and benefits an individual or group from a background different from their own (Wallen \& Pandit, 2009).

Another example is part of the Praxis series of engineering design courses in the University of Toronto's Engineering Science program. First-year students in their second 
semester (Praxis II) spend the first half of the semester engaging with communities to "identify, learn about, and define a design problem to help a local community in the Greater Toronto Area" (Chong, Irish, \& Foster, 2019, p. 2); they use the acquired information to write a Request for Proposal (RFP) for their classmates to solve. After the teaching team selects approximately eight RFPs to proceed to the second stage, the rest of the semester is dedicated for students to engage with the communities involved to solve the problems as defined in the RFPs (Chong, Irish, \& Foster, 2019). The resulting designs are presented at an end-of-semester showcase open to the public; attendees typically include government officials, project stakeholders, and the media. Past projects include an improved green bin latch (Annable, 2012), a more efficient naloxone kit (Gignac, 2018), and a device to improve firefighters' navigation during active fires (Mitchell \& Do, 2019).

\subsubsection{Examples of humanitarian engineering in community-engaged learning}

A particular focus of community-engaged learning is humanitarian engineering, which focuses on "clean water supply, health and safety supplies or devices, or renewable energy technology in low-resource foreign locations” (Eseonu \& Cortes, 2018, p. 1). Humanitarian engineering projects are common with co-curricular clubs such as Engineers Without Borders (EWB) and B2P (Bielefeldt \& Lima, 2019, p. 3). These projects are praised for their charity work, but the term 'charity' is itself problematic. The 'outreach' approach common to these projects has two major flaws: first, engineers (or engineering students) position themselves as experts going in to a community needing 'charity' help, establishing an unequal power dynamic and thus inhibiting collaboration; 
second, there are only two main points of communication, at the beginning during project definition and at the end when presenting the final design (Eseonu \& Cortes, 2018; Cardenas, 2013). The outreach approach also tends to lead to the application of modern technology in lower resource areas that do not (yet) support it (Gilbert, Held, Ellzey, Bailey, \& Young, 2015). For example, engineers have designed cookstoves that are more efficient and less polluting than conventional wood stoves for use in villages across Africa, Asia, and the Americas, but the improved stoves are underutilized because consumer behaviour was not considered in the design (ASME, 2016). Instead, Ernst Friedrich Schumacher's 'intermediate technologies' are often more appropriate, fitting into the context of the recipient communities (Gilbert, Held, Ellzey, Bailey, \& Young, 2015). The design solutions are often unique to each situation and thus need to be developed with community members (Bielefeldt \& Lima, 2019).

Research shows examples of humanitarian engineering projects shifting to more of an 'engagement' approach, similar to human-centred design. These projects are often in the context of community-engaged learning programs in engineering design courses. One example is the Community Driven Technology Innovation and Investment (CDTII) program at Oregon State University. As part of a capstone course in mechanical, industrial, and manufacturing engineering, the program engages communities in developing local engineering-related start-ups that can contribute to long-term economic development. The start-ups are formed around a technology created in response to a community need; for example, students designed a device which improved the efficiency and safety of the process for making sopes, a Latin American food item. The program emphasizes engagement with the community at all stages of design, from having the 
community drive project ideas, to engaging community members in brainstorming solutions, to having end users test prototypes of conceptual designs (Eseonu \& Cortes, 2018).

Another example is the Projects in Underserved Communities (PUC) program at the University of Texas at Austin. The three-semester-long series of courses has engineering students collaborate with social work students to take community projects such as well installations, building construction, or environmental technology from problem definition to implementation. The social work students are expected to lend their expertise in community rapport-building, cultural competence, and communication skills, from which the engineering students can learn. A notable feature of this program is that it includes creating a plan for the project's long-term sustainability so that it continues to benefit the community environmentally, economically, and socially after the students hand the project over to the community (Gilbert, Held, Ellzey, Bailey, \& Young, 2015).

\subsubsection{Lessons learned from community-engaged learning}

Despite the variety in these courses, spanning all years and all engineering disciplines, the students who participated in these community-engaged learning programs learned several common lessons. First, students recognized the value in engaging with the end users of their designs throughout the design process. Often, stakeholders provided critical information that went into the design (Wallen \& Pandit, 2009; Stott, Schultz, Brei, Hoffman, \& Markus, 2000). In addition, stakeholders felt valued and respected for being able to share their knowledge with engineering students who may be able to help improve their standard of living (Eseonu \& Cortes, 2018). Second, students developed a new set 
of non-technical skills, including communication and listening, observation and notetaking, and research (Chong, Irish, \& Foster, 2019; Gilbert, Held, Ellzey, Bailey, \& Young, 2015). Despite being outside of the standard engineering curriculum, these skills are crucial for $21^{\text {st }}$ century engineers as they face global challenges that are complex and require interdisciplinary solutions (Harsh, et al., 2017; Wallen \& Pandit, 2009). Third, students learned that engagement necessitates a heavy time investment, as they found it challenging to complete the project thoroughly under the time constraints of the course. In particular, they found that it took a significant amount of time to meet with stakeholders and interpret/validate the information from those meetings (Chong, Irish, \& Foster, 2019; Wallen \& Pandit, 2009). Overall, students gained an enriched learning experience compared to a traditional engineering design course, as well as a deeper understanding of the importance of stakeholder engagement in engineering design. Students can take this experience with them as they advance their engineering careers; community-engaged learning has been shown to increase students' interests in "working with others to make the community a better place to live" (Stott, Schultz, Brei, Hoffman, \& Markus, 2000, p. 12). 


\section{THE GUIDELINES - a proposal}

The guidelines proposed in this chapter are directed to engineers looking or needing to incorporate public engagement into their design processes for renewable energy projects. They draw on the research from the previous two chapters, presenting the insights in a practical, applicable form relevant to the engineering profession. They highlight the similarities between the social science and engineering literature, as well as important points that are unique to one or the other. The validity and applicability of the guidelines as proposed here are tested through the case study in Chapter 6 .

\section{Guideline 0: The intention of the guidelines}

These guidelines are meant to be just guidelines; they do not tell you what to do, but rather prepare you to approach public engagement with a mindset prepared to undertake the work required and appreciative of the importance of engagement.

As models of engineering design can be descriptive or prescriptive (Section 3.1), these guidelines fall somewhere in between. The guidelines are not purely descriptive, because that would imply that one is a bystander in the public engagement process, which should not be the case. They are also not purely prescriptive; they do not take the form of yet another six-step design process. The guidelines fall somewhere in the middle to allow for adaptability; they account for the fact that engineers may not get to choose how directly involved they are in the public engagement process. As such, the intention of these guidelines is not to dictate what one must do, although there are many recommendations for what one should do. Rather, the intention is to create a mindset ready to approach 
public engagement, prepared to undertake the work required and appreciative of the importance of engagement.

\section{Guideline 1: The role of legislation}

Treat legislated public engagement requirements like the Code of Ethics; you must comply with the law, but if circumstances require you to go above and beyond, then you should do so.

Engineers understand that the professional Code of Ethics is written in provincial legislation, and thus is legally enforceable (Section 3.3.1). However, the Code does not dictate exactly what should be done in every situation; rather, it serves as a guideline for professional conduct. Engineers study ethics so that they can interpret the Code and apply it to any situation. Circumstances will determine what action is appropriate, whether simply complying with law is sufficient, or if more is required.

Legislation regarding renewable energy projects, specifically public engagement requirements, should be treated in a similar way (Section 2.5.1). Of course, the legal requirements must be met; if they are prescriptive, as they are in Ontario's REA regulation, then that procedure must be followed. However, the procedure needs to be applied appropriately to the circumstances of the project. The Code states that engineers have an obligation to the public (Section 3.3.1); in some cases, relying on procedural compliance may be insufficient to meet that obligation and additional efforts may be required. 


\section{Guideline 2: The engineer's role in public engagement}

You may not be directly responsible for public engagement, but you have a role in the process.

The proponent is ultimately responsible for public engagement, as they must submit proof of engagement to the government as part of the project application process (Section 2.2). Engineers as consultants need to respect the role of the proponent in leading public engagement (Section 3.3.2). However, this does not imply that engineers cannot be involved in the process.

Engineers are encouraged to be present at engagement sessions, to listen as well as to answer questions (Sections 3.4.2, 2.5.4). In this role, engineers are expected to be agents of the proponent, but otherwise neutral parties, presenting information objectively, fairly, and accurately (Section 3.3.2). Being an active participant protects against information loss when public input is transferred from the engagement facilitators to the engineers, thus maintaining process competence / efficiency (Section 2.3). In the case that engineers cannot attend a session, they could reference the documentation from the session, including submitted public input, transcripts (if available), and summaries of the meeting written by project representatives who attended it.

In addition, as the consultant, engineers can encourage the proponent to hold engagement sessions at strategic points in the design process. Engaging the public at the right time(s) not only improves the project, but allows for genuine human-centred design (Sections 
2.2, 3.4.1). Further discussion on timing can be found in Guideline 5: The opportunities for public input to feed into design.

\section{Guideline 3: The fundamental principles of effective public engagement}

Apply the principles from the Code of Ethics to public engagement; not only are they necessary for the engineering profession, they are also fundamental to effective engagement processes.

Recall that effectiveness is fairness combined with competence / efficiency. Fairness means that participants believe the engagement process was conducted honestly, with serious intent to collect participant views, and to address any concerns brought forward. Competence / efficiency means that relevant information is sought from relevant sources and transferred efficiently to the appropriate receivers. Also, recall the Government of Canada's principles for meaningful public participation: engagement is inclusive and transparent, and information is available to the public; engagement increases the knowledge of participants and the government and builds relationships; it ensures that members of the public have an opportunity to share their views; and it influences decision-making and participants see how their input was considered (Section 2.3).

Conducting an effective and meaningful engagement process requires the principles from the Code of Ethics (Section 3.3.1): a fair process requires integrity, honesty, and respect; an inclusive and transparent process requires openness and accountability; building relationships requires courtesy, good faith, and trustworthiness; and allowing public input to influence design demonstrates responsibility and competence. 


\section{Guideline 4: The importance of the process}

You may be used to focusing solely on the end result, but shift your focus to the process; focusing on the process will almost certainly improve the overall outcome.

One of the insights from studying various models of engineering design was that there is a clear focus on the end product, with little evidence of people or process management (Section 3.1). When public engagement is involved, this focus should shift from the outcome to the process given that fairness of process may be more important than fairness in outcomes (Section 2.5.3). Recall that fairness and equity in the decisionmaking process leads to procedural justice, which is also one of the four categories of justice that engineers should consider when solving ethical dilemmas (Section 3.3.1).

Focusing on the process is necessary because contrary to engineers' expectations, public engagement is not a fully structured process. There will likely be differences of opinion, even within the public; as such, engineers need to be flexible and adaptable to deal with uncertainty (Section 2.4). This will likely result in extended timelines; both proponents and engineers should be prepared for this possibility (Sections 2.5.2, 3.5.3). When differences of opinion on the design cannot be settled, ensuring the process is fair may

alleviate potential animosity. Participants have a right to be heard; thus, the process must provide opportunities for opposing positions to be aired and recognized as legitimate. If participants are treated fairly throughout the public engagement process, they are more likely to accept the decisions resulting from the process, even if they perceive the outcome as negative (Section 2.5.3). 
This shift of focus should not be completely new, as ethical considerations for foreign consulting require engineers to focus on the process. Avoiding exploitation, paternalism, and bribery requires treating participants fairly. Respecting human rights, cultural norms and laws requires giving participants a chance to provide input in the way that allows them to communicate most comfortably. Promoting the community's welfare requires listening to community members as they describe how their livelihoods can be improved (Section 3.3.2).

Note that this shift of focus from the outcome to the process does not imply ignoring the outcome completely. Obviously, proponents still want their projects built, and policymakers still care about reducing greenhouse gases and boosting the renewable energy industry. However, there is a possibility that achieving the optimal technical outcome (for example, maximizing production capacity in a given area) results in a less desirable societal outcome. The point of this shift is to emphasize the importance of the process. By focusing on the process, the overall outcome is more likely to be positive, even without necessarily focusing on the outcome (technical or societal).

\title{
Guideline 5: The opportunities for public input to feed into design
}

\author{
Public input can feed into every stage of design, from problem definition to \\ implementation.
}

Referring to the engineering design cycle in Section 1.3.2, there are opportunities for public input to feed into every stage of design: 
1. Identify: While the proponent would be wise to wait until a potential project has been proven feasible to inform the public about it, they would be unwise to wait any longer than that. Starting engagement early in the process is important so that community members with different ideas and values can express those and have them accounted for in project design (Sections 2.5.2, 3.2.4). This approach does not go as far as allowing the community to define the problem, as in humancentred design; the public is not in a position to determine whether the electricity grid needs more renewable energy capacity. However, by allowing public input to influence the problem definition, the proponent can still develop an equal partnership with the public. In addition, speaking with community members to learn about the broader societal context for the project can help the engineers develop appropriate design requirements (Sections 3.4.1, 3.4.2).

2. Ideate: As the type of renewable energy technology is fundamentally dependent on the geography of the project site (as that determines whether there is adequate wind or solar resource available), there is little room for ideation in terms of the entire project. However, specific design features may be more flexible; for example, public input may influence the type of solar tracking system used, or the colour of wind turbines. These features may provide local benefits that are peripheral to the main objectives of the project, thus warranting public input. The public may come with unconventional ideas; engineers responsible for the technical design should acknowledge and consider them. Sometimes, collaborating with a community member on developing their idea may turn what seemed irrational into something that works (Sections 3.4.1, 3.5.2). 
3. Refine: Similar to step 2, this step mainly applies to specific design features rather than the entire project. Public input may help to narrow down the range of ideas, as they are evaluated under local constraints and criteria. Recall that when the public comes into the design process, the criteria for evaluation may change, and may even differ between subgroups of the public (Section 3.4.1).

4. Analyze: Engineers will conduct the technical analysis of the alternative designs. However, community members may have local expertise that might be relevant for the analysis; for example, knowledge about historical land use in the area (Sections 3.4.1, 3.5.3). This expertise can be particularly important in the context of an EA, which requires an assessment of the project's impacts on the local ecosystem (Section 2.5.1).

5. Decide: Design selection is primarily based on the technical analysis, but should also consider professional ethics and public input (Sections 3.3.1, 3.4.1). This approach does not go as far as allowing the community to pick the 'optimal' design, as in human-centred design, but still accounts for local criteria (Section 3.4.1). In addition, using this approach, the public has direct influence on project decisions, which is essential for effective public engagement (Section 2.3).

6. Implement: Like step 4, engineers are responsible for the detailed design. One option to engage the public is to build scale models (prototypes) for community members to see and provide feedback on (Sections 3.4.1, 3.5). Any feedback gathered should be considered and, if possible, incorporated through an iteration of steps 3 to 5 (Section 1.3.2). Finally, the contractor handles construction, so while there is no opportunity for public engagement per se, having a local 
contractor and/or hiring local employees keeps the project and its economic benefits within the community (Sections 3.3.2, 3.4.1).

While all these opportunities for public input to feed into design are possible, they may not be feasible for every project. Feasibility will depend on how willing the proponent is to engage the public (beyond legislated requirements), as well as how invested and engaged the public is. Regardless, providing these opportunities allows the proponent to demonstrate accountability, as well as build their partnership with the public by showing that they value public input (Sections 2.2, 2.5.1, 3.5.3).

\section{Guideline 6: The engagement mechanism(s)}

You may not get to choose the engagement mechanism(s), but chances are you will be providing information to members of the public.

As the proponent is ultimately responsible for conducting public engagement, most likely

they will choose which engagement mechanism(s) to use. Guidance is available to inform the development of a public engagement strategy, such as CEAA's Public Participation Guide, or IAP2 resources (Section 2.5.4). Of course, if legislation dictates what engagement mechanism(s) to use, then the proponent does not have a choice, at least not until they have met legislative requirements (Section 2.5.1).

Current practice is to focus on information provision, with exhibitions being the most popular choice of mechanism. If the proponent chooses to follow suit, engineers should make themselves available as technical experts to provide information and answer 
questions (Section 2.5.4). However, to avoid the engineer's fallacy, they should not assume that the public is a homogenous body. In addition, to avoid the traps of the information-deficit model or NIMBYism, they should approach engagement with an open mind rather than a preconceived notion of the public as uninformed or selfinterested (Section 2.4). Even though they are technical experts, engineers should treat every interaction as an opportunity to develop the equal partnership between the proponent and the public (Sections 2.3, 3.4.1). As such, they should communicate with the public in plain language, avoiding the use of technical terms and jargon (Section 3.3.3).

If current practice evolves as a result of legislation updates or adopting research findings, then the engagement mechanisms used could change (Section 2.5.1). The focus may no longer be on information provision, but rather collaborating with the public or empowering the community (Section 2.5.4). In this case, engineers may find themselves in more of an active listening role, which can be a rather foreign environment for most engineers (Section 3.4.2). To adapt, engineers will require a new skillset which is described in Guideline 8: The need for new skills.

\section{Guideline 7: The integration of public input into design}

Make an active effort to integrate public input into your design, so long as doing so does not undermine your professional obligation to public safety, health, and welfare. Be sure to justify your decisions and report back to the public. 
Soliciting public input at various points in the design process is one thing, but integrating the input into design is another. Recall that with the various non-technical factors (environment, sustainability, human behaviour), they were often considered independently of design as opposed to integrated into the design process, ultimately limiting their potential added value to the design (Section 3.2.4). Similarly, soliciting public input but not integrating it into the design process can limit its potential value. In fact, not integrating public input can undermine the public engagement process, as the public loses influence on project decisions, thus returning to one of the problems with current engagement practices (Section 2.3).

As such, engineers should make an active effort to integrate public input into design. If a concern is brought up, they should address it; if a suggestion is made, they should consider it (Sections 1, 2.2, 3.4.1). However, this does not mean that they should blindly use every idea suggested by members of the public. Engineers are ultimately the technical experts and can determine what is feasible in the design; the priority should always be public safety as specified in the Code of Ethics (Section 3.3.1). Whether or not public input is incorporated into the project, engineers need to be accountable and report back to the public with any decisions that were made and justifications for those decisions (Sections 2.3, 3.3.1). By doing so, the process is transparent and the public gets to see how their input was considered and used in the design (or if not used, the reasons for that decision) (Sections 2.3, 3.4). Of course, transparency can only happen to the extent where it does not violate rules around confidentiality (Section 3.3.2). 


\section{Guideline 8: The need for new skills}

Your formal engineering education may not have prepared you for public engagement; take advantage of professional development opportunities and pair them with practical experience.

The engineering curriculum has only recently started to adapt to prepare engineering students to engage with the public (Section 3.5). While engineers still require a technical foundation, it needs to be complemented with non-technical skills such as communication and listening, observation and note-taking, and research (Section 3.5.3). In addition, engineers need to develop emotional qualities such as humility, empathy, and patience, as well as an awareness of the broader context of engineering projects including historical, social, and political considerations (Section 3.4.2).

The ideal way to acquire the aforementioned skills is through experiential learning. Community-engaged learning is very valuable in this regard, as it exposes students to the challenges inherent to public engagement, and forces students to develop the skills required to tackle these challenges (Section 3.5). For those already out of school, there are professional development workshops and short courses on public engagement. For example, in June 2019, the Canada School of Public Service (CSPS) ran a six-week public online course called Learning Together for Better Public Engagement (Learn4PE). The course offered tools and tips on planning for engagement, running and facilitating an engagement session, and analyzing public input (CSPS, 2019). Of course, a workshop or short course cannot provide the full learning experience that community-engaged 
learning provides, but paired with practical experience it can equip engineers to engage in public engagement processes and to integrate public input into design (Section 3.4.2). 


\section{The Ontario Context}

This chapter provides the provincial context for the case study in Chapter 6; first, outlining the regulatory framework for renewable energy in Ontario; and second, summarizing relevant guidance provided by provincial professional engineering organizations.

\subsection{Regulatory Framework}

Ontario has seen a rapid expansion of its renewable energy capacity over the past ten years, driven largely by three policies: the Green Energy Act, the Feed-In Tariff Program, and the Renewable Energy Approval Process. These policies enabled renewable energy development by creating the market for renewable energy and specifying exactly what project proponents had to do to get a project approved and built. While these policies worked as intended, they were by no means perfect; local academics have analyzed and critiqued the policies and their implementation, sharing lessons for other jurisdictions considering a transition to renewable energy. This section provides an overview of each of the three policies mentioned above, supplemented by the academic commentary.

\subsubsection{Green Energy Act}

In May 2009, the provincial government enacted the Green Energy and Green Economy Act, often referred to as simply the Green Energy Act (GEA). The goals of the Act were to promote renewable energy production, promote energy conservation, and stimulate job creation (Government of Ontario, 2019). The Act supported Ontario's plan to phase out 
coal-fired electricity generation, while providing a boost to the economy in the wake of the 2008 recession. The Act also enabled amendments to 16 other Acts which contributed to driving renewable energy development in the province (McRobert, Tennent-Riddell, \& Walker, 2016). Two notable features that came out of these changes are the Feed-In Tariff (FIT) program and the Renewable Energy Approval (REA) process, to be discussed in Sections 5.1.2 and 5.1.3 respectively.

In the ten years prior to 2009 , a broad coalition had formed and grown to advance renewable energy policy in Ontario. The Green Energy Act Alliance became the main proponent of the GEA, and consisted of environmental non-government organizations (ENGOs), energy and engineering consultants, renewable energy industry stakeholders, farmers, First Nations, and organized labour (McRobert, Tennent-Riddell, \& Walker, 2016; Stokes, 2013). Perhaps due to the support for the Act from such a wide range of actors, it was pushed through the legislative process in about eight weeks. The speed at which this happened clearly demonstrated the government's determination to create favourable conditions for deploying renewable energy (Hill \& Knott, 2010). However, there was little opportunity for stakeholders who had concerns to bring them forward and have them addressed (McRobert, Tennent-Riddell, \& Walker, 2016). The lack of engagement mechanisms in the creation of the GEA would foreshadow the engagement process at the project level.

As the GEA's associated policies and programs were implemented, the opposition movement grew substantially. The most vocal opponents were anti-wind groups, who expressed concerns about the visual impact of turbines on the rural landscape, the hazard 
to bats and birds, and the noise from turbines and its adverse effects on health (Jami \& Walsh, 2017). Both industry and government have done little to address these concerns; rather, they downplayed the significance and legitimacy of them (Hill \& Knott, 2010). As a result, 90 Ontario townships and counties have passed resolutions declaring themselves "non-willing hosts" for wind turbines (Walker \& Baxter, 2017). This movement had the support of the government opposition, and when they were voted into power in June 2018, they moved quickly to repeal the GEA, officially doing so on January 1, 2019 (Government of Ontario, 2019).

\subsubsection{Feed-In Tariff Program}

The GEA enabled the creation of the FIT program, which was designed to stimulate renewable energy production by creating a market for the associated technology (Stokes, 2013). The program applied to bioenergy, solar energy, water power, and wind energy, and provided 20-year (40-year for water power) contracts for guaranteed prices for electricity generated by these sources. The program was split into two streams depending on the size of the project; projects 10 kilowatts $(\mathrm{kW})$ and smaller fell into the microFIT stream, while projects larger than $10 \mathrm{~kW}$ fell into the FIT stream (Yatchew \& Baziliauskas, 2011).

FIT programs are used around the world as a policy instrument to support large-scale, rapid renewable energy development. While they vary in design and implementation, they generally share three components: a standard purchasing price per unit of electricity supplied, a requirement that the electric utility buy all available electricity, and a longterm contract at the given price (Stokes, 2013). FIT programs can provide multiple 
benefits if designed well: they can remove barriers to entering the electricity market, provide stability and investor certainty, allow for diverse participation across society, and encourage technological learning. However, there are also a few factors to be cautious about: governments have historically struggled with subsidies for energy technologies; the cost structure is transparent, opening it up to criticism; there is a risk of clustering projects in geographical areas with the right resources (wind or sun, access to grid, access to load center); and if the cost of the tariff is passed on to ratepayers, there may be complaints about rising electricity costs, putting the program's political sustainability at risk (Stokes, 2013; Mabee, Mannion, \& Carpenter, 2012; Yatchew \& Baziliauskas, 2011).

The FIT program in Ontario received a strong supply response; in the first year, the Ontario Power Authority (OPA) received applications totalling 15,000 MW. The majority $(69 \%)$ of that capacity was for wind, followed by solar photovoltaic (PV) $(28 \%)$. The large amount of capacity procured is attributed to several factors, including the attractiveness of the prices offered for electricity, the priority access to the transmission and distribution grids, and the streamlined process for approval. In addition, while project proponents are responsible for the costs of connecting their projects to the grid, they are not responsible for the costs of transmission expansions where needed to accommodate FIT projects; that cost is passed on to ratepayers (Yatchew \& Baziliauskas, 2011).

As problems arose during implementation, the FIT program underwent a few rounds of changes. The government adjusted prices between scheduled biennial reviews; for example, in the summer of 2010, the prices for ground-mounted solar in the microFIT 
program had to be reduced because the number of applications was higher than expected, and production costs were rapidly declining (Yatchew \& Baziliauskas, 2011). In addition, the government adjusted the criteria on which it judged proposals for contracts; for example, in 2012, the FIT program started prioritizing projects that could demonstrate municipal support, as well as community-based and First Nations projects. While this change responded to concerns about the lack of public engagement for what were mostly developer-led projects, it did not appease the growing anti-wind movement, and the FIT program for large wind projects was cancelled a year later (Fast, et al., 2016). In 2015, the FIT was replaced with the Large Renewable Procurement (LRP) Program, which had explicit incentives for community and municipal engagement activities. The points-based system for assessing potential projects awarded additional points for "demonstrating quality community engagement prior to being offered contracts" (Songsore \& Buzzelli, 2016, p. 14).

The eventual demise of the FIT program (for all energy sources) came from its upward push on electricity prices. Neither the FIT nor the microFIT were independently well researched and evaluated before implementation, so the quantitative outcomes of the program were unclear (McRobert, Tennent-Riddell, \& Walker, 2016). In 2011, the Ontario Auditor General issued a report criticizing the implementation and costs of the FIT program (Fast, et al., 2016). By 2016, rates had escalated to the point where people were choosing between paying their electricity bill and buying food or paying rent (The Canadian Press, 2016). In response, the government suspended the LRP program in September 2016, and subsequently enacted the Fair Hydro Act, 2017, which reduced residential electricity bills by an average of 25\% (Ontario Ministry of Energy, 2017). The 
reduction of electricity bills was not enough to appease citizens, and in the next year's election, citizens voted the opposition party into power. Although renewable energy was only one of multiple factors contributing to the rise of electricity prices, it was perceived as the key culprit, thus making the FIT program politically unpopular. The new government repealed the GEA, and cancelled 758 renewable energy projects which were contracted under the FIT program. This move received harsh criticism because most of the cancelled projects were small-scale community projects, predominantly rooftop solar (The Canadian Press, 2018).

\subsubsection{Renewable Energy Approval Process}

The GEA also enabled the creation of Regulation 359/09, commonly known as the REA regulation (Government of Ontario, 2016). Most wind, solar, and bioenergy projects require a REA from the Ministry of the Environment (MOE); exemptions include some classes of small-scale wind and solar projects (Ontario MOE, 2017). The Regulation contains rules on topics including (but not limited to) application procedures, public engagement, project siting, and protection of cultural and natural heritage sites (Fast \& Mabee, 2015; Mulvihill, Winfield, \& Etcheverry, 2013).

The GEA established a Renewable Energy Facilitation Office to work with project proponents to speed FIT contract approval and grid connection. The REA process is heavily streamlined; municipal jurisdiction and local authority is nonexistent, public engagement requirements are minimal, and the opportunity to appeal is very limited. While this streamlining removed uncertainty for proponents and resulted in the procurement of a large amount of renewable capacity, it is strongly criticized for its 
procedural injustice to communities, specifically, the lack of meaningful public engagement in project-related decision-making processes (Fast, et al., 2016; Stokes, 2013; McRobert, Tennent-Riddell, \& Walker, 2016).

The intent of removing municipal jurisdiction through amendments to the Planning Act was to limit the possibility of delays due to resistance at the local level, characterized by the Ontario Premier as NIMBYism (Fast, et al., 2016). In addition, by removing municipal authority, proponents could avoid the patchwork of municipal requirements around setbacks, bylaws, and community benefit arrangements, making the approval process more predictable. However, by removing municipal jurisdiction, local planners and politicians were effectively structured out of the process; due to their knowledge and skills in local context, they are often the most trusted to navigate the balance between development and protecting land use. Without a local advocate for projects, citizens have difficulty getting answers to their questions, and ultimately trusting that the developer has the community's best interests in mind (Fast \& Mabee, 2015; Hill \& Knott, 2010). As such, Fast and Mabee (2015) argue that the removal of municipal authority is itself a reason to protest the REA and the GEA.

The REA regulation mandates public engagement activities as part of the approval process, with further instructions provided in the Technical Guide to Renewable Energy Approvals (Ontario MOE, 2013). After acquiring a FIT contract, the proponent is required to host a minimum of two public meetings. The first meeting is for notifying the community about the project; a draft of the Project Description Report (PDR) must be made available to the public 30 days prior. The final meeting is for sharing the completed 
reports and studies; the project description, construction plan, design and operations, and decommissioning plan reports, as well as the cultural heritage, natural heritage, and water body assessments must be made available to the public 60 days prior to the meeting. Other reports that may be required at this stage include an archaeological assessment, an effluent management plan, an emission summary and dispersion modelling report, an environmental impact study (EIS), a heritage assessment, a hydrogeological assessment, a noise study, an odour study, a property line setback written assessment, a surface water assessment, and a specifications report for wind facilities.

To demonstrate proof of public engagement, proponents must prepare a consultation report. The report has two purposes: to document how engagement activities were undertaken, and to provide a record of public input as well as how it was considered. Only after all consultation and report requirements have been completed can the proponent submit their project application to the MOE for a REA (Ontario MOE, 2013). Figure 12 shows an overview of the REA application process, including the general timing of public engagement. 


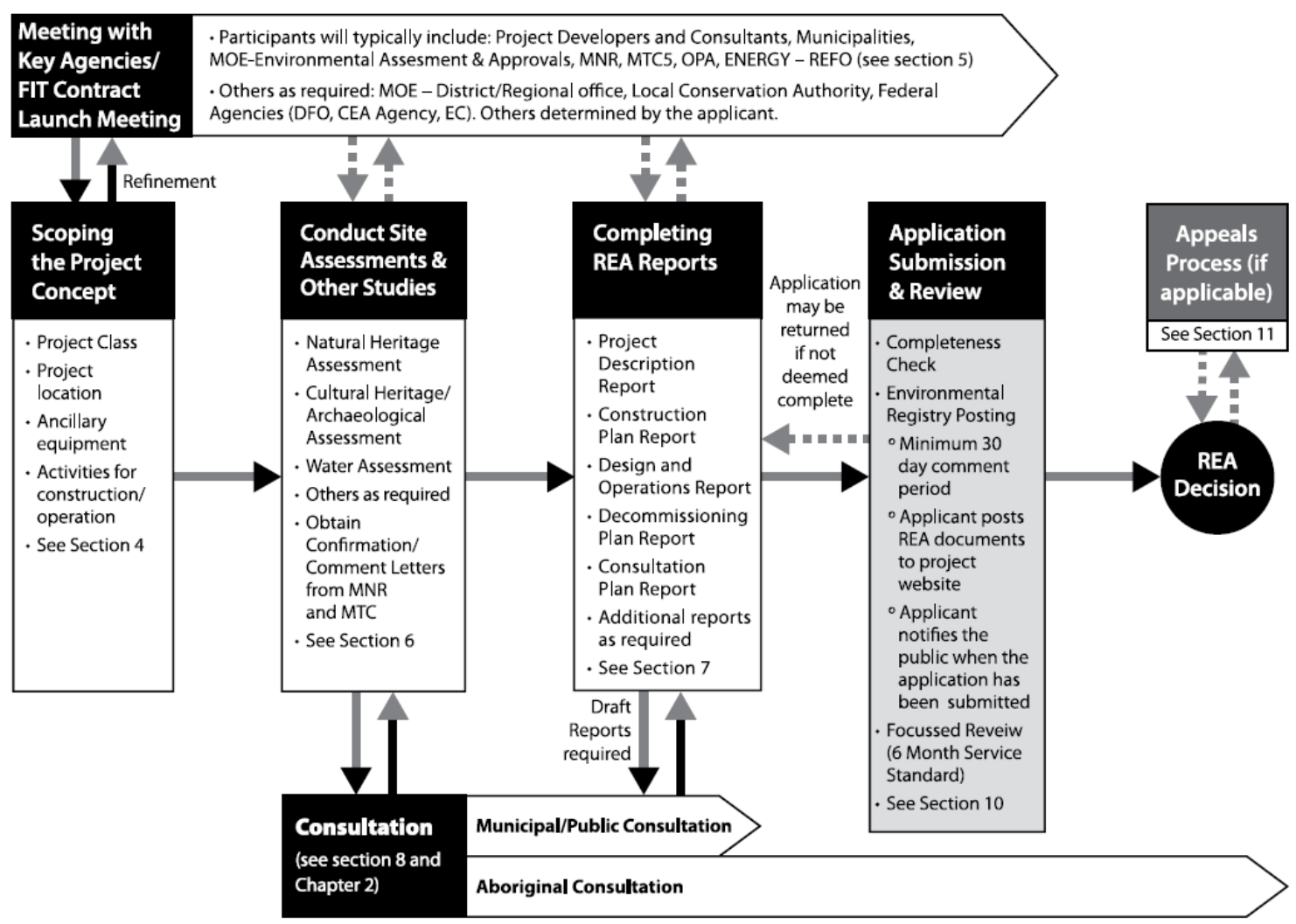

Figure 12: Overview of the principal elements of the REA application process

(Ontario MOE, 2013, p. 23)

Critics of the REA process highlight two major issues. First, these minimum requirements were often treated as maximum requirements; while the Technical Guide encourages proponents to go above and beyond these requirements, this was rare in practice. Second, the structure of contracts discouraged early and broad engagement; the first-come, first-serve awarding of approvals prioritized speed over quality and effective engagement (Fast, et al., 2016). Since the format of the public meetings was not specified, most meetings adopted the exhibition format, in which information is presented on various display stalls or information booths, similar to the conventional EA format described in Section 2.5.4. While intended to avoid group antagonism, this generally 
created one-way information flow, leading participants to perceive these meetings as tokenistic (McRobert, Tennent-Riddell, \& Walker, 2016; Fast, et al., 2016). The lack of meaningful engagement appears to be an unintended consequence of the requirements; the technical guide encourages proponents to "be a good neighbour" by engaging the public early and often, getting involved in local community projects, making it easy for community members to express and resolve concerns, minimizing project impacts on the community, and keeping the lines of communication open for the entire project lifecycle (Ontario MOE, 2013, pp. 209-210).

The public engagement process as typically implemented provides little opportunity for stakeholders to express concerns. This leaves many to resort to the "polarizing process" of submitting a formal appeal to the Environmental Review Tribunal after the project has been approved (Fast, et al., 2016, p. 5). The appeal process was updated under the GEA to further streamline the REA process; the window to appeal is only 15 days starting when the project is posted on the Environmental Registry website. The test for appeals is stringent and narrow; a hearing is only required if the project "will cause either serious harm to human health or serious and irreversible harm to plant life, animal life, or the natural environment" (McRobert, Tennent-Riddell, \& Walker, 2016, p. 103). The chance for a successful appeal is unlikely, given the high standard and the need for substantive evidence; for example, with regards to large wind projects, "while virtually every approval has been appealed by project opponents they have repeatedly failed to convince adjudicators of serious human health impacts" (Fast \& Mabee, 2015, p. 34). Like the public engagement process, the appeal process limited chances for opposition, thus eliminating some of the uncertainty and frustration proponents had experienced under the 
previous third party appeal process under the Environmental Bill of Rights (McRobert, Tennent-Riddell, \& Walker, 2016).

As a condition of receiving the approval, proponents have three months to establish a community liaison committee (CLC). Establishing a CLC "demonstrates [the proponent's] intent to establish long-term positive relations and encourage local participation in the development process" (Ontario MOE, 2013, p. 209). While the meetings are intended to engage the public, they often do not address project design considerations or other issues supposedly addressed through the REA process. As such, in many cases they seem like little more than a formality: "CLC notices give the impression that they are rubberstamp committees in which public participation remains superficial at best” (Jami \& Walsh, 2017, p. 19).

Overall, the streamlining of the REA process and the lack of meaningful public engagement has resulted in many renewable energy projects operating without their host community's widespread support. Projects have polarized community members into two camps: those who support a local renewable energy project versus those who do not. The GEA has already suffered as a result, placing the durability of renewable energy policy in Ontario at risk (McRobert, Tennent-Riddell, \& Walker, 2016). As of September 2019, the Long-Term Energy Plan published by the previous government has been archived online, and the current government has not announced any future plans for renewable energy (Ontario Ministry of Energy, 2017). 


\subsubsection{What about Environmental Assessment?}

Projects that require a REA are exempt from the requirements of the provincial Environmental Assessment Act (Government of Ontario, 2010). Only water power projects are still subject to EA legislation; specifically, projects $200 \mathrm{MW}$ or larger require an Individual EA, while those less than $200 \mathrm{MW}$ fall under the Class EA for Waterpower projects (Ontario Ministry of Energy, 2019). The exemption from EAs for most renewable energy projects is a cause for concern; in the REA, the assessment of potential environmental impacts is minimal (Mulvihill, Winfield, \& Etcheverry, 2013). The only requirement in the REA that resembles an EA is encompassed within the natural heritage assessment (NHA) (Ontario MOE, 2013).

Eliminating project-level EAs would not be as concerning if the government conducted regional EAs. However, in the case of the GEA, there was no large-scale spatial planning strategy; there were few restrictions on where projects could be sited. This led to the exploitation of areas with favourable geographical conditions and resources, likely resulting in adverse cumulative environmental effects. For example, there are at least five wind projects within an area internationally recognized for its significant bird populations. While no massive fatality events have occurred, annual avian mortality rates are higher than other wind projects in North America. This has caused concern among many residents, especially local birders (Fast \& Mabee, 2015).

Given that there were no project EAs or regional EAs, the lack of a strategic environmental assessment (SEA) for the GEA is even more concerning. A SEA complements project and regional EAs by assessing the impacts of policies and 
programs, acknowledging that individual projects are components of larger plans (Mulvihill, Winfield, \& Etcheverry, 2013). SEAs are a relatively new idea in Canadian environmental policy (at least formally); the federal government is only starting to develop them as part of the ERR. The government's SEAs are intended to "provide transparent, consistent guidance on how existing environmental frameworks are considered in the impact assessment process". For example, the Strategic Assessment of Climate Change, to be released in early 2020, will apply to projects assessed under the Impact Assessment Act (Strategic Assessment of Climate Change, 2019).

Mulvihill et al. (2013) argue that the lack of a SEA can "slow down or hamper the implementation of policies, plans, programs, and projects, and reinforce, rather than resolve social conflicts around them" (p. 10). In the case of the GEA, a SEA would analyze the sustainability of the province's overall approach to electricity system planning, as well as the viability of the FIT program. A SEA would also help to optimize the economic, social, and ecological dimensions of renewable energy. An evident consequence of not having a SEA is that Ontario has not maximized its geographic potential for renewable energy; for example, while the Canadian Wind Energy Association (CanWEA) claims that Ontario has the potential for 24,000 MW of wind supply, the province has only $5076 \mathrm{MW}$ of installed capacity as of December 2018 (CanWEA, 2019). This underachievement can be attributed to political, technical, and commercial factors, but also reflects a lack of strategic planning. The value of the SEA is that it can inform the design of policy to achieve broad, yet interlinked social, economic, and environmental goals (Mulvihill, Winfield, \& Etcheverry, 2013). 
Overall, the lack of EA at any level has undermined the GEA and renewable energy development in Ontario. While conducting an EA may seem like extra work for both the proponent and the government, the process of doing so would help to identify and mitigate potential adverse impacts early, thus contributing to the sustainability of renewable energy in the province.

\subsubsection{Other Approvals}

While the REA exempts most projects from the requirement for an EA, other approvals, permits and/or authorizations may be required depending on the location and nature of the project. The project proponent is responsible for acquiring all the required approvals, permits and authorizations for the project. The following is a non-exhaustive list of other potentially relevant ministries and approving bodies (Ontario MOE, 2017):

- Ministry of Natural Resources (MNR)

- Ministry of Transportation (MTO)

- Ministry of Agriculture and Food

- Conservation Authorities

- Niagara Escarpment Commission

- Municipalities (i.e., building permits)

- Electricity System Operators / Energy Agencies

OPA, now the Independent Electricity System Operator (IESO)

○ Ontario Energy Board (OEB)

- Federal Government / Agencies 


\subsection{Ontario-specific engineering guidance}

Professional engineers in Ontario are represented by two organizations: Professional Engineers Ontario (PEO) and the Ontario Society of Professional Engineers (OSPE). PEO is the licensing and regulating body for professional engineering in Ontario, while OSPE is the advocacy body for the engineering profession in Ontario. While the two organizations have different mandates with minimal overlap, they work together for the future of engineering in Ontario as "two sides of the same coin" (OSPE, 2016). This section expands on Section 3.3 by summarizing guidance from each organization as it relates to renewable energy projects and the GEA.

\subsubsection{Professional Engineers Ontario (PEO)}

PEO operates under the authority of the Professional Engineers Act, which restricts the practice of engineering to those who are qualified and licensed (PEO, 2018). The Act defines the 'practice of engineering' as:

any act of planning, designing, composing, evaluating, advising, reporting, directing or supervising that requires the application of engineering principles and concerns the safeguarding of life, health, property, economic interests, the public welfare or the environment, or the managing of any such act (Government of Ontario, 2018).

A unique aspect of this definition is that it explicitly mentions safeguarding of the environment, thus making protection of the environment a legal responsibility of professional engineers in Ontario (Andrews, Shaw, \& McPhee, 2019). 
Regulation 941 provides additional details and guidance for implementation of the Act. The Regulation contains the Code of Ethics, which is an adaptation of the Engineers Canada Code of Ethics. Unlike the national Code, the provincial Code is legally enforceable under the Act. The Regulation also restricts designation as a consulting engineer in Ontario. Professional engineers who want to be consulting engineers need to apply to PEO for the designation. To be designated, they require a Certificate of Authorization, five years of experience additional to the four required for licensure, of which two must be in private practice, and liability insurance (Andrews, Shaw, \& McPhee, 2019).

PEO's Professional Engineering Practice Guideline elaborates on the nature of the clientconsultant relationship. To reiterate from Section 3.3.2, consulting engineers (practitioners) "should serve their clients... with integrity and objectivity, making every effort to carry out assigned activities in a professional manner" (PEO, 2017, p. 11). PEO recommends developing a written agreement between the client and the practitioner that contains the following:

- The client organization and the contact to whom the practitioner will report;

- The fees and expenses to be charged to the client;

- Any ongoing assurances or guarantees to be given by either party;

- Any limitations to liabilities or services provided by the practitioner;

- Any information the client will provide and in what form, and a schedule of when this information will be released;

- The scope of work detailing the services the practitioner is expected to provide; 
- A list of items to be delivered by the practitioner;

- A schedule for completion of various phases of the work, submission of deliverables, and payment of fees;

- Any remedies for breach of contract by non-payment or by early termination of services by either party; and

- A right to terminate the agreement in appropriate circumstances.

The agreement should also contain the procedure for dealing with unexpected issues. The client and the contractor should "inform the practitioner of problems and/or changes to project definition at the earliest opportunity"; the practitioner should also "agree to inform the client, in writing and as soon as possible, of any situation that will delay the project or require alterations to the scope of work" (PEO, 2017, p. 12). In addition, if the client-consultant relationship follows the 'agent' model, the agreement should specify the responsibilities of the practitioner as an agent. PEO also provides guidance to practitioners on determining whether to accept an assignment, with the priority being that the terms of reference and/or the project budget must allow them to "provide a service commensurate with their professional obligations to the client and the public" (PEO, 2017, p. 12).

PEO engages in public policy matters through its Government Liaison Program (GLP); as implied by the name, the GLP liaises between PEO and the government. The program's main objective is "to ensure that government, PEO members and the public continue to recognize its regulatory mandate, in particular its contributions to maintaining the highest level of professionalism among engineers working in the public interest" (PEO, 2018). 
One of the GLP's initiatives is to monitor and take action on policy proposals and legislation that may affect PEO and the Professional Engineers Act. In 2012, the GLP

published an information note on the GEA, as it is relevant to the profession, "involving the expertise of many engineers". Following a brief summary of key elements of the GEA, the note states that "there are no regulatory impacts to PEO at this time, so no involvement by the GLP is required". The note then refers engineers who want to get involved with matters concerning the GEA to OSPE (PEO, 2012).

\subsubsection{Ontario Society of Professional Engineers (OSPE)}

OSPE is "the voice of the engineering profession in Ontario", representing professional engineers, engineering graduates, and engineering students. OSPE advocates with the government on issues important to society and the engineering profession, such as energy, the environment, infrastructure, and research. It speaks on the critical role that the engineering profession plays in growing the economy while protecting the environment and improving the quality of life in Ontario (OSPE, 2019).

OSPE supports renewable energy, but not policies that make renewables unsustainable. For the most part, it is critical of the implementation of the GEA. In 2012, OSPE's Energy Task Force published a report identifying risks to Ontario's power mix and calling on the government to scale back its plans to rapidly expand renewable energy generation (OSPE, 2012). The report predicted that continuing rapid expansion of renewable generation capacity in Ontario would result in adverse effects for both the electricity system and the economy: electricity rates for consumers would increase, clean generation would be significantly curtailed, and future corrections to the trend would 
result in a boom-and-bust cycle for the renewable energy sector. As the government did not act on OSPE's recommendations and the report's predictions came true, OSPE highlighted that these adverse effects could have been avoided if the government took its advice. Since then, OSPE has advocated for the government to consult with engineers on energy policy issues early in the planning process (OSPE, 2016). The Past Chair of OSPE took that position a step further, stating that "professional engineers must be given independence in planning and designing integrated power and energy system plans" (OSPE, 2017).

OSPE's stance implies that when it comes to electricity system planning, the government should take a step back and invite engineers to provide their insight. The Past Chair's statement above can be interpreted as an extreme stance in which he does not want the government involved at all; rather, he thinks engineers should be solely responsible for electricity system planning. By extension, OSPE would likely look down upon the idea of engaging the public in renewable energy projects. However, the reality is that the government is not going to give up decision-making power and the public wants to be involved in project planning.

Overall, neither PEO nor OSPE guidance on the GEA considers public engagement. Both organizations only look at the technical and professional implications of the GEA. This thesis aims to fill that gap by preparing engineers to work within the current political reality of Ontario's electricity system. 


\section{The Case Study}

Contributing to a separate but related ongoing project, entitled "Under Whose Authority?

Re-examining interactions within renewable energy projects and processes in Eastern Ontario" (CUREB clearance \#109229), the case study focuses on solar and wind projects in the area surrounding Kingston, Ontario. This area was chosen because its renewable energy development has been controversial in the affected communities. Consultation reports filed as part of the REA process were found online for six solar projects and two wind projects, all currently in operation. Figure 13 is a map of the projects in Google Earth Pro based on location data from the Clean Energy Resources and Projects (CERP) database hosted by Natural Resources Canada (NRCan) (NRCan, 2018).

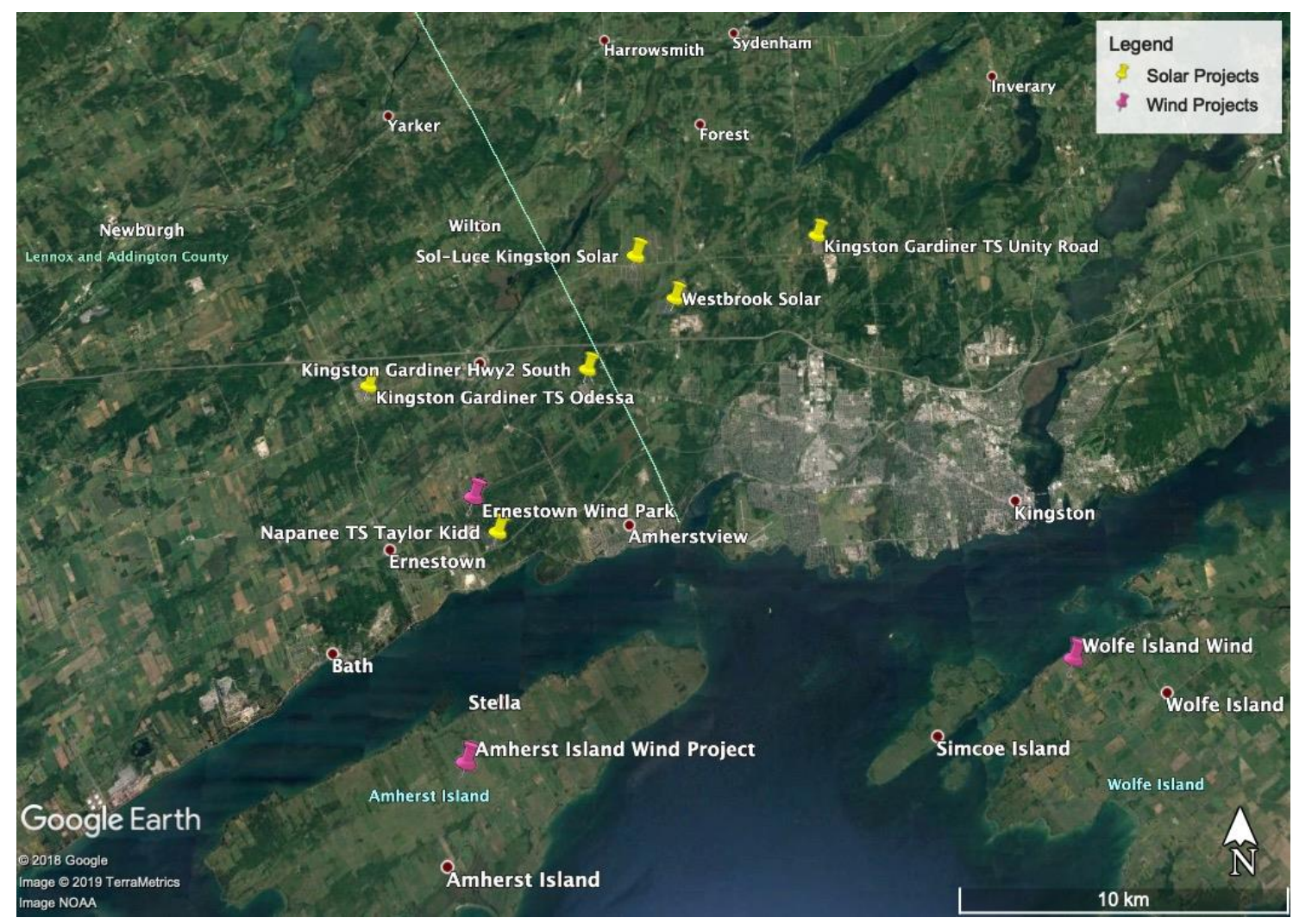

Figure 13: Map of renewable energy projects in the Kingston area 
Section 6.1 provides a historical overview of renewable energy development in the case study area. The consultation reports are described in Section 6.2, supplemented by interviews that were conducted with renewable energy stakeholders in the same geographical area, which are described in Section 6.3.

\subsection{A history of renewable energy development in the case study area}

In the 1960s and 1970s, Kingston, Ontario was home to many who considered themselves hippies. They were ahead of the times in that they consciously lived with a lower environmental footprint (Lapp, 2018). In the 1970s, a local company called Plum Hollow was founded with a mission to move towards energy independence. The company primarily sold wood stoves, but evolved with technology to provide services in wood heating, fireplace inserts, and solar power. In the 1990s, the company renamed itself Renewable Energy of Plum Hollow and began selling and installing PV solar panels, solar hot water heaters, solar pool heaters, and wind powered technologies (North American Solar Stores, 2017). As a result, renewable energy started to appear around the Kingston area. Soon, other local solar companies emerged: Quantum Renewable Energy in 2002, specializing in grid-connected solar PV systems, solar water heaters, solar pool heaters, and off-grid solar PV systems (Quantum Renewable Energy Inc., 2019); and Downunder Solar in 2007, specializing in off-grid solar power systems (Downunder Solar Inc., 2019). These three companies dominated the local solar energy market, designing, selling, and installing solar projects. Many of these companies' technicians graduated from the Energy Systems Engineering Technician (ESET) program at St. Lawrence College in Kingston, which started in 2005 (St. Lawrence College, 2019). 
Around the same time, in 2002, the non-profit organization SWITCH was formed. SWITCH is home to Kingston's sustainable energy community, boasting a network of approximately 140 businesses, research and educational institutions, public sector participants, energy professionals, students and community volunteers. Its mission is to "improve the environmental and economic sustainability of Southeastern Ontario through promoting development and commercialization of energy efficient and alternative energy technologies, products, processes, and services" (SWITCH, 2019). SWITCH is credited as one of the major advocates driving renewable energy development in the Kingston area. In addition to being a networking hub, SWITCH provides technical information and business advice related to alternative energy research, education, project development, policy work, and entrepreneurship. Monthly meetings are open to the public and sometimes feature guest speakers; the speaker for September 2019 was former Environmental Commissioner of Ontario Dianne Saxe (SWITCH, 2019).

The first wind project in the Kingston area began commercial operation in 2009, prior to the GEA. The Wolfe Island Wind Farm has a nameplate capacity of $198 \mathrm{MW}$ and includes 86 wind turbines (TransAlta, 2018). The project is owned by TransAlta, a major power generation company, but a community benefit agreement was critical to the project ultimately being built. TransAlta contributes $\$ 645,000$ annually to a "community amenities fund"; this amount is a significant portion of the township government's annual budget. In addition, after the wind farm was constructed, TransAlta allowed free use of its equipment to build a community ice rink on Wolfe Island (Fast \& Mabee, 2015). 
After the creation of the GEA, Kingston and the surrounding area experienced a significant amount of renewable energy development. According to the renewable energy database from the Government of Ontario, $850 \mathrm{MW}$ of renewable generation capacity has been approved under the REA in the Eastern Ontario Region, which encompasses Kingston. This includes eight wind projects totalling 226.5 MW of capacity, 55 solar projects totalling $612 \mathrm{MW}$ of capacity, and five bioenergy projects totalling $12 \mathrm{MW}$ of capacity (Government of Ontario, 2017). Like Wolfe Island, the proponents for many of these projects were private corporations; for example, the 100 MW Sol-Luce Kingston Solar Project is owned by Samsung (Samsung Renewable Energy Inc., 2018), and the 74.3 MW Amherst Island Wind Farm Project is owned by Windlectric Inc. (Stantec, 2017).

The provincial government's later decision to prioritize community-based projects led to the development of renewable energy cooperatives. Kingston-based Wintergreen Renewable Energy Co-op (WGC) was created in 2012 by local farmers, green energy advocates, and community partners. Its goal is to "ensure a sustainable energy future for the region by building community power" (emphasis in original). WGC develops and invests in local, community-based renewable energy projects, and emphasizes community ownership and participation in all its projects (WGC, 2019). WGC has collaborated with SolarShare, a Toronto-based renewable energy cooperative, to develop three ground mounted solar projects in the Kingston area, including the Abbey Dawn (now Wintergreen) $600 \mathrm{~kW}$ solar project which has been producing power since May 2017 (WGC, 2019; SolarShare, 2019). 
In September 2016, the provincial government suspended the LRP Program, making the future of renewable energy development in Ontario uncertain (IESO, 2016). As a result, Plum Hollow, which merged with fireplace and barbecue retailer Friendly Fires in 2012, decided to turn its focus back to fireplaces and stop pursuing renewable energy (Friendly Fires, 2019). The repeal of the GEA in 2019 has made renewable energy even less promising; cooperatives such as Wintergreen are starting to look at alternative investment opportunities, with one possible path being energy efficiency (Lapp, 2018).

\subsection{Consultation reports}

Recall from Section 5.1.3 that project proponents must prepare a consultation report as part of the REA application. The report documents how engagement activities were undertaken, and provides a record of public input as well as how it was considered. The Technical Guide stipulates the required content for the consultation report and provides recommendations for how that content can be presented (Ontario MOE, 2013). Given those guidelines, all eight of the consultation reports in the case study contain the following:

- Overviews of the project, the REA requirements, and the consultation process;

- A report on public consultation activities, including public notices, public meetings, the feedback received, and the proponent's response;

- A report on municipal consultation activities;

- A report on agency consultation activities (government, conservation authority, utility, telecommunication); 
- A report on Indigenous (Aboriginal) consultation activities; and

- Appendices containing stakeholder lists and the materials displayed, distributed, and received from each of the engagement activities.

The consultation report is a large document as it serves as a complete record of all engagement activities associated with a project; the largest in this case study is over 900 pages in length including appendices. The case study focuses on the sections of the reports relevant to public engagement (as opposed to municipal, agency, or Indigenous engagement); the following subsections contain summaries of the relevant sections from each consultation report. Note that the terminology used in these summaries comes straight from the consultation reports and may not align with the definitions given in Section 2.1. The projects are organized in chronological order based on the publication date of the consultation report (see Figure 14): Subsections 6.2.1 to 6.2.6 happen to be all solar projects: Hwy 2 South, Odessa, Unity Road, Taylor Kidd, Westbrook, and SolLuce; while subsections 6.2.7 and 6.2.8 are the two wind projects: Ernestown and Amherst Island. A table of all the public engagement events from the eight projects can be found in Appendix A.

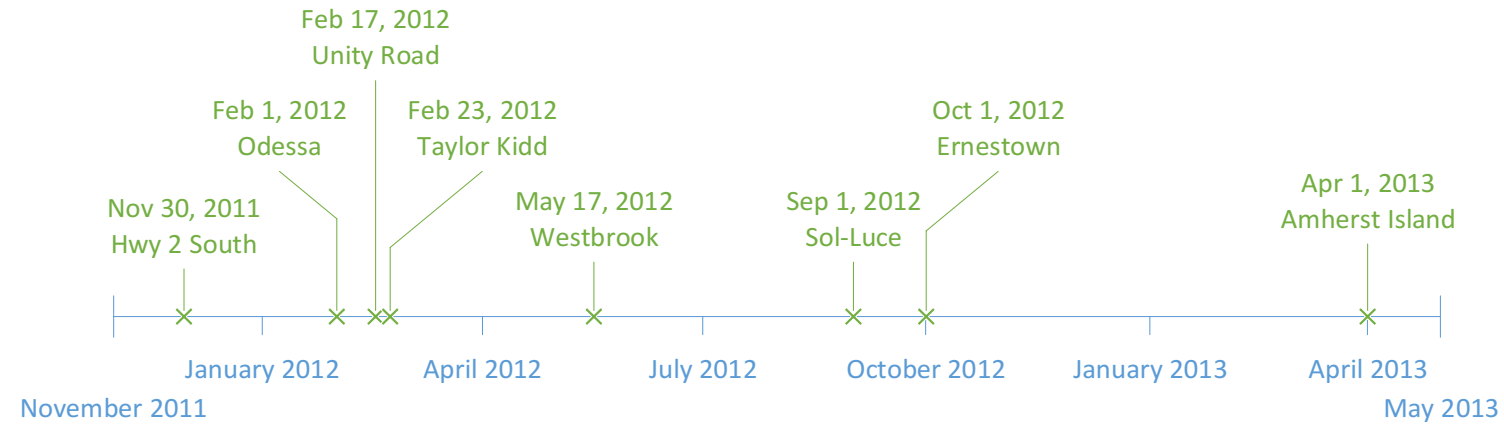

Figure 14: Consultation Report Publication Timeline 


\subsubsection{Kingston Gardiner Hwy 2 South}

Axio Power Canada Inc. and SunEdison Canada are the proponents of the Kingston Gardiner Hwy 2 South Solar Energy Project (Axio Power was acquired by SunEdison in 2011 (Wesoff, 2011), and SunEdison filed for bankruptcy in 2016 (Blackwell, 2016)). The 10 MW solar PV facility covers approximately 34 hectares of privately-owned land located on Part of Lot 40, Concession 3, Loyalist Township, County of Lennox and Addington. The Project is considered a Class 3 solar facility (ground mounted solar with a nameplate capacity greater than $12 \mathrm{~kW}$ ) and thus requires a REA. The engineering consultant, Hatch, prepared the consultation report; a draft version was published online on November 30, 2011 (Hatch Ltd., 2011).

Stakeholders considered in the consultation process include adjacent landowners, government agencies, local municipalities, Aboriginal communities, and the public. The objectives of the consultation process were:

- to identify issues and potential concerns;

- to obtain information about the project location;

- to identify potential impacts associated with the Project; and

- to identify specific stakeholders in order to establish an open and meaningful dialogue between the Proponents and the stakeholders.

A list of public stakeholders was developed early in the consultation process, initially consisting of property owners within 120 metres $(\mathrm{m})$ of the project location (the REA regulation requires notices to be sent to all assessed landowners within this distance), as 
well as local residents who could be affected by or may have an interest in the Project. As more stakeholders corresponded with the project team about the Project, they were added to the list on an ongoing basis.

The public consultation process is summarized by the timeline in Figure 15. Each of the events is described in the following subsections.

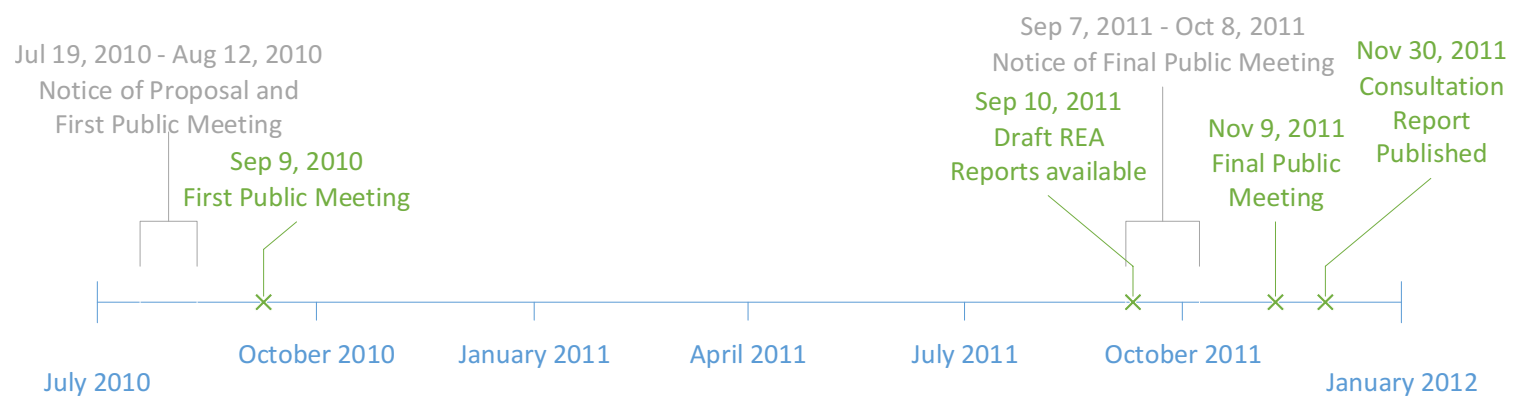

Figure 15: Hwy 2 South public consultation timeline

\subsubsection{First Public Meeting}

The Notice of Proposal to Engage in a Renewable Energy Project and First Public Meeting was mailed to 14 landowners within $120 \mathrm{~m}$ of the project location on July 19, 2010. The notice was also published in two local newspapers: the Kingston WhigStandard on July 31 and August 7, 2010; and the Kingston \& Frontenac This Week on August 5 and 12,2010. A copy of the notice was published on the project website along with the Draft PDR. A hard copy of the Draft PDR was available at the Loyalist Township municipal office for public review.

The First Public Meeting was held on September 9, 2010 at the Odessa Fairgrounds. Figure 16 shows the location of the Odessa Fairgrounds relative to the Project. 


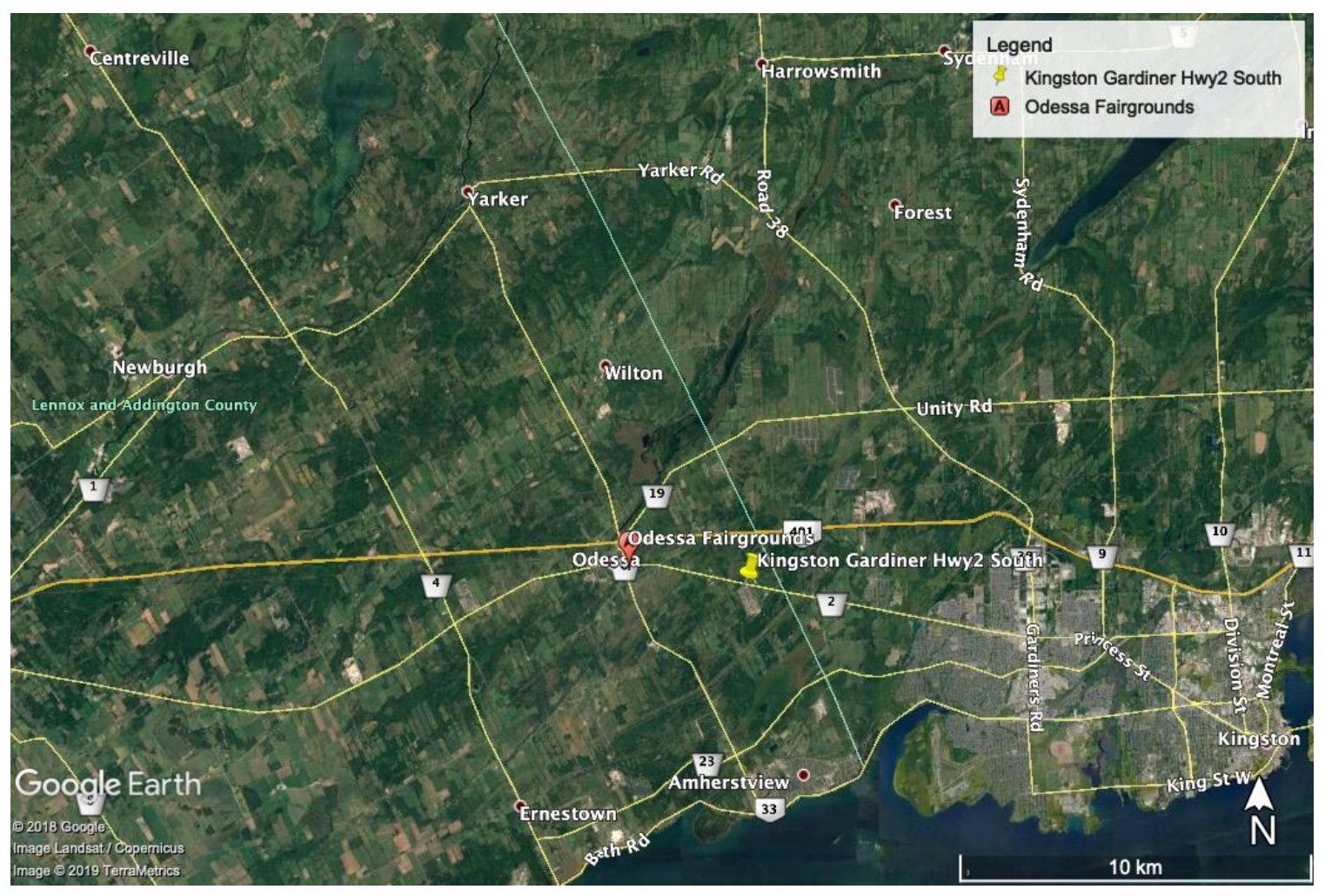

Figure 16: Hwy 2 South project map

The objectives of the meeting were:

- to introduce the Project and the Proponent to the community;

- to identify project contacts and avenues for comment or question submission; and

- to solicit feedback on the Draft PDR.

The meeting was held in an open house format, where information was provided on display boards, and project representatives were available to answer questions and solicit feedback. Proponent representatives answered project-specific questions, while Hatch representatives answered questions about the REA process or the environmental impact 
of the Project. Comment sheets were available for attendees to record and submit any comments or concerns. Any feedback received contributed to scoping the assessment and ensuring that local issues were addressed.

There were 16 attendees (who signed in) at the meeting. One comment sheet was submitted at the meeting, with additional comments sent in by email after the meeting. Each comment received a direct response.

\subsubsection{Final Public Meeting}

The Notice of Final Public Meeting was mailed to 21 landowners on September 7, 2011. The larger number of mailings reflects an expanded adjacent property owner list as well as other individuals who requested mail updates. The notice was also published in the Kingston Whig-Standard on September 9 and October 8, 2011. A copy of the notice was published on the project website on September 10, 2011, along with Draft copies of the project documents required as part of the REA process. The same day, hard copies of all project documents were made available for public review at the municipal offices of Loyalist Township and the County of Lennox and Addington.

The Final Public Meeting was held on November 9, 2011 at the Odessa Fairgrounds, the same location as the First Public Meeting. The objectives of the meeting were:

- to provide the community with detailed information about the Project;

- to answer any questions about the Project; and

- to obtain any comments or concerns with respect to the Project. 
The meeting was held in an open house format, similar to the first public meeting. Display boards showed general information about the Project and the Proponent, feedback from the first public meeting and how it was addressed, and more specific information from the project documents. As in the first public meeting, representatives of both the Proponent and Hatch were available to answer questions. In addition, comment sheets were available for attendees to record and submit any comments or concerns.

There were seven attendees (who signed in) at the meeting. No comment sheets were submitted.

\subsubsection{Other public consultation methods}

Throughout the consultation process, and especially early in the process, public stakeholders were encouraged to submit comments or questions to the Proponent or to Hatch by phone, fax, email or mail. Each correspondence would receive a direct response. Some stakeholders capitalized on this opportunity to interact with the Proponent directly:

- One email was received. The Proponent followed up by phone.

- The Proponent held two meetings with interested members of the public to discuss concerns.

- The Proponent sent letters to public stakeholders who expressed interest or concern, either in response to specific queries or to provide a general update. 
- The Proponent met with a landowner who was unable to attend the first public meeting. In response to concerns over shading, the Proponent sent him project documents to review.

\subsubsection{Public comments and concerns}

Public stakeholders expressed concerns regarding noise, property values, and visual impact. Table 3 extracted from the consultation report shows a thematic summary of the comments received and the Proponent's or Hatch's response. Where applicable the response includes references to details in the project documents.

Table 3: Hwy 2 South Public Comments and Responses (pp. 9-10)

\begin{tabular}{|c|c|c|}
\hline Category & Comment & Response \\
\hline Noise & $\begin{array}{l}\text { Verbal comments made at } \\
\text { final public meeting with } \\
\text { regards to a new house that } \\
\text { was recently built on a lot } \\
\text { opposite the northeast part of } \\
\text { the Project Location, which } \\
\text { may not have been taken into } \\
\text { account during noise studies. }\end{array}$ & $\begin{array}{l}\text { Hatch representatives at the final public meeting took note } \\
\text { of where this residence is situated. A review of the Noise } \\
\text { Study Report indicates that this residence lies well outside } \\
\text { the } 40 \text { dBA noise contour and will not be impacted. The } \\
\text { Noise Study Report will be updated to take this residence } \\
\text { into account. }\end{array}$ \\
\hline $\begin{array}{l}\text { Socio- } \\
\text { economic }\end{array}$ & $\begin{array}{l}\text { Concern that property value } \\
\text { will be decreased. }\end{array}$ & $\begin{array}{l}\text { It is not anticipated that having a solar photovoltaic (PV) } \\
\text { project next to existing properties will impact property } \\
\text { values. Experience with larger and more visible wind } \\
\text { energy projects in Canada, the United States and Europe, } \\
\text { show no impact. Currently the Proponent is not aware of } \\
\text { an equivalent study available for solar energy facilities. }\end{array}$ \\
\hline \multirow[t]{3}{*}{ Visual } & $\begin{array}{l}\text { Concern about the type of } \\
\text { fence that will be built, and } \\
\text { how close the panels are to } \\
\text { the property line. }\end{array}$ & \multirow{3}{*}{$\begin{array}{l}\text { A PV farm is likely to be no greater than } 10 \text { feet }(3 \mathrm{~m}) \\
\text { high, and coupled with the fact that the system has no } \\
\text { moving parts, PV systems are a fairly unobtrusive } \\
\text { neighbour. A woodland buffer will remain along Highway } \\
\text { 2, situated north of the Project Location. As such, most of } \\
\text { the Project will be concealed from the majority of } \\
\text { neighbours. Two meetings occurred between several } \\
\text { neighbours in the vicinity of the Project Location and the } \\
\text { Proponent, where the Proponent was able to address their } \\
\text { concerns. } \\
\text { Vegetative clearing will be kept to an absolute minimum. } \\
\text { The preference is not to cut down trees. Along the fence }\end{array}$} \\
\hline & $\begin{array}{l}\text { Concern about the location of } \\
\text { the access road. }\end{array}$ & \\
\hline & $\begin{array}{l}\text { Concern about the project } \\
\text { compromising the rural } \\
\text { lifestyle of neighbours, } \\
\text { making them feel as though } \\
\text { they are living in an industrial } \\
\text { area. If the project is approved } \\
\text { the concerned party would }\end{array}$ & \\
\hline
\end{tabular}




\begin{tabular}{|l|l|l|}
\hline Category & Comment & Response \\
\hline & $\begin{array}{l}\text { like the project to fit in with } \\
\text { the natural surrounding and be } \\
\text { hidden from the road and } \\
\text { properties that are bordering } \\
\text { the project. }\end{array}$ & $\begin{array}{l}\text { line, only trees above approximately } 15 \text { feet will need to } \\
\text { be removed to allow sunlight to pass onto the panels. The } \\
\text { Proponent aims to use a ground cover that includes native, } \\
\text { soil-enhancing varieties. }\end{array}$ \\
\cline { 2 - 3 } $\begin{array}{l}\text { Concern regarding the visual } \\
\text { impact to adjacent } \\
\text { neighbours. }\end{array}$ & $\begin{array}{l}\text { The Proponent will work constructively with MNR and } \\
\text { local Conservation Authorities to ensure that the } \\
\text { development is constructed in a responsible and compliant } \\
\text { manner. }\end{array}$ \\
\hline
\end{tabular}

Overall, the project was well received in the community as demonstrated by the few negative comments. All issues raised were addressed to the satisfaction of the public.

\subsubsection{Kingston Gardiner TS Odessa}

SunEdison Canada is the proponent of the Kingston Gardiner TS Odessa Solar Energy Project in Odessa. The $10 \mathrm{MW}$ solar PV facility covers approximately 45 hectares of privately-owned land located on Part of Lot 4, Concession 3, Loyalist Township, County of Lennox and Addington. The facility generates electricity which is fed into the Hydro One Networks Inc. (HONI) distribution grid. With a 20-year FIT contract from the OPA, the facility is expected to operate until at least 2033. The Project is considered a Class 3 solar facility and thus requires a REA. Hatch was the engineering consultant for the project, but SunEdison prepared the consultation report which was published online on February 1, 2012 (Kingston Gardiner TS Odessa Solar Energy Project - Consultation Report, 2012).

As with the Hwy 2 South project, stakeholders considered in the consultation process include adjacent landowners, government agencies, local municipalities, Aboriginal communities, and the public. The objectives of the consultation process were the same as those of the Hwy 2 South project: 
- to identify issues and potential concerns;

- to obtain information about the project location;

- to identify potential impacts associated with the Project; and

- to identify specific stakeholders in order to establish an open and meaningful dialogue between the Proponents and the stakeholders.

The public consultation process is summarized by the timeline in Figure 17. Each of the events is described in the following subsections.

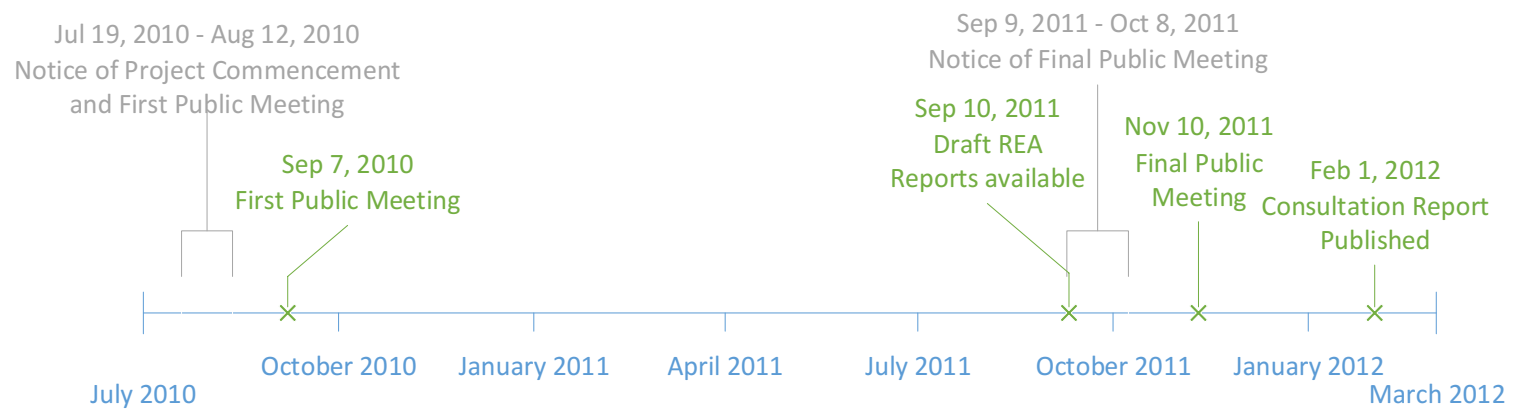

Figure 17: Odessa public consultation timeline

\subsubsection{First Public Meeting}

The Notice of Project Commencement and First Public Meeting was mailed to 15 landowners within $120 \mathrm{~m}$ of the project location on July 19, 2010. The notice was also published in two local newspapers: the Kingston Whig-Standard on July 31 and August 7, 2010; and the Kingston This Week on August 5 and 12, 2010. A copy of the notice was published on the project website along with the Draft PDR. The notice contained information on the project location, the proposed size of the project, the Proponent, and the REA process, as well as a map of the project area. 
The First Public Meeting was held on September 7, 2010 at the Odessa Fairgrounds.

Figure 18 shows the location of the Odessa Fairgrounds relative to the Project.

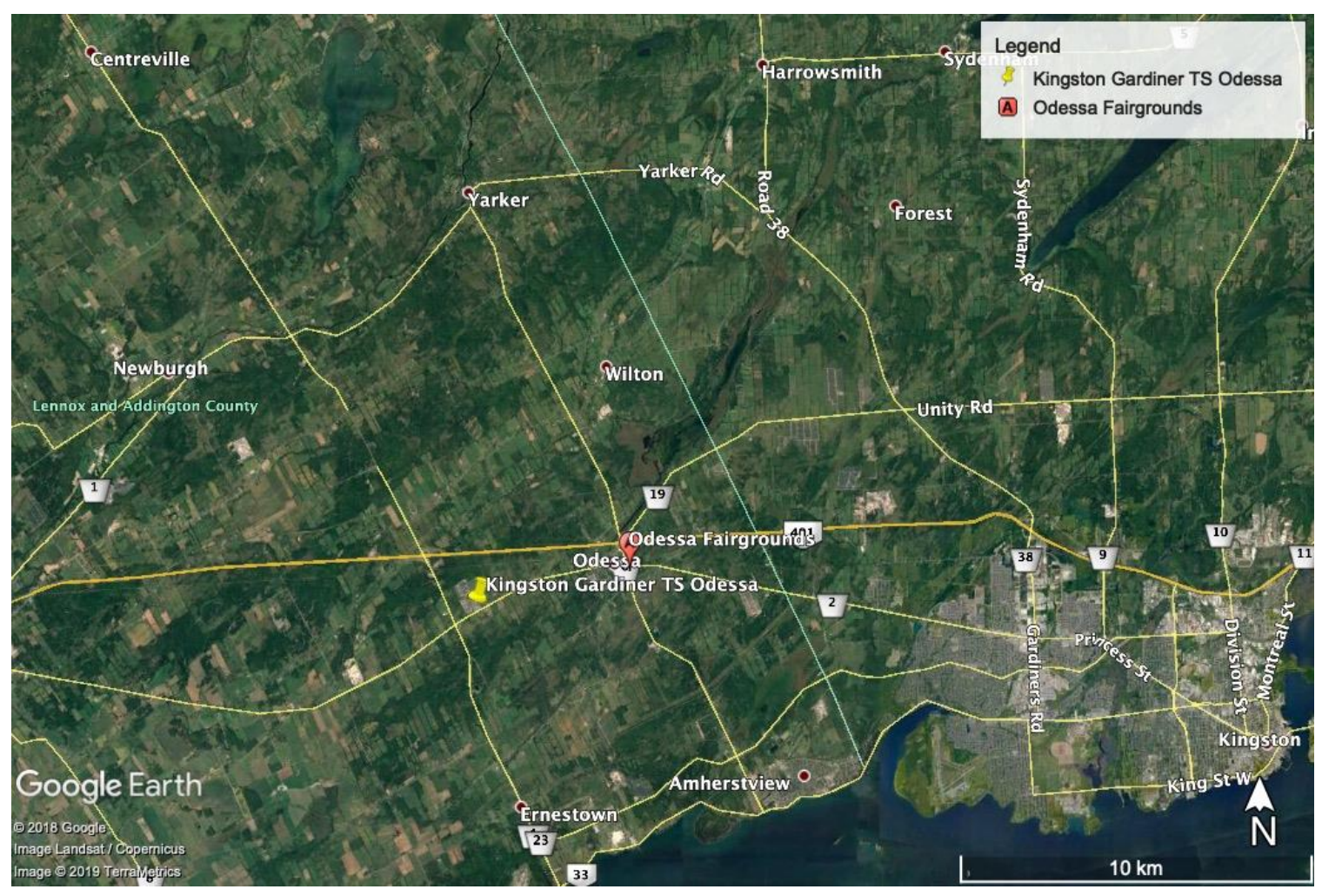

Figure 18: Odessa project map

The meeting was held in an open house format, where information was provided on display boards, and project representatives were available to answer questions and solicit feedback. Comment sheets were available for attendees to record and submit any comments or concerns.

There were four attendees (who signed in) at the meeting. Comments were generally positive. Attendees asked questions about how solar PV works, the extent of site 
visibility after construction is complete, construction traffic, and project noise and reflection.

\subsubsection{Final Public Meeting}

The Notice of Final Public Meeting was mailed to 15 landowners within $120 \mathrm{~m}$ of the project location on September 18, 2011. The notice was also published in the Kingston Whig-Standard on September 9 and October 8, 2011. A copy of the notice was published on the project website on September 10,2011, along with Draft copies of the project documents required as part of the REA process. The same day, hard copies of all project documents were made available for public review at the municipal offices of Loyalist Township and the County of Lennox and Addington.

Like the Notice of Project Commencement, the notice contained information on the project location, the proposed size of the project, the Proponents, and the REA process, as well as a map of the Project area. In addition, the notice contained the location, date, and time of the Final Public Meeting, the locations where draft project reports were available for public review, the dates of the review period, and the contact information for submitting comments.

The Final Public Meeting was held on November 10, 2011 at the South Stormont Community Hall (this location is assumed to be an error in the consultation report, as it is $182 \mathrm{~km}$ away from Odessa). Like the first public meeting, the meeting was held in an open house format. Display boards showed project information, while project 
representatives were available to answer questions. In addition, comment sheets were

available for attendees to record and submit any comments or concerns.

There were six attendees (who signed in) at the meeting. Comments were generally

positive with no significant concerns. No comment sheets were submitted.

\subsubsection{Public comments and concerns}

Public stakeholders expressed concerns regarding noise, water, and soil. Table 4

extracted from the consultation report shows a thematic summary of the comments

received and the Proponent's or Hatch's response. Where applicable the response

includes references to details in the project documents.

Table 4: Odessa Public Comments and Responses (pp. 17-18)

\begin{tabular}{|c|c|c|}
\hline Category & Comment & Response \\
\hline Noise & $\begin{array}{l}\text { Verbal comments made at the } \\
\text { Final Public Meeting with } \\
\text { regards to a new house that } \\
\text { was recently built on a lot } \\
\text { opposite the southeast part of } \\
\text { the Project Location, which } \\
\text { may not have been taken into } \\
\text { account during noise studies. }\end{array}$ & $\begin{array}{l}\text { Hatch representative at the Final Public Meeting took } \\
\text { note of where these residences are situated, and will } \\
\text { review the Noise Study Report to ensure that all noise } \\
\text { receptors are accounted for. If it is determined that any } \\
\text { noise receptors/dwellings were previously unaccounted } \\
\text { for, additional studies will be carried out to make the } \\
\text { necessary adjustments, and the report will be updated } \\
\text { accordingly. }\end{array}$ \\
\hline $\begin{array}{l}\text { Water: } \\
\text { Surface, } \\
\text { Ground, } \\
\text { Storm }\end{array}$ & $\begin{array}{l}\text { Concern about well water } \\
\text { volume. }\end{array}$ & $\begin{array}{l}\text { The Proponent phoned the neighbours around December } \\
1,2011 \text { and committed to perform a volume test as part } \\
\text { of the well testing scope. }\end{array}$ \\
\hline $\begin{array}{l}\text { Terrestrial, } \\
\text { Soil }\end{array}$ & $\begin{array}{l}\text { Would like the Project to } \\
\text { consider vegetation under the } \\
\text { solar panels, to improve soil } \\
\text { (recommended blossoms for } \\
\text { bees; want to fixate nitrogen). } \\
\text { Concern regarding } \\
\text { uncontrolled growth of weeds } \\
\text { or invasive species. }\end{array}$ & $\begin{array}{l}\text { The Proponent sent a letter response on November } 11 \text {, } \\
2010 \text { indicating that further communication would } \\
\text { follow. } \\
\text { On April } 21,2011 \text { the Proponent responded with a letter } \\
\text { stating that vegetative clearing will be kept to an } \\
\text { absolute minimum and that there will be an effort to } \\
\text { ensure that the ground cover re-planted would be native } \\
\text { and soil enhancing. }\end{array}$ \\
\hline
\end{tabular}




\begin{tabular}{|l|l|l|}
\hline Category & Comment & Response \\
\hline & $\begin{array}{l}\text { Want to ensure that soil } \\
\text { conditions are improved so } \\
\text { that land can be used for } \\
\text { agriculture after } \\
\text { decommissioning. }\end{array}$ & $\begin{array}{l}\text { The Proponent sent a letter response on November 11, } \\
\text { 2010 indicating that further communication would } \\
\text { follow. }\end{array}$ \\
& $\begin{array}{l}\text { On April 21, 2011 the Proponent responded with a letter } \\
\text { stating that as part of the REA Environmental Approval } \\
\text { process, a decommissioning plan has been developed to } \\
\text { outline how the site can be fully rehabilitated to its } \\
\text { original state. }\end{array}$ \\
\hline
\end{tabular}

Overall, there were no significant concerns with the project proposal. Public feedback contributed to minor changes as outlined above.

\subsubsection{Kingston Gardiner TS Unity Road}

SunEdison Canada is the proponent of the Kingston Gardiner TS Unity Road Solar Energy Project in Kingston. The 10 MW solar PV facility covers approximately 34 hectares of privately-owned land located on Part of Lot 12, Concession 6, City of Kingston, County of Frontenac. The facility generates electricity which is fed into the HONI distribution grid. With a 20-year FIT contract from the OPA, the facility is expected to operate until at least 2033. The Project is considered a Class 3 solar facility and thus requires a REA. Hatch was the engineering consultant for the project, but SunEdison prepared the consultation report which was published online on February 17, 2012 (Kingston Gardiner TS Unity Road Solar Energy Project - Consultation Report, 2012).

As with the previous two projects, stakeholders considered in the consultation process include adjacent landowners, government agencies, local municipalities, Aboriginal communities, and the public. The objectives of the consultation process were the same as those of the previous two projects: 
- to identify issues and potential concerns;

- to obtain information about the project location;

- to identify potential impacts associated with the Project; and

- to identify specific stakeholders in order to establish an open and meaningful dialogue between the Proponents and the stakeholders.

The public consultation process is summarized by the timeline in Figure 19. Each of the events is described in the following subsections.

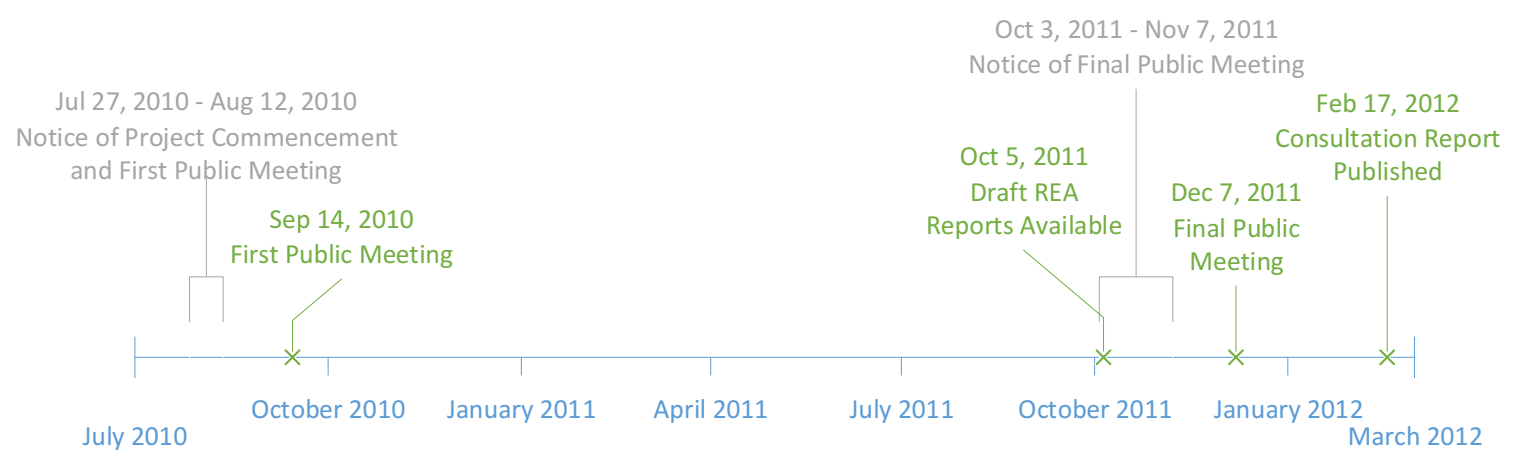

Figure 19: Unity Road public consultation timeline

\subsubsection{First Public Meeting}

The Notice of Project Commencement and First Public Meeting was mailed to 16 landowners within $120 \mathrm{~m}$ of the project location on July 27, 2010. The notice was also published in two local newspapers: the Kingston Whig-Standard on July 31 and August 7, 2010; and the Kingston This Week on August 5 and 12, 2010. A copy of the notice was published on the project website along with the Draft PDR. The notice contained 
information on the project location, the proposed size of the project, the Proponent, and the REA process, as well as a map of the project area.

The First Public Meeting was held on September 14, 2010 at Glenburnie United Church.

Figure 20 shows the location of Glenburnie United Church relative to the Project.

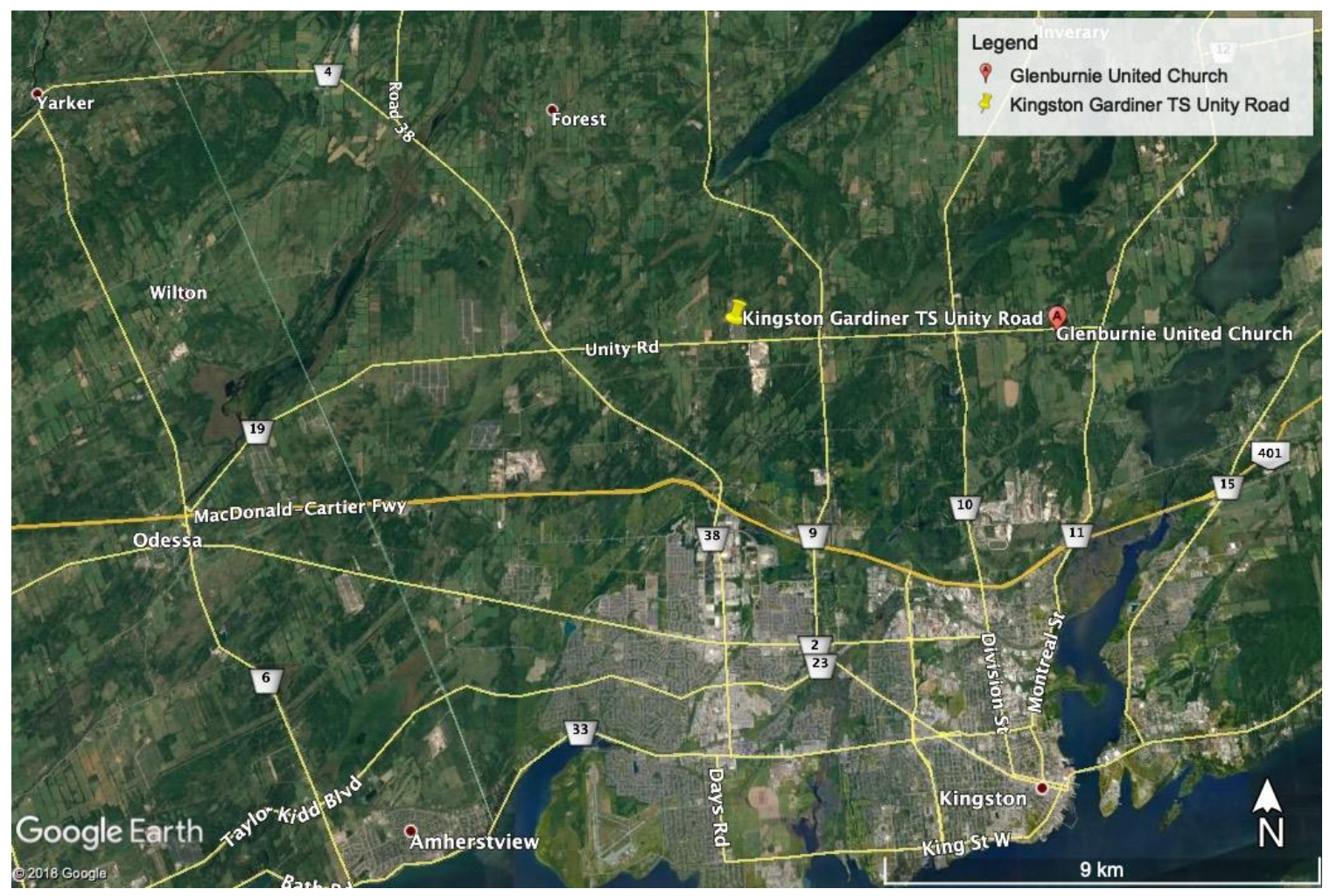

Figure 20: Unity Road project map

The meeting was held in an open house format, where information was provided on display boards, and project representatives were available to answer questions and solicit feedback. Comment sheets were available for attendees to record and submit any comments or concerns. 
There were seven attendees (who signed in) at the meeting. Comments were generally positive. Attendees asked questions about how solar PV works, and the extent of site visibility after construction is complete. One comment sheet was submitted at the meeting; the Proponent responded directly by letter.

\subsubsection{Final Public Meeting}

The Notice of Final Public Meeting was mailed to 18 landowners within $120 \mathrm{~m}$ of the project location on October 3, 2011. The notice was also published in the Kingston WhigStandard on October 5 and November 7,2011. A copy of the notice was published on the project website on October 5, 2011, along with Draft copies of the project documents required as part of the REA process. The same day, hard copies of all project documents were made available for public review at the municipal offices of City of Kingston and the County of Frontenac.

Like the Notice of Project Commencement, the notice contained information on the project location, the proposed size of the project, the Proponents, and the REA process, as well as a map of the Project area. In addition, the notice contained the location, date, and time of the Final Public Meeting, the locations where draft project reports were available for public review, the dates of the review period, and the contact information for submitting comments.

The Final Public Meeting was held on December 7, 2011 at Glenburnie United Church, the same location as the First Public Meeting. Like the first public meeting, the meeting was held in an open house format. Display boards showed project information, while 
project representatives were available to answer questions. In addition, comment sheets

were available for attendees to record and submit any comments or concerns.

There were 16 attendees (who signed in) at the meeting. Comments were mixed positive and negative. Common concerns included property value, visual appearance, and groundwater. One comment sheet was submitted.

\subsubsection{Public comments and concerns}

Public stakeholders expressed concerns regarding a variety of topics. Table 5 extracted from the consultation report shows a thematic summary of the comments received and the Proponent's or Hatch's response. Where applicable the response includes references to details in the project documents.

Table 5: Unity Road Public Comments and Responses (pp. 14-19)

\begin{tabular}{|c|c|c|}
\hline Category & Comment & Response \\
\hline \multirow[t]{2}{*}{ Noise } & $\begin{array}{l}\text { What will the hours of } \\
\text { construction be? Will } \\
\text { residents have assurances } \\
\text { of the hours? }\end{array}$ & $\begin{array}{l}\text { As identified in the Construction Plan Report (Hatch, } \\
\text { 2011), the hours of construction will typically be from } \\
\text { 7:00 a.m. to 6:00 p.m., Monday through Friday, in } \\
\text { accordance with local municipal by-laws. }\end{array}$ \\
\hline & $\begin{array}{l}\text { What about inverter } \\
\text { noise levels over time? }\end{array}$ & $\begin{array}{l}\text { The noise levels emitted by the inverters are not } \\
\text { expected to change over time. The solar farm must } \\
\text { comply with the MOE's noise regulations over its } \\
\text { entire operational life. }\end{array}$ \\
\hline \multirow[t]{3}{*}{ Visual } & $\begin{array}{l}\text { Would like to ensure that } \\
\text { the project looks as } \\
\text { natural as possible and } \\
\text { can not be seen from the } \\
\text { road or any neighbouring } \\
\text { houses. }\end{array}$ & $\begin{array}{l}\text { A combination of mitigation will be considered, } \\
\text { depending on what is feasible and desired, for } \\
\text { example, wooden fencing, deciduous and/or coniferous } \\
\text { shrubs, either on SunEdison's property or a directly } \\
\text { affected neighboring property. }\end{array}$ \\
\hline & $\begin{array}{l}\text { Would like to see } \\
\text { immediate disposal of } \\
\text { any unusable or residual } \\
\text { construction materials. }\end{array}$ & $\begin{array}{l}\text { During construction of the Project, the Contractor will } \\
\text { be responsible for removing and disposing of all } \\
\text { recyclable and nonrecyclable waste from the Project } \\
\text { site in accordance with Provincial and municipal } \\
\text { requirements under the supervision of SunEdison. }\end{array}$ \\
\hline & $\begin{array}{l}\text { The Project should be } \\
\text { bermed and include } \\
\text { fences inside of berms. }\end{array}$ & $\begin{array}{l}\text { SunEdison will incorporate vegetative plantings and } \\
\text { possibly, low level berms (if they do not interfere with }\end{array}$ \\
\hline
\end{tabular}




\begin{tabular}{|c|c|c|}
\hline Category & Comment & Response \\
\hline & & $\begin{array}{l}\text { surface drainage) along portions of the south Project } \\
\text { boundary to address visual concerns from Unity Road. }\end{array}$ \\
\hline & $\begin{array}{l}\text { What type of panels will } \\
\text { be installed, low rise, } \\
\text { tall, tracker, fixed pole } \\
\text { etc.? }\end{array}$ & $\begin{array}{l}\text { The solar PV modules will be mounted on single-axis } \\
\text { tracker systems arranged in rows facing north-south. } \\
\text { Each tracker system will be able to rotate } 90^{\circ} \text { to track } \\
\text { the sun as it moves east to west across the sky. The } \\
\text { tracker units and rows of PV modules will be } \\
\text { supported by steel supports that will extend into the } \\
\text { ground. }\end{array}$ \\
\hline $\begin{array}{l}\text { Safety and } \\
\text { Security }\end{array}$ & $\begin{array}{l}\text { Will there be a speed } \\
\text { limit during construction, } \\
\text { posted and enforced? }\end{array}$ & $\begin{array}{l}\text { Yes, this will be the responsibility of the construction } \\
\text { Contractor under the supervision of SunEdison. }\end{array}$ \\
\hline \multirow[t]{6}{*}{$\begin{array}{l}\text { Water: Surface, } \\
\text { Ground, Storm }\end{array}$} & $\begin{array}{l}\text { Would like to have } \\
\text { greater minimal } \\
\text { separation distances from } \\
\text { watersheds and ponds. }\end{array}$ & $\begin{array}{l}\text { The Project well exceeds the REA Regulations } \\
\text { requirements for minimum setbacks to natural features } \\
\text { and EIS demonstrates that there will be no significant } \\
\text { negative impacts to woodlands or significant wildlife } \\
\text { habitat as a result of the Project construction and } \\
\text { operation. }\end{array}$ \\
\hline & $\begin{array}{l}\text { What are the short term } \\
\text { effects of construction on } \\
\text { shallow/dug wells? }\end{array}$ & $\begin{array}{l}\text { Refer to Construction Plan Report (Hatch, 2011), } \\
\text { Stormwater Management Report (McIntosh Perry, } \\
\text { 2011) and the Groundwater Monitoring Scoping } \\
\text { Report (McIntosh Perry, 2011). }\end{array}$ \\
\hline & $\begin{array}{l}\text { What are the long term } \\
\text { effects of the overall } \\
\text { project on shallow/dug } \\
\text { wells? }\end{array}$ & $\begin{array}{l}\text { Refer to Design and Operations Report (Hatch, 2011), } \\
\text { and Stormwater Management Report (McIntosh Perry, } \\
\text { 2011). }\end{array}$ \\
\hline & $\begin{array}{l}\text { Will there be Ministry of } \\
\text { Environment } \\
\text { confirmation of the long } \\
\text { term effects of the } \\
\text { project on water and } \\
\text { natural habitat beyond } \\
\text { developer studies? }\end{array}$ & $\begin{array}{l}\text { The MOE will review all of the various REA reports } \\
\text { and will provide their 'confirmation' of the Project by } \\
\text { virtue of issuing the REA, which may impose } \\
\text { conditions on the Project for aspects such as the } \\
\text { monitoring and reporting for sewage works (e.g., } \\
\text { transformer spill containment facility, storm water } \\
\text { management facility) regarding the quality of storm } \\
\text { water discharged to receiving watercourses. }\end{array}$ \\
\hline & $\begin{array}{l}\text { Will blasting be } \\
\text { involved, how deep will } \\
\text { each post be drilled? }\end{array}$ & $\begin{array}{l}\text { Blasting is not currently envisioned refer to Design and } \\
\text { Operations Report (Hatch, 2011), depending upon the } \\
\text { soil conditions and the type of support posts to be used } \\
\text { (e.g., driven steel piles, steel helical screw piles or } \\
\text { cast-in-drilled-hole foundations), the piles will be } \\
\text { installed to a design depth of up to } 3 \mathrm{~m} \text { below the } \\
\text { ground surface. }\end{array}$ \\
\hline & $\begin{array}{l}\text { What compensation } \\
\text { plans do developers have } \\
\text { for landowners when or } \\
\text { if well water goes bad? }\end{array}$ & $\begin{array}{l}\text { Refer to Construction Plan Report (Hatch, 2011) and } \\
\text { the Design and Operations Report (Hatch, 2011), } \\
\text { construction and operation of the Project is not } \\
\text { expected to have any negative effect on local well } \\
\text { water quality. As a precautionary measure, SunEdison } \\
\text { has prepared a groundwater monitoring plan (McIntosh } \\
\text { Perry, 2011) based on consultation with the MOE. }\end{array}$ \\
\hline Terrestrial, Soil & $\begin{array}{l}\text { What are the short term } \\
\text { effects of construction on } \\
\text { ground cover? }\end{array}$ & $\begin{array}{l}\text { Refer to the Construction Plan Report (Hatch, 2011) } \\
\text { and the Natural Heritage Assessment EIS Report } \\
\text { (Ecological Services, 2011). }\end{array}$ \\
\hline
\end{tabular}




\begin{tabular}{|c|c|c|}
\hline Category & Comment & Response \\
\hline & $\begin{array}{l}\text { What are the long term } \\
\text { effects of the overall } \\
\text { project on ground cover? }\end{array}$ & $\begin{array}{l}\text { Refer to the Design and Operations Report (Hatch, } \\
\text { 2011), and the Natural Heritage Assessment EIS } \\
\text { Report (Ecological Services, 2011). }\end{array}$ \\
\hline & $\begin{array}{l}\text { Where will the soil } \\
\text { needed for landscaping } \\
\text { berms come from? }\end{array}$ & $\begin{array}{l}\text { Any excess topsoil and subsoil removed from the site } \\
\text { for construction and not reused as part of the site } \\
\text { restoration activities may be used for landscaping } \\
\text { berms (if berms are constructed). If berms are to be } \\
\text { constructed and there is insufficient soil, clean soil will } \\
\text { be brought in from off-site. }\end{array}$ \\
\hline & $\begin{array}{l}\text { Will pesticides / } \\
\text { herbicides be used to } \\
\text { control foliage and } \\
\text { insects? }\end{array}$ & $\begin{array}{l}\text { Vegetation will be properly managed and maintained } \\
\text { using mechanical methods (grass mowing, tree branch } \\
\text { trimming); no chemical herbicides will be used for } \\
\text { vegetation control. }\end{array}$ \\
\hline Wildlife & $\begin{array}{l}\text { What are the short term } \\
\text { effects of construction on } \\
\text { wildlife? What are the } \\
\text { long term effects of the } \\
\text { overall project on } \\
\text { wildlife? }\end{array}$ & See answer above for Terrestrial, Soil. \\
\hline $\begin{array}{l}\text { Restoration / } \\
\text { Re-vegetation }\end{array}$ & $\begin{array}{l}\text { What is the plan for } \\
\text { reforestation? }\end{array}$ & $\begin{array}{l}\text { Refer to Decommissioning Plan Report (Hatch, 2011) } \\
\text { which documents the plan for restoration of the site if } \\
\text { the Project was to cease to operate at some future date. }\end{array}$ \\
\hline \multirow[t]{2}{*}{ Roads } & $\begin{array}{l}\text { What are the short term } \\
\text { effects of construction on } \\
\text { roadways? What are the } \\
\text { long term effects of the } \\
\text { overall project on } \\
\text { roadways? }\end{array}$ & $\begin{array}{l}\text { Please refer to the Construction Plan Report (Hatch, } \\
\text { 2011) and the Design and Operations Report (Hatch, } \\
\text { 2011). }\end{array}$ \\
\hline & $\begin{array}{l}\text { Where will the } \\
\text { secondary construction } \\
\text { roads be located, how } \\
\text { will they be maintained? }\end{array}$ & $\begin{array}{l}\text { The locations of the construction access roads are } \\
\text { expected to be the same as the internal maintenance } \\
\text { access driveways used for the Project operation. These } \\
\text { driveways are depicted on the drawings provided in the } \\
\text { Construction Plan Report (Hatch, 2011) and the } \\
\text { Design and Operations Report (Hatch, 2011). }\end{array}$ \\
\hline \multirow[t]{4}{*}{$\begin{array}{l}\text { Transmission } \\
\text { Lines }\end{array}$} & $\begin{array}{l}\text { What are the short term } \\
\text { effects of construction on } \\
\text { transmission lines? What } \\
\text { are the long term effects } \\
\text { of the overall project on } \\
\text { transmission lines? }\end{array}$ & $\begin{array}{l}\text { Please refer to the Construction Plan Report (Hatch, } \\
\text { 2011) and the Design and Operations Report (Hatch, } \\
\text { 2011). }\end{array}$ \\
\hline & $\begin{array}{l}\text { Will this be strictly a } \\
\text { grid tie in system? }\end{array}$ & $\begin{array}{l}\text { Yes. The proposed solar farm will connect to HONI's } \\
\text { existing } 44 \text { kilovolt }(\mathrm{kV}) \text { feeder. }\end{array}$ \\
\hline & $\begin{array}{l}\text { Where will the collector } \\
\text { lines run, above ground, } \\
\text { in concrete or below } \\
\text { ground? }\end{array}$ & $\begin{array}{l}\text { Refer to Design and Operations Report (Hatch, 2011) } \\
\text { and the Construction Plan Report (Hatch, 2011), } \\
\text { collector electrical cabling will run underground in an } \\
\text { excavated trench which will be backfilled and levelled } \\
\text { to match the existing or proposed grading. }\end{array}$ \\
\hline & $\begin{array}{l}\text { What is the plan for the } \\
\text { additional transmission } \\
\text { lines, underground or } \\
\text { above? }\end{array}$ & $\begin{array}{l}\text { Refer to Design and Operations Report (Hatch, 2011), } \\
\text { the electrical connecting line will be run overhead on } \\
\text { poles between the Project's } 44 \mathrm{kV} \text { substation and the } \\
\text { existing HONI electrical line running along Unity } \\
\text { Road. }\end{array}$ \\
\hline
\end{tabular}




\begin{tabular}{|c|c|c|}
\hline Category & Comment & Response \\
\hline & $\begin{array}{l}\text { What about battery } \\
\text { backups, will there be } \\
\text { lead acid storage } \\
\text { required? }\end{array}$ & No backup batteries will be used for the Project. \\
\hline \multirow[t]{3}{*}{ Socio-economic } & $\begin{array}{l}\text { How will this project } \\
\text { impact or benefit the } \\
\text { local tax payer? }\end{array}$ & $\begin{array}{l}\text { The property itself will be taxed at a higher rate and } \\
\text { therefore pay higher municipal taxes, which will be of } \\
\text { benefit to the community and all of Ontario. } \\
\text { Construction of the project will create local jobs, and } \\
\text { the domestic content rule will provide economic } \\
\text { benefit and jobs to Ontario. The Municipal Property } \\
\text { Assessment Corporation (MPAC) governs tax } \\
\text { assessments; please contact MPAC regarding } \\
\text { assessments, which can change annually. }\end{array}$ \\
\hline & $\begin{array}{l}\text { What are the short-term } \\
\text { effects of construction on } \\
\text { real estate values? What } \\
\text { are the long-term effects } \\
\text { of the overall project on } \\
\text { real estate values? }\end{array}$ & $\begin{array}{l}\text { SunEdison does not anticipate any long-term impacts } \\
\text { on property values due to its solar farms. Historically, } \\
\text { over time, the trend for property value is to increase. } \\
\text { Many variables affect property values. }\end{array}$ \\
\hline & $\begin{array}{l}\text { Who is paying for the } \\
\text { new infrastructure? }\end{array}$ & $\begin{array}{l}\text { SunEdison is responsible for its connection to the } \\
\text { HONI distribution system. All renewable energy } \\
\text { developers are obligated to pay for a Connection } \\
\text { Impact Assessment (CIA), which is governed by the } \\
\text { OEB's Distribution System Code (DSC). Once the } \\
\text { CIA has been completed, the next step in the process is } \\
\text { to put in place a Connection Cost Agreement (CCA) } \\
\text { with the Local Distribution Company (LDC); in this } \\
\text { case, HONI. Developers prepay } 100 \% \text { of the } \\
\text { interconnection cost, which is estimated by and } \\
\text { provided by the LDC. For } 10 \text { MW FIT projects the } \\
\text { OEB has allowed up to } \$ 90,000 / \text { MW, or up to a } \\
\text { maximum of } \$ 900,000 \text { to be available to Hydro One } \\
\text { for upgrading its distribution lines. The cost of any } \\
\text { interconnection infrastructure or hardware, for } \\
\text { example transformers, circuit breakers, or switchgear } \\
\text { is } 100 \% \text { the responsibility of the developer. }\end{array}$ \\
\hline \multirow[t]{3}{*}{ Site Selection } & $\begin{array}{l}\text { Would like project } \\
\text { location to be further } \\
\text { away from houses. } \\
\text { Would like to have } \\
\text { greater minimum } \\
\text { separation distances of } \\
\text { project location from } \\
\text { houses. }\end{array}$ & $\begin{array}{l}\text { REA Regulations do not prescribe minimum setback } \\
\text { requirements for solar projects from houses other than } \\
\text { they must meet the MOE's requirements for noise } \\
\text { emissions at the nearest receptors (i.e., residential } \\
\text { homes). In this regard, the computer modeling noise } \\
\text { simulations of the Project operations have confirmed } \\
\text { that the Project is compliant. }\end{array}$ \\
\hline & $\begin{array}{l}\text { Would like the project to } \\
\text { be setback from Unity } \\
\text { Rd. }\end{array}$ & $\begin{array}{l}\text { A setback of approximately } 30 \mathrm{~m} \text { is currently proposed } \\
\text { from the Project facilities (i.e., the project fence) and } \\
\text { Unity Road. The type of use and setback proposed for } \\
\text { the Project are consistent with other comparable uses } \\
\text { and their associated setbacks in the City of Kingston's } \\
\text { Zoning By-law. }\end{array}$ \\
\hline & $\begin{array}{l}\text { Have developers } \\
\text { considered land along }\end{array}$ & $\begin{array}{l}\text { SunEdison has examined using marginal lands, such as } \\
\text { brownfields, for solar development. However, often } \\
\text { times it is not possible to negotiate an agreement that }\end{array}$ \\
\hline
\end{tabular}




\begin{tabular}{|c|c|c|}
\hline Category & Comment & Response \\
\hline & $\begin{array}{l}\text { power corridors and are } \\
\text { studies available? }\end{array}$ & $\begin{array}{l}\text { addresses any potential environmental liability that } \\
\text { may be present on the site or the landowner is simply } \\
\text { not interested in leasing or selling these lands to } \\
\text { SunEdison. In terms of using power (transmission line) } \\
\text { corridors, other than potential shading concerns, it has } \\
\text { been SunEdison's experience that transmission line } \\
\text { corridor owners such as HONI are simply not willing } \\
\text { to allow the use of their lands beneath their } \\
\text { transmission lines, citing liability concerns and } \\
\text { concern for the loss of access to their facilities and } \\
\text { restrictions for the possible future expansion of their } \\
\text { facilities. }\end{array}$ \\
\hline Decommissioning & $\begin{array}{l}\text { What is the plan for } \\
\text { decommissioning of the } \\
\text { fields, the panels and the } \\
\text { posts? }\end{array}$ & Refer to Decommissioning Plan Report (Hatch, 2011). \\
\hline \multirow[t]{3}{*}{ Other } & $\begin{array}{l}\text { Will residents have } \\
\text { input? }\end{array}$ & $\begin{array}{l}\text { Yes, in particular, SunEdison has discussed visual and } \\
\text { other aspects with several adjacent landowners at open } \\
\text { house and continues to have on-going discussions with } \\
\text { landowners to pin-point specific plantings and } \\
\text { 'buffering' locations as input to the landscaping plan. } \\
\text { Furthermore, SunEdison has committed to meeting } \\
\text { with the City of Kingston Rural Affairs Committee, } \\
\text { and with the Unity Road Rate Payers Association to } \\
\text { answer any questions and comments it has. }\end{array}$ \\
\hline & $\begin{array}{l}\text { Will a dispute resolution } \\
\text { mechanism be created to } \\
\text { act on resident concerns? }\end{array}$ & Refer to Design and Operations Report (Hatch, 2011). \\
\hline & $\begin{array}{l}\text { Will residents see the } \\
\text { "community feedback" } \\
\text { shared with the Ministry } \\
\text { of the Environment? }\end{array}$ & $\begin{array}{l}\text { All public input to the Project, including public } \\
\text { comments received, responses provided by SunEdison } \\
\text { and any changes made to the Project as a result of } \\
\text { public input is documented in this Consultation Report. } \\
\text { The Consultation Report is submitted to, and reviewed } \\
\text { by, the MOE as part of the REA process and posted on } \\
\text { SunEdison's website for public review. }\end{array}$ \\
\hline
\end{tabular}

Overall, there were no significant concerns with the project proposal which could not be resolved. Public feedback contributed to minor changes as outlined above. In addition, to address public concerns about construction effects on Unity Road, SunEdison committed to surveying the road condition before and after construction and repairing any damages; and to address public concerns about visual impacts, SunEdison committed to collaborating with the public to create a natural landscaping plan that is both appropriate for the project and satisfactory to the community. 


\subsubsection{Napanee TS Taylor Kidd}

SunEdison Canada is the proponent of the Napanee TS Taylor Kidd Solar Energy Project in Millhaven. The 10 MW solar PV facility covers approximately 34 hectares of privately-owned land located on Part of Lots 27 and 28, Concession 1, Loyalist Township, County of Lennox and Addington. The facility generates electricity which is fed into the HONI distribution grid. With a 20-year FIT contract from the OPA, the facility is expected to operate until at least 2033. The Project is considered a Class 3 solar facility and thus requires a REA. Hatch was the engineering consultant for the project, but SunEdison prepared the consultation report which was published online on February 23, 2012 (Napanee TS Taylor Kidd Solar Energy Project - Consultation Report, 2012).

As with the previous three projects, stakeholders considered in the consultation process include adjacent landowners, government agencies, local municipalities, Aboriginal communities, and the public. The objectives of the consultation process were the same as those of the previous three projects:

- to identify issues and potential concerns;

- to obtain information about the project location;

- to identify potential impacts associated with the Project; and

- to identify specific stakeholders in order to establish an open and meaningful dialogue between the Proponents and the stakeholders.

The public consultation process is summarized by the timeline in Figure 21. Each of the events is described in the following subsections. 


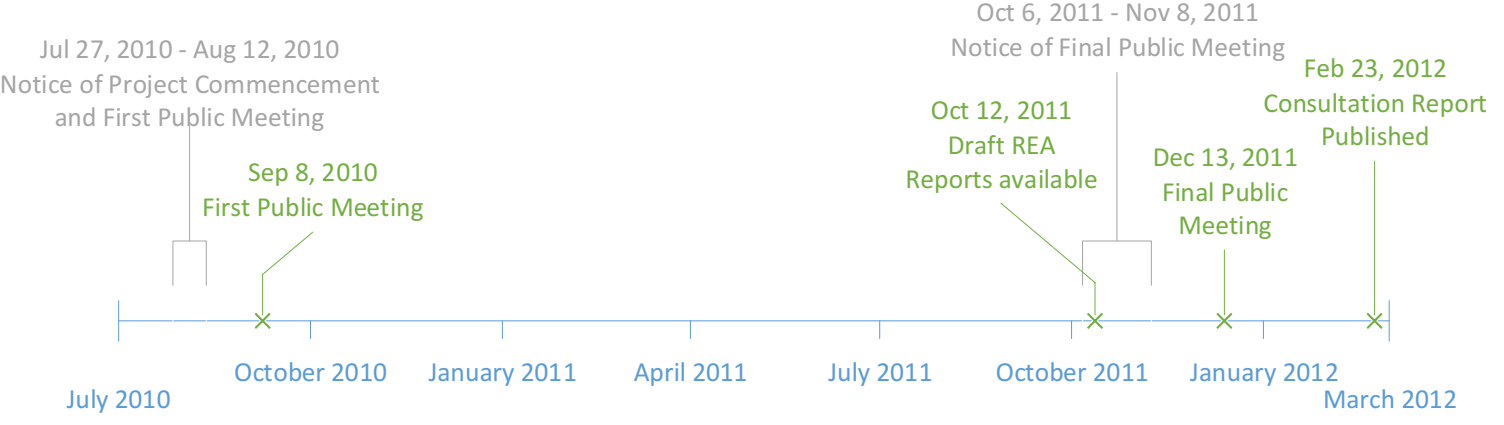

Figure 21: Taylor Kidd public consultation timeline

\subsubsection{First Public Meeting}

The Notice of Project Commencement and First Public Meeting was mailed to six landowners within $120 \mathrm{~m}$ of the project location on July 27, 2010. The notice was also published in two local newspapers: the Kingston Whig-Standard on July 31 and August 7, 2010; and the Kingston This Week on August 5 and 12,2010. A copy of the notice was published on the project website along with the Draft PDR. The notice contained information on the project location, the proposed size of the project, the Proponent, and the REA process, as well as a map of the project area.

The First Public Meeting was held on September 8, 2010 at the Odessa Fairgrounds. Figure 22 shows the location of the Odessa Fairgrounds relative to the Project. The meeting was held in an open house format, where information was provided on display boards, and project representatives were available to answer questions and solicit feedback. Comment sheets were available for attendees to record and submit any comments or concerns. 


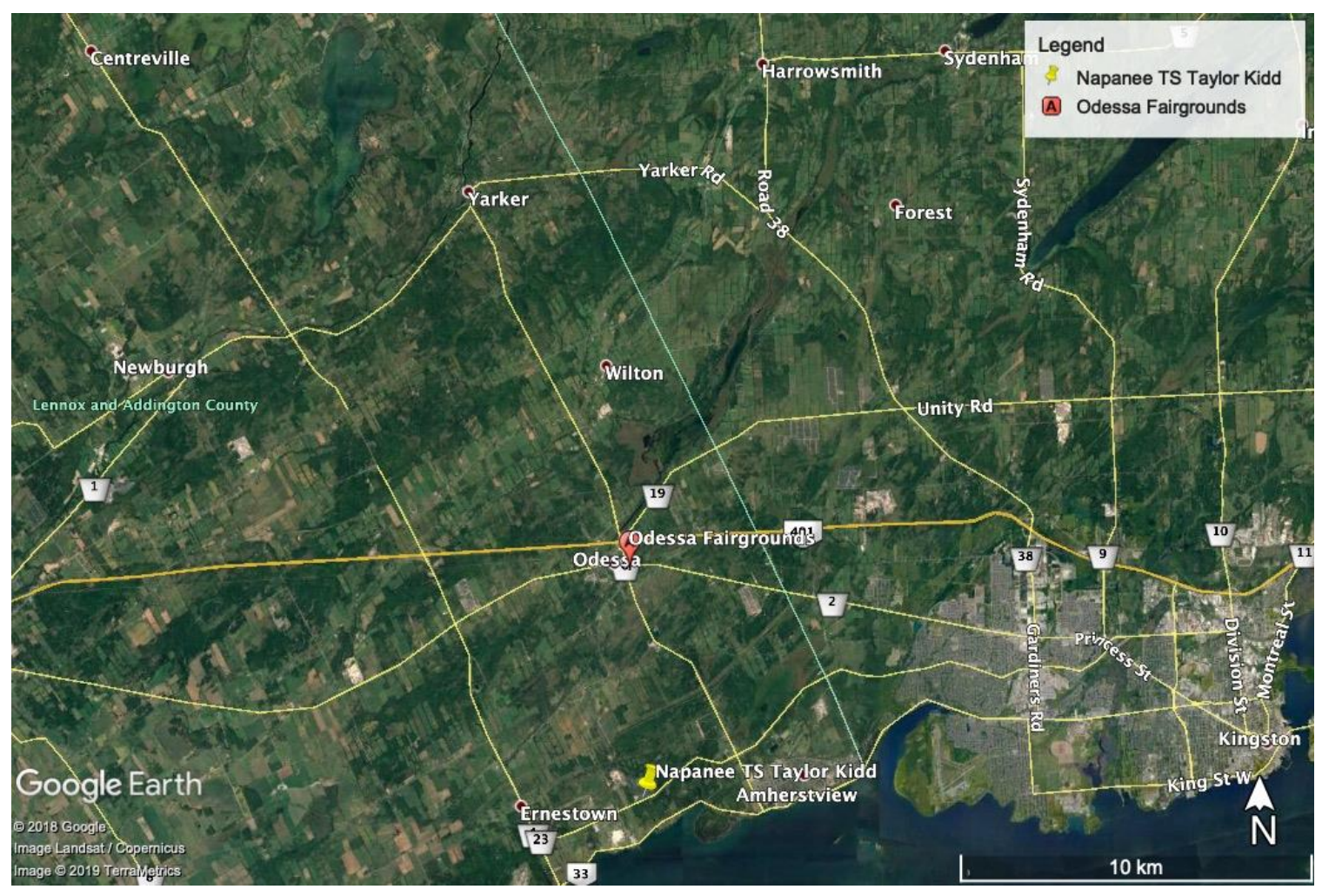

Figure 22: Taylor Kidd project map

There were five attendees (who signed in) at the meeting. Comments were generally positive. Attendees asked questions about how solar PV works, and the extent of site visibility after construction is complete. No comment sheets were submitted.

\subsubsection{Final Public Meeting}

The Notice of Final Public Meeting was mailed to 11 landowners within $120 \mathrm{~m}$ of the project location on October 6, 2011. The notice was also published in the Kingston WhigStandard on October 8 and November 8, 2011. A copy of the notice was published on the project website on October 12, 2011, along with Draft copies of the project documents required as part of the REA process. The same day, hard copies of all project documents 
were made available for public review at the municipal offices of Loyalist Township and the County of Lennox and Addington.

Like the Notice of Project Commencement, the notice contained information on the project location, the proposed size of the project, the Proponents, and the REA process, as well as a map of the Project area. In addition, the notice contained the location, date, and time of the Final Public Meeting, the locations where draft project reports were available for public review, the dates of the review period, and the contact information for submitting comments.

The Final Public Meeting was held on December 13, 2011 at the Odessa Fairgrounds, the same location as the First Public Meeting. Like the first public meeting, the meeting was held in an open house format. Display boards showed project information, while project representatives were available to answer questions. In addition, comment sheets were available for attendees to record and submit any comments or concerns.

There were five attendees (who signed in) at the meeting. Comments were generally positive with no significant concerns. No comment sheets were submitted.

\subsubsection{Public comments and concerns}

Public stakeholders expressed few comments and concerns. Table 6 extracted from the consultation report shows a thematic summary of the comments received and the Proponent's response. Where applicable the response includes references to details in the project documents. 
Table 6: Taylor Kidd Public Comments and Responses (p. 16)

\begin{tabular}{|l|l|l|}
\hline Category & Comment & Response \\
\hline $\begin{array}{l}\text { Terrestrial, } \\
\text { Soil }\end{array}$ & $\begin{array}{l}\text { One attendee at the final public meeting was } \\
\text { interested in seeing the air photo of the project site. }\end{array}$ & $\begin{array}{l}\text { SunEdison sent the air photo by } \\
\text { email on December 6, 2011. }\end{array}$ \\
\hline
\end{tabular}

Overall, there were no significant concerns with the project proposal. In response to concerns about the Project being in the vicinity of Cooke's Creek, the project location was adjusted to be at least $120 \mathrm{~m}$ south of Cooke's Creek.

\subsubsection{Westbrook Solar}

SunEdison Canada is the proponent of the SunE Westbrook Solar Farm in Kingston. The 10 MW solar PV facility covers approximately 70 hectares of agricultural zoned land located on Burbrook Road. The facility generates electricity which is fed into the HONI distribution grid. The Project is considered a Class 3 solar facility and thus requires a REA (SunE Westbrook Solar Farm - Executive Summary, 2012). GENIVAR (now WSP Global) was the engineering consultant for the project, but SunEdison prepared the consultation report which was published online on May 17, 2012 (SunE Westbrook Solar Farm - Consultation Report, 2012). The public consultation process is summarized by the timeline in Figure 23. Each of the events is described in the following subsections.

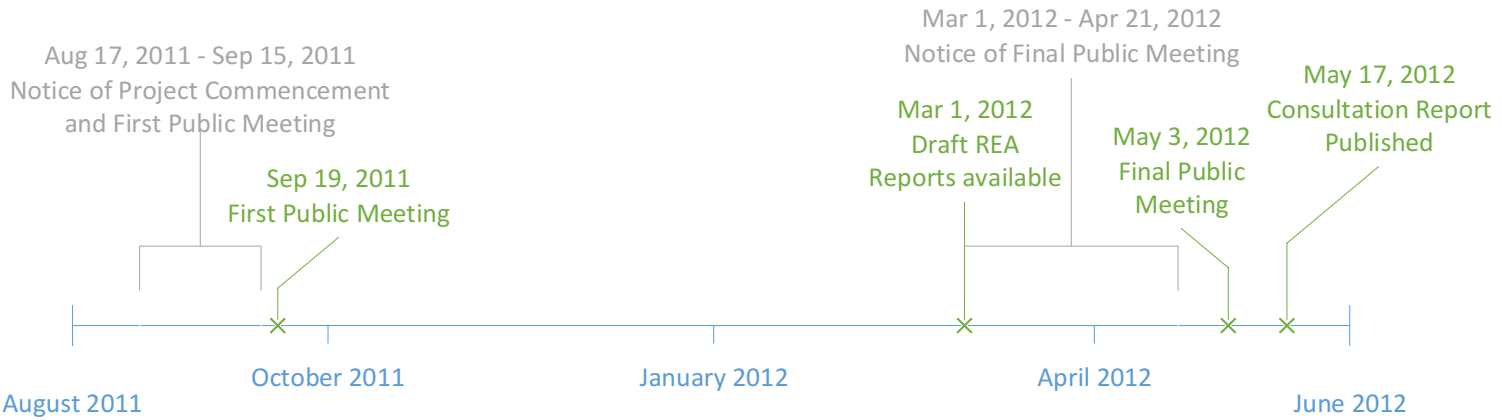

Figure 23: Westbrook public consultation timeline 


\subsubsection{Public Meeting \#1}

The Notice of Project Commencement and Public Meeting \#1 was published in two local newspapers: the Kingston Whig-Standard on August 17, 2011; and the Kingston This Week on September 15, 2011. The notice was also hand distributed to all residences within $120 \mathrm{~m}$ of the project location, as well as additional residences along Highway 401. A copy of the notice was published on the project website along with the Draft PDR. The notice contained information on the project location, the proposed size of the project, the Proponent, and the REA process, as well as a map of the project area.

Public Meeting \#1 was held on September 19, 2011 at the INVISTA Centre in Kingston. Figure 24 shows the location of the INVISTA Centre relative to the Project.

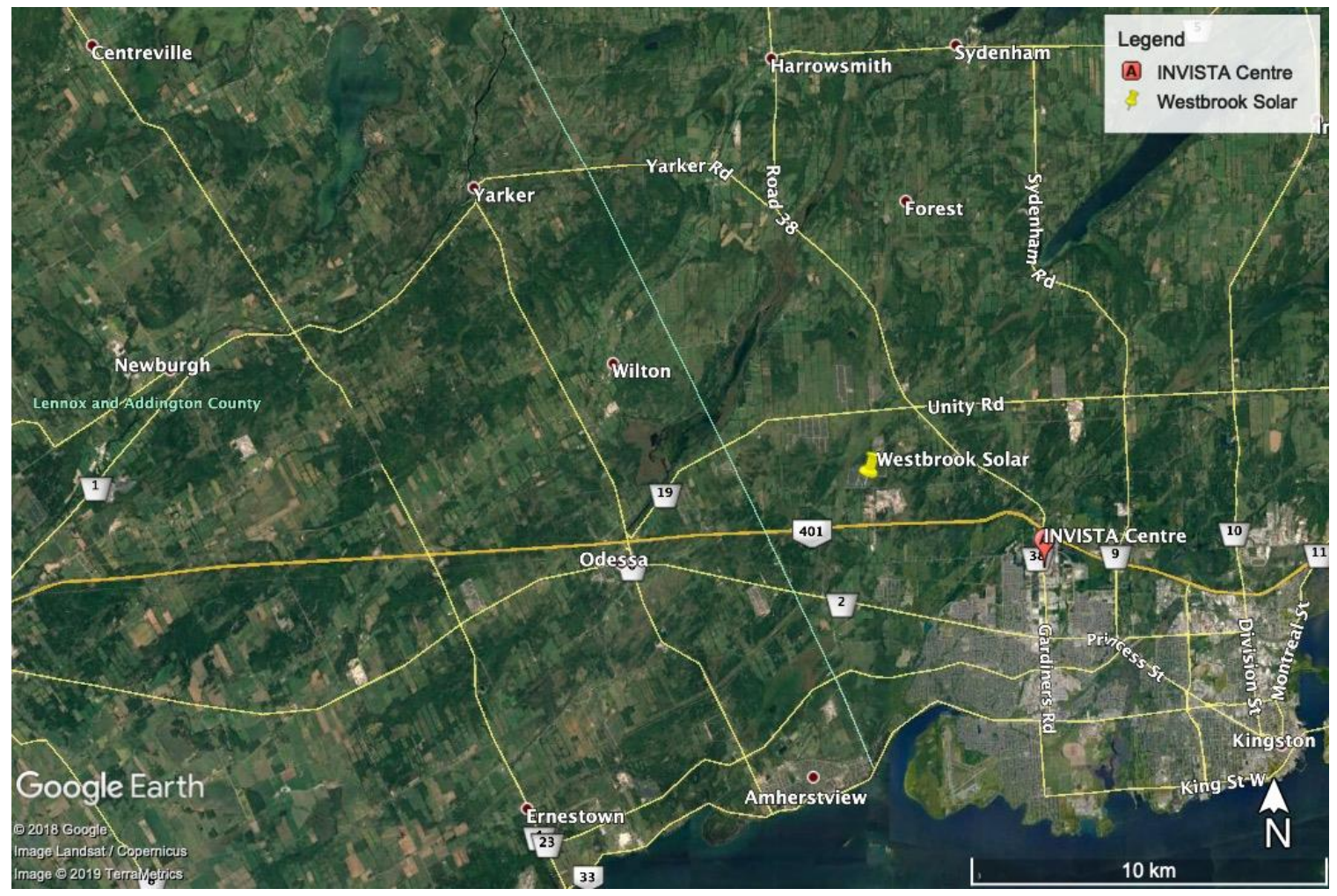

Figure 24: Westbrook project map 
The meeting was held in an open house format, where information was provided on display boards, and project representatives were available to answer questions and solicit feedback. Comment sheets were available for attendees to record and submit any comments or concerns.

There were four attendees (who signed in) at the meeting. Comments were mixed positive and negative. Attendees asked questions about how solar PV works, whether people would notice the site after construction, visual impact, noise, and property values. Table 7 is a summary of the written comments submitted along with the Proponent's response, extracted from the consultation report. Where applicable the response includes references to details in the project documents.

Table 7: Westbrook Public Meeting \#1 Comments and Responses (p. 16)

\begin{tabular}{|c|c|}
\hline Comment & Response \\
\hline $\begin{array}{l}\text { Please maintain a green space as a visual } \\
\text { barrier to disguise fencing along property } \\
\text { lines. }\end{array}$ & $\begin{array}{l}\text { Landscape plans will be developed and SunEdison } \\
\text { will continue to work with directly affected } \\
\text { neighbours on minimizing the visual impact. } \\
\text { Landscape plan will look at trees along fence line } \\
\text { that directly affects nearby residences (not an REA } \\
\text { requirement but will be discussed at Public } \\
\text { Meeting \#2). }\end{array}$ \\
\hline $\begin{array}{l}\text { Thank you for the information, coffee, } \\
\text { and cookies. } \\
\text { Too bad you are restricted in the size of } \\
\text { your projects. }\end{array}$ & - $\quad$ None required. \\
\hline $\begin{array}{l}\text { - Concerns: Natural Wetlands, tree removal } \\
\text { Would like trees planted to avoid the } \\
\text { noise and view of fence } \\
\text { Wildlife: endangered/fragile species- } \\
\text { frog ponds, Eastern Newt, } \\
\text { Hawks/Vultures, Blue Spotted } \\
\text { Salamanders, Painted Turtles, Grey Tree } \\
\text { Frogs } \\
\text { - Concerned about house value going down } \\
\text { - Concerned that the noise levels will } \\
\text { irritate, as we are noise sensitive }\end{array}$ & $\begin{array}{l}\text { Natural Heritage Assessment Studies and } \\
\text { Waterbody Reports were undertaken and } \\
\text { developed for this project. MNR will be required } \\
\text { to provide sign off on the project in order to obtain } \\
\text { REA approval. Reference: MNR sign off and } \\
\text { Natural Heritage Assessment Reports and } \\
\text { Waterbody Reports, Appendix C of the REA } \\
\text { submission. } \\
\text { Noise levels will be below the MOE standards and } \\
\text { are generally limited to the substation and its } \\
\text { proximity to receptors. Reference: Noise Study } \\
\text { Report, Appendix E of the REA submission. }\end{array}$ \\
\hline
\end{tabular}




\subsubsection{Public Meeting \#2}

The Notice of Public Meeting was published in the Kingston Whig-Standard on March 3 and April 21, 2012, and in the Kingston This Week on March 1 and April 19, 2012. The notice was also distributed to all landowners (mailed to non-resident landowners) within $120 \mathrm{~m}$ of the project location, as well as others who had requested to be added to the mailing list. A copy of the notice was published on the project website on March 1, 2012, along with Draft copies of the project documents required as part of the REA process. The same day, hard copies of all project documents were made available for public review at the City of Kingston municipal office.

Like the Notice of Project Commencement, the notice contained information on the project location, the proposed size of the project, the Proponents, and the REA process, as well as a map of the Project area. In addition, the notice contained the location, date, and time of the Final Public Meeting, the locations where draft project reports were available for public review, the dates of the review period, and the contact information for submitting comments.

Public Meeting \#2 was held on May 3, 2012 at the INVISTA Centre in Kingston, the same location as the Public Meeting \#1. Like the first public meeting, the meeting was held in an open house format. Display boards showed project information, while project representatives were available to answer questions. In addition, comment sheets were available for attendees to record and submit any comments or concerns. 
There were 14 attendees (who signed in) at the meeting, including a local councillor.

Comments were generally negative, with the main concerns regarding cumulative

impacts of multiple solar projects in the area (specifically referring to Sol-Luce Kingston

Solar), visual impacts, and potential groundwater impacts. Generally, concerns were not specific to the Westbrook project, particularly those regarding cumulative impacts. Table 8 is a summary of the written comments submitted along with the Proponent's response, extracted from the consultation report. Where applicable the response includes references to details in the project documents.

Table 8: Westbrook Public Meeting \#2 Comments and Responses (p. 17)

\begin{tabular}{|c|c|}
\hline Comment & Response \\
\hline $\begin{array}{l}\text { Consistent fence line along east- } \\
\text { northeast portion of site and provide } \\
\text { vegetation } \\
\text { - Looking to build retirement home in } \\
\text { future }\end{array}$ & $\begin{array}{l}\text { - SunEdison provided visual display of landscape plans } \\
\text { for the fence line that potentially affects neighbouring } \\
\text { residences } \\
\text { - Will look at straightening out fence line and providing } \\
\text { vegetative cover along portion of the fence line } \\
\text { - Landscape plans are not part of the REA submission but } \\
\text { SunEdison is committed to working with adjacent } \\
\text { neighbours and will develop the fenceline and } \\
\text { vegetation similar to that presented on the boards at } \\
\text { Public Meeting \#2 }\end{array}$ \\
\hline $\begin{array}{l}\text { Lack of oversight and the } \\
\text { community should be listened to } \\
\text { and not argued with } \\
\text { Groundwater - massive fire in the } \\
\text { area years ago had no impact but } \\
\text { another would no take out the solar } \\
\text { farm and will this affect the aquifer }\end{array}$ & $\begin{array}{l}\text { - Solar panels are not flammable and would withstand fire } \\
\text { Groundwater monitoring program was provided to } \\
\text { address groundwater now, during construction and } \\
\text { following construction of the project }\end{array}$ \\
\hline $\begin{array}{l}\text { - So far I'm impressed and pleased } \\
\text { with the project } \\
\text { I look forward to it taking place }\end{array}$ & - No response required. \\
\hline
\end{tabular}

\subsubsection{Consideration of public comments and concerns}

Overall, there were no significant concerns with the project proposal which could not be resolved. Public feedback contributed to minor changes as outlined above. In addition, to 
address concerns about pesticide use, a statement was added to the Design and Operations report specifying that no pesticides or herbicides will be used; and to address concerns about vegetation around the arrays, a statement was added to the Construction Plan and Decommissioning Plan reports specifying that native plant species would be used if possible for re-vegetation of disturbed areas.

\subsubsection{Sol-Luce Kingston Solar}

Kingston Solar LP, also known as Samsung Renewable Energy Inc., is the proponent of the Sol-Luce Kingston Solar PV Energy Project. The 100 MW solar PV facility spans multiple sites in both the City of Kingston and Loyalist Township, covering approximately 261 hectares. The facility generates electricity which is fed into the provincial grid via a substation located next to the HONI transmission line which crosses the project area. The Project is considered a Class 3 solar facility and thus requires a REA. The engineering consultant, AMEC Environment \& Infrastructure (now Wood Group PLC), prepared the consultation report which was published online in September 2012 (AMEC Environment \& Infrastructure, 2012).

The consultation report defines engagement as "a two-way exchange of information between Project applicants and stakeholders (interested or potentially affected local groups, members of the public as well as municipalities and local boards) and Aboriginal communities" (p. 5). The purposes of engagement were:

- To ensure that relevant project information is provided to stakeholders;

- To identify relevant local knowledge from stakeholders; 
- To identify concerns that may arise from the Project; and

- To address identified concerns by providing additional information, explanation, or changing Project design, or making commitments in response to input, where possible.

The Proponent felt it was important to involve stakeholders in order to:

- Build new or strengthen existing relationships with potentially affected stakeholders;

- Discuss site-specific details and potential impacts to gain insight into specific impacts on potentially affected stakeholders, and determine appropriate management measures to avoid or mitigate such impacts;

- Implement delegated procedural aspects of consultation from the Crown;

- Reduce regulatory risks for the project and streamline the application process; and

- Ensure social licence to operate (approval within the local community and stakeholders) through construction and operation phases of the Project.

The Proponent adopted the following principles of public participation to guide the engagement process:

- Early notification: providing information to stakeholders in a timely manner to facilitate early and meaningful engagement;

- Honest, open, and transparent communication: sharing all pertinent information about the Project with stakeholders; 
- Accessibility: using a variety of engagement methods to disseminate information and solicit feedback;

- Inclusion: striving to include all known or self-identified stakeholders and welcoming their input;

- Flexibility: adapting the engagement process based on feedback to ensure sufficient opportunities to provide input;

- Relationship building and capacity building: evaluating and implementing opportunities to further enhance the engagement process;

- Mutual respect: respecting the different cultures, values, and constraints of each stakeholder, and following through on commitments;

- Efficiency: making effective use of existing processes and resources; and

- Timeliness: initiating engagement early before decisions are made, and establishing clear and reasonable timelines for input and comments.

The Proponent believed that implementing the consultation process based on the above principles would generate overall benefits for the Project, including:

- The provision of first-hand information to all interested parties;

- Recognition and integration of stakeholder issues and concerns;

- A better understanding of shared interests;

- Better informed, environmentally-sound decisions;

- Positive working relationships;

- Compliance with permits, licences, and regulatory requirements and guidelines; and 
- Long-term opportunities and benefits.

A Project distribution list was developed early in the consultation process, consisting of assessed landowners in the original Study Area. As more stakeholders corresponded with the Project team through meetings, phone calls, or email, they were added to the list on an ongoing basis.

The public consultation process included a variety of methods for disseminating project information, collecting information from stakeholders, and having ongoing correspondence with interested parties. The process is summarized by the timeline in Figure 25. Each of the events is described in the following subsections.

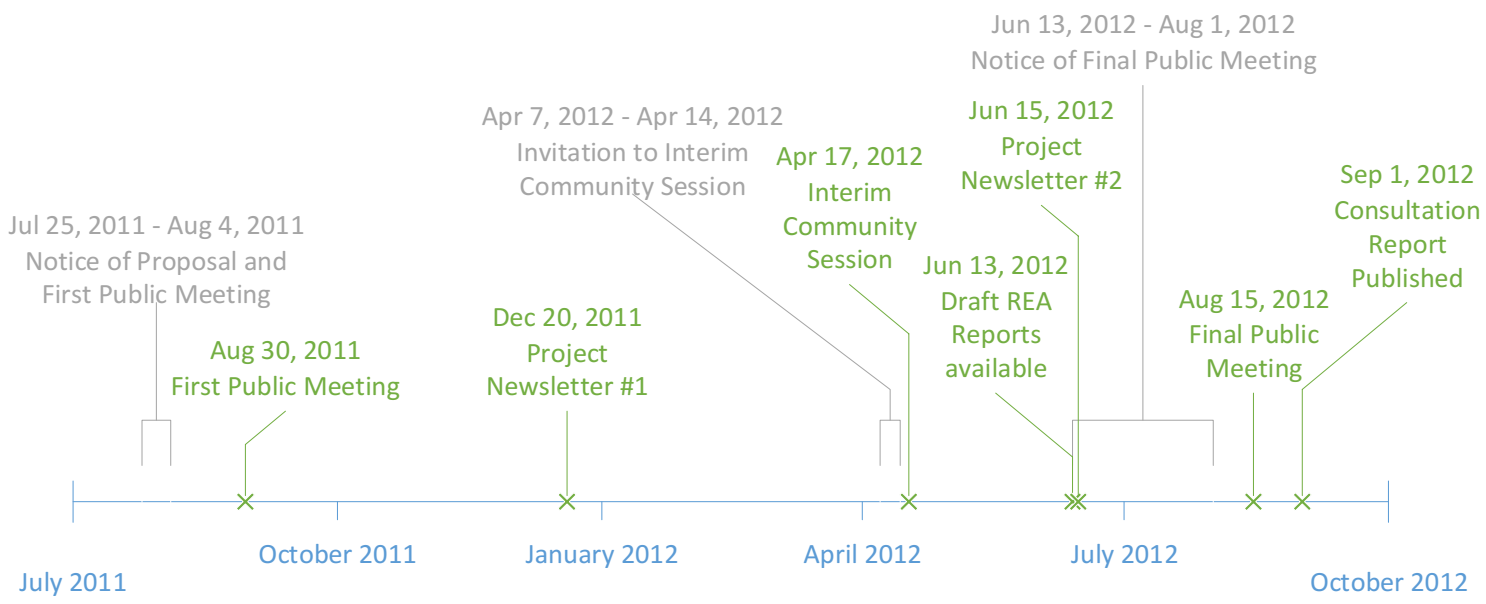

Figure 25: Sol-Luce public consultation timeline

\subsubsection{First Public Meeting}

The Notice of Proposal to Engage in a Renewable Energy Project and First Public Meeting was published in two local newspapers: the Kingston Whig-Standard on July 25, 
2011; and the Kingston EMC on August 4, 2011. The notice was also sent by mail or email to the project distribution list, and hand delivered to approximately 230 mailboxes in the Study Area. A copy of the notice was published on the project website along with the Draft PDR. Hard copies of the Draft PDR were available for public review at the City of Kingston Clerk's office, the Kingston Frontenac Public Library, the Loyalist Township municipal office, and the Odessa Branch Library.

The First Public Meeting was held on two consecutive evenings at two different locations: on August 30, 2011 at the Odessa Fairgrounds, and on August 31, 2011 at the INVISTA Centre in Kingston. Figure 26 shows the locations of the Odessa Fairgrounds and the INVISTA Centre relative to the Project. The Project consists of all the areas outlined in turquoise.

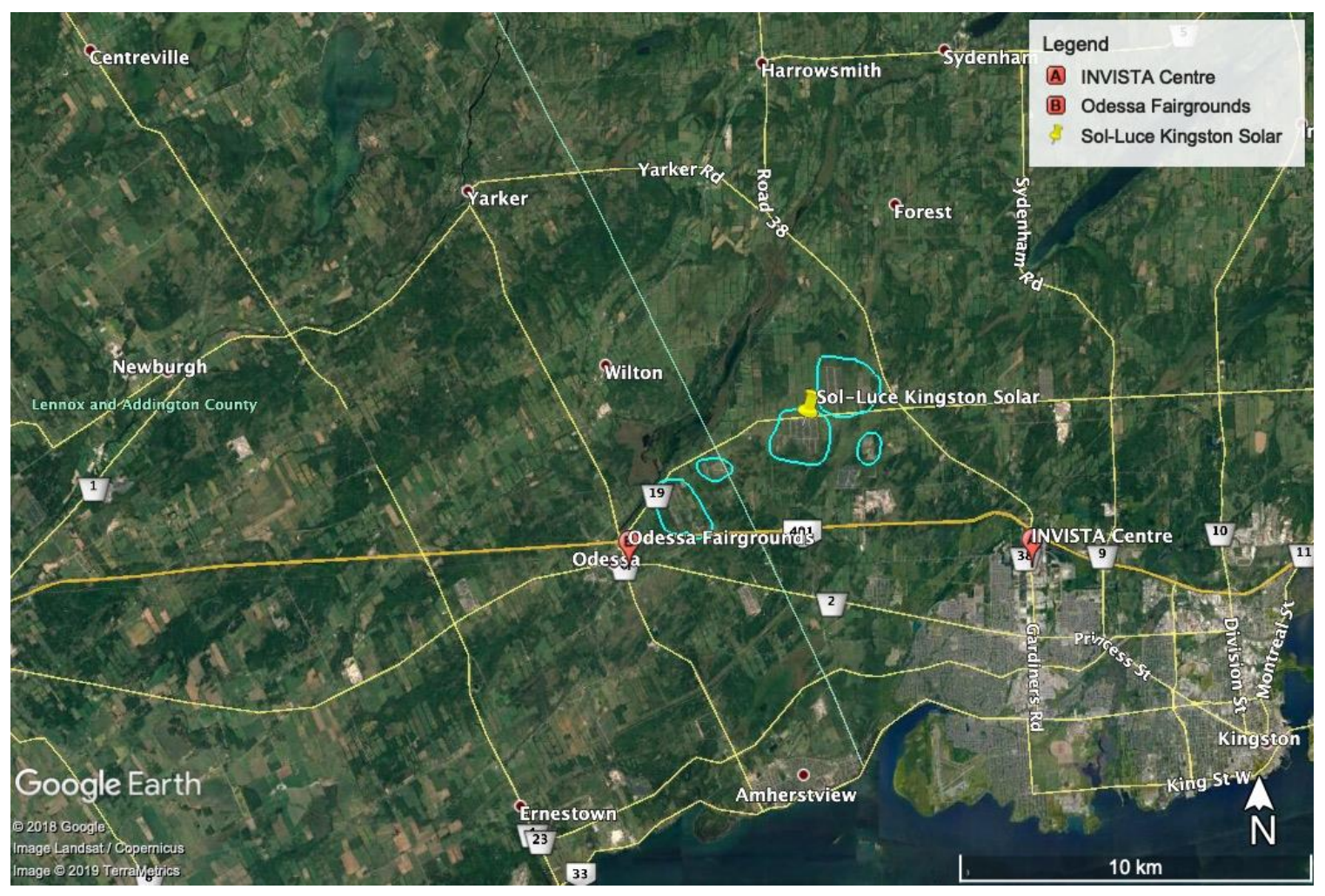

Figure 26: Sol-Luce project map 
The meeting provided the communities an early opportunity to hear more about the project and to identify local interests and concerns. The meeting was held in an open house format, where 13 display boards provided information on the Project (including the location, schedule, technology, environment, and health and safety), as well as the REA process and the environmental studies required. Attendees could view the information at their leisure or have a project team member guide them through. Proponent representatives were available to provide information, answer questions, and hear local interests and concerns. Comment sheets were also available for attendees to record and submit any comments or concerns.

There were 26 attendees at the open house in Odessa, and 32 attendees at the open house in Kingston. There were 22 comment sheets submitted between the two locations. Comments and concerns expressed included the location of the panels, visual impact and mitigation, impact on property values, truck traffic during construction, species at risk, and impact to local wildlife. This feedback was taken into consideration during the Project planning and siting process. Table 9 is a thematic summary of the comments received along with the Proponent's response, extracted from Appendix D of the consultation report. Where applicable the response includes references to details in the project documents.

Table 9: Sol-Luce First Public Meeting Comments and Responses (pp. 1-3)

\begin{tabular}{|l|l|l|}
\hline Category & Comment & Response \\
\hline Archaeology & $\begin{array}{l}\text { Why do you need to plough } \\
\text { the fields? }\end{array}$ & $\begin{array}{l}\text { The REA process requires proponents to undertake an } \\
\text { archaeological investigation of the project lands. In } \\
\text { order to determine whether there are artifacts beneath } \\
\text { the soil, fields need to be ploughed to expose the sub- } \\
\text { soil. Archaeologists then walk over the fields and look }\end{array}$ \\
\hline
\end{tabular}




\begin{tabular}{|c|c|c|}
\hline Category & Comment & Response \\
\hline & & $\begin{array}{l}\text { for artifacts that may indicate past occupation of the } \\
\text { lands. The first round of ploughing was conducted in } \\
\text { October and November of } 2011 \text {. A second round of } \\
\text { ploughing will occur (weather permitting) throughout } \\
\text { Spring } 2012 \text {. }\end{array}$ \\
\hline Employment & $\begin{array}{l}\text { Are there any job opportunities } \\
\text { during the construction stage? }\end{array}$ & $\begin{array}{l}\text { There will be job opportunities available during the } \\
\text { construction of the solar facility. It is anticipated that } \\
\text { about } 100 \text { people will be required on a monthly basis } \\
\text { during the } 18 \text {-month construction schedule. Further } \\
\text { details will be available once the necessary approvals } \\
\text { have been received. }\end{array}$ \\
\hline \multirow[t]{6}{*}{ General } & $\begin{array}{l}\text { Are there other solar projects } \\
\text { in eastern Ontario? }\end{array}$ & $\begin{array}{l}\text { There are a number of proposed solar energy projects } \\
\text { going through the REA process in Ontario. }\end{array}$ \\
\hline & $\begin{array}{l}\text { Non-participating landowners } \\
\text { identified a concern that they } \\
\text { will be surrounded by mirrors } \\
\text { because Samsung is not the } \\
\text { only developer proposing solar } \\
\text { projects in the area. Will there } \\
\text { be glare? }\end{array}$ & $\begin{array}{l}\text { The anti-reflection coating (AR coating) applied to } \\
\text { the solar panels, any glare is minimized. Mitigation } \\
\text { for glare is part of the solar facility design process. }\end{array}$ \\
\hline & $\begin{array}{l}\text { Samsung should look into the } \\
\text { policies for Commercial-Scale } \\
\text { Solar Energy Generation } \\
\text { System (Section 5.12.3) under } \\
\text { the amended official plan of } \\
\text { the Loyalist Township, which } \\
\text { will be used as the policy } \\
\text { framework for the municipal } \\
\text { review on the renewable } \\
\text { energy approval process. }\end{array}$ & $\begin{array}{l}\text { Thank-you for the comment; the Project team will } \\
\text { further investigate. }\end{array}$ \\
\hline & $\begin{array}{l}\text { What are the economic } \\
\text { benefits to the landowners? }\end{array}$ & $\begin{array}{l}\text { Local benefits that may be realized as a result of this } \\
\text { Project include: } \\
\text { - Employment including direct (engineering, } \\
\text { construction, suppliers, and service providers) } \\
\text { and indirect (accommodations, restaurants, and } \\
\text { retail). } \\
\text { - Income to property owners where leases have } \\
\text { been established. } \\
\text { New property and sales tax revenues for the local } \\
\text { tax base. } \\
\text { Environmental benefits through the reduction of } \\
\text { greenhouse gas emissions. }\end{array}$ \\
\hline & $\begin{array}{l}\text { Will the project also include } \\
\text { wind turbines some day? }\end{array}$ & $\begin{array}{l}\text { There are no wind turbines considered for this solar } \\
\text { facility. }\end{array}$ \\
\hline & Will the project expand? & $\begin{array}{l}\text { Currently, Kingston Solar LP is not considering future } \\
\text { expansion of the Project; however, if in the future this } \\
\text { need arises, Kingston Solar LP will inform the } \\
\text { community. }\end{array}$ \\
\hline $\begin{array}{l}\text { Layouts and } \\
\text { setbacks }\end{array}$ & $\begin{array}{l}\text { How was the study area } \\
\text { chosen? }\end{array}$ & $\begin{array}{l}\text { This location was selected by Kingston Solar LP } \\
\text { based on multiple factors, including: } \\
\text { a) On solar radiation data. } \\
\text { b) Proximity to the transmission line. }\end{array}$ \\
\hline
\end{tabular}




\begin{tabular}{|c|c|c|}
\hline Category & Comment & Response \\
\hline & & $\begin{array}{l}\text { c) Available capacity on Hydro One's transmission } \\
\text { system. } \\
\text { d) Readily available Canadian Land Inventory Class } \\
4 \text { to } 7 \text { lands. } \\
\text { e) Landowners willing to participate in this project. }\end{array}$ \\
\hline & $\begin{array}{l}\text { Can the Community see a } \\
\text { footprint of where the solar } \\
\text { panels will be? }\end{array}$ & $\begin{array}{l}\text { There is currently no layout as the required studies } \\
\text { and reports need to be completed before the layouts } \\
\text { can be determined. The information gathered from the } \\
\text { studies will identify areas where panels can and } \\
\text { cannot be placed. }\end{array}$ \\
\hline Noise & $\begin{array}{l}\text { Has there ever been a study on } \\
\text { the collaborative noise effect } \\
\text { of such a large solar project? }\end{array}$ & $\begin{array}{l}\text { A Noise Study Report is required by the MOE to } \\
\text { ensure that the proposed solar facility, specifically the } \\
\text { transformers, is strategically located to minimize } \\
\text { noise effects. }\end{array}$ \\
\hline $\begin{array}{l}\text { Property } \\
\text { Value }\end{array}$ & $\begin{array}{l}\text { Concern from adjacent } \\
\text { landowners about the decrease } \\
\text { in the property value due to the } \\
\text { development of the solar panel } \\
\text { surrounding their property. }\end{array}$ & $\begin{array}{l}\text { There is no information available to date that links the } \\
\text { location of a solar facility with impacts on property } \\
\text { values. }\end{array}$ \\
\hline Schedule & $\begin{array}{l}\text { Interest in the project schedule } \\
\text { - when is construction starting } \\
\text { and when will it begin to } \\
\text { deliver power. }\end{array}$ & $\begin{array}{l}\text { Kingston Solar LP will work with a Construction } \\
\text { Contractor once the designs are finalized and } \\
\text { approvals are received. The construction schedule is } \\
\text { currently estimated to be } 1 \frac{1 / 2}{2} \text { years. Operation is } \\
\text { currently anticipated to begin in } 2014 \text {. }\end{array}$ \\
\hline Vegetation & $\begin{array}{l}\text { What are Samsung's plans for } \\
\text { tree compensation? }\end{array}$ & $\begin{array}{l}\text { Kingston Solar LP will work with the City of } \\
\text { Kingston, Loyalist Township and Cataraqui Region } \\
\text { Conservation Authority to identify appropriate } \\
\text { mitigation measures to meet the requirements of } \\
\text { municipal tree bylaws. }\end{array}$ \\
\hline \multirow[t]{4}{*}{ Visual } & $\begin{array}{l}\text { Will there be screening to } \\
\text { block the view of the panels? }\end{array}$ & $\begin{array}{l}\text { As part of the planning process, Kingston Solar LP } \\
\text { will be evaluating mitigation measures for potential } \\
\text { visual impacts and the scope of visual screening may } \\
\text { be established as the detail design progresses. }\end{array}$ \\
\hline & $\begin{array}{l}\text { Will there be fencing? If so, } \\
\text { will it be like Sarnia - } 8 \text { feet } \\
\text { high with razor wire? }\end{array}$ & $\begin{array}{l}\text { As part of the planning process, Kingston Solar LP } \\
\text { will be evaluating mitigation measures for potential } \\
\text { visual impacts and the scope of visual screening may } \\
\text { be established as the detail design progresses. }\end{array}$ \\
\hline & $\begin{array}{l}\text { Rather have a berm than } \\
\text { fences to block the view. }\end{array}$ & $\begin{array}{l}\text { As part of the planning process, Kingston Solar LP } \\
\text { will be evaluating mitigation measures for potential } \\
\text { visual impacts and the scope of visual screening may } \\
\text { be established as the detail design progresses. }\end{array}$ \\
\hline & $\begin{array}{l}\text { Provide a rendering or photos } \\
\text { to show what the project will } \\
\text { look like from ground level. }\end{array}$ & $\begin{array}{l}\text { Thank-you for your suggestion; the Project team will } \\
\text { take it under consideration. }\end{array}$ \\
\hline Wildlife & $\begin{array}{l}\text { I have a species at risk on my } \\
\text { property, will you be } \\
\text { monitoring it? Are you looking } \\
\text { for more land? }\end{array}$ & $\begin{array}{l}\text { Species at Risk (SAR) habitat areas have been } \\
\text { identified by the MNR. This identified habitat will not } \\
\text { be developed for this project and for the project } \\
\text { components including: panels, fences, roads, } \\
\text { underground transmission lines, inverter stations, or } \\
\text { buildings. Facility component development will occur } \\
\text { at a distance greater than } 120 \text { m away from areas } \\
\text { designated by the MNR. Any requests for this } \\
\text { information should be directed to the MNR. }\end{array}$ \\
\hline
\end{tabular}




\subsubsection{Interim Community Session}

The Interim Community Session was planned in response to the numerous questions and comments raised by the local community and municipal government representatives. The invitation for the Interim Community Session was published in the Kingston WhigStandard on April 7 and 14, 2012, and in the Kingston EMC on April 12, 2012. The invitation was also sent by mail or email to the project distribution list. The invitation included a document of Frequently Asked Questions (FAQs) which included over 100 questions that had arisen over the course of the project, along with the Proponent's response. The FAQ document was also available on the project website.

The Interim Community Session was held on April 17, 2012 at the INVISTA Centre, one

of the locations of the First Public Meeting. Unlike the other public meetings, this session was only held on one date at one location; community members had suggested holding the session at a single, central location so that they could hear from other community members in attendance. The session was held in an open house format with 23 poster boards providing information on various aspects of the Project, including the regulatory process, the updated project location and schedule, and the environmental studies that were underway. Attendees could view the information at their leisure or have a project team member guide them through. The Proponent and AMEC had representatives available to provide information, answer questions, and hear local interests and concerns. Specialists in biology, hydrogeology, civil engineering, and electrical engineering were available at the session to answer more specific questions. In addition, round table discussions allowed interested individuals to sit with a specialist to discuss concerns or 
issues. Comment sheets were also available for attendees to record and submit any comments or concerns.

There were 56 attendees at the Community Session. Eleven comment sheets were submitted. Comments and concerns expressed included impact on groundwater and well water, impact on property values, species at risk, communication with residents, impact on the rural residential lifestyle, and visual aesthetics. Attendees also generally wanted more details about the project, which were not necessarily available since the studies were still in progress. The feedback received was taken into consideration during the Project planning and siting process. Table 10 is a thematic summary of the comments received along with the Proponent's response, extracted from Appendix D of the consultation report. Where applicable the response includes references to details in the project documents.

Table 10: Sol-Luce Interim Community Session Comments and Responses (pp. 3-4)

\begin{tabular}{|l|l|l|}
\hline Category & Comment & Response \\
\hline Communications & $\begin{array}{l}\text { Should provide notice to non- } \\
\text { participating landowners that } \\
\text { field studies are on-going. }\end{array}$ & $\begin{array}{l}\text { Thank-you for your comment. We will advise the } \\
\text { field survey teams of your comments. } \\
\text { The times for conducting field visits will be } \\
\text { weather dependant and will often occur in April } \\
\text { and May. Our consultants will have signs (with } \\
\text { AMEC logo) attached to the side of their vehicles } \\
\text { that are easily identifiable when there are } \\
\text { professionals in the project boundary area } \\
\text { conducting field work. }\end{array}$ \\
\hline Employment & $\begin{array}{l}\text { Are there any job } \\
\text { opportunities during the } \\
\text { construction stage? }\end{array}$ & $\begin{array}{l}\text { There will be job opportunities available during } \\
\text { the construction of the solar facility. It is } \\
\text { anticipated that about 100 people will be required } \\
\text { on a monthly basis during the 18-month } \\
\text { construction schedule. Further details will be } \\
\text { available once the necessary approvals have been } \\
\text { received. }\end{array}$ \\
\hline $\begin{array}{l}\text { Layouts and } \\
\text { setbacks }\end{array}$ & $\begin{array}{l}\text { Why aren't the properties } \\
\text { shown so that people can tell if } \\
\text { they may be impacted? }\end{array}$ & $\begin{array}{l}\text { The final layout of the proposed solar facility is } \\
\text { still under development. Until the studies and }\end{array}$ \\
\hline
\end{tabular}




\begin{tabular}{|l|l|l|}
\hline Category & Comment & Response \\
\hline Noise & $\begin{array}{l}\text { Can we see a footprint of } \\
\text { where the solar panels will be? } \\
\text { known. }\end{array}$ \\
\hline & $\begin{array}{l}\text { The exact layout of the solar facility is still under } \\
\text { development. Until the studies and reports are } \\
\text { complete the final locations are not known. } \\
\text { there ever been a study on the } \\
\text { collaborative noise effect of } \\
\text { such a large solar project? } \\
\text { What will the noise levels be } \\
\text { during construction and } \\
\text { operation? }\end{array}$ & $\begin{array}{l}\text { A Noise Study Report is required by the MOE. } \\
\text { The purpose of the report is to demonstrate that } \\
\text { the facility design complies with the regulation } \\
\text { and to mitigate any potential noise effects. } \\
\text { Kingston Solar LP revised this report, at the } \\
\text { direction of the MOE, to include the cumulative } \\
\text { noise effects of the surrounding solar projects. }\end{array}$ \\
\hline Property Value & $\begin{array}{l}\text { Concern from adjacent } \\
\text { landowners about the decrease } \\
\text { in the property value due to } \\
\text { the development of the solar } \\
\text { panel surrounding their } \\
\text { property. }\end{array}$ & $\begin{array}{l}\text { There is no information available to date that } \\
\text { links the location of a solar facility with impacts } \\
\text { on property values. }\end{array}$ \\
\hline $\begin{array}{l}\text { Will there be screening to } \\
\text { block the view of the panels? }\end{array}$ & $\begin{array}{l}\text { Landscaping designs will be developed on a } \\
\text { property-by-property basis as the requirements } \\
\text { are different from one location to another. As the } \\
\text { planning process progresses, detailed designs will } \\
\text { be developed. }\end{array}$ \\
\hline Visual & $\begin{array}{l}\text { Thank-you for your comment. Landscaping } \\
\text { designs will be developed on a property-by- } \\
\text { property basis as the requirements are different } \\
\text { from one location to another. As the planning } \\
\text { process progresses, detailed designs will be } \\
\text { developed. }\end{array}$ \\
\hline $\begin{array}{l}\text { Rather have a berm than } \\
\text { fences to block the view. }\end{array}$ \\
$\begin{array}{l}\text { Phank-you for your comment; we will share this } \\
\text { to show what the project will } \\
\text { look like from ground level. } \\
\text { suggestion with the project team as planning } \\
\text { progresses. }\end{array}$ \\
\hline
\end{tabular}

\subsubsection{Final Public Meeting}

The Notice of Final Public Meeting was published in the Kingston Whig-Standard on

June 13 and August 1, 2012, and in the Kingston EMC on June 13, June 21, and August

1, 2012. The notice was also sent by mail or email to the project distribution list, and

hand delivered to approximately 6000 residences to make up for a newspaper distribution

error. A copy of the notice was published on the project website on June 13, 2012, along

with Draft copies of the project documents required as part of the REA process. The same 
day, hard copies of all project documents were made available for public review at the City of Kingston, Loyalist Township, and County of Lennox and Addington municipal offices, as well as the Kingston Frontenac Public Library and the Odessa Branch Library.

The Final Public Meeting was held on two consecutive evenings at two different locations: on August 15, 2012 at the INVISTA Centre, and on August 16, 2012 at the Odessa Fairgrounds. These locations are the same as those of the First Public Meeting. The meeting allowed the Proponent to share updated information about the Project including the final layout, schedule, and technology, the REA process, and the environmental studies that had been completed. The consultation report acknowledges that this constitutes a large volume of information, and consideration was given to how to best present it.

The meeting was held in an open house format, where 27 display boards provided information on the Project. Attendees could view the information at their leisure or have a project team member guide them through. The Proponent and AMEC had representatives available to provide information, answer questions, and hear local interests and concerns. Specialists in biology, hydrogeology, and electrical engineering were available at the session to answer more specific questions. In addition, in response to concerns over groundwater, the Proponent had contracted Dillon Consulting to conduct a private well sampling program; the hydrogeologist responsible for the program was available at the meeting to address those specific concerns. Comment sheets were also available for attendees to record and submit any comments or concerns. 
There were 23 attendees at the open house in Kingston, and nine attendees at the open

house in Odessa. There were eight comment sheets submitted between the two locations.

Comments and concerns expressed included visual aesthetics and setbacks,

communication with residents, water quality and quantity, and impact on well water.

Table 11 is a thematic summary of the written comments submitted along with the

Proponent's response, extracted from Appendix D of the consultation report. Where

applicable the response includes references to details in the project documents.

Table 11: Sol-Luce Final Public Meeting Comments and Responses (pp. 4-8)

\begin{tabular}{|c|c|c|}
\hline Category & Comment & Response \\
\hline \multirow[t]{2}{*}{ Communications } & $\begin{array}{l}\text { Will we have another } \\
\text { opportunity to review } \\
\text { comments to see if } \\
\text { everything was entered? }\end{array}$ & $\begin{array}{l}\text { Once the MOE accepts the REA application and has } \\
\text { confirmed that the application meets all requirements } \\
\text { set out in the regulation, the REA application will be } \\
\text { posted on the Environmental Registry, which indicates } \\
\text { that the application is under review. This is another } \\
\text { opportunity for community members to submit } \\
\text { comments on the proposed project directly to MOE. } \\
\text { MOE takes all comments received into account when } \\
\text { making decisions on project applications. }\end{array}$ \\
\hline & $\begin{array}{l}\text { What have you done to } \\
\text { change the project to } \\
\text { address our concerns? }\end{array}$ & $\begin{array}{l}\text { The project layout has been modified to reduce the } \\
\text { impact on sensitive wildlife habitat in the Project area. } \\
\text { Panels have been removed from the property } \\
\text { immediately east of Quabbin Road to provide a greater } \\
\text { visual buffer. } \\
\text { Kingston Solar LP also completed a pre-construction } \\
\text { water well sampling program in response to } \\
\text { community and MOE concerns regarding the potential } \\
\text { impact on groundwater quality. }\end{array}$ \\
\hline Construction & $\begin{array}{l}\text { The information provided } \\
\text { is not detailed enough. } \\
\text { Would like more detail } \\
\text { on the design, } \\
\text { construction and } \\
\text { operation of the project; } \\
\text { more detail about the } \\
\text { foundation design, } \\
\text { boreholes, concrete, } \\
\text { duration of borehole } \\
\text { being open, and ground } \\
\text { cover. Stated that } \\
\text { Samsung was not } \\
\text { listening to concerns. }\end{array}$ & $\begin{array}{l}\text { Kingston Solar LP has shared all the information that } \\
\text { is currently available for the Project. Copies of all the } \\
\text { REA reports are available on the website } \\
\text { (www.SamsungRenewableEnergy.ca/Kingston) }\end{array}$ \\
\hline
\end{tabular}




\begin{tabular}{|c|c|c|}
\hline Category & Comment & Response \\
\hline & $\begin{array}{l}\text { How deep will the } \\
\text { installations be? What } \\
\text { size are the pillars? }\end{array}$ & $\begin{array}{l}\text { The pillars that the panels will be mounted on will be } \\
\text { approximately } 2 \text { metres deep. }\end{array}$ \\
\hline \multirow[t]{2}{*}{ Drainage } & $\begin{array}{l}\text { Concerned with drainage } \\
\text { issues associated with the } \\
\text { potential blockage of } \\
\text { ephemeral creeks that } \\
\text { discharge westward from } \\
\text { his fields. The attendee } \\
\text { identified the } \\
\text { approximate location of } \\
\text { the streams on a map. }\end{array}$ & $\begin{array}{l}\text { Kingston Solar LP will ensure that drainage to his } \\
\text { fields is not impeded by the project. }\end{array}$ \\
\hline & $\begin{array}{l}\text { How will storm water be } \\
\text { affected by tree and } \\
\text { vegetation removal? Will } \\
\text { water retention and } \\
\text { absorption be different? }\end{array}$ & $\begin{array}{l}\text { Impacts to groundwater quantity are not anticipated as } \\
\text { long as proper mitigation measures are followed. The } \\
\text { mitigation measures pertaining to ground water } \\
\text { quantity are described in Section } 4.3 .2 \text { of the } \\
\text { Construction Plan Report. }\end{array}$ \\
\hline $\begin{array}{l}\text { Layouts and } \\
\text { setbacks }\end{array}$ & $\begin{array}{l}\text { Why haven't the City of } \\
\text { Kingston guidelines for } \\
\text { setbacks been } \\
\text { incorporated? }\end{array}$ & $\begin{array}{l}\text { Kingston Solar LP understands that the purpose of the } \\
\text { City of Kingston Landscaping and Site Design } \\
\text { Guidelines for Large-Scale, Ground -Oriented Solar } \\
\text { energy Facilities document is to outline the minimum } \\
\text { standards that the Municipality would ask for with } \\
\text { respect to the landscaping and site design for solar } \\
\text { energy facilities located within the Municipality and } \\
\text { are intended to be a starting point in helping to } \\
\text { mitigate visual impacts that such facilities may have } \\
\text { on surrounding landscapes. Although compliance with } \\
\text { the Guidelines is not required as part of the REA, O. } \\
\text { Reg. } 359 / 09 \text { under the Environmental Protection Act, } \\
\text { Kingston Solar LP acknowledges the value and role of } \\
\text { municipalities in the development of renewable energy } \\
\text { projects in Ontario and will take the necessary steps to } \\
\text { implement certain aspects of the Guidelines, including } \\
\text { design aimed to address setbacks, visual appearance } \\
\text { and impacts, landscaping, and berms in the Project. }\end{array}$ \\
\hline Maintenance & $\begin{array}{l}\text { Will there be any } \\
\text { chemicals used in } \\
\text { cleaning the solar panels? }\end{array}$ & $\begin{array}{l}\text { Appropriate environmentally-friendly vegetation } \\
\text { control methods will be used by local contractors as } \\
\text { administered by the operations and maintenance } \\
\text { contractor. There is no cleaning regime for the panels } \\
\text { (i.e., naturally through rainwater). There will be no } \\
\text { chemicals used in cleaning of the solar panels. }\end{array}$ \\
\hline \multirow[t]{2}{*}{ Roads } & $\begin{array}{l}\text { Unity Road is a major } \\
\text { road. The secondary } \\
\text { roads are not suitable for } \\
\text { construction traffic. How } \\
\text { will this be dealt with? }\end{array}$ & $\begin{array}{l}\text { Prior to construction, the construction contractor will } \\
\text { review potential road restrictions with the } \\
\text { municipalities and prepare a traffic management plan } \\
\text { for the construction phase of the project. }\end{array}$ \\
\hline & $\begin{array}{l}\text { How will the potential } \\
\text { impact to the } \\
\text { swale/seasonal wetland } \\
\text { on Rock Road be dealt } \\
\text { with? }\end{array}$ & $\begin{array}{l}\text { During the detailed design phase of the Project, } \\
\text { Kingston Solar LP will be preparing detailed erosion } \\
\text { and sediment control measures for all areas of the } \\
\text { project. The potential impact and site-specific } \\
\text { mitigation, if required, will be determined at that stage } \\
\text { of the Project. }\end{array}$ \\
\hline Vegetation & $\begin{array}{l}\text { Why hasn't a tree } \\
\text { inventory been done for }\end{array}$ & $\begin{array}{l}\text { Tree inventory studies are not required for the REA } \\
\text { process. Tree inventories are a municipal requirement }\end{array}$ \\
\hline
\end{tabular}




\begin{tabular}{|c|c|c|}
\hline Category & Comment & Response \\
\hline & $\begin{array}{l}\text { the significant } \\
\text { hardwoods? }\end{array}$ & $\begin{array}{l}\text { and it is anticipated that these will be completed at a } \\
\text { later stage as required by municipal tree by-laws. }\end{array}$ \\
\hline & $\begin{array}{l}\text { The fields that were } \\
\text { ploughed for archaeology } \\
\text { were not seeded or } \\
\text { restored and have just } \\
\text { been left to grow to } \\
\text { weeds. There are big ruts } \\
\text { and there was no } \\
\text { reparation. What will be } \\
\text { done about this? }\end{array}$ & $\begin{array}{l}\text { Kingston Solar LP will repair any damage it causes to } \\
\text { the land as result of the activities it undertakes on the } \\
\text { lands. Such repairs will take place in consultation with } \\
\text { affected landowners provided that the construction } \\
\text { activities could potentially start during the spring or } \\
\text { summer of } 2013 \text {. If construction does not start then the } \\
\text { proponent will restore the lands to the same condition, } \\
\text { as far as practicable, as existed before any damage. }\end{array}$ \\
\hline \multirow[t]{5}{*}{ Water } & $\begin{array}{l}\text { Disappointed that water } \\
\text { quantity testing was not } \\
\text { completed as requested } \\
\text { by residents. }\end{array}$ & $\begin{array}{l}\text { The scope of the water studies was based on } \\
\text { consultation with the MOE. No net reduction in } \\
\text { infiltration by rainwater is expected and groundwater } \\
\text { levels will not be affected. }\end{array}$ \\
\hline & $\begin{array}{l}\text { At the SunEdison project } \\
\text { (Rideau Lakes } \\
\text { Township), the aquifer } \\
\text { was contaminated during } \\
\text { construction. Boreholes } \\
\text { were left open during } \\
\text { construction for up to } 3 \\
\text { months prior to filling, } \\
\text { which caused sediment to } \\
\text { migrate into the aquifer. }\end{array}$ & $\begin{array}{l}\text { Mitigation plans are in place for parts of the solar } \\
\text { project that are within } 100 \mathrm{~m} \text { of a well. Kingston Solar } \\
\text { LP recognizes that sedimentation in the aquifer could } \\
\text { be an issue if construction is not well managed and } \\
\text { have made plans to ensure this does not happen. }\end{array}$ \\
\hline & $\begin{array}{l}\text { Monitoring of the sites } \\
\text { will not be adequate } \\
\text { during construction or } \\
\text { operations as MOE does } \\
\text { not have sufficient } \\
\text { resources to adequately } \\
\text { undertake this role. }\end{array}$ & $\begin{array}{l}\text { Recommended mitigation measures that are } \\
\text { hydrogeology related will be part of the contract with } \\
\text { the contractor. Monitoring, mitigation and contingency } \\
\text { measures will also be part of the conditions that are } \\
\text { placed on approval by the MOE. }\end{array}$ \\
\hline & $\begin{array}{l}\text { An adequate assessment } \\
\text { was not performed for } \\
\text { either water quality or } \\
\text { quantity. Indicated that } \\
\text { there was a discrepancy } \\
\text { between the preliminary } \\
\text { water quality sample } \\
\text { report for Total Coliform } \\
\text { that was verbally reported } \\
\text { to him, and the sample } \\
\text { that was analyzed by the } \\
\text { health unit. }\end{array}$ & $\begin{array}{l}\text { A qualified Hydrogeologist from Dillon Consulting } \\
\text { Limited (Dillon), on behalf of Kingston Solar LP, } \\
\text { explained that the cause of the discrepancy was in the } \\
\text { methodology used by the laboratory subcontractor. As } \\
\text { a precautionary measure, the attendee was originally } \\
\text { notified of the high total coliform result when we first } \\
\text { received the report from the lab. After the results were } \\
\text { verbally reported, both through Dillon's and the lab's } \\
\text { internal QA/QC process it was identified that the } \\
\text { results were suspicious (reported concentrations too } \\
\text { high). Dillon then offered to resample his well; } \\
\text { however, after further discussions it was decided to use } \\
\text { the Health Unit results, as their lab is qualified for this } \\
\text { type of analysis, and Dillon personnel were in } \\
\text { attendance at the time the attendee obtained the } \\
\text { sample. It was also stated that the issue was only with } \\
\text { the microbiology results, and not the other parameters. } \\
\text { As an added precaution, all wells that were analyzed } \\
\text { by the lab's subcontractor were re-sampled. }\end{array}$ \\
\hline & $\begin{array}{l}\text { People are worried about } \\
\text { water quantity. How will } \\
\text { storm water and drainage }\end{array}$ & $\begin{array}{l}\text { No adverse effects to water quantity are expected as } \\
\text { long as appropriate mitigation measures are followed. } \\
\text { The mitigation measures pertaining to ground water }\end{array}$ \\
\hline
\end{tabular}




\begin{tabular}{|c|c|c|}
\hline & \multicolumn{2}{|l|}{ Comment } \\
\hline & $\begin{array}{l}\text { affect groundwater } \\
\text { recharge? Will the solar } \\
\text { project cause } \\
\text { groundwater infiltration } \\
\text { patterns to change? Will } \\
\text { water yields in wells be } \\
\text { affected? }\end{array}$ & $\begin{array}{l}\text { quantity are described in Section } 4.3 .2 \text { of the } \\
\text { Construction Plan Report. Efforts will be made during } \\
\text { construction to keep general pre and postconstruction } \\
\text { infiltration patterns as similar as possible. Water } \\
\text { infiltration should remain the same as water will shed } \\
\text { off the panel drip line and recharge the subsurface in } \\
\text { the same general area. }\end{array}$ \\
\hline & $\begin{array}{l}\text { How will residents be } \\
\text { compensated should } \\
\text { wells be impacted? }\end{array}$ & $\begin{array}{l}\text { MOE requires a complaint mechanism to be in place as } \\
\text { a condition of approval. The complaint mechanism } \\
\text { would include review by a qualified professional } \\
\text { engineer or geoscientists. If the impact is a result of the } \\
\text { solar project, mitigation efforts, including provisions } \\
\text { of an alternate water supply (as needed) are required. }\end{array}$ \\
\hline & $\begin{array}{l}\text { Will the installation affect } \\
\text { the quality of the water? }\end{array}$ & $\begin{array}{l}\text { The installation is not anticipated to have an effect on } \\
\text { water quality. Kingston Solar LP has undertaken a } \\
\text { baseline water testing program prior to construction to } \\
\text { be able to monitor whether well and ground water } \\
\text { quality will be affected by construction and operation. } \\
\text { Furthermore, mitigation strategies have been put in } \\
\text { place to protect water quality during construction and } \\
\text { operation. }\end{array}$ \\
\hline & $\begin{array}{l}\text { What about depression } \\
\text { storage (of water)? Will } \\
\text { this be affected if the } \\
\text { ground is levelled too } \\
\text { much? }\end{array}$ & $\begin{array}{l}\text { A ground water assessment will be conducted but it is } \\
\text { expected that infiltration patterns will remain the same. } \\
\text { Efforts will be made during construction to keep } \\
\text { general pre and post-construction infiltration patterns } \\
\text { as similar as possible. }\end{array}$ \\
\hline & $\begin{array}{l}\text { Are there any } \\
\text { underground streams that } \\
\text { could be affected (Karst } \\
\text { topography)? }\end{array}$ & $\begin{array}{l}\text { Hydrogeological studies indicate that there is no Karst } \\
\text { topography in the region. No underground streams will } \\
\text { be affected. }\end{array}$ \\
\hline Wildlife & $\begin{array}{l}\text { What is being done about } \\
\text { the blue salamander that } \\
\text { was identified on the one } \\
\text { of the properties? }\end{array}$ & $\begin{array}{l}\text { Basic salamander surveys were conducted but as } \\
\text { outlined in the Natural Heritage Assessment Report } \\
\text { (approved by the MNR), none of the salamander } \\
\text { species were found. }\end{array}$ \\
\hline
\end{tabular}

\subsubsection{Other public consultation methods}

As previously mentioned, the public consultation process included a variety of methods

for disseminating project information, collecting information from stakeholders, and

having ongoing correspondence with interested parties. In addition to the required public

meetings, the Proponent held face to face meetings and phone calls with concerned

landowners and other interested parties. Both the Proponent and AMEC published their 
mailing addresses to which people could send comments and concerns. The project website was always available for those looking for information, as well as the project email and toll-free phone number for those wanting to connect with the Proponent directly.

In addition, a project newsletter was established to periodically update the community on the status of the project. Two issues were published and mailed to stakeholders on the project distribution list: the first on December 20, 2011, and the second on June 15, 2011. In addition to providing pertinent project information, the newsletter showed the preliminary layout for the Project, and directed readers to the project website for more details.

\subsubsection{Consideration of public comments and concerns}

To address concerns about visual impacts, the Proponent proposed visual mitigation for interior properties and adjacent inhabited residential properties. The Proponent submitted the mitigation plan to the City of Kingston under the City's Landscaping and Site Design Guidelines for Large- Scale, Ground-Oriented Solar Energy Facilities.

To address concerns about impacts to groundwater, the MOE suggested the Proponent conduct a water well study. As previously mentioned, the Proponent contracted Dillon Consulting to conduct the study to provide a baseline of groundwater quality prior to construction. An information sheet was delivered to participating well owners and the final study report was posted on the project website. 


\subsubsection{Ongoing public consultation}

The consultation report provides a plan for ongoing consultation following the submission of the REA application. This plan covers the construction, operation, and decommissioning phases of the Project. Under the plan, the Proponent and/or the construction contractor and/or the operations firm would maintain contact with stakeholders through the project website, letters and/or newsletters, newspaper notices, and/or direct contact. In case of an emergency, the emergency response plan would be implemented so that concrete actions can be taken to protect the health and safety of affected stakeholders.

The Proponent and/or the construction contractor and/or the operations firm would also publish their phone number, mailing address, and email address on the project website in case a stakeholder has a concern or complaint during the construction or operation phases of the Project. The phone number for this purpose would be equipped with a voicemail system; messages would be recorded in a Complaint Response Document and responded to within 24 hours. The actions taken to remediate the cause of the complaint as well as proposed actions to prevent the reoccurrence of the issue would also be recorded in the document.

A Consultation Report Addendum was published in January 2014 after a major design change and technical changes to the Project necessitated additional consultation (Dillon Consulting, 2014). However, since this consultation is outside of the original REA application, it is not considered in this case study. 


\subsubsection{Ernestown Wind Park}

Ernestown Windpark Inc., as general partner of Ernestown Windpark LP, is the proponent of the Ernestown Wind Park (the Project). The $10 \mathrm{MW}$ wind energy generation facility is located on privately owned agricultural and industrial land in Loyalist Township, Ontario. The facility consists of five 2.0 MW turbines. The project requires the construction of new access roads to the turbine sites, as well as a new $44 \mathrm{kV}$ (kilovolt) overhead electrical connection line which will connect with an existing distribution line by way of a new switching station. The project is considered a Class 4 wind facility and thus requires a REA. The Proponent opted to follow the amended REA regulation which came into force on July 1, 2012; transition provisions allowed the Proponent to choose whether to remain under the previous regulation or adopt the new one. The Proponent prepared the consultation report which was published online in October 2012 (Ernestown Windpark Inc., 2012).

Stakeholders considered in the consultation process include the public, Aboriginal communities, local municipalities, and government agencies. The objectives of the consultation process were adapted from the International Association for Impact Assessments (IAIA) Best Practice Principles for Public Participation:

- Undertake consultation early in the planning process and continue throughout the design, development, construction, operation, and decommissioning of the Project;

- Ensure that relevant, accurate, and consistent information about the Project is provided to Project stakeholders, and ensure effective, proactive and responsive 
communications occur to incorporate feedback into the planning process to the greatest extent possible;

- Provide opportunities to obtain/identify relevant information and local knowledge in possession of the local communities, municipalities, and Aboriginal communities;

- Ensure that consultation and communication is context-appropriate, credible, open and transparent, with an attempt to build community support and demonstrate a commitment to the well-being of the community; and

- Track and document all communications between the Project team and interested parties and to ensure the information is incorporated into the planning of the Project, to the greatest extent possible.

The public consultation process included a variety of methods for interested stakeholders to learn about the Project and provide their input to the project team. The process is summarized by the timeline in Figure 27. The extended timeline on top outlines community outreach events outside of the formal public meetings. Each of the events is described in the following subsections. 


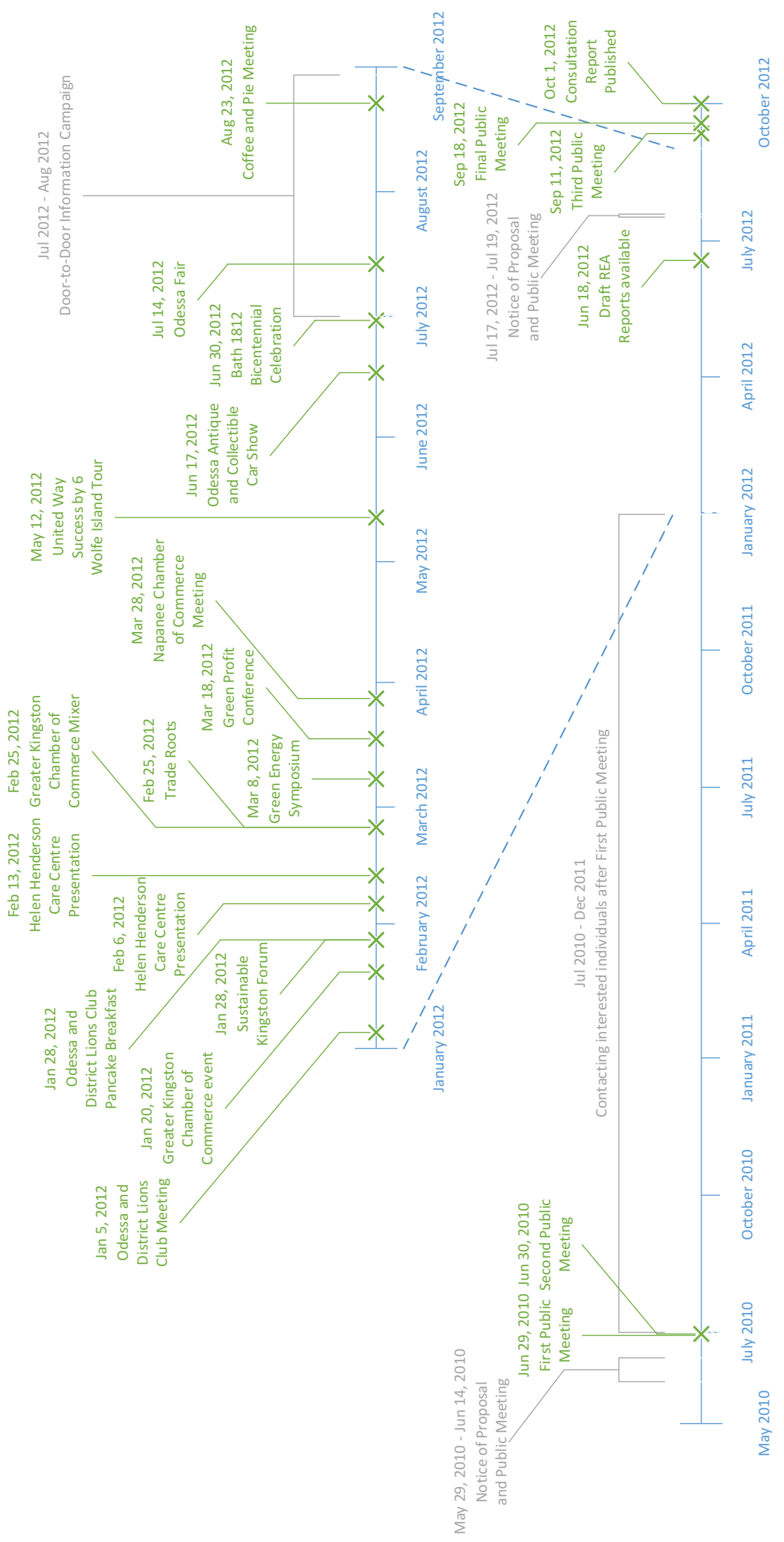

Figure 27: Ernestown public consultation timeline 


\subsubsection{First and Second Public Meetings}

The Notice of Proposal to Engage in a Renewable Energy Project and Public Meeting was published in two local newspapers: the Kingston Whig-Standard on May 29 and 31, 2010; and the Kingston EMC on June 3 and 10, 2010. The notice was also mailed to landowners within $120 \mathrm{~m}$ of the project location on June 14, 2010. The same day, a copy of the notice was published on the project website along with the Draft PDR.

The First Public Meeting was held on June 29, 2010 at the Amherstview Community Hall. The Second Public Meeting was held the next day, on June 30, 2010 at the INVISTA Centre in Kingston. Figure 28 shows the locations of the Amherstview Community Hall and the INVISTA Centre relative to the Project.

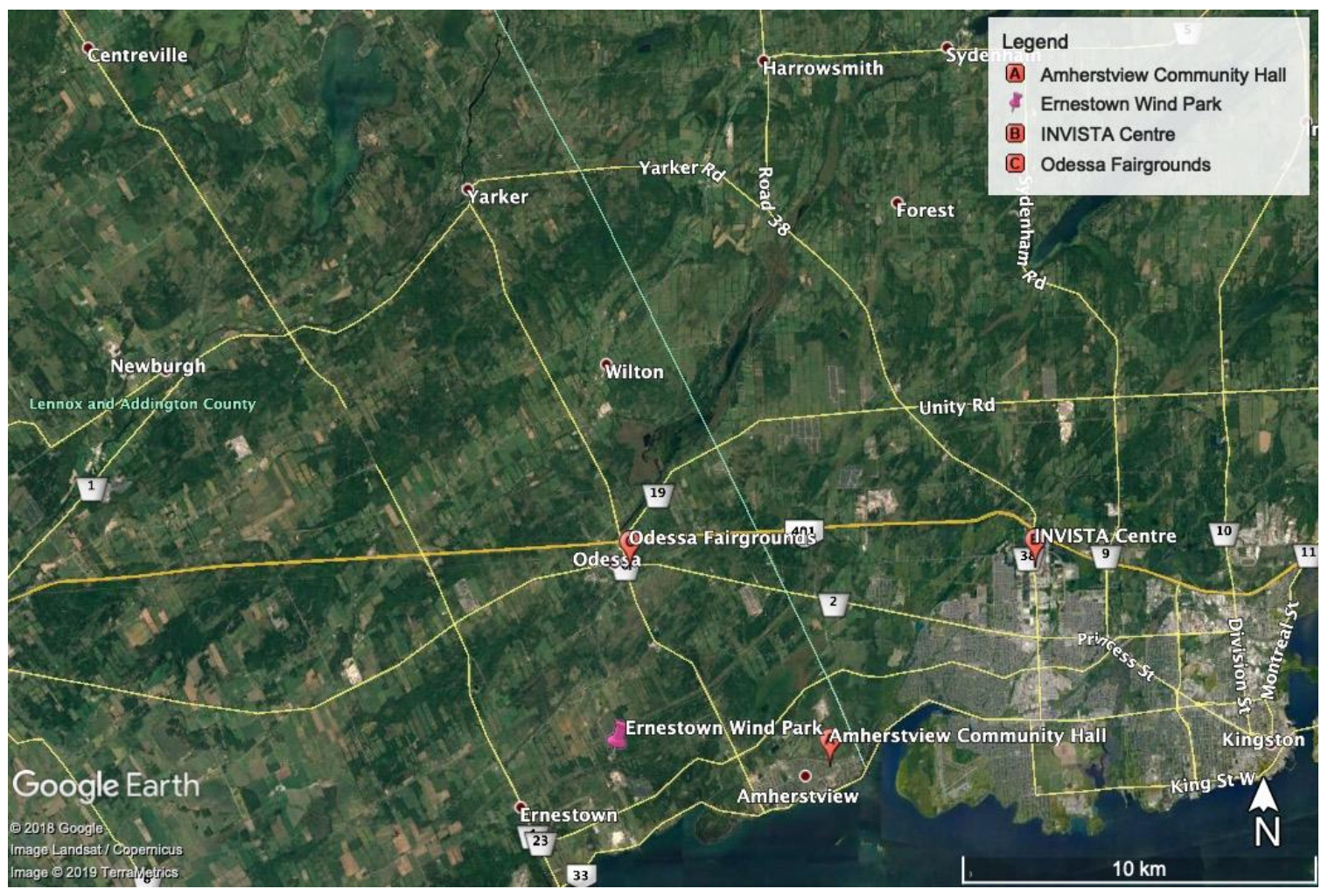

Figure 28: Ernestown project map 
The meetings were an opportunity for the Proponent to present information about the Project as well as to engage with the public. There were 50 attendees at the meeting in Amherstview, and 10 attendees at the meeting in Kingston.

The meetings were held in an open house format, designed so that attendees could arrive and leave freely. Information was presented through display boards around the room, supplemented by relevant academic and industry studies on wind energy. Members of the project team were stationed at the display boards that corresponded with their areas of expertise; they answered project-related questions and sought feedback on the Project. Questionnaires were also available for attendees to express their opinions about the Project; attendees could submit completed forms upon leaving the open house or mail them in afterwards. According to the questionnaire results (aggregated and presented in Table 8 of the consultation report), opinions of the Project were mixed, with $25 \%$ of respondents supportive, $28 \%$ neutral, $31 \%$ non-supportive, and $16 \%$ with no opinion, as shown in Figure 29.

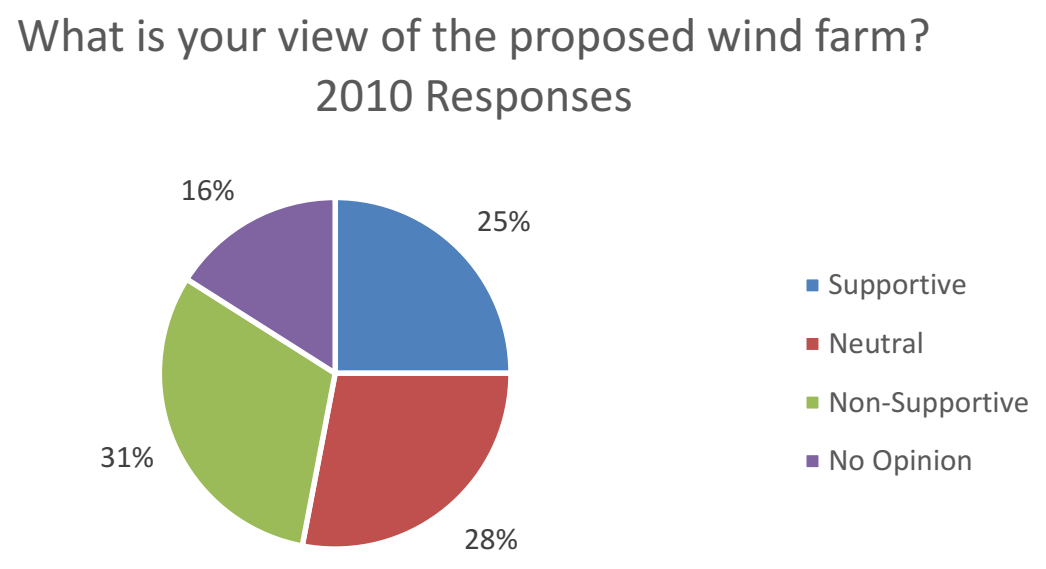

Figure 29: Ernestown 2010 Meetings Questionnaire Responses 


\subsubsection{Community Outreach Events}

Between the first two meetings and the next set of public meetings, the Proponent participated in many community events, including group meetings, networking events, and community activities. The objective of doing this was two-fold: to increase the visibility and exposure of the Project, and to offer interested individuals more information about the Project. At these community events, the Proponent set up public information displays, consisting of information handouts, a project location map, general information about wind energy, and contact cards for the Proponent. Table 12 is a summary of all the community outreach events, extracted from the consultation report.

Table 12: Ernestown Community Outreach Events (pp. 8-9)

\begin{tabular}{|l|l|}
\hline Date & Event \\
\hline Up to end of 2011 & Contacting interested individuals after first public meeting \\
\hline January 5, 2012 & Odessa and District Lions Club January Monthly Meeting \\
\hline January 20, 2012 & Greater Kingston Chamber of Commerce new members introduction event \\
\hline January 28, 2012 & Odessa and District Lions Club Pancake Breakfast \\
\hline January 28, 2012 & Sustainable Kingston Forum \\
\hline February 6, 2012 & Helen Henderson Care Centre presentation to residents \\
\hline February 13, 2012 & Helen Henderson Care Centre presentation to residents \\
\hline February 25, 2012 & Greater Kingston Chamber of Commerce Annual Member's Mixer \\
\hline February 25, 2012 & Trade Roots, organized by St. Lawrence College \\
\hline March 8, 2012 & Green Energy Symposium \\
\hline March 18, 2012 & Green Profit Conference \\
\hline March 28, 2012 & Napanee Chamber of Commerce Monthly Networking Meeting \\
\hline May 12, 2012 & United Way Success by 6 Wolfe Island Wind Turbine Tour \\
\hline June 17, 2012 & Odessa Antique and Collectible Car Show \\
\hline June 30, 2012 & Bath 1812 Bicentennial Celebration \\
\hline July 14, 2012 & Odessa Fair \\
\hline Summer 2012 & Door-to-Door Information Campaign \\
\hline August 23, 2012 & Coffee and Pie Meeting \\
\hline August 24, 2012 & Coffee and Pie Meeting \\
\hline
\end{tabular}

The Proponent also undertook two door-to-door information campaigns, in which a proponent representative delivered newsletters, provided general information about the 
Project, and answered any questions that were asked about the Project. The campaign took place in the residential areas surrounding the project location, up to a 3-kilometre $(\mathrm{km})$ radius from the project boundaries.

\subsubsection{Third and Final Public Meetings}

Draft copies of the project documents required as part of the REA process were posted to the project website on June 18, 2012, three months before the Final Public Meeting. The same day, hard copies of all project documents were made available for public review at the municipal offices of Loyalist Township and County of Lennox and Addington, as well as the Amherstview, Bath, and Odessa Branches of the Lennox and Addington Public Library.

The Notice of Public Meeting was mailed to 56 registered landowners within $550 \mathrm{~m}$ of the project location (as required by the REA regulation for Class 4 wind facilities) on July 17, 2012, and to 689 residences within $3 \mathrm{~km}$ of the project location the following day. The notice was also published in the Kingston Whig-Standard on July 18 and 19, 2012, and in the Napanee Beaver, the Kingston This Week, and the Kingston EMC on July 19, 2012. A copy of the notice was also published on the project website.

The Third Public Meeting was held on September 11, 2012 at the Amherstview Community Hall. The Final Public Meeting was held a week later, on September 18, 2012 at the Odessa Fairgrounds. Figure 28 shows the locations of the Amherstview Community Hall and the Odessa Fairgrounds relative to the Project. Like the first set of public meetings, these were an opportunity for the Proponent to present information 
about the Project as well as to engage with the public. There were 39 attendees at the meeting in Amherstview, and 98 attendees at the meeting in Odessa.

Like the first set of public meetings, these meetings were held in an open house format, designed so that attendees could arrive and leave freely. Information was presented through display boards around the room, supplemented by relevant academic and industry studies on wind energy. Members of the project team were stationed at the display boards that corresponded with their areas of expertise; they answered projectrelated questions and sought feedback on the Project. Questionnaires were also available for attendees to express their opinions about the Project; attendees could submit completed forms upon leaving the open house or mail them in afterwards. According to the questionnaire results (aggregated and presented in Table 8 of the consultation report), opinions of the project were more negative than positive, with $30 \%$ of respondents supportive, $10 \%$ neutral, $58 \%$ negative, and 2\% with no opinion, as shown in Figure 30.

What is your view of the proposed wind farm? 2012 Responses

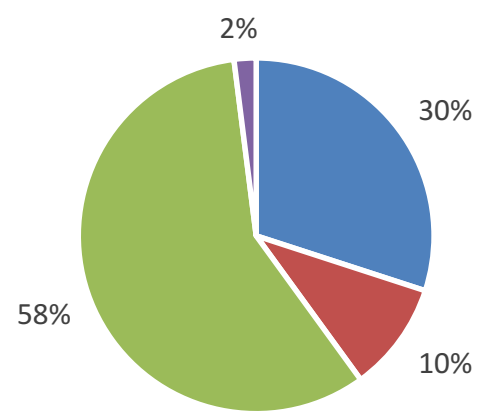

- Supportive

- Neutral

- Non-Supportive

- No Opinion

Figure 30: Ernestown 2012 Meetings Questionnaire Responses 
Interestingly, $25 \%$ of attendees did not identify as a direct stakeholder in the project. This fact combined with the abnormally large number of attendees at the final public meeting might imply that some general wind opposition groups may have attended the meeting to try and sway the results.

\subsubsection{Other public consultation methods}

As previously mentioned, the public consultation process included a variety of methods for interested stakeholders to learn about the Project and provide their input to the project team. The Proponent published a mailing address to which people could send comments and concerns. The project website was always available for those looking for information, as well as the project email and toll-free phone number for those wanting to connect with the Proponent directly.

Over the course of the consultation process, the Proponent received 11 emails and letters from members of the public. The emails and letters were either requesting more information about the Project or asking for clarification of information contained in the draft reports. The Proponent used these forms of correspondence to focus on information exchange and relationship building with members of the public. As such, each email or letter was responded to individually. To supplement these individual responses, the Proponent prepared a FAQ document which was posted on the project website.

In addition to the required public meetings, the Proponent held face to face meetings and phone calls with local landowners and interest groups. Landowners were able to ask sitespecific questions about the impacts of the Project on their property, while interest groups 
were able to collectively discuss the Project with Proponent representatives. In both cases, Proponent representatives directly answered any questions they could; if a question needed to be deferred to the development team, a response came later in writing. The interest groups that met with the Proponent were the Odessa \& District Lions Club, the residents of Helen Henderson Care Centre, the Kingston Chamber of Commerce, SWITCH Ontario, the Odessa Fair Committee, and the Lennox \& Addington Snowmobile Association.

\subsubsection{Public comments and concerns}

Throughout the consultation process, participants raised many different concerns. The Proponent used an adaptive response strategy where they considered all concerns and questions, and if required, they conducted further investigations on a case by case basis. The Proponent developed responses and mitigation strategies for each category of concern expressed; Table 13 extracted from the consultation report lists the concerns and responses in order of frequency, with the most commonly raised concern listed first.

Table 13: Ernestown Public Comments and Responses (pp. 16-22)

\begin{tabular}{|c|c|c|}
\hline Comment & Response & Consideration of Comment \\
\hline $\begin{array}{l}\text { Visual Impact } \\
\text { - I don't like how } \\
\text { they look } \\
\text { - Why are they } \\
\text { going so close to } \\
\text { all these homes } \\
\text { where they are the } \\
\text { only thing we'll } \\
\text { see }\end{array}$ & $\begin{array}{l}\text { The project is sited in industrial, } \\
\text { rural, and agricultural areas in } \\
\text { excess of all setback distances from } \\
\text { residences and sound receptors. The } \\
\text { sight of the proposed wind farm is } \\
\text { subjective and is not anticipated to } \\
\text { have negative impacts. }\end{array}$ & $\begin{array}{l}\text { A Visual Impact Study was conducted } \\
\text { and presented to the public } 60 \text { days } \\
\text { before the final public meeting. } \\
\text { Additionally, landowners living } \\
\text { within } 3 \mathrm{~km} \text { of the project location } \\
\text { who indicated concerns were offered a } \\
\text { visual simulation for their property. At } \\
\text { the time this report was written, eight } \\
\text { landowners had requested a Visual } \\
\text { Impact Study, which will be } \\
\text { completed in Fall } 2012 \text {. }\end{array}$ \\
\hline Wildlife Impact & $\begin{array}{l}\text { The proponent has conducted } \\
\text { detailed Natural Heritage }\end{array}$ & $\begin{array}{l}\text { Concerned residents were given the } \\
\text { opportunity to speak with the principal }\end{array}$ \\
\hline
\end{tabular}




\begin{tabular}{|c|c|c|}
\hline Comment & Response & Consideration of Comment \\
\hline $\begin{array}{l}\text { - How do you know } \\
\text { if the wind turbines } \\
\text { will kill animals or } \\
\text { affect their natural } \\
\text { habitat? }\end{array}$ & $\begin{array}{l}\text { Assessments and investigations on } \\
\text { wildlife. The consultants who } \\
\text { conducted the studies have } \\
\text { concluded that there are no } \\
\text { substantial impacts to the wildlife or } \\
\text { natural features in the project } \\
\text { location or on migratory species } \\
\text { known to frequent the area, due to } \\
\text { lack of suitable habitat within the } \\
\text { project location. }\end{array}$ & $\begin{array}{l}\text { consultant of the firm which } \\
\text { conducted the Natural Heritage } \\
\text { Assessments to ask questions or for } \\
\text { clarification. No new information was } \\
\text { collected which would trigger } \\
\text { additional studies or changes to } \\
\text { project plans. Concerns were noted } \\
\text { and residents were given contact } \\
\text { information for the proponent in case } \\
\text { they should have additional questions } \\
\text { or concerns. }\end{array}$ \\
\hline $\begin{array}{l}\text { Noise Impact } \\
\text { - Will I hear these } \\
\text { wind turbines from } \\
\text { my home?) }\end{array}$ & $\begin{array}{l}\text { The project is sited in industrial, } \\
\text { rural, and agricultural areas in } \\
\text { excess of all setback distances from } \\
\text { residences and sound receptors. The } \\
\text { sound of the proposed wind farm is } \\
\text { subjective and is not anticipated to } \\
\text { have negative impacts. }\end{array}$ & $\begin{array}{l}\text { A Noise Impact Assessment was } \\
\text { conducted and presented to the public } \\
60 \text { days before the final public } \\
\text { meeting. Additionally, landowners } \\
\text { living within } 3 \mathrm{~km} \text { of the project } \\
\text { location who indicated concerns were } \\
\text { offered a Noise Impact Study for their } \\
\text { property. At the time this report was } \\
\text { written, four landowners had } \\
\text { requested a Noise Impact Study, } \\
\text { which will be completed in Fall } 2012 \text {. }\end{array}$ \\
\hline $\begin{array}{l}\text { Construction } \\
\text { Schedule / Routes } \\
\text { - When is } \\
\text { construction and } \\
\text { how long will it } \\
\text { take? } \\
\text { - What roads will be } \\
\text { used? }\end{array}$ & $\begin{array}{l}\text { The construction is planned to begin } \\
\text { in late spring 2013, beginning with } \\
\text { engineering and surveying and } \\
\text { concluding with the erection of the } \\
\text { wind turbines. The process will } \\
\text { occur over approximately six } \\
\text { months. The details of construction } \\
\text { routing will be finalized with the } \\
\text { Municipality in Fall } 2012 \text {. }\end{array}$ & $\begin{array}{l}\text { The proponent presented a detailed } \\
\text { Draft Construction Plan Report and } \\
\text { Draft Transportation Plan to the public } \\
60 \text { days before the final Public } \\
\text { Meeting. At this meeting, the } \\
\text { proponent spoke to concerns about } \\
\text { dust, erosion, noise and traffic by } \\
\text { explaining the standard practices that } \\
\text { will be in place to abide by all laws } \\
\text { and by-laws as well as to minimize } \\
\text { disturbances to neighbors. No new } \\
\text { information was collected which } \\
\text { would trigger additional studies or } \\
\text { changes to project plans. Concerns } \\
\text { were noted and residents were given } \\
\text { contact information for the proponent } \\
\text { in case they should have additional } \\
\text { questions or concerns. }\end{array}$ \\
\hline $\begin{array}{l}\text { Property Values } \\
\text { - My house is going } \\
\text { to lose most of its } \\
\text { value because of } \\
\text { the wind park. }\end{array}$ & $\begin{array}{l}\text { The research that exists in } \\
\text { academic, peer-reviewed journals } \\
\text { concludes that if property values are } \\
\text { affected at all, the effect is observed } \\
\text { during construction and rebounds } \\
\text { postconstruction. }\end{array}$ & $\begin{array}{l}\text { Concerned parties were given an } \\
\text { opportunity to review the cited } \\
\text { literature and ask questions before and } \\
\text { during the public meetings. No new } \\
\text { information was collected which } \\
\text { would trigger additional studies or } \\
\text { changes to project plans. Concerns } \\
\text { were noted and residents were given } \\
\text { contact information for the proponent } \\
\text { in case they should have additional } \\
\text { questions or concerns. }\end{array}$ \\
\hline $\begin{array}{l}\text { Human Health } \\
\text { - I have heard that } \\
\text { these wind farms }\end{array}$ & $\begin{array}{l}\text { The research that exists in } \\
\text { academic, peer-reviewed journals } \\
\text { concludes that there is no scientific }\end{array}$ & $\begin{array}{l}\text { Concerns were addressed by } \\
\text { providing the public with access to } \\
\text { published research and reviews from }\end{array}$ \\
\hline
\end{tabular}




\begin{tabular}{|c|c|c|}
\hline Comment & Response & Consideration of Comment \\
\hline $\begin{array}{l}\text { make people sick, } \\
\text { is this true? }\end{array}$ & $\begin{array}{l}\text { evidence that correlates wind } \\
\text { turbine operation with adverse } \\
\text { health effects. The proposed wind } \\
\text { park is not only compliant with } \\
\text { setback regulations, but exceeds } \\
\text { distances where possible. }\end{array}$ & $\begin{array}{l}\text { academic journals and the opportunity } \\
\text { to speak with an independent senior } \\
\text { scientist whose area of focus is } \\
\text { assessment of human health impacts. } \\
\text { No new information was collected } \\
\text { which would trigger additional studies } \\
\text { or changes to project plans. Concerns } \\
\text { were noted and residents were given } \\
\text { contact information for the proponent } \\
\text { in case they should have additional } \\
\text { questions or concerns. }\end{array}$ \\
\hline $\begin{array}{l}\text { Well Water Quality } \\
\text { and Availability / } \\
\text { Changes to Existing } \\
\text { Wells } \\
\text { - I have a dug well } \\
\text { and am concerned } \\
\text { that the blasting } \\
\text { during construction } \\
\text { will affect the } \\
\text { quality of the water } \\
\text { or drain the well. }\end{array}$ & $\begin{array}{l}\text { The regional topography indicates } \\
\text { that the surface and ground water } \\
\text { flows north to south towards Lake } \\
\text { Ontario. As all residentially zoned } \\
\text { land is located north of the project } \\
\text { location. Additionally, the blasting } \\
\text { zone is located within the upper } 9 \mathrm{~m} \\
\text { below grade, whereas the } \\
\text { preliminary water studies show } \\
\text { ground water tables to be located } \\
\text { approximately } 20 \mathrm{~m} \text { below grade. } \\
\text { Finally, the distance from the } \\
\text { project location to residences is } \\
\text { large enough to be far outside the } \\
\text { range of influence, which is } \\
\text { estimated by engineers to be } 150 \mathrm{~m} \text {. }\end{array}$ & $\begin{array}{l}\text { Concerned land owners within } \\
\text { approximately } 2 \mathrm{~km} \text { of the project } \\
\text { location that could be impacted were } \\
\text { provided the opportunity to continue } \\
\text { consultation with the proponent and } \\
\text { pre-construction well water testing to } \\
\text { establish a baseline prior to the } \\
\text { commencement of construction. } \\
\text { Additionally, the Draft Construction } \\
\text { Plan Report was made available in } \\
\text { writing } 60 \text { days prior to the final } \\
\text { public meeting and the Ernestown } \\
\text { Windpark Inc. Vice President and } \\
\text { Construction Manager was present to } \\
\text { speak to specific issues and concerns. } \\
\text { No new information was collected } \\
\text { which would trigger additional studies } \\
\text { or changes to project plans. Concerns } \\
\text { were noted and residents were given } \\
\text { contact information for the proponent } \\
\text { in case they should have additional } \\
\text { questions or concerns. }\end{array}$ \\
\hline $\begin{array}{l}\text { Cost to Consumers } \\
\text { - Will this project } \\
\text { make my energy } \\
\text { costs lower or } \\
\text { higher? }\end{array}$ & $\begin{array}{l}\text { The proposed wind park is financed } \\
\text { privately, not from any form of } \\
\text { Government subsidy. The wind park } \\
\text { is a small part of a larger provincial } \\
\text { movement to replace energy from } \\
\text { coal plants with renewable energy. } \\
\text { The cost to consumers on their } \\
\text { energy bill will not change in the } \\
\text { short term, and as a result of the FIT } \\
\text { contract's } 20 \text {-year fixed price for } \\
\text { generated electricity, as the costs of } \\
\text { energy production rise, the rate paid } \\
\text { for wind energy is guaranteed not to } \\
\text { rise; this is where consumers will } \\
\text { see a noticeable difference. }\end{array}$ & $\begin{array}{l}\text { The Vice President of Development } \\
\text { was in attendance at the public } \\
\text { meetings to speak to concerned } \\
\text { residents about the economics of } \\
\text { renewable energy as well as an } \\
\text { independent consultant who } \\
\text { specializes in renewable energy } \\
\text { approvals and policies. Concerns were } \\
\text { noted and residents were given contact } \\
\text { information for the proponent in case } \\
\text { they should have additional questions } \\
\text { or concerns. }\end{array}$ \\
\hline $\begin{array}{l}\text { Turbine Location } \\
\text { - Why are the } \\
\text { proposed wind }\end{array}$ & $\begin{array}{l}\text { The siting of wind turbines is } \\
\text { dependent on a number of factors, } \\
\text { including, but not limited to: wind } \\
\text { resources, provincial setbacks from } \\
\text { residences and sound receptors, } \\
\text { natural heritage features, pre- }\end{array}$ & $\begin{array}{l}\text { The project overview was presented in } \\
\text { the Draft Project Description, posted } \\
\text { on the project website in } 2010 \text { and } \\
\text { revised in print and online in } 2012 \text { to } \\
\text { discuss the general features of the site } \\
\text { and summarize the regulatory }\end{array}$ \\
\hline
\end{tabular}




\begin{tabular}{|c|c|c|}
\hline Comment & Response & Consideration of Comment \\
\hline $\begin{array}{l}\text { turbines sited } \\
\text { where they are? }\end{array}$ & $\begin{array}{l}\text { existing infrastructure setbacks, } \\
\text { accessibility for road construction } \\
\text { and pre-existing land uses. We } \\
\text { worked diligently to maximize the } \\
\text { distance of the proposed wind } \\
\text { turbines from residences and remain } \\
\text { in compliance with all mandated } \\
\text { setbacks and easements from natural } \\
\text { features. }\end{array}$ & $\begin{array}{l}\text { requirements of the O.Reg. } 359 / 09 \text {. } \\
\text { Additionally, the siting process was } \\
\text { described in writing and in person at } \\
\text { the final public meeting. No new } \\
\text { information was collected which } \\
\text { would trigger additional studies or } \\
\text { changes to project plans. Concerns } \\
\text { were noted and residents were given } \\
\text { contact information for the proponent } \\
\text { in case they should have additional } \\
\text { questions or concerns. }\end{array}$ \\
\hline $\begin{array}{l}\text { Birds and Bats } \\
\text { - How many birds or } \\
\text { bats will be killed } \\
\text { by the turbines? }\end{array}$ & $\begin{array}{l}\text { The natural heritage features of the } \\
\text { project location identified the types } \\
\text { of habitat that is potentially used by } \\
\text { birds and bats. The conclusion, } \\
\text { based on these studies is that there } \\
\text { is only a small amount of potentially } \\
\text { significant habitat for birds or bats. } \\
\text { The possibility of migratory bird } \\
\text { mortality is slim based on the lack } \\
\text { of habitat for these species to use as } \\
\text { stop-over and the pre-existing land } \\
\text { uses being potentially disruptive to } \\
\text { birds, such as farming machinery } \\
\text { and quarry blasting. There is no } \\
\text { significant bat roosting habitat in } \\
\text { the project location; therefore the } \\
\text { studies concluded that the likelihood } \\
\text { of significant mortality is negligible. }\end{array}$ & $\begin{array}{l}\text { In addition to the Draft Natural } \\
\text { Heritage Assessment that was made } \\
\text { available to the public more than } 60 \\
\text { days before the final public meeting, a } \\
\text { Draft Post-Construction Bird and Bat } \\
\text { Monitoring Plan was published with } \\
\text { the draft REA reports. Concerned } \\
\text { residents were given the opportunity } \\
\text { to speak with the principal consultant } \\
\text { of the firm which conducted the } \\
\text { Natural Heritage Assessments to ask } \\
\text { questions or for clarification. No new } \\
\text { information was collected which } \\
\text { would trigger additional studies or } \\
\text { changes to project plans. Concerns } \\
\text { were noted and residents were given } \\
\text { contact information for the proponent } \\
\text { in case they should have additional } \\
\text { questions or concerns. }\end{array}$ \\
\hline $\begin{array}{l}\text { Municipal Policy } \\
\text { Why are wind } \\
\text { farms allowed to } \\
\text { be on residential } \\
\text { lands? } \\
\text { What authority } \\
\text { does the } \\
\text { Municipality have } \\
\text { in the development } \\
\text { of the wind farm? }\end{array}$ & $\begin{array}{l}\text { The Municipality of Loyalist } \\
\text { Township supports the Ernestown } \\
\text { Wind Park plans and previously } \\
\text { stated that the project was sited in } \\
\text { areas deemed appropriate for wind } \\
\text { development, based on the } \\
\text { Municipal Official Plan } \\
\text { Amendment to develop a "green" } \\
\text { industrial park by expanding the } \\
\text { pre-existing industrial lands and } \\
\text { incorporating renewable energy } \\
\text { projects, including wind energy. } \\
\text { The lands that the proposed wind } \\
\text { park is situated on are rural- } \\
\text { residential and industrially zoned, } \\
\text { which is lawful per the Green } \\
\text { Energy Act. }\end{array}$ & $\begin{array}{l}\text { The Vice President of Development } \\
\text { was in attendance at the public } \\
\text { meetings to speak to concerned } \\
\text { residents about the Green Energy Act, } \\
\text { as well as an independent consultant } \\
\text { who specializes in renewable energy } \\
\text { approvals and policies. Information } \\
\text { about legal jurisdiction and scope of } \\
\text { consultation was discussed. Concerns } \\
\text { were noted and residents were given } \\
\text { contact information for the proponent } \\
\text { in case they should have additional } \\
\text { questions or concerns. }\end{array}$ \\
\hline $\begin{array}{l}\text { Tree Removal } \\
\text { - How many trees } \\
\text { are being removed } \\
\text { and how will the } \\
\text { developer make up }\end{array}$ & $\begin{array}{l}\text { The plan for construction and } \\
\text { transportation of materials and } \\
\text { components outside of the Project } \\
\text { Location is not anticipated to result } \\
\text { in tree removal. If any trees are } \\
\text { removed from public lands, the trees } \\
\text { will be replaced at the discretion of }\end{array}$ & $\begin{array}{l}\text { The Draft Construction Plan and Draft } \\
\text { Decommissioning Plan were provided } \\
\text { online and in print } 60 \text { days before the } \\
\text { final public meeting. During the final } \\
\text { public meetings, the lead consultant } \\
\text { speaking to the environmental impacts } \\
\text { of the project discussed the impact of }\end{array}$ \\
\hline
\end{tabular}




\begin{tabular}{|c|c|c|}
\hline Comment & Response & Consideration of Comment \\
\hline $\begin{array}{l}\text { for the loss of } \\
\text { trees? }\end{array}$ & $\begin{array}{l}\text { the Loyalist Township and } \\
\text { Ernestown Windpark Inc. The trees } \\
\text { removed within the project location } \\
\text { during construction will be replaced } \\
\text { at the landowner's discretion } \\
\text { following the decommissioning of } \\
\text { the project. }\end{array}$ & $\begin{array}{l}\text { the tree removal and confirmed that } \\
\text { rehabilitation of the area post- } \\
\text { construction and post- } \\
\text { decommissioning would be reasonable } \\
\text { and no permanent impacts were } \\
\text { anticipated. Concerns were noted and } \\
\text { residents were given contact } \\
\text { information for the proponent in case } \\
\text { they should have additional questions } \\
\text { or concerns. }\end{array}$ \\
\hline $\begin{array}{l}\text { Vibrations } \\
\text { - What vibrations } \\
\text { will be felt } \\
\text { outdoors and inside } \\
\text { my home? }\end{array}$ & $\begin{array}{l}\text { No vibrations are anticipated to be } \\
\text { present during operation of the wind } \\
\text { park due to normal operations. }\end{array}$ & $\begin{array}{l}\text { Concerns were noted and residents } \\
\text { were given contact information for the } \\
\text { proponent in case they should have } \\
\text { additional questions or concerns. }\end{array}$ \\
\hline $\begin{array}{l}\text { Maintenance } \\
\text { - What is the } \\
\text { maintenance } \\
\text { schedule and what } \\
\text { takes place? }\end{array}$ & $\begin{array}{l}\text { The normal maintenance schedule } \\
\text { will have a technician on-site at } \\
\text { least once monthly to conduct a } \\
\text { visual inspection and any } \\
\text { outstanding technical work which is } \\
\text { required in the normal operations of } \\
\text { the turbines. During the } 20 \text {-year life } \\
\text { of the project the access roads and } \\
\text { crane pads will be maintained and } \\
\text { kept clear for the safety and } \\
\text { accessibility of the technicians. }\end{array}$ & $\begin{array}{l}\text { The Draft Design and Operations } \\
\text { Report was prepared and made } \\
\text { available to the public in print and } \\
\text { online } 60 \text { days before the final public } \\
\text { meeting. Additionally, at the final } \\
\text { public meetings, the Ernestown } \\
\text { Windpark Inc. Construction Manager } \\
\text { was available to speak in detail about } \\
\text { the operational activities of the wind } \\
\text { park. Concerns were noted and } \\
\text { residents were given contact } \\
\text { information for the proponent in case } \\
\text { they should have additional questions } \\
\text { or concerns. }\end{array}$ \\
\hline $\begin{array}{l}\text { Ice Throw } \\
\text { - I am concerned } \\
\text { that ice will form } \\
\text { on the turbines } \\
\text { during the winter } \\
\text { and fly off, } \\
\text { creating a threat to } \\
\text { my safety and } \\
\text { property }\end{array}$ & $\begin{array}{l}\text { The Enercon Turbines which will be } \\
\text { commissioned for the Ernestown } \\
\text { Wind Park were designed to have } \\
\text { heated blades that prevent the } \\
\text { formation of ice. As such, the issue } \\
\text { of ice throw is not a concern for this } \\
\text { project. }\end{array}$ & $\begin{array}{l}\text { Concerns were noted and residents } \\
\text { were given contact information for the } \\
\text { proponent in case they should have } \\
\text { additional questions or concerns. }\end{array}$ \\
\hline $\begin{array}{l}\text { Lightning } \\
\text { I do not want } \\
\text { lightning to come } \\
\text { closer and hit my } \\
\text { home because of } \\
\text { the proximity of } \\
\text { the turbines. }\end{array}$ & $\begin{array}{l}\text { The wind park is sited in excess of } \\
\text { all mandated setbacks under the } \\
\text { O.Reg. 359/09. The turbines are } \\
\text { designed to withstand lightning } \\
\text { strikes during operation without } \\
\text { damage and are grounded to } \\
\text { channel current into the ground. The } \\
\text { likelihood of a lightning strike is } \\
\text { likely less near a wind turbine with } \\
\text { the presence of a grounded structure } \\
\text { significantly taller than residences. }\end{array}$ & $\begin{array}{l}\text { Concerns were noted and residents } \\
\text { were given contact information for the } \\
\text { proponent in case they should have } \\
\text { additional questions or concerns. }\end{array}$ \\
\hline $\begin{array}{l}\text { Seasonal Changes } \\
\text { - How does the wind } \\
\text { and noise from the } \\
\text { wind park change }\end{array}$ & $\begin{array}{l}\text { Our wind resource analysis on this } \\
\text { project and others that we have } \\
\text { conducted in other Canadian } \\
\text { projects concluded that typically } \\
\text { wind speeds are higher and more }\end{array}$ & $\begin{array}{l}\text { A Noise Impact Assessment was } \\
\text { conducted and presented to the public } \\
60 \text { days before the final public } \\
\text { meeting. Additionally, landowners } \\
\text { living within } 3 \mathrm{~km} \text { of the project }\end{array}$ \\
\hline
\end{tabular}




\begin{tabular}{|c|c|c|}
\hline Comment & Response & Consideration of Comment \\
\hline $\begin{array}{l}\text { through the } \\
\text { seasons? }\end{array}$ & $\begin{array}{l}\text { constant in the winter and lower } \\
\text { throughout the summer. As a result, } \\
\text { the sounds emanating from the } \\
\text { turbines will scale up and down } \\
\text { with the speed of operation. } \\
\text { Independent consultants conducted } \\
\text { a Noise Impact Assessment in } 2012 \\
\text { for the Ernestown Wind Park and } \\
\text { found that the sound levels for all } \\
\text { residences and vacant lots were well } \\
\text { within regulated limits at all times } \\
\text { of the year at predicted wind speeds. }\end{array}$ & $\begin{array}{l}\text { location who indicated concerns were } \\
\text { offered a Noise Impact Study for their } \\
\text { property. At the time this report was } \\
\text { written, four landowners had } \\
\text { requested a Visual Impact Study, } \\
\text { which will be completed in Fall } 2012 .\end{array}$ \\
\hline $\begin{array}{l}\text { Decommissioning } \\
\text { What happens } \\
\text { when the project } \\
\text { contract is up? } \\
\text { Who pays to take } \\
\text { everything away? }\end{array}$ & $\begin{array}{l}\text { At the end of the } 20 \text {-year FIT } \\
\text { contract, the Ernestown Wind Park } \\
\text { may be refurbished and a new } \\
\text { contract incited, but if it is decided } \\
\text { to end the project, the process for } \\
\text { decommissioning the wind park is } \\
\text { the same process for construction, } \\
\text { but in reverse. Ernestown Windpark } \\
\text { Inc. will be responsible for } \\
\text { financing the project if they } \\
\text { continue to hold ownership. The } \\
\text { components from the turbines are } \\
\text { valuable in materials that can be } \\
\text { recycled by many industries. The } \\
\text { process takes six months or less and } \\
\text { is followed by habitat restoration at } \\
\text { the discretion of the land owner and } \\
\text { the proponent. }\end{array}$ & $\begin{array}{l}\text { The Draft Decommissioning Report } \\
\text { was prepared and made available to } \\
\text { the public in print and online } 60 \text { days } \\
\text { before the final public meeting. } \\
\text { Additionally, at the final public } \\
\text { meetings, the Ernestown Windpark } \\
\text { Inc. Construction Manager was } \\
\text { available to speak in detail about the } \\
\text { decommissioning activities of the } \\
\text { wind park. Concerns were noted and } \\
\text { residents were given contact } \\
\text { information for the proponent in case } \\
\text { they should have additional questions } \\
\text { or concerns. }\end{array}$ \\
\hline $\begin{array}{l}\text { Shadow Flicker } \\
\text { - How far away does } \\
\text { shadow flicker fall } \\
\text { and does it cause } \\
\text { health problems? }\end{array}$ & $\begin{array}{l}\text { Ernestown Windpark Inc. has not } \\
\text { developed a formal public shadow } \\
\text { flicker analysis; however, we do } \\
\text { understand that there are concerns } \\
\text { about the health effects of these } \\
\text { moving shadows. What we do know } \\
\text { is that the rising and setting sun will } \\
\text { cast shadows on an east-west track. } \\
\text { Some residents may experience } \\
\text { brief periods of shadow flicker, but } \\
\text { in terms of the health effects of } \\
\text { shadow flicker, the academic } \\
\text { research available concludes that } \\
\text { there is no evidence that shadow } \\
\text { flicker causes adverse health effects. }\end{array}$ & $\begin{array}{l}\text { Concerns were addressed by } \\
\text { providing the public with access to } \\
\text { published research and reviews from } \\
\text { academic journals and the opportunity } \\
\text { to speak with an independent senior } \\
\text { scientist whose area of focus is } \\
\text { assessment of human health impacts. } \\
\text { Additionally, concerned citizens who } \\
\text { requested a shadow flicker study for } \\
\text { their property were consulted on a } \\
\text { personal basis and offered a site- } \\
\text { specific analysis for their property. At } \\
\text { the time of the writing of this report, } \\
\text { only two people have requested } \\
\text { shadow flicker analyses. No new } \\
\text { information was collected which } \\
\text { would trigger additional studies or } \\
\text { changes to project plans. Concerns } \\
\text { were noted and residents were given } \\
\text { contact information for the proponent } \\
\text { in case they should have additional } \\
\text { questions or concerns. }\end{array}$ \\
\hline
\end{tabular}




\begin{tabular}{|c|c|c|}
\hline Comment & Response & Consideration of Comment \\
\hline $\begin{array}{l}\text { Impacts on Farming } \\
\text { - What are the } \\
\text { potential impacts } \\
\text { on livestock } \\
\text { productivity or } \\
\text { yields? }\end{array}$ & $\begin{array}{l}\text { At present we are unaware of any } \\
\text { scientific research that has been } \\
\text { conducted on this issue. We take } \\
\text { some comfort in the fact that there } \\
\text { are thousands of turbines across } \\
\text { Europe, Australia and the United } \\
\text { States and this issue does not appear } \\
\text { to have surfaced around these } \\
\text { existing facilities, some of which } \\
\text { have been in operation for decades. }\end{array}$ & $\begin{array}{l}\text { Concerns were noted and residents } \\
\text { were given contact information for the } \\
\text { proponent in case they should have } \\
\text { additional questions or concerns. }\end{array}$ \\
\hline $\begin{array}{l}\text { Notices } \\
\text { - When was the } \\
\text { public notified of } \\
\text { the project and } \\
\text { meetings held to } \\
\text { inform the } \\
\text { community? }\end{array}$ & $\begin{array}{l}\text { In } 2010 \text {, more than } 700 \text { notices were } \\
\text { sent out via Canada Post and were } \\
\text { published in the Kingston Whig- } \\
\text { Standard, EMC, Kingston this Week } \\
\text { and Napanee Beaver, as well as on } \\
\text { the project website. In 2012, notices } \\
\text { were sent to the } 53 \text { registered land } \\
\text { owners within } 550 \mathrm{~m} \text { of the project } \\
\text { location on two occasions. A mass } \\
\text { mailing was sent to } 689 \text { to land } \\
\text { owners and residents within } 3 \mathrm{~km} \text { of } \\
\text { the project via first class mail as } \\
\text { well as notices were published in } \\
\text { the Kingston Whig-Standard, EMC, } \\
\text { Kingston this Week, Napanee } \\
\text { Beaver and the project website. } \\
\text { Ernestown Windpark's Community } \\
\text { Relations Manager and Project } \\
\text { Coordinators hand delivered } \\
\text { notices, newsletters and printed } \\
\text { updates to more than } 100 \text { homes on } \\
\text { multiple occasions, as well as } \\
\text { holding information booths } \\
\text { throughout the summer at local } \\
\text { events. }\end{array}$ & $\begin{array}{l}\text { Concerns were noted and residents } \\
\text { were given contact information for the } \\
\text { proponent in case they should have } \\
\text { additional questions or concerns. }\end{array}$ \\
\hline
\end{tabular}

Based on public input, the Proponent made a few revisions, changes, and additions to the project design. The key changes include conducting well water testing for concerned residents, removing wetland water crossings, conducting a shadow flicker study for concerned land owners, and adding turbine lighting beacons (to signal oncoming aircraft). In addition, the Proponent agreed to conduct additional visual impact and noise impact studies for specific residents who expressed concerns. 


\subsubsection{Amherst Island Wind Project}

Windlectric Inc. is the proponent of the Amherst Island Wind Project. The 74.3 MW wind energy generation facility is located on Amherst Island within Loyalist Township in the County of Lennox and Addington, Ontario. The facility consists of 27, 3.2 MW turbines, operating at an average of 2.75 MW each (Stantec, 2017). The project requires the construction of multiple additional components, including a $34.5 \mathrm{kV}$ underground and/or overhead electrical power line collector system, a transmission line, a substation, a submarine cable, and access roads. The electrical power line collector system transports the electricity generated from each turbine to the substation, along the submarine cable to the mainland, and then to a switching station located near an existing HONI $115 \mathrm{kV}$ transmission line. The project is considered a Class 4 wind facility and thus requires a REA. The engineering consultant, Stantec, prepared the consultation report which was published online in April 2013 (Stantec Consulting Ltd., 2013).

As the siting process for wind projects is an iterative process, the Study Area for the project was considered a general area within which the Project components may be sited; this broad Study Area was used for assessed landowner and public notification throughout the consultation process. In addition, the Proponent chose to assess and seek approval for multiple alternative Project configurations; the final specific site selection and configuration of project components would be decided based on results of consultation activities, detailed design and engineering work, and the conditions experienced during construction. The since refined Project Location consists of lands on

Amherst Island, a corridor between the island and the mainland for the submarine cable, 
and a portion on the mainland. In accordance with the REA regulation, the Project Location includes all land and buildings/structures associated with the Project as well as any air space that the Project occupies.

Consultation played multiple roles in the development of the Project:

- It helped to ensure that concerns regarding the Project are identified early and addressed where possible in a transparent manner;

- It helped to identify potentially interested parties and the nature of their interest, so that the Proponent could inform these parties of the Project and incorporate their concerns or interests into the planning and design process;

- It allowed for the development of relationships between the Proponent and interested parties, and provided opportunities for interested parties to provide feedback to the Project Team; and

- It assisted in the identification of potential environmental and socioeconomic issues to ensure that they are given appropriate consideration in all phases of the Project.

The objectives of the consultation process were:

- To share information about the Project so that stakeholders are well-informed;

- To ensure that relevant, accurate, and consistent information about the Project is provided to stakeholders as early as possible;

- To identify and obtain relevant information and local knowledge;

- To identify potential issues and areas of concern that may arise from the Project; 
- To address concerns by providing additional information, clarifying misconceptions, considering alterations in the Project design, or making commitments, where appropriate;

- To promote effective, proactive, and reasonable responsive communications with stakeholders;

- To resolve issues where possible, in a transparent manner;

- To track and document communications between the Project Team and interested parties, and to ensure the information is incorporated into project planning, to the extent possible and as appropriate; and

- To demonstrate that Windlectric is committed to considering input and concerns from the public of the communities within which it works.

A Project distribution list was developed early in the consultation process to identify key contacts that may have an interest in the Project. The list initially included provincial and federal agencies, municipalities and townships, Aboriginal communities, local interest groups and non-governmental organizations (NGOs), and assessed landowners within $550 \mathrm{~m}$ of the original Study Area. As more stakeholders requested to be placed on the list, they were added on an ongoing basis.

The Project was initially proposed in 2008 before the GEA; however, the consultation report only covers consultation activities within the REA process. A variety of communication tools were used for disseminating Project information and for collecting information from interested parties on an ongoing basis. The public consultation process 
is summarized by the timeline in Figure 31. Each of the events is described in the following subsections.

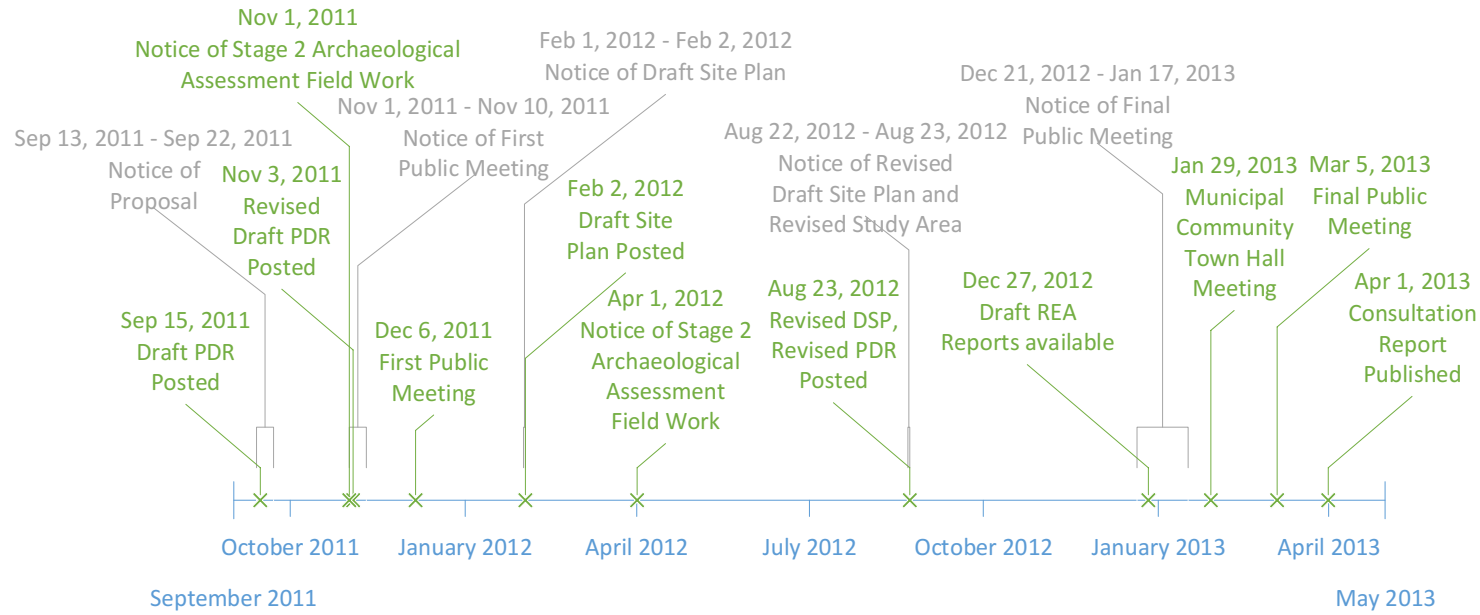

Figure 31: Amherst Island public consultation timeline

\subsubsection{First Public Meeting}

The Notice of Proposal to Engage in a Renewable Energy Project was sent by mail or email to the distribution list on September 13, 2011. The notice was also published in two local newspapers: the Kingston Whig-Standard on September 15 and 22, 2011; and the Napanee Guide on September 15 and 22, 2011. A copy of the notice was published on the project website on September 15, 2011, along with the Draft PDR. Hard copies of the Draft PDR were made available for public review at the municipal offices of Loyalist Township and the County of Lennox and Addington.

The Notice of First Public Meeting was sent by mail or email to the distribution list on November 1, 2011. It was also published in two local newspapers: the Kingston WhigStandard on November 3 and 5, 2011; and the Napanee Guide on November 3 and 10, 
2011. A copy of the notice was published on the project website on November 3, 2011, along with a revised version of the Draft PDR. Hard copies of the Revised Draft PDR were made available for public review at the municipal offices of Loyalist Township and the County of Lennox and Addington. The revisions reflected the decision to change the turbine manufacturer and model.

The First Public Meeting was held on two consecutive evenings at two different locations: on December 6, 2011 at Amherst Island Public School (on the island), and on December 7, 2011 at St John's Memorial Hall (on the mainland). Figure 32 shows the locations of Amherst Island Public School and St. John's Memorial Hall relative to the Project.

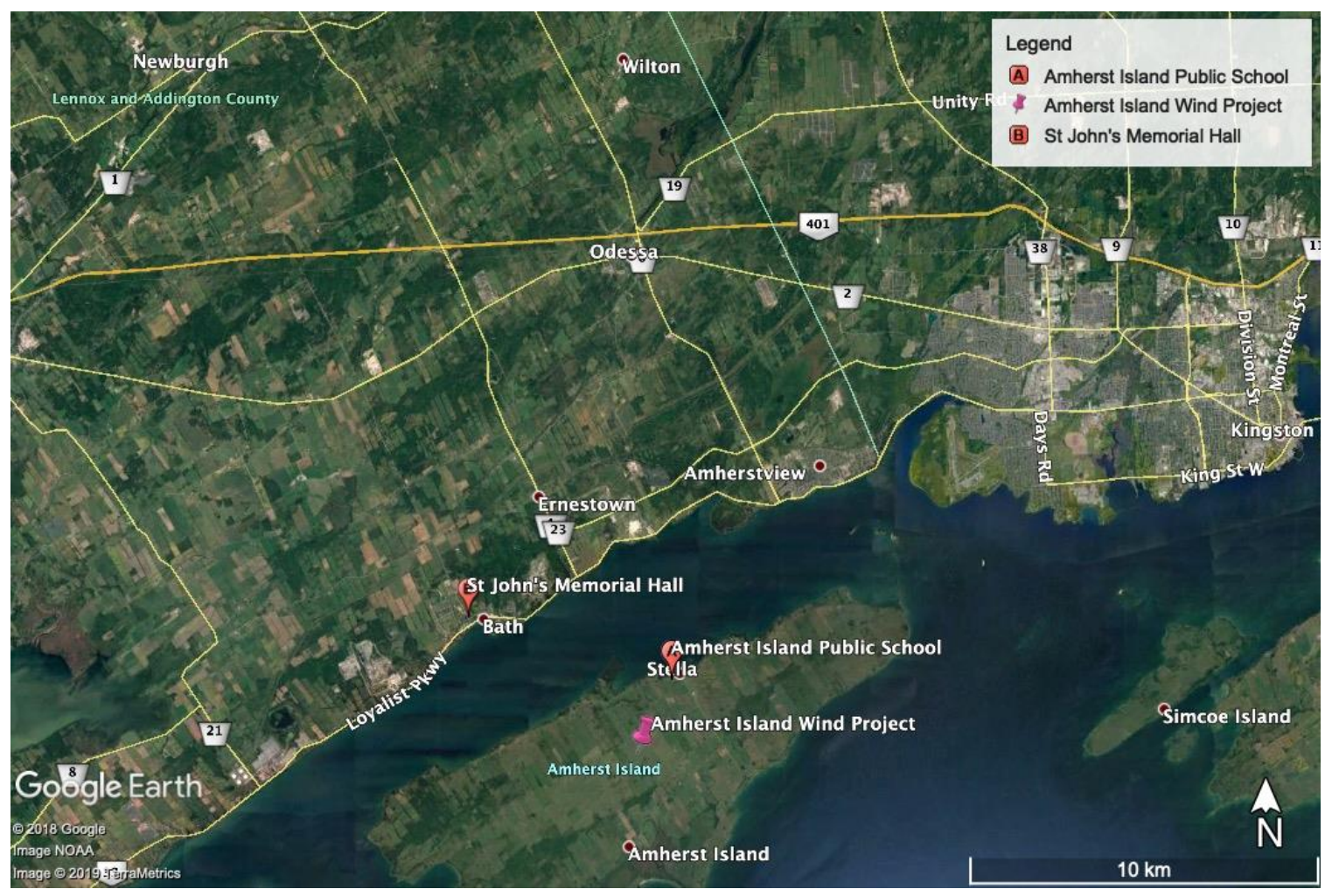

Figure 32: Amherst Island project map 
The purpose of the meeting was two-fold: to introduce the Project and the Project Team to the community, with the intention of providing information as early in the process as possible; and to provide an opportunity for community members to learn about the Project and the REA process, to ask questions of the Project Team, and to provide input into the Project.

The meeting was held in an open house format, where display boards around the room provided information on the Project. The display boards covered a variety of topics, including background information on the Proponent, an overview of the Project, information on the REA process, preliminary results from environmental studies underway, and relevant academic and industry studies on the wind industry. In addition, the Proponent took the proactive step of presenting the preliminary layout of the Project; typically, the layout would be presented at the Final Public Meeting, but many stakeholders had asked the Project Team to see the layout early in the process. Other project related material such as drawings, handouts, and industry information were also available for public review. Members of the Project team, including representatives of the Proponent and its consultants, were available to discuss the Project, to answer questions, and seek feedback. Questionnaires and comment forms were also available for attendees to express their opinions about the Project; attendees could submit completed forms upon leaving the meeting or mail them in afterwards.

There were approximately 225 attendees at the meeting on the island; 34 questionnaires and comment forms were submitted, and 64 letters were received. There were approximately 175 attendees at the meeting on the mainland; 14 questionnaires or 
comments forms were submitted, and five letters were received. After the meetings, 22 questionnaires were mailed in. The Project Team considered all feedback received during Project planning and siting and within the REA Reports.

\subsubsection{Additional Notices}

In early November 2011, a Notice of Stage 2 Archaeological Assessment Field Work was delivered to all residents of Amherst Island. The notice advised that between November 3 and December 2, 2011, residents could expect to see field staff staking boundaries and walking and digging within the staked areas. In addition, the notice communicated that project construction was not taking place during that time.

The Notice of Draft Site Plan was sent by mail or email to the distribution list on February 1 and 2, 2012. It was also published in two local newspapers: the Kingston Whig-Standard on February 2, 2012; and the Napanee Guide also on February 2, 2012. The same day, a copy of the notice was published on the project website, along with the Draft Site Plan Report for public review. Hard copies of the Draft Site Plan Report were made available for public review at the municipal offices of Loyalist Township and the County of Lennox and Addington.

In early April 2012, another Notice of Stage 2 Archaeological Assessment Field Work was delivered to all residents of Amherst Island. The notice was very similar to the one from November 2011, advising that field work would be taking place throughout the rest of April 2012, and residents could expect to see field staff staking boundaries and 
walking and digging within the staked areas. In addition, the notice communicated that project construction was not taking place during that time.

The Notice of Revised Draft Site Plan and Revised Study Area was sent by mail or email to the distribution list on August 22 and 24, 2012. It was also published in two local newspapers: the Kingston Whig-Standard on August 23, 2012; and the Napanee Guide also on August 23, 2012. The same day, a copy of the notice was published on the project website, along with the Revised Draft Site Plan Report and Revised PDR. Hard copies of the Revised Draft Site Plan Report were made available for public review at the municipal offices of Loyalist Township and the County of Lennox and Addington. The revisions in the Draft Site Plan Report reflected the decision to relocate two of the turbines based on public input, while the revisions in the PDR reflected the refinement of the Project Study Area.

\subsubsection{Final Public Meeting}

The Notice of Final Public Meeting was sent by mail or email to the distribution list on December 21, 2012. The notice was also published in two local newspapers: the Kingston Whig-Standard on December 27, 2012, and January 3 and 10, 2013; and the Napanee Guide on January 10 and 17, 2013. A copy of the notice was published on the project website on December 26, 2012; the Draft copies of the project documents required as part of the REA process were posted the next day. Hard copies of all project documents were made available for public review at the municipal offices of Loyalist Township and the County of Lennox and Addington. The notice contained information about the Final 
Public Meeting, as well as the location where the Draft REA Reports and proposed Project layout were available for public review.

The Final Public Meeting was held on two consecutive evenings at two different locations: on March 5, 2013 at Amherst Island Public School (on the island), and on March 6, 2013 at St. John's Memorial Hall (on the mainland). The two locations are the same as those for the First Public Meeting. The purpose of the meeting was two-fold: to provide community members an update on the project, including the revised project layout, the results of the studies conducted, and the Draft REA Reports; and to gather feedback on the Project.

The meeting was held in an open house format, where display boards around the room provided information on the Project. The display boards covered a variety of topics, including background information on the Proponent, an overview of the Project, information on the REA process, results from the environmental studies and the Draft REA Reports, changes to the reports since the release of the draft reports, the project schedule, relevant academic and industry studies on the wind industry, and an overview of how the project could benefit the community. Other project related material such as drawings, handouts, and industry information were also available for public review. Members of the Project team, including representatives of the Proponent and its consultants, were available to discuss the Project, to answer questions, and seek feedback. Questionnaires and comment forms were also available for attendees to express their opinions about the Project; attendees could submit completed forms upon leaving the meeting or mail them in afterwards. 
There were approximately 160 attendees at the meeting on the island; 16 questionnaires and comment forms were submitted, and 23 letters were received. There were approximately 52 attendees at the meeting on the mainland; 10 questionnaires or comments forms were submitted, and one letter was received. In the week following the meetings, 17 questionnaires and one letter were mailed in. The Project Team considered all feedback received when finalizing the Project site plan and REA Reports.

\subsubsection{Other public consultation methods}

As previously mentioned, the public consultation process included a variety of methods for disseminating Project information and for collecting information from interested parties on an ongoing basis. In addition to the required public meetings, the Proponent held face to face meetings and phone calls with concerned landowners and other interested parties. Both the Proponent and Stantec published their mailing addresses to which people could send comments and concerns. The project website was always available for those looking for information, as well as the project email and toll-free phone number for those wanting to connect with the Proponent directly.

Between September 13, 2011, when the Notice of Proposal was published, and March 15, 2013, the end of the public comment period, the Proponent received 349 emails and phone calls and 151 written letters from stakeholders. The Project Team responded directly to each email, phone call, and letter. Communications were tracked through comment and response tables, which were filed in an appendix to the consultation report. To supplement these individual responses, the Proponent prepared a FAQ document which was posted on the project website. 
Throughout the consultation process, the Proponent communicated with various interest groups and community organizations who were either interested in the Project or who potentially had information that could be considered in the Project. These groups were the Algonquin and Lakeshore Catholic District School Board; CanWEA; the City of Kingston; CN Rail; Jefferson County, New York; the Kingston Field Naturalists; the Limestone District School Board; the New York State Department of Environmental Conservation; Ontario Nature; the Ontario Woodlot Association; the St. Lawrence Parks Commission; the St. Lawrence Seaway Management Corporation; the Technical Standards and Safety Authority; and the Village of Cape Vincent, New York. Only two of these groups raised concerns about the Project; the Limestone District School Board requested that one of the turbines close to a school building be relocated, while the Kingston Field Naturalists were opposed to the Project due to its impacts on the environment and on animals.

In early 2011, the Proponent formed a Public Liaison Committee (PLC), consisting of four public individuals from Amherst Island. Membership on the committee was by direct invitation from the Proponent; both those who supported the project and those who opposed it were invited to join the committee. The purpose of the PLC was two-fold: to solicit public input on the Project, and to hear and disseminate accurate information about the Project (as it comes straight from the Proponent). The committee met six times between July 2011 and December 13, 2012.

On January 29, 2013, Loyalist Township invited the Proponent to present at a public town hall meeting on project infrastructure design and planning. The presentation was 
supplemented by message boards providing information on the preliminary conceptual design, and followed by a question and answer session based on the presentation. Representatives of the Proponent, the consultant (Hatch Engineering), and the general constructor (Mortenson Canada) were in attendance to answer questions. A moderator was hired to manage the question and answer session.

\subsubsection{Public comments and concerns}

Throughout the consultation process, participants raised many different concerns. Table

14 extracted from the consultation report is a thematic summary of the key public concerns along with the Proponent's response.

Table 14: Amherst Island Public Comments and Responses (pp. 5.9-5.23)

\begin{tabular}{|c|c|c|}
\hline Comment & Response & Consideration of Comment \\
\hline $\begin{array}{l}\text { Project Overall, } \\
\text { Project Schedule, } \\
\text { Basic } \\
\text { Components }\end{array}$ & $\begin{array}{l}\text { The Amherst Island Wind Energy Project is } \\
\text { located on Amherst Island, ON (Loyalist } \\
\text { Township in the County of Lennox and } \\
\text { Addington). Windlectric Inc. (subsidiary of } \\
\text { Algonquin Power Co.) is the owner of the } \\
\text { project and responsible for all aspects of } \\
\text { construction and operation. The development } \\
\text { of this project is in response to the } \\
\text { Government of Ontario's initiative to promote } \\
\text { the development of renewable electricity in } \\
\text { the province. Windlectric Inc. Initiated the } \\
\text { REA process in May } 2011 \text { and followed the } \\
\text { MOE regulations with respect to complying } \\
\text { with the REA requirements. [details in } \\
\text { consultation report] }\end{array}$ & $\begin{array}{l}\text { - } \begin{array}{l}\text { Provided responses to } \\
\text { relevant public comments by } \\
\text { email/mail. }\end{array} \\
\text { - } \quad \text { Information provided on } \\
\text { Project website. } \\
\text { - FAQ document created, } \\
\text { updating regularly, and } \\
\text { posted to the Project website. }\end{array}$ \\
\hline $\begin{array}{l}\text { Electrical } \\
\text { Interconnection }\end{array}$ & $\begin{array}{l}\text { The plan is to place the electrical power line } \\
\text { collector system, on the island, underground } \\
\text { where physically possible (considering all } \\
\text { technical and regulatory constraints). The } \\
\text { location of the electrical collection system } \\
\text { will be finalized during the siting process. } \\
\text { Windlectric Inc. has committed to Loyalist } \\
\text { Township to work to place the collector line } \\
\text { underground as much as practical. }\end{array}$ & $\begin{array}{l}\text { - } \begin{array}{l}\text { Provided responses to } \\
\text { relevant public comments by } \\
\text { email/mail. }\end{array} \\
\text { - } \quad \text { Information provided on } \\
\text { Project website. } \\
\text { - FAQ document created, } \\
\text { updating regularly, and } \\
\text { posted to the Project website. }\end{array}$ \\
\hline
\end{tabular}




\begin{tabular}{|c|c|c|}
\hline Comment & Response & Consideration of Comment \\
\hline & $\begin{array}{l}\text { The Project will also require the installation of } \\
\text { an electrical submarine cable from the island } \\
\text { to the mainland. The final preferred landing } \\
\text { location of the submarine cable on the } \\
\text { mainland has not been completed. Work on } \\
\text { this segment of the Project is ongoing and } \\
\text { further details will be provided during the } \\
\text { permitting phase of the project. }\end{array}$ & \\
\hline $\begin{array}{l}\text { Adequacy of } \\
\text { Wind Supply on } \\
\text { the Island }\end{array}$ & $\begin{array}{l}\text { Windlectric Inc. has undertaken the } \\
\text { appropriate due diligence with respect to } \\
\text { determining that the wind resources are } \\
\text { sufficient for the construction of the proposal } \\
\text { wind project. In addition, the internal business } \\
\text { analysis has also determined that the land that } \\
\text { is under signed agreement the will be } \\
\text { sufficient for the development of the Project. }\end{array}$ & $\begin{array}{l}\text { Provided responses to } \\
\text { relevant public comments by } \\
\text { email/mail. } \\
\text { - Information provided on } \\
\text { Project website. } \\
\text { - FAQ document created, } \\
\text { updating regularly, and } \\
\text { posted to the Project website. }\end{array}$ \\
\hline Setbacks & $\begin{array}{l}\text { A key component of the REA process is the } \\
\text { establishment of common setbacks for all } \\
\text { renewable energy facilities in the Province. } \\
\text { Where Project related infrastructure will be } \\
\text { located within the setback distances, } \\
\text { additional analysis (ie. Environmental Impact } \\
\text { Study) will be provided in the REA } \\
\text { application and summarized in the final } \\
\text { Project Description Report. Key setbacks } \\
\text { which will be applied throughout the design } \\
\text { of the Project are listed on the project website. }\end{array}$ & $\begin{array}{l}\text { A copy of the setbacks } \\
\text { required under O.Reg. } \\
\text { 359/09 were posted to the } \\
\text { project website. } \\
\text { FAQ document created, } \\
\text { updating regularly, and } \\
\text { posted to the Project website. } \\
\text { Technical experts were on } \\
\text { hand at all public open } \\
\text { houses to discuss setback } \\
\text { requirements. } \\
\text { Information about setbacks } \\
\text { was provided at all public } \\
\text { open houses. } \\
\text { Provided responses to } \\
\text { relevant public comments by } \\
\text { email/mail. }\end{array}$ \\
\hline $\begin{array}{l}\text { Health } \\
\text { Concerns, } \\
\text { Hazards of } \\
\text { Sound, Shadow } \\
\text { Flicker, Stray } \\
\text { Voltage }\end{array}$ & $\begin{array}{l}\text { Health and medical agencies agree that when } \\
\text { sited properly, wind turbines are not causally } \\
\text { related to adverse effects. This information } \\
\text { was discussed with many stakeholders during } \\
\text { the meetings by the subject matter experts } \\
\text { from Intrinsik Consulting. Note: the proposed } \\
\text { Amherst Island wind project will adhere to the } \\
\text { provincial regulations for setbacks related to } \\
\text { non-participating residents. [details in } \\
\text { consultation report] } \\
\text { Scientific evidence suggests that shadow } \\
\text { flicker from wind turbines does not pose a risk } \\
\text { of photo-induced seizures; modern wind } \\
\text { turbines simply don't rotate at a speed that has } \\
\text { been linked to this condition (generally less } \\
\text { than } 20 \text { rpm vs. over } 60 \text { rpm). } \\
\text { Stray voltage is an extraneous voltage that is } \\
\text { related to the transmission of electricity, not } \\
\text { the production of electricity. Stray voltage }\end{array}$ & $\begin{array}{l}\text { - Windlectric retained an } \\
\text { environmental health expert } \\
\text { to assist in assessing the } \\
\text { science relating to this topic, } \\
\text { and to help keep the Project } \\
\text { Team informed of new } \\
\text { information. This expert also } \\
\text { provided information in } \\
\text { response to health questions } \\
\text { and comments related to } \\
\text { wind energy and the Project. } \\
\text { Third party health experts } \\
\text { and recent health literature } \\
\text { were available at all public } \\
\text { open houses. } \\
\text { Recent health literature was } \\
\text { posted to the project website. } \\
\text { FAQ document created, } \\
\text { updating regularly, and } \\
\text { posted to the Project website. }\end{array}$ \\
\hline
\end{tabular}




\begin{tabular}{|c|c|c|}
\hline Comment & Response & Consideration of Comment \\
\hline & $\begin{array}{l}\text { appears on grounded surfaces in buildings, } \\
\text { barns and other structures. Stray voltage is a } \\
\text { direct result of poor grounding practices, } \\
\text { improper or inadequate wiring or the } \\
\text { breakdown of insulation in old wires or } \\
\text { electrical loads. } \\
\text { The Project's electrical collection system } \\
\text { would avoid these causes of stray voltage by } \\
\text { incorporating all new construction in } \\
\text { accordance with standard utility practice and } \\
\text { meeting the required stringent design and } \\
\text { inspection requirements of the Electrical } \\
\text { Safety Authority. }\end{array}$ & $\begin{array}{l}\text { Provided responses to } \\
\text { relevant public comments by } \\
\text { email/mail. } \\
\text { Windlectric provided a } \\
\text { shadow flicker report at the } \\
\text { final public open house and } \\
\text { on the project website. }\end{array}$ \\
\hline $\begin{array}{l}\text { Noise Impact } \\
\text { Assessment } \\
\text { Methodology }\end{array}$ & $\begin{array}{l}\text { The following is a general overview of the } \\
\text { noise impact assessment methodology. For a } \\
\text { complete and full understanding of the } \\
\text { process required to conduct a Noise Impact } \\
\text { Assessment please refer to O. Reg. } 359 / 09 \\
\text { and "Noise Guidelines for Wind Farms } \\
\text { (October 2008)". [details in consultation } \\
\text { report] } \\
\text { As per MOE/ O. Reg. } 359 / 09 \text { requirements, } \\
\text { all turbines will meet the minimum setback of } \\
550 \text { m from any non-participating receptors. } \\
\text { As per MOE requirements, turbine locations } \\
\text { will be selected such that all non-participating } \\
\text { receptors comply with the } 40.0 \text { dBA } \\
\text { performance limit established by MOE during } \\
\text { a predictable worst case scenario. [details in } \\
\text { consultation report] }\end{array}$ & $\begin{array}{l}\text { - Third party health experts } \\
\text { were available at all public } \\
\text { open houses. } \\
\text { FAQ document created, } \\
\text { updating regularly, and } \\
\text { posted to the Project website. } \\
\text { Provided responses to } \\
\text { relevant public comments by } \\
\text { email/mail. } \\
\text { A third party consultant has } \\
\text { undertaken a noise impact } \\
\text { study, as required under the } \\
\text { regulation, included as part } \\
\text { of the REA application. The } \\
\text { noise impact assessment was } \\
\text { made available for public } \\
\text { review as required under O. } \\
\text { Reg. } 352 / 09 \text {. }\end{array}$ \\
\hline Visual Impacts & $\begin{array}{l}\text { The Project Team recognizes there are } \\
\text { different views and perspectives on wind } \\
\text { turbines. The Project Team has received } \\
\text { comments about the visual nature of the } \\
\text { turbines and auxiliary facilities proposed for } \\
\text { the Project. } \\
\text { The Project Team is interested in reducing } \\
\text { visual impacts from the Project by burying } \\
\text { collector lines and the transmission line where } \\
\text { possible. } \\
\text { Although the positive or negative visual } \\
\text { impact of the project is a subjective } \\
\text { consideration that does not form part of REA } \\
\text { process, Windlectric has completed a Visual } \\
\text { Impact Assessment which created photo } \\
\text { simulations of what the wind farm project } \\
\text { may look like during operations. The photo } \\
\text { simulations were provided during the final } \\
\text { open house for the Project and are available } \\
\text { on the Project website within the Draft } \\
\text { Heritage Assessment Report. }\end{array}$ & $\begin{array}{l}\text { The REA reports identify that } \\
\text { where possible, underground } \\
\text { collector lines will be } \\
\text { incorporated into the design } \\
\text { of the access roads to reduce } \\
\text { the area required for } \\
\text { construction and minimize } \\
\text { the potential construction } \\
\text { impacts and where possible } \\
\text { the transmission line will be } \\
\text { installed underground. Note } \\
\text { that the location of the } \\
\text { collector lines and } \\
\text { transmission line is done in } \\
\text { consultation with required } \\
\text { agencies (i.e. the Township } \\
\text { and/or MTO). } \\
\text { Windlectric is considering } \\
\text { landscaping options at the } \\
\text { Project auxiliary facilities, } \\
\text { while still ensuring that the }\end{array}$ \\
\hline
\end{tabular}




\begin{tabular}{|c|c|c|}
\hline Comment & Response & Consideration of Comment \\
\hline & & $\begin{array}{l}\text { site visibility and building } \\
\text { security are maintained. } \\
\text { A third party visual impact } \\
\text { assessment expert was } \\
\text { available at the final public } \\
\text { open houses. } \\
\text { A mapbook showing the } \\
\text { results of the visual impact } \\
\text { assessment was provided at } \\
\text { the final public open houses. } \\
\text { FAQ document created, } \\
\text { updating regularly, and } \\
\text { posted to the Project website. } \\
\text { Provided responses to } \\
\text { relevant public comments by } \\
\text { email/mail. } \\
\text { A visual impact assessment } \\
\text { was completed and included } \\
\text { in the Protected Properties } \\
\text { Assessment report and the } \\
\text { Heritage Assessment report } \\
\text { which were submitted as part } \\
\text { of the REA application. }\end{array}$ \\
\hline Property Values & $\begin{array}{l}\text { Windlectric acknowledges public comments } \\
\text { and concerns related to potential property } \\
\text { value impacts. Based upon the published } \\
\text { reports reviewed to date based on data from } \\
\text { other areas with established wind plants, there } \\
\text { is little evidence of a material negative effect } \\
\text { on property value as a result of the presence } \\
\text { of a wind project. [details in consultation } \\
\text { report] }\end{array}$ & $\begin{array}{l}\text { Recent literature pertaining } \\
\text { to property values and wind } \\
\text { farms was available at all } \\
\text { public open houses. } \\
\text { Recent literature pertaining } \\
\text { to property values and wind } \\
\text { farms was posted to the } \\
\text { project website. } \\
\text { FAQ document created, } \\
\text { updating regularly, and } \\
\text { posted to the Project website. } \\
\text { Provided responses to } \\
\text { relevant public comments by } \\
\text { email/mail. }\end{array}$ \\
\hline $\begin{array}{l}\text { Community } \\
\text { Benefits, Taxes }\end{array}$ & $\begin{array}{l}\text { Windlectric has voluntarily submitted a } \\
\text { draft commitment agreement to the } \\
\text { Township to contribute monies on an } \\
\text { annual basis to provide a continuous, } \\
\text { reliable source of income for the } \\
\text { Township. The original draft agreement } \\
\text { contribution to the fund will be based on } \\
\text { a proposed fixed rate multiplied by the } \\
\text { total size of the project. Township and } \\
\text { Windlectric are currently negotiating the } \\
\text { draft agreement. [details in consultation } \\
\text { report] } \\
\text { Indemnity Agreement signed with } \\
\text { Township to reimburse their cost for } \\
\text { hiring a third party consultant to review } \\
\text { the Project REA documents. }\end{array}$ & $\begin{array}{l}\text { Windlectric has voluntarily } \\
\text { submitted a Community } \\
\text { Benefits Agreement to the } \\
\text { Township. The original draft } \\
\text { proposed payment of an } \\
\text { estimated } \$ 7.5 \text { million to the } \\
\text { Township over the lifespan } \\
\text { of the Project. Windlectric } \\
\text { proposes a portion of the } \\
\text { Fund be allocated to Amherst } \\
\text { Island specifically. } \\
\text { An Indemnity Agreement } \\
\text { was signed with the } \\
\text { Township to reimburse their } \\
\text { cost for hiring a third party }\end{array}$ \\
\hline
\end{tabular}




\begin{tabular}{|c|c|c|}
\hline Comment & Response & Consideration of Comment \\
\hline & $\begin{array}{l}\text { Windlectric is working with the } \\
\text { Municipality on a draft Road User } \\
\text { Agreement that will ensure the repair (if } \\
\text { required) and maintenance of roads } \\
\text { utilized by Windlectric on Amherst } \\
\text { Island. } \\
\text { Local businesses will be supported } \\
\text { through goods and services procured by } \\
\text { construction contractor workers } \\
\text { (restaurants, accommodation, local } \\
\text { hardware stores etc.). } \\
\text { Windlectric and its contractors will } \\
\text { employ maintenance staff in eastern } \\
\text { Ontario. } \\
\text { Locally-provided trades could include } \\
\text { heavy equipment operators, truck drivers, } \\
\text { pipefitters, electricians, ironworkers, } \\
\text { millwrights and carpenters. } \\
\text { Landowners with Project infrastructure } \\
\text { on their property will receive lease } \\
\text { payments from Windlectric (turbines, } \\
\text { substations, access roads, etc.). } \\
\text { Farm operations can continue adjacent to } \\
\text { Project infrastructure. } \\
\text { Following decommissioning, agricultural } \\
\text { areas will be restored, and normal } \\
\text { farming practices can resume. } \\
\text { Subject to landowner approval and } \\
\text { private property restrictions, hunting and } \\
\text { other recreational uses can continue } \\
\text { adjacent to Project infrastructure. } \\
\text { Tax payments to the municipality of } \\
\text { approximately } \$ 100,000 \text { to } \$ 150,000 \\
\text { annually in new tax revenues to Loyalist } \\
\text { Township. }\end{array}$ & $\begin{array}{l}\text { consultant to review the } \\
\text { Project REA documents. } \\
\text { Windlectric working with the } \\
\text { Township on a Road User } \\
\text { Agreement. } \\
\text { A summary of community } \\
\text { tax benefits posted to the } \\
\text { project website. } \\
\text { - FAQ document created, } \\
\text { updating regularly, and } \\
\text { posted to the Project website. } \\
\text { An overview of community } \\
\text { benefits was provided at all } \\
\text { public open houses. } \\
\text { Provided responses to } \\
\text { relevant public comments by } \\
\text { email/mail. }\end{array}$ \\
\hline $\begin{array}{l}\text { Traffic Impacts, } \\
\text { Impacts to } \\
\text { Roads, Traffic } \\
\text { Management and } \\
\text { Safety }\end{array}$ & $\begin{array}{l}\text { Available details regarding the potential } \\
\text { transportation routes to the site are provided } \\
\text { in the draft REA reports. Discussions will take } \\
\text { place with county and township staff related } \\
\text { to the development of a Traffic Management } \\
\text { Plan to address aspects such as the } \\
\text { identification of the transportation route(s), } \\
\text { road upgrades/repairs, and traffic planning } \\
\text { issues. Preliminary, design and planning work } \\
\text { completed to date was presented on January } \\
\text { 29th at the Loyalist Township town hall road } \\
\text { infrastructure meeting, and is available on the } \\
\text { Project website. } \\
\text { Any damages/repairs to local roads as a result } \\
\text { of Project construction including the } \\
\text { transportation of Project components will be } \\
\text { the responsibility of Windlectric. Windlectric } \\
\text { will also develop a Traffic Management Plan }\end{array}$ & $\begin{array}{l}\text { - FAQ document created, } \\
\text { updating regularly, and } \\
\text { posted to the Project website. } \\
\text { Algonquin Power staff } \\
\text { members were on hand at all } \\
\text { public open houses to discuss } \\
\text { traffic activities, the traffic } \\
\text { management plan, and safety. } \\
\text { In addition, a third party } \\
\text { construction expert was } \\
\text { available at the final public } \\
\text { open houses to discuss } \\
\text { construction activities } \\
\text { including traffic. } \\
\text { Information about traffic } \\
\text { management was provided at } \\
\text { the final public open houses. }\end{array}$ \\
\hline
\end{tabular}




\begin{tabular}{|c|c|c|}
\hline Comment & Response & Consideration of Comment \\
\hline & $\begin{array}{l}\text { with the County and Township to specifically } \\
\text { address local concerns related to the transport } \\
\text { of Project components and impacts to County } \\
\text { and Township roads/traffic. } \\
\text { A Traffic Management Plan (with Public } \\
\text { Safety considered) will be developed which } \\
\text { will identify and deal with specific traffic } \\
\text { planning issues including the management of } \\
\text { traffic and the delivery of materials. }\end{array}$ & $\begin{array}{l}\text { Participated in a Municipal } \\
\text { Town Hall meeting to discuss } \\
\text { the road user agreement. } \\
\text { Provided responses to } \\
\text { relevant public comments by } \\
\text { email/mail. }\end{array}$ \\
\hline $\begin{array}{l}\text { Heritage } \\
\text { Resources, Stone } \\
\text { Fences }\end{array}$ & $\begin{array}{l}\text { Specific sections of the O. Reg. } 359 / 09 \\
\text { pertain to Heritage Resources, specifically } \\
\text { heritage resources and cultural heritage } \\
\text { landscapes. In order to meet the conditions of } \\
\text { the regulation, a Heritage Assessment of the } \\
\text { location of the Project will be conducted. The } \\
\text { Heritage Assessment Report that is required } \\
\text { as part of the REA application package is } \\
\text { available for public review on the Project } \\
\text { website. } \\
\text { The project layout has been designed to avoid } \\
\text { the stone fences wherever possible. At this } \\
\text { time it is anticipated that, in order to minimize } \\
\text { potential effects to the stone fences, a pre- } \\
\text { construction survey will be undertaken to } \\
\text { determine the stability of the walls prior to } \\
\text { any below-grade construction in their vicinity. } \\
\text { Construction activities in those areas will be } \\
\text { monitored to determine that vibration levels } \\
\text { that may damage the walls are not exceeded. } \\
\text { [details in consultation report] }\end{array}$ & $\begin{array}{l}\text { FAQ document created, } \\
\text { updating regularly, and } \\
\text { posted to the Project website. } \\
\text { Met with the Heritage } \\
\text { Committee to discuss the } \\
\text { Heritage Assessment report. } \\
\text { A third party heritage planner } \\
\text { drove the island with local } \\
\text { residents on March } 5^{\text {th }} \text { and } 6^{\text {th }} \\
\text { to identify heritage resources. } \\
\text { A third party heritage planner } \\
\text { was available at the final } \\
\text { public open houses. } \\
\text { A mapbook showing the } \\
\text { results of the visual impact } \\
\text { assessment was provided at } \\
\text { the final public open houses. } \\
\text { Provided responses to } \\
\text { relevant public comments by } \\
\text { email/mail. }\end{array}$ \\
\hline $\begin{array}{l}\text { Stage } 1 \text { and } 2 \\
\text { Archaeological } \\
\text { Assessment } \\
\text { methodology }\end{array}$ & $\begin{array}{l}\text { The Project is subject to the Environmental } \\
\text { Protection Act of Ontario (Act) Part V.0.1 and } \\
\text { Ontario Regulation 359/09. Sections s.22 (1), } \\
\text { (2), and (3) of Ontario Regulation 359/09, } \\
\text { Renewable Energy Approvals (REA) under } \\
\text { Part V.0.1 of the Act pertain to } \\
\text { Archaeological Resources. The Stage } 1 \text { and } \\
\text { Stage } 2 \text { Archaeological Assessment, which } \\
\text { are available on the Project website, were } \\
\text { conducted in accordance with these sections } \\
\text { of Ontario Regulation 359/09 and the Ministry } \\
\text { of Tourism and Culture's } 2011 \text { Standards and } \\
\text { Guidelines for Consultant Archaeologists. } \\
\text { [details in consultation report] }\end{array}$ & $\begin{array}{l}\text { FAQ document created, } \\
\text { updating regularly, and } \\
\text { posted to the Project website. } \\
\text { A notice of Stage } 2 \\
\text { archaeological assessment } \\
\text { was provided to residents of } \\
\text { the island to notify them that } \\
\text { field work was taking place } \\
\text { on the island. } \\
\text { A third party heritage planner } \\
\text { was available at the final } \\
\text { public open houses. } \\
\text { A mapbook showing the } \\
\text { results of the visual impact } \\
\text { assessment was provided at } \\
\text { the final public open houses. } \\
\text { Provided responses to } \\
\text { relevant public comments by } \\
\text { email/mail. }\end{array}$ \\
\hline $\begin{array}{l}\text { Construction } \\
\text { Activities, Batch } \\
\text { Plant }\end{array}$ & $\begin{array}{l}\text { Algonquin Power will consider modifying the } \\
\text { location of the batch plant within the laydown } \\
\text { area. They may also consider installing a }\end{array}$ & $\begin{array}{l}\text { FAQ document created, } \\
\text { updating regularly, and } \\
\text { posted to the Project website. }\end{array}$ \\
\hline
\end{tabular}




\begin{tabular}{|c|c|c|}
\hline Comment & Response & Consideration of Comment \\
\hline & $\begin{array}{l}\text { noise abatement wall between the batch plant } \\
\text { and the school and will also install fencing } \\
\text { around the laydown area and batch plant to } \\
\text { prevent access by the public. Tree lines may } \\
\text { also be planted on the east and north sides of } \\
\text { the laydown area and batch plant to obstruct } \\
\text { the view and aid in abating noise and dust. } \\
\text { Operational limitations may also be imposed } \\
\text { to restrict some activities during cultural or } \\
\text { public events. } \\
\text { Construction will be completed in accordance } \\
\text { with applicable local by-laws. } \\
\text { Prudent industry practices will be employed to } \\
\text { reduce dust levels at construction areas. }\end{array}$ & $\begin{array}{l}\text { - Algonquin Power staff } \\
\text { members were on hand at all } \\
\text { public open houses to discuss } \\
\text { construction activities. In } \\
\text { addition, a third party } \\
\text { construction expert was } \\
\text { available at the final public } \\
\text { open houses to discuss } \\
\text { construction activities. } \\
\text { Information about } \\
\text { construction was provided at } \\
\text { the final public open houses. } \\
\text { Provided responses to } \\
\text { relevant public comments by } \\
\text { email/mail. }\end{array}$ \\
\hline $\begin{array}{l}\text { Operations, } \\
\text { Extreme } \\
\text { Weather, } \\
\text { Monitoring }\end{array}$ & $\begin{array}{l}\text { The owner of the Project will be responsible } \\
\text { for all operations activities throughout the } \\
\text { useful life of the Project expected to be at } \\
\text { least } 20 \text { years after which the Project may be } \\
\text { repowered or decommissioned. Although } \\
\text { Windlectric currently intends to own and } \\
\text { operate the Project for the entire life the } \\
\text { Project could be sold or transferred to another } \\
\text { owner who would then be required to operate } \\
\text { the Project in accordance with applicable } \\
\text { regulations and the REA. } \\
\text { Project components will be designed to } \\
\text { withstand the effects from extreme weather } \\
\text { events including high winds. Considering the } \\
\text { design features of the turbine which act to } \\
\text { reduce or eliminate the potential for damage } \\
\text { from extreme events, no adverse net effects } \\
\text { from extreme weather events are anticipated } \\
\text { during operation of the Project. } \\
\text { Project staff from Windlectric and } \\
\text { maintenance contractors will be on site during } \\
\text { normal business hours and will be on call } 24 / 7 \\
\text { to address any issues or emergencies which } \\
\text { may arise during operation. The Wind } \\
\text { turbines are highly instrumented and are } \\
\text { monitored } 24 / 7 \text { by local and remote staff. }\end{array}$ & $\begin{array}{l}\text { FAQ document created, } \\
\text { updating regularly, and } \\
\text { posted to the Project website. } \\
\text { Algonquin Power staff } \\
\text { members were on hand at all } \\
\text { public open houses to discuss } \\
\text { operation activities. } \\
\text { Technical experts with } \\
\text { experience monitoring } \\
\text { operating wind farms were } \\
\text { on hand at all public open } \\
\text { houses to discuss monitoring } \\
\text { activities. } \\
\text { Provided responses to } \\
\text { relevant public comments by } \\
\text { email/mail. }\end{array}$ \\
\hline $\begin{array}{l}\text { Complaint } \\
\text { Response } \\
\text { Protocol }\end{array}$ & $\begin{array}{l}\text { Windlectric Inc. will continue its pre- } \\
\text { construction contact with Project stakeholders } \\
\text { during construction and operations as long as } \\
\text { this seems an effective two-way channel for } \\
\text { communication. Windlectric and/or the } \\
\text { Construction Contractor and/or the Operations } \\
\text { Contractor will develop and implement a } \\
\text { Complaint Response Protocol for the } \\
\text { construction and operation phase to address } \\
\text { any reasonable concern from the public. Any } \\
\text { issues brought forward will be assessed and } \\
\text { addressed on a case by case basis. All }\end{array}$ & $\begin{array}{l}\text { FAQ document created, } \\
\text { updating regularly, and } \\
\text { posted to the Project website. } \\
\text { Algonquin Power staff } \\
\text { members were on hand at all } \\
\text { public open houses to discuss } \\
\text { the complaint response } \\
\text { protocol and how they plan } \\
\text { to handle inquiries during the } \\
\text { life of the Project. }\end{array}$ \\
\hline
\end{tabular}




\begin{tabular}{|c|c|c|}
\hline Comment & Response & Consideration of Comment \\
\hline & $\begin{array}{l}\text { reasonable commercial efforts would be made } \\
\text { to take appropriate action as a result of } \\
\text { concerns as soon as practicable. }\end{array}$ & $\begin{array}{l}\text { Provided responses to } \\
\text { relevant public comments by } \\
\text { email/mail. }\end{array}$ \\
\hline $\begin{array}{l}\text { Community } \\
\text { opposition }\end{array}$ & $\begin{array}{l}\text { Windlectric acknowledges that not everyone } \\
\text { in the community is supportive of the Project. }\end{array}$ & $\begin{array}{l}\text { Provided the public with } \\
\text { details on the REA } \\
\text { application process including } \\
\text { instruction on the EBR } \\
\text { posting and options to appeal } \\
\text { the decision through the } \\
\text { ERT. } \\
\text { Algonquin Power staff } \\
\text { members were on hand at all } \\
\text { public open houses to discuss } \\
\text { concerns. }\end{array}$ \\
\hline $\begin{array}{l}\text { Decommissioning } \\
\text { the Project }\end{array}$ & $\begin{array}{l}\text { At the end of the project's life expected to be } \\
\text { at least } 20 \text { years, Windlectric will repower or } \\
\text { decommission the project. Windlectric is } \\
\text { responsible for the decommissioning of the } \\
\text { project including the cost of component } \\
\text { removal. Windlectric has committed to } \\
\text { returning the site to a safe and clean condition } \\
\text { after decommissioning of the Project in } \\
\text { accordance with requirements to be } \\
\text { determined prior to decommissioning. A site } \\
\text { restoration plan would be developed based on } \\
\text { the standards and best practices at the time of } \\
\text { decommissioning. } \\
\text { Decommissioning would include the } \\
\text { dismantling and removal of facility } \\
\text { components including foundations to a depth } \\
\text { of } 1 \mathrm{~m} \text { below grade, and restoring the land. } \\
\text { Components would be recycled or reused } \\
\text { wherever possible. }\end{array}$ & $\begin{array}{l}\text { FAQ document created, } \\
\text { updating regularly, and } \\
\text { posted to the Project website. } \\
\text { Algonquin Power staff } \\
\text { members were on hand at all } \\
\text { public open houses to discuss } \\
\text { decommissioning activities. } \\
\text { Provided responses to } \\
\text { relevant public comments by } \\
\text { email/mail. }\end{array}$ \\
\hline $\begin{array}{l}\text { Natural } \\
\text { Heritage; } \\
\text { Impacts to Birds, } \\
\text { Bats, Owls; } \\
\text { Building within } \\
\text { an Important } \\
\text { Bird Area; How } \\
\text { the Owl Woods } \\
\text { was considered; } \\
\text { Species at Risk }\end{array}$ & $\begin{array}{l}\text { Scientific studies indicate that few waterfowl } \\
\text { fatalities occur as a result of contact with wind } \\
\text { turbines, relative to the numbers of waterfowl } \\
\text { present, due to avoidance behaviours. } \\
\text { Waterfowl often fly at blade height, however, } \\
\text { waterfowl are known to increase their flight } \\
\text { height to avoid collisions with turbines. It is } \\
\text { anticipated that waterfowl would avoid and } \\
\text { adapt to the presence of wind turbines. } \\
\text { Collision and direct mortality of migratory } \\
\text { waterfowl is not expected to be a significant } \\
\text { issue for a wind plant on Amherst Island. } \\
\text { The Amherst Island Important Bird Areas } \\
\text { (IBA) encompasses the entire island and } \\
\text { adjacent off-shore areas. It has been identified } \\
\text { as an IBA for the high numbers of Brant } \\
\text { recorded in off-shore waters surrounding the } \\
\text { island during their fall migration. While IBAs } \\
\text { do not have any legal protection under } \\
\text { provincial government, the functions for }\end{array}$ & $\begin{array}{l}\text { FAQ document created, } \\
\text { updating regularly, and } \\
\text { posted to the Project website. } \\
\text { Third party natural heritage } \\
\text { experts were available at all } \\
\text { public open houses. } \\
\text { - A map of the natural heritage } \\
\text { features in the Project Study } \\
\text { Area was displayed at all } \\
\text { public open houses. } \\
\text { - Information about IBAs was } \\
\text { provided at the final public } \\
\text { open houses. } \\
\text { Provided responses to } \\
\text { relevant public comments by } \\
\text { email/mail. }\end{array}$ \\
\hline
\end{tabular}




\begin{tabular}{|c|c|c|}
\hline Comment & Response & Consideration of Comment \\
\hline & $\begin{array}{l}\text { which they are identified are assessed and } \\
\text { considered within the NHA. The process will } \\
\text { involve field studies to assess the bird } \\
\text { communities and their habitats, identification } \\
\text { of significant wildlife habitat, assessment of } \\
\text { potential impacts and avoidance and } \\
\text { mitigation measures, where required. } \\
\text { The Owl Woods, located in the eastern } \\
\text { portion of the island, is a well-known area } \\
\text { where wintering owls roost. The presence of } \\
\text { this woodland, and the function it provides as } \\
\text { a roost area, has been considered through the } \\
\text { NHA process. The potential for other } \\
\text { woodlands on the island to provide a similar } \\
\text { function has also been studied. In developing } \\
\text { the preliminary layout, the significance of the } \\
\text { Owl Woods was considered. The closest } \\
\text { turbine (from blade tip) was established } 100 \mathrm{~m} \\
\text { from the Owl Woods and } 500 \text { m from the pine } \\
\text { plantation within the woods where the } \\
\text { majority of owls can be found. } \\
\text { The Project has considered SAR habitat } \\
\text { during the siting process. To reduce potential } \\
\text { impacts to species at risk turbines and other } \\
\text { project components have been sited outside of } \\
\text { habitats that support these species, wherever } \\
\text { possible. The MNR will be consulted as to } \\
\text { ensure the project is compliant with the } \\
\text { Endangered Species Act (ESA). Where } \\
\text { required, a permit application under the ESA } \\
\text { will be submitted, which will address any } \\
\text { habitat loss and/or any risk of fatalities. The } \\
\text { permit under the ESA would only be issued if } \\
\text { it has been demonstrated that compensation } \\
\text { measures have been put in place that will } \\
\text { achieve an overall benefit for each species. }\end{array}$ & \\
\hline $\begin{array}{l}\text { How waterbodies } \\
\text { were considered, } \\
\text { Impacts to } \\
\text { groundwater and } \\
\text { well }\end{array}$ & $\begin{array}{l}\text { If water bodies were identified within } 120 \mathrm{~m} \\
\text { of the Project Location, an aquatic habitat } \\
\text { assessment was completed and a Draft Water } \\
\text { Body Report was prepared. The Draft Water } \\
\text { Body Report identifies and assesses any } \\
\text { adverse environmental effects of the Project } \\
\text { on a water body and on land within } 30 \text { m of } \\
\text { the water body, identifies mitigation measures } \\
\text { in respect of any adverse environmental } \\
\text { effects, and describes the monitoring plan to } \\
\text { address any environmental effects. The } \\
\text { Conservation Authority will be consulted for } \\
\text { any permits required with respect to work } \\
\text { required in or near water bodies. } \\
\text { There should be no impact (on drinking water } \\
\text { / to groundwater) as a result of the project. }\end{array}$ & $\begin{array}{l}\text { FAQ document created, } \\
\text { updating regularly, and } \\
\text { posted to the Project website. } \\
\text { Third party consultant staff } \\
\text { were on hand at all public } \\
\text { open houses to discuss water } \\
\text { bodies. } \\
\text { - A map of the waterbodies in } \\
\text { the Project Study Area was } \\
\text { displayed at all public open } \\
\text { houses. } \\
\text { Provided responses to } \\
\text { relevant public comments by } \\
\text { email/mail. }\end{array}$ \\
\hline
\end{tabular}




\begin{tabular}{|c|c|c|}
\hline Comment & Response & Consideration of Comment \\
\hline & $\begin{array}{l}\text { Before excavation commences, a geotechnical } \\
\text { study is completed at all potential sites for } \\
\text { ground water depth as well as to determine } \\
\text { necessary parameters required for foundation } \\
\text { design. If water is encountered at any time, } \\
\text { good construction practices will be used such } \\
\text { as minimizing the length of time that the } \\
\text { excavation is open and monitoring seepage } \\
\text { during excavation. Should pumping be } \\
\text { required to dewater excavated areas, water } \\
\text { will be directed to the closest drain or spread } \\
\text { across the construction area and appropriate } \\
\text { energy dissipation techniques will be used to } \\
\text { reduce the potential for erosion and sourcing. }\end{array}$ & \\
\hline Turbine lighting & $\begin{array}{l}\text { Transport Canada will provide } \\
\text { recommendations as to lighting requirements } \\
\text { for the turbine towers and Windlectric Inc. } \\
\text { will examine all options in order to satisfy } \\
\text { Transport Canada. Windlectric is aware of } \\
\text { and will consider installation of a radar } \\
\text { activated lighting system. }\end{array}$ & $\begin{array}{l}\text { FAQ document created, } \\
\text { updating regularly, and } \\
\text { posted to the Project website. } \\
\text { Algonquin Power staff } \\
\text { members were on hand at all } \\
\text { public open houses to discuss } \\
\text { turbine lighting. } \\
\text { Provided responses to } \\
\text { relevant public comments by } \\
\text { email/mail. }\end{array}$ \\
\hline $\begin{array}{l}\text { How Project } \\
\text { Liaison } \\
\text { Committee was } \\
\text { established }\end{array}$ & $\begin{array}{l}\text { The Liaison Committee includes four local } \\
\text { community representatives and a Lead } \\
\text { Facilitator (Owner's management } \\
\text { representative). Members of the Liaison } \\
\text { Committee were solicited by direct invitation } \\
\text { to community stakeholders and were } \\
\text { appointed by the project proponent. Local } \\
\text { community representatives were selected } \\
\text { based on their ability and willingness to bring } \\
\text { a variety of perspectives from/to the local } \\
\text { community. Note that membership on the } \\
\text { Liaison Committee does not constitute } \\
\text { support, endorsement, or opposition of the } \\
\text { Amherst Island Wind Energy Project. }\end{array}$ & $\begin{array}{l}\text { FAQ document created, } \\
\text { updating regularly, and } \\
\text { posted to the Project website. } \\
\text { Algonquin Power staff } \\
\text { members and a third party } \\
\text { public consultation lead were } \\
\text { on hand at all public open } \\
\text { houses to discuss the Public } \\
\text { Liaison Committee. } \\
\text { Members of the Public } \\
\text { Liaison Committee were } \\
\text { voluntarily in attendance at } \\
\text { the public open houses. } \\
\text { Provided responses to } \\
\text { relevant public comments by } \\
\text { email/mail. }\end{array}$ \\
\hline $\begin{array}{l}\text { Emergency } \\
\text { Response } \\
\text { Planning }\end{array}$ & $\begin{array}{l}\text { During pre-construction and pre-operational } \\
\text { mobilization Windlectric, the Construction } \\
\text { Contractor and/or the Operation and } \\
\text { Maintenance Contractor would finalize an } \\
\text { Emergency Response Plan for the } \\
\text { construction and operational activities in } \\
\text { collaboration with the County and Township's } \\
\text { Emergency Services Department. The detailed } \\
\text { Emergency Response Plans may include } \\
\text { protecting the public from equipment and } \\
\text { construction areas by posting warning signs, } \\
\text { use of personal protective equipment, accident } \\
\text { reporting, equipment operation, and confined }\end{array}$ & $\begin{array}{l}\text { - FAQ document created, } \\
\text { updating regularly, and } \\
\text { posted to the Project website. } \\
\text { Algonquin Power staff } \\
\text { members were on hand at all } \\
\text { public open houses to discuss } \\
\text { Emergency Response } \\
\text { Planning. } \\
\text { - Information about the } \\
\text { Emergency Response Plan } \\
\text { was provided at the final } \\
\text { public open houses. }\end{array}$ \\
\hline
\end{tabular}




\begin{tabular}{|c|c|c|}
\hline Comment & Response & Consideration of Comment \\
\hline & $\begin{array}{l}\text { space entry. Discussions with local emergency } \\
\text { services personnel will take place prior to } \\
\text { construction and operations to address } \\
\text { concerns of local emergency services } \\
\text { personnel. If required, Windlectric would } \\
\text { participate in a training session for these } \\
\text { workers. The development of and proper } \\
\text { execution of the Emergency Response Plans } \\
\text { would help ensure public safety is maintained } \\
\text { throughout the operation of the facility. } \\
\text { Windlectric Inc is corresponding with Ornge } \\
\text { to ensure there are no potential effects to the } \\
\text { safe use of the emergency helicopter pad on } \\
\text { the island. }\end{array}$ & $\begin{array}{l}\text { - Provided responses to } \\
\text { relevant public comments by } \\
\text { email/mail. }\end{array}$ \\
\hline $\begin{array}{l}\text { Landowner } \\
\text { Lease } \\
\text { Agreements and } \\
\text { if gag orders are } \\
\text { in place }\end{array}$ & $\begin{array}{l}\text { There is no gag order in place within the } \\
\text { landowner lease agreement. } \\
\text { Windlectric Inc. does not publicly release } \\
\text { details of contracts. A copy of the landowner } \\
\text { lease agreement will not be made publicly } \\
\text { available. }\end{array}$ & $\begin{array}{l}\text { FAQ document created, } \\
\text { updating regularly, and } \\
\text { posted to the Project website. } \\
\text { Algonquin Power staff } \\
\text { members were on hand at all } \\
\text { public open houses to discuss } \\
\text { the lease agreements. } \\
\text { - Provided responses to } \\
\text { relevant public comments by } \\
\text { email/mail. }\end{array}$ \\
\hline $\begin{array}{l}\text { Interference with } \\
\text { TV or internet } \\
\text { signals }\end{array}$ & $\begin{array}{l}\text { It has been our experience that wireless } \\
\text { internet services will not be affected by wind } \\
\text { turbine operation. We will review potential } \\
\text { incidents of telecommunication (including } \\
\text { internet) interference and/or electrical related } \\
\text { concerns on a case by case basis. Windlectric } \\
\text { will undertake a telecommunications impact } \\
\text { assessment to determine the effect if any wind } \\
\text { turbines will have on local } \\
\text { telecommunications assets. The criteria for } \\
\text { this assessment have been developed through } \\
\text { consultation of the wind development industry } \\
\text { and the Radio Advisory Board of Canada. In } \\
\text { the unlikely event that signal disruption is } \\
\text { experienced, mitigation measures are } \\
\text { available to alleviate the impact. This may } \\
\text { include replacing the receiving antenna with } \\
\text { one that has a better discrimination to the } \\
\text { unwanted signals, relocating either the } \\
\text { transmitter or receiver, or switching to an } \\
\text { alternate means of receiving the information } \\
\text { (satellite or other means). }\end{array}$ & $\begin{array}{l}\text { FAQ document created, } \\
\text { updating regularly, and } \\
\text { posted to the Project website. } \\
\text { Provided responses to } \\
\text { relevant public comments by } \\
\text { email/mail. }\end{array}$ \\
\hline $\begin{array}{l}\text { Is the project } \\
\text { economically } \\
\text { viable? }\end{array}$ & $\begin{array}{l}\text { Windlectric Inc. received a contract from the } \\
\text { Ontario Power Authority to supply renewable } \\
\text { energy to the Province under the Feed-in- } \\
\text { Tariff (FIT) program. The power purchase } \\
\text { rate that the program provides is for } 13.5 \\
\text { cents/kWh. Windlectric believes the } \\
\text { economics of the Project make it viable. }\end{array}$ & $\begin{array}{l}\text { - FAQ document created, } \\
\text { updating regularly, and } \\
\text { posted to the Project website. } \\
\text { Algonquin Power staff } \\
\text { members were on hand at all } \\
\text { public open houses to discuss } \\
\text { the economics of the Project. }\end{array}$ \\
\hline
\end{tabular}




\begin{tabular}{|c|c|c|}
\hline Comment & Response & Consideration of Comment \\
\hline & & $\begin{array}{l}\text { Provided responses to } \\
\text { relevant public comments by } \\
\text { email/mail. }\end{array}$ \\
\hline $\begin{array}{l}\text { Compatibility } \\
\text { with Land Use }\end{array}$ & $\begin{array}{l}\text { The amount of land area that a wind turbine } \\
\text { occupies (turbine pad with access road) is } \\
\text { small compared to the overall acreage that a } \\
\text { participating landowner has optioned to lease } \\
\text { for a project. The landowner can still use the } \\
\text { remaining property for farming or other } \\
\text { purposes. The placement of wind turbines } \\
\text { adjacent to nonparticipating property does not } \\
\text { prohibit the use (building of homes, barns or } \\
\text { other structures) of the land. The only } \\
\text { consideration that the adjacent landowner } \\
\text { must be aware of is that if the turbine } \\
\text { locations have been crystallized (finalized by } \\
\text { the developer) and a neighbouring property } \\
\text { owner (participating or non-participating) } \\
\text { decides to build a home closer than } 550 \mathrm{~m} \\
\text { from the turbine location then the developer } \\
\text { does not have to consider this structure as a } \\
\text { noise receptor in the project noise modeling } \\
\text { assessment (as per the MOE regulations). }\end{array}$ & $\begin{array}{l}\text { FAQ document created, } \\
\text { updating regularly, and } \\
\text { posted to the Project website. } \\
\text { - Provided responses to } \\
\text { relevant public comments by } \\
\text { email/mail. }\end{array}$ \\
\hline $\begin{array}{l}\text { Effective } \\
\text { Consultation }\end{array}$ & $\begin{array}{l}\text { There are a number of ways to conduct a } \\
\text { Public Open House. Algonquin Power chose } \\
\text { to have information panels and staff members } \\
\text { available throughout the venue to answer } \\
\text { questions on a one-on-one basis or in small } \\
\text { discussion groups. This format gave } \\
\text { Algonquin Power a chance to meet many } \\
\text { members of the community and address some } \\
\text { of their personal concerns and questions. Staff } \\
\text { members were able to speak to a diverse } \\
\text { number of topics, to meet different interests. } \\
\text { There were subject experts on topics including } \\
\text { environmental assessment, the REA process, } \\
\text { engineering, natural heritage, public health, } \\
\text { noise assessment, archaeology, heritage } \\
\text { resources, visual impact assessment, shadow } \\
\text { flicker assessment, and community benefits. } \\
\text { Extra staff were on hand at both open houses } \\
\text { to assist participants with completing } \\
\text { questionnaires and providing their comments, } \\
\text { signing in, and contacting Algonquin Power } \\
\text { in other formats if they preferred (i.e. phone, } \\
\text { fax, e-mail, letter). } \\
\text { In the event that an individual was not able to } \\
\text { ask their question, questionnaires with a } \\
\text { comments section were provided upon } \\
\text { entrance to the venue and available } \\
\text { throughout the venue. In addition, staff wrote } \\
\text { down individual comments, as appropriate, on } \\
\text { comment forms. }\end{array}$ & $\begin{array}{l}\text { - The Project website was } \\
\text { updated regularly with } \\
\text { Project information and } \\
\text { industry information. } \\
\text { - FAQ document created, } \\
\text { updating regularly, and } \\
\text { posted to the Project website. } \\
\text { All Project Team members } \\
\text { were provided with } \\
\text { consistent information prior } \\
\text { to open houses regarding } \\
\text { stakeholder comment } \\
\text { questions and concerns. All } \\
\text { Project Team members were } \\
\text { instructed to direct questions } \\
\text { to those Team members } \\
\text { directly responsible to the } \\
\text { particular subject material, to } \\
\text { ensure consistency and } \\
\text { quality of responses. }\end{array}$ \\
\hline
\end{tabular}


Based on public feedback, there were no significant changes to the Project design (as the design had never been solidified); however, there were many minor amendments to the REA reports. These amendments reflected the state of Project planning, responses to comments from the consultation process, and corrections to editorial errors.

\subsubsection{Ongoing public consultation}

The consultation report provides a plan for ongoing consultation following the submission of the REA application. This plan covers the construction, operation, and decommissioning phases of the Project. Under the plan, the Proponent and/or the Contractor would maintain contact with stakeholders through the project website, letters, newspaper notices, and/or direct contact. In case of an emergency, the emergency response plan would be implemented so that concrete actions can be taken to protect the health and safety of affected stakeholders.

The Proponent and/or the Contractor would also publish their phone number, mailing address, and email address on the project website in case a stakeholder has a concern or complaint during the construction or operation phases of the Project. The phone number for this purpose would be equipped with a voicemail system; messages would be recorded in an Issue Response Document and responded to within 48 hours. The actions taken to remediate the cause of the complaint as well as proposed actions to prevent the reoccurrence of the issue would also be recorded in the document. 


\subsection{Interviews}

As part of the separate but related ongoing project, interviews are being conducted with renewable energy stakeholders in the same geographical area as the projects outlined above. For the purposes of this thesis, the interviews are intended to supplement the consultation reports and/or serve as commentary on them.

Interview requests were sent out to approximately 30 candidates, who were selected based on research identifying them as past or present renewable energy stakeholders in the Kingston area. They represent some of the entities mentioned in Section 6.1: project proponents, municipalities and government agencies, local politicians, NGOs, renewable energy cooperatives, local solar companies, and academics researching local renewable energy policy and projects. A full list of interview questions can be found in Appendix B, and a full list of potential interviewees can be found in Appendix C.

At the time of writing, eight interviews have been conducted. The following subsections contain summaries of the information gathered from each interview. Each summary includes a brief biography of the interviewee, the rationale for selecting them for an interview, and some highlights from their responses.

\subsubsection{Interview \#1}

This interviewee is the Project Manager at SolarShare, a Toronto-based renewable energy cooperative with projects in the Kingston area. As project manager, she has direct 
experience with the REA process, which this interview hoped to capture. The following are some highlights from her interview:

- SolarShare develops its projects through partnerships with other developers. The other developer will undertake the initial work for the project, such as siting, prospecting, and leasing, while SolarShare acts as a community partner in charge of design and financing, only buying out the project at the end.

- While SolarShare is based in Toronto, its audience is province-wide. SolarShare is active throughout Ontario, although Kingston is a relatively recent addition (the first two of SolarShare's Kingston projects started operating in May 2017). SolarShare has found the most success engaging with the public in communities where it already has existing projects.

- The largest difficulty of the REA application is predicting bureaucratic timelines. Although applicants try hard to meet deadlines set by the IESO, the IESO may take a long time to review and respond to applications. The issue is exacerbated if the applicant wants to do something that "doesn't fit the form"; for example, the IESO had not considered that applicants would want to reassign contracts from one coop to another.

- Another challenge of the REA process is the competitiveness factor. Especially in the beginning when the OPA was receiving more applications than it could handle, the standards for approval were very high and very strict. Applicants needed to be meticulous in filing their applications; if a minor error was found, 
the application would be rejected. In addition, because of the volume of applications, there would be no feedback accompanying a rejected application.

- SolarShare would have invested in virtual net metering under FIT rounds 4 and 5. However, given that the current provincial political landscape is not favourable for renewable energy, SolarShare is currently looking into investing in other jurisdictions.

\subsubsection{Interview \#2}

This interviewee is an engineering consultant and former professor for the Energy Systems Engineering Technician program at St. Lawrence College. He has been involved in the renewable energy space in Kingston for many years; this interview hoped to capture some of his personal experiences. The following are some highlights from his interview:

- The ESET program at St. Lawrence College has been running since 2005. Students can go into one of two streams: renewable energy technology or building energy efficiency. Each cohort ranges between 35 and 50 students, about equally split between the two streams. Graduates typically find work in the energy efficiency sector, for example, doing lighting retrofits in schools and hospitals. The GEA opened up more job opportunities for graduates, for example, in solar project design and installation.

- Through his role at St. Lawrence College, he has been peripherally involved in local renewable energy projects. His students have conducted feasibility studies on potential project sites, and he has participated in community workshops and 
green energy events. These events provide an opportunity to affect the general knowledge of renewable energy in the Kingston area, as well as to recruit prospective students.

- While there were local interests and champions for renewable energy in Kingston, it was government incentives such as the federal Renewable Energy Deployment Initiative (REDI) and the provincial GEA that opened up the renewable energy market. These government programs were the primary drivers of renewable energy development in Kingston. However, government programs may not be necessary now that momentum exists in the sector; for example, the building efficiency industry is continuing without government support.

- Kingston is home to multiple renewable energy and sustainability advocacy organizations, including Wintergreen Energy Coop, SWITCH, 350.org, the Kingston Environmental Action Committee, and Sustainable Kingston. Kingston is also home to opponents of renewable energy, as organized resistance movements have built around the multiple wind farms proposed or operating in the area.

- Public engagement may be useful outside of the project process to educate the public on renewable energy and its benefits. Some methods that could work include workshops, town halls, and educational outreach by public institutions and green energy organizations. However, conversion of public attitudes is a large undertaking that requires support from governments at all levels (federal, provincial, municipal). 


\subsubsection{Interview \#3}

This interviewee is the Community Investment and Marketing Manager at SolarShare. He is responsible for recruiting and managing SolarShare's members; this interview hoped to draw on his experience engaging with the public and prospective investors. The following are some highlights from his interview:

- SolarShare's business model consists of four stages:

1. Identify a project;

2. Acquire separate financing, often from a small group of private investors;

3. Build the project; and

4. Sell bonds against the project. These bonds are not specific to any project or site but rather finance SolarShare's overall portfolio.

- SolarShare engages in various marketing and recruitment initiatives to attract potential investors. While online and transit advertisements target members of the general public, specifically targeting those who already support renewable energy is easier and more successful. For example, having an information booth at community events such as farmers markets and Earth Day events allows SolarShare to engage with like-minded organizations such as local, communityrun ENGOs, and thus recruit already interested prospective investors.

- In Kingston, SolarShare's relationship with Wintergreen was key to the success of the projects there. For one of the projects, Wintergreen was initially awarded the contract, but SolarShare worked with them to acquire and build the project. 
Having a local representative in the area was particularly important for building trust with the community.

- Social media has been an important tool in heightening SolarShare's profile. Investing in their social media presence has led to a growth in their membership base, to the point where they needed to slow down bond sales because they were reaching their target. SolarShare has also seen more hits to their website from diverse geographical locations.

- While social media is an easy form of outreach that can be done centrally, face-toface communication leads to the best engagement. Conversations with people lead to building trust; people are more likely to support a project and invest in it. For example, in Timiskaming (a region in Northeastern Ontario) where the public engagement strategy included a local representative going door-to-door, SolarShare had positive results and found strong support for the project proposed there.

\subsubsection{Interview \#4}

This interviewee is a technical consultant for renewable energy cooperatives. He is responsible for conducting maintenance on SolarShare's Kingston facilities. He was also heavily involved in the public engagement process, drumming up support for SolarShare's projects. This interview hoped to draw on his experience engaging with the public and prospective supporters. The following are some highlights from his interview:

- The province looks for coops to have significant community support in order to approve a community-owned project; the coop needs to have at least 35 local 
members (in the upper-tier municipality), but there is a monetary incentive to have 50 local members. As such, SolarShare needs to actively recruit members in areas where a project is proposed.

- If starting in a new area with no existing coop membership, the recruitment strategy would start with tapping into local events and using those as outreach opportunities. In addition, reaching out to local community groups who share similar values can help to capture a wider audience. Finding a local champion, a "mover and shaker" individual, helps greatly with outreach efforts.

- Based on how well outreach efforts are received as well as the stage of project planning, SolarShare will determine a good date and time to host an information session. Project representatives would provide information on the proposed location of the project as well as the nature of the installation. They would come prepared with as much information as possible in order to adequately answer questions, which tend to be very specific. There could be up to six of these meetings in the run up to a project application.

- As a coop, establishing trust and credibility with the community is crucial. This can be done by having a demonstrable track record of bringing people together and handling large sums of money. The experience does not necessarily have to be in the renewable energy field; for example, the coop Options for Homes has established credibility in building affordable housing, which made its transition into Options for Energy relatively smooth. Of course, the best way to establish credibility is to be able to point to one or more renewable energy projects that are underway, even if they are still in the construction phase. 
- Working as a technician on renewable energy projects, there is still an element of public and community relations, particularly with property owners near the project. If passersby only see the construction crew, barbed fences, and signs to keep out, the project will seem imposing rather than being a part the community. As the most visible people on site, technicians would help the reputation of the project by engaging with passersby about the project and the company (coop) behind it.

\subsubsection{Interview \#5}

This interviewee is the Associate Dean and Director of the School of Policy Studies at Queen's University. His research focuses on the interface between renewable energy policy and technologies; one of his major research projects was an evaluation of renewable energy opportunities and challenges specific to Eastern Ontario. This interview hoped to draw on his subject matter expertise as well as his knowledge of the public engagement processes surrounding local renewable energy projects. The following are some highlights from his interview:

- The three most important stakeholders in any project are (broadly) the government, the community, and the industry (proponent). Representatives of all three of these entities must be at the decision-making table. While industry is the most monolithic and best organized, governments at different levels may be at odds, and community groups can be all over the place as some receive different benefits/impacts than others.

- His main criticisms of the GEA are the following: 
1. The GEA is very industry driven. A proponent can go into a community and build a project even if community opposition exists.

2. The GEA suffers from a lack of resource planning, resulting in a patchwork approach. Ideally, a larger strategy would involve identifying where solar and wind resources exist and then engaging communities in those areas before projects are planned there.

3. The GEA took power away from municipalities. Ideally, the municipalities should act as partners; while the project development process will take longer, it will be more cohesive, and the project will be better accepted by the community.

4. The GEA did not provide enough incentives for community ownership (at least in the early iterations). By making community ownership fundamental, attitudes towards renewable energy would shift from "stupid wind/solar" to "our wind/solar".

- The best engagement processes start early. Under the GEA, the proponent typically starts engaging the public after the planning is already done, leaving the public and stakeholders to react. Ideally, engagement would start when the proponent has financing but before the project site is selected. While starting engagement so early may be difficult to do, project design needs to be responsive to the needs of the stakeholders; early engagement would mitigate the risk of having to scrap a planned project. The government could encourage early engagement by taking on some of the early financial burden, especially for small companies who do not have two years of money to burn on early engagement. 
- The current open house format with display boards works adequately, so long as the representatives present are able to answer questions from the public. Ideally these representatives can claim ownership and responsibility for decisions, as opposed to the typical case where a firm is hired to manage the engagement and pass on the information to the decision makers. Technical experts should also be in the room to answer specific questions; this includes those working on the project, as well as independent experts who are not directly involved but can speak to the project.

- The desired outcome from public engagement varies between stakeholder groups. For industry, the desired outcome is to get the project built. More generally, the desired outcome is a sense of partnership. Government and industry would achieve their goals, while the community benefits and derives meaning from the project.

\subsubsection{Interview \#6}

This interviewee is a former postdoctoral fellow at the Institute for Energy and Environmental Policy at Queen's University. His research focused on community responses and conflicts around wind energy in the Kingston area. This interview hoped to draw on his subject matter expertise as well as his knowledge of the public engagement processes surrounding local renewable energy projects. The following are some highlights from his interview:

- The important stakeholders in renewable energy projects are community members who live in the area where a project is situated; the municipal government which 
represents the community; the proponent or developer; landowners who lease land for the projects (considered a subset of the community); the provincial government who is (indirectly) responsible for operating the electricity grid; and broader interests including investors and environmental advocates.

- His main criticisms of the GEA are the following:

- The GEA removed municipal authority, which should be returned. While not all municipalities will want to get involved and set up their own rules, there are some who do because of significant pushback from their communities.

- The REA process is treated as a tick box process, where proponents simply do the minimum and think they are done. Instead, a measure of outcome would be more useful, for example, a declaration of support or a community benefit agreement would signify that engagement was sufficient. More flexibility in the process would be required in order to achieve this.

- While open houses are necessary, they should be supplemented with other engagement activities. One that has proven to be successful is door-knocking by a local project representative who presents the project outside of the open house setting. In addition, a broader regional assessment process would allow communities to see how they fit into the larger picture rather than feeling specifically targeted.

- Wind project engagement processes became problematic when developers did not see their role in contributing to the well-being of residents. Most opposition 
arguments were ignored or dismissed; visual impact was a matter of personal opinion, wildlife habitat impacts were downplayed, and health concerns were not backed up by science and thus were considered invalid. This strained social relations between the proponent and the host communities. Opponents would resort to the appeals process to express their views, repeating their arguments for different projects.

- Policy analysis of the GEA is rather complicated. It was criticized from all directions; conservatives criticized the financial aspect while environmentalists criticized the social aspect. However, it was a bold step that kickstarted the renewable energy industry in Ontario. In addition, it was improving with each iteration; the government was responding to issues by amending the legislation, for example, adding community-based projects as a criterion for approval. With the GEA now repealed, all that progress is gone. While the GEA had its problems, it should be praised at some level.

\subsubsection{Interview \#7}

This interviewee is the former Director of Planning and Development Services at Loyalist Township. In that role, he was responsible for long term planning and development approvals. During the time the GEA was in force, he was the main municipal contact for project proponents. This interview hoped to draw on his experiences with the various renewable energy projects in the Township. The following are some highlights from his interview: 
- Under the Planning Act, the municipality was responsible for the approval of projects. Once the GEA came into force, the municipality lost that authority and became primarily a commenting agency, becoming more involved depending on the scale of the project. The repeal of the GEA gave the municipality back its approval authority, but of course, there are no renewable energy project applications coming in now.

- Loyalist Township has an official plan which outlines an engagement strategy for project proponents. In contrast with the REA process, it mandates a preconsultation session with Township representatives, in which the municipality and the proponent collectively agree on the requirements for the project application. The municipality cannot mandate open houses, but would highly recommend them. The municipality would attend these open houses, recording attendees' questions and ensuring they are answered adequately.

- Public engagement is important because renewable energy depends on land usage; projects will be in residents' neighbourhoods for a long time. Construction, operation, and decommissioning all impact residents, in most cases, introducing industrial activity into a rural environment. Public engagement can also bring out residents' local knowledge that the proponent may not be aware of. A good public engagement process shows respect for the public; it is democratic and allows people to express their views, regardless of whether they are agreeable or not.

- There are three important components of public engagement:

- Informing the public: what is this project; what are the impacts; how will impacts be mitigated? 
- Listening to the public: ask them questions and listen to their responses; when they ask questions, give meaningful responses.

- Responding to the public's concerns: based on the information received, decide whether the project should go ahead as proposed, or whether it needs to be modified, or whether it should not go ahead. The proponent needs to demonstrate how (legitimate) concerns were addressed.

- Some projects had better engagement processes than others:

- The best engagement process was for the Ernestown Wind Park. The proponent approached the municipality early and often, held more than the required two public meetings, went door-to-door to speak with residents individually and answer their questions, provided plenty of information on the project, and overall was very respectful of stakeholders.

- The engagement processes for the $10 \mathrm{MW}$ solar projects were generally mediocre. The proponent had not informed the municipality in advance of publishing newspaper notices. Two of the sites were acceptable but one was not due to its unique environmental features; the proponent ended up having to move that project to a different site in the City of Kingston.

- The engagement process for Sol-Luce Kingston Solar was relatively poor. The municipality only discovered the project when the notice appeared in the newspaper. The sites were not necessarily bad, but the proponent did the bare minimum in terms of public engagement and only seriously engaged the municipality after the provincial government changed the 
rules for the project's approval (it was not procured under the FIT program, but it still required a REA).

- The worst engagement process was for the Amherst Island Wind Project. The proponent provided very little information in an attempt to protect the project from the organized opposition movement. The answers provided to residents' questions were canned and provided little to no detail. The decision to withhold information ultimately hurt the project, as its development timeline was vastly extended.

\subsubsection{Interview \#8}

This interviewee is the owner of Quantum Renewable Energy, which is one of the two surviving solar companies in the Kingston area. This interview hoped to draw on his experience in the solar industry, particularly during the GEA era. The following are some highlights from his interview:

- Quantum has been in business for 17 years. It started out specializing in solar thermal systems, but shifted almost completely to PV once the GEA and the FIT program came into force. Initially, Quantum's technicians did many PV installations, but in the last two years they have shifted to service work, as many systems are now over ten years old. Quantum focuses on residential projects, but has been involved with some commercial scale projects. The company does everything from designing a system to procurement, installation, and maintenance. 
- He does not see much in terms of public engagement processes, but has experience with government incentive programs. When Quantum started business, the federal REDI program was active. He had fantastic experiences with the program; if he had questions about his application, he could call and speak to a live person. He felt that the team bent over backwards to help make his applications successful so that they could give him the money he was applying for.

- In the GEA era, many of Quantum's projects went through the microFIT process, with small commercial projects going through the FIT process. In contrast with REDI, he had poor experiences dealing with the OPA/IESO; he could not speak to a live person to ask questions about his application. If there was an error in an application, even a minor one such as omitting the customer's middle name, the application would be "terminated". He felt that the IESO was trying to block the whole process, as if he was stealing money from the government.

- The FIT program grew the solar industry as it was intended to do; however, the rollout of the program made the industry so unpredictable that those in the industry called it "the solar coaster". The prices offered for solar electricity started out unnecessarily high; when demand became unmanageable for the government, the program was halted. Multiple solar businesses had to close because the incentives were suddenly gone. After the first price adjustment, in which the price drastically dropped; the Canadian Solar Industries Association (CanSIA) advocated for the government to consult them before the next price adjustment. The government asked industry members to fill out a lengthy survey; a solar 
industry working group put together a report with recommendations, but the OPA ultimately ignored the information that the working group submitted. Every price adjustment, sales would drop for almost six months, in the same way that a gas price shock would have drivers waiting as long as they could before buying gas. The overall deployment of the FIT program was nerve-wracking, as the number of Quantum's employees also fluctuated based on the level of incentives, leading to business instability.

- Now that the GEA has been repealed, incentives are gone, and the industry is mature, Quantum is getting good business. People feel comfortable with PV technology and are either installing their own PV systems or engaging in net metering. He finds satisfaction in seeing people want to do their part in tackling climate change and acting with their money by investing in a PV system. 


\section{Discussion}

This chapter discusses the case study as presented in Chapter 6, focusing primarily on the consultation reports, but drawing on the interviews where appropriate. Section 7.1 lists some observations, identifying characteristics that are shared by some or all of the consultation reports. Section 7.2 discusses the reports in the context of the guidelines presented in Chapter 4.

This discussion is based on the assumption that the consultation reports are complete and accurate representations of what occurred, including the summary tables of comments and concerns received. This assumption is reasonable because a false or incomplete report would have resulted in the project application being rejected. The procedure for incomplete applications is outlined in the Technical Guide:

If the application is determined to be incomplete, the applicant will be notified and the deficiencies that led to the not-complete determination will be identified to the applicant. If an application is not accepted, the applicant must address all deficiencies identified prior to resubmitting a complete application (Ontario MOE, 2013, p. 50).

Clearly, none of the applications for the eight projects were rejected as all eight projects are currently in operation. As such, the appendices containing the raw data (public notices, public meeting display boards, handwritten comment forms, email and mail correspondence) were not referenced; in fact, the appendices were only available for four of the eight projects featured in the case study. 


\subsection{Observations}

Each consultation report provides insight into the engagement process for only one project. By contrast, seeing multiple consultation reports in succession, as in Section 6.1, provides insight into the implementation of the REA process across different projects. The remainder of this section lists some observations from reading all eight consultation reports, supplemented by the interviews.

First, the consultation report seems rather formulaic. The structure of the reports was the same or very similar across all of the projects. The reports for projects by the same proponent were almost identical, only changing the dates, locations, statistics, and comments that were specific to each project. Some of the later reports borrowed text from the earlier reports, even from different proponents. These commonalities were likely a result of the REA process being overly prescriptive; each proponent conducted the engagement process as was required, and reported on it as was required, following the structure recommended in the Technical Guide. The reports would not have been so similar if there was more flexibility in the engagement process, as Interviewee \#6 (Section 6.3.6) suggested was necessary.

Second, with so many projects being proposed at the same time, no single consultation report could capture the inevitable cumulative effects (nor did it have to, as assessments were only conducted at the project level). Referring to the publication timeline in Figure 14, all eight projects published their consultation reports (and submitted REA applications) within 16 months. The only report that mentioned cumulative effects was 
for Westbrook Solar, where attendees at the final public meeting expressed concerns in reference to Sol-Luce Kingston Solar. As the multi-site $100 \mathrm{MW}$ project was being proposed, residents became aware of the potential effects of multiple solar projects in their area. Issues with cumulative effects could have been mitigated with a larger regional planning strategy, as Interviewee \#5 (Section 6.3.5) suggested.

Third, multiple interviewees objectively (none were affiliated with the project proponents) agreed on which projects had better or worse engagement processes. Ernestown was applauded for its robust engagement process; the door-to-door residential campaign was specifically cited as contributing to the project's positive reception in the community. By contrast, Amherst Island was considered a poor example of engagement; the developer did not have much of a local presence, and provided scripted answers to residents' concerns and opponents' arguments, ultimately dividing the community. Interviewee \#7 (Section 6.3.7) described Ernestown as having done "an excellent job" with their engagement process, compared to the Amherst Island engagement process which was "one of the worst I have ever seen".

\subsection{Discussion of the projects in the context of the guidelines in}

\section{Chapter 4}

This section discusses the contents of the consultation reports (supplemented by the interviews) in the context of the guidelines proposed in Chapter 4. Based on this discussion, the guidelines are refined as necessary and then restated in Section 7.3. 


\subsubsection{The role of legislation}

For many of the projects, the REA regulation seemed to be the only thing that mattered. So long as the proponent complied with all aspects of the regulation, the application was approved. As such, project proponents often treated the REA engagement requirements as maximum requirements, checking them off a checklist as they were completed (as Interviewee \#6 described). This was reflected in the similarities between the consultation reports, as discussed in the previous section. Reinforcing the role of the REA regulation in the engagement process, each consultation report included a sentence very similar if not identical to this one from the Odessa consultation report: "This Consultation Report has been prepared in accordance with the requirements of the REA Regulations and the MOE technical bulletin” (SunEdison Canada, 2012, p. 1).

There were a few efforts to go above and beyond the legislated requirements. Kingston Solar LP held an Interim Community Session for the Sol-Luce project in response to the numerous questions and concerns that arose after the First Public Meeting. Windlectric participated in a municipal town hall after Loyalist Township requested they do so to answer questions about the Amherst Island project infrastructure. Ernestown went well above and beyond with their engagement process as a whole, participating in numerous community events and going door-to-door to discuss the project with residents. These efforts to exceed legislative requirements were never viewed as excessive or unnecessary, but provided additional opportunities for community members to learn more and ask questions about the projects. In fact, these efforts could be considered necessary given 
that community members had many questions and concerns that would have otherwise gone unanswered.

Part of the reason for Ernestown's engagement process having such a positive reputation is that the proponent took the initiative to go above and beyond legislative requirements. This confirms the suggestion in Guideline 1 that while proponents need to comply with the law, they should be prepared to go above and beyond if they want their engagement process to be effective.

\subsubsection{The engineer's role in public engagement}

For most of the projects, technical experts were in attendance at public meetings, whether that was representatives of the engineering consultant, or the specialists who conducted the studies required for the project. The most explicit example of this was at the Interim Community Session for Sol-Luce Kingston Solar; representatives of Kingston Solar LP and AMEC as well as specialists in biology, hydrogeology, civil engineering, and electrical engineering were available to answer questions in their areas of expertise. A unique feature of that meeting was the roundtable discussions where multiple attendees could sit with a specialist to discuss concerns. The specialists' attendance was valuable as they could answer specific technical questions that may not have been answerable by someone with more general knowledge, such as a representative of the proponent.

Unfortunately, the documentation did not show whether these technical experts had decision-making power or whether they were merely representatives. As Interviewee \#5 mentioned, ideally, the experts who attend an engagement session should be able to claim 
ownership and responsibility for decisions. The implication is that a project engineer attending an engagement session should be a chief or principal engineer, rather than a subordinate. However, a subordinate could also attend an engagement session, so long as any input they receive from the public is directly transferred to the chief engineer, to maintain competence and efficiency.

As Interviewee \#5 suggested, technical experts who are not involved in the project could also be valuable at public meetings, in the role of an objective community member. They could answer questions from other community members regarding their area of expertise. They could provide an informal independent assessment of the proposal to those who are undecided on whether or not they support the project. They could also flag issues that the proponent may have missed or challenge the proponent on problematic elements of the proposal. Researchers from the local university or retired engineers would be able to fulfill this role.

Outside of the formal project process, technical experts can (and should) engage with the public on renewable energy more broadly. As Interviewee \#4 suggested, technicians working on the project during construction, operation, and/or decommissioning can discuss the project with people who pass by and stop to look. Or as Interviewee \#2 suggested, technical experts can educate the public on renewable energy and its benefits, addressing concerns people might have that are not related to any specific project.

Whether or not the technical experts are involved with the project, their public presence is valuable and beneficial to the public engagement process. This confirms the suggestion in Guideline 2 that engineers have a role to play in public engagement. 


\subsubsection{The fundamental principles of effective public engagement}

This discussion gives project proponents the benefit of the doubt that they conducted their public engagement processes in good faith, with good intentions. Those that listed objectives and/or guiding principles were in alignment with the ideals of effective and meaningful engagement: they wanted to provide relevant, accurate, and consistent information to stakeholders; they wanted to build and strengthen relationships with stakeholders; they aspired to honest, open, and transparent communication, accessibility, inclusivity, and respect; and they promised to address any concerns raised by members of the public as well as incorporate any new relevant information provided to them.

However, stating these objectives and principles at the beginning of the consultation report does not necessarily mean the engagement process was perceived to be in alignment with them. Windlectric may have stated that one of their objectives for the Amherst Island engagement process was "to ensure that relevant, accurate, and consistent information about the Project is provided to stakeholders as early as possible" (Stantec, 2017, p. 2.1), but Interviewee \#7 said he felt like he was "pulling teeth" to get information about the Project. He felt that their intention was to hide information so that it could not be used against them by the opposition movement. Whether that was truly Windlectric's intention or not, the fact that the perception exists and it conflicts with their objectives is a cause for concern.

Recall from the discussion of fairness in Section 2.3, engagement processes are not intrinsically fair or unfair but become so through the intentions of those involved in the process and how those intentions are acted upon. While the fundamental principles of 
effective public engagement listed in Guideline 3 are important values, professing them is insufficient; they must also be practised and implemented.

\subsubsection{The importance of the process}

The tick box approach to the REA process meant that proponents were focused on completing the requirements rather than ensuring the process was effective. There was little flexibility in the process, which was reflected in the commonalities among the consultation reports. For projects that faced significant opposition, such as the Amherst Island Wind Project, the inflexibility of the process meant that opponents had little opportunity to air their grievances or have their concerns adequately addressed. This led to a lack of procedural justice, only intensifying the feelings of opposition towards the project. While the other wind project, Ernestown, also faced opposition, the proponent provided many additional opportunities for community members to discuss the project. This made the engagement process more procedurally just, leading to overall less opposition by the time the project was approved.

In addition, the comparison of the two projects' engagement processes reveals different priorities in terms of outcomes. Amherst Island's 27 turbine, 74 MW project combined with a lack of procedural justice shows that the proponent prioritized maximizing the wind energy production potential over community acceptance of the project. While the project's size is impressive, the host community is bitter towards the project. In comparison, Ernestown's five turbine, $10 \mathrm{MW}$ project combined with a robust engagement process shows that the proponent aimed to balance technical and societal 
outcomes. Ernestown has the overall better outcome in this case: a decently-sized project in an accepting community.

One way to get proponents to focus more on the process is to define the 'completeness' of the engagement process by a measure of outcome, as Interviewee \#6 suggested. For example, if the project needs $75 \%$ community approval to go ahead, the proponent would have to genuinely convince community members to support the project. In the same way that an election campaign is as much about reaching out to voters as it is about winning the election, the public engagement process should be as much about talking to community members, answering their questions, and addressing their concerns, as it is about getting a project built.

As current practice demonstrates that focusing solely on the outcome is the norm, Guideline 4, which suggests shifting focus to the process, stands as is.

\subsubsection{The opportunities for public input to feed into design}

The REA regulation's two-meeting mandate does not maximize the potential value of incorporating public input at various stages of the design process. Interviewee \#7 describes the approach as simply "one meeting to [provide] information, and one meeting to [provide] more information". This approach is like traditional engineering design pedagogy, when student teams would meet with their client once during problem definition and once at the end to demonstrate the final product. As engineering design pedagogy is moving away from the traditional model, so should mandated public engagement processes. 
Taking advantage of all the opportunities to incorporate public input into design implies creating more opportunities to engage with the public throughout the process. Proponents who held additional meetings were better at soliciting public input throughout the design process, simply because they provided more opportunities for the public to provide their input. However, the number of meetings is as important as the timing of these meetings; holding the same meeting on consecutive nights in different locations should not count as two separate meetings, as the project is practically at the same stage of design. SolarShare seems to have hit the mark with six meetings leading up to a project application, but without knowing the timing of those meetings, whether they correspond with the various stages of the design process remains uncertain.

Of course, acquiring valuable public input depends on the public being actively engaged. Based on some of the attendance numbers for public meetings, the public did not seem particularly engaged. With the $10 \mathrm{MW}$ solar projects, meeting attendance was usually below 10. Consultation fatigue may have been a factor in the low attendance rates; the meetings for those small solar projects were held within a very short time span of one another, and often announced on the same day in the newspapers. The First Public Meetings for Odessa, Taylor Kidd, Hwy 2 South, and Unity Road were held on September 7, 8, 9, and 14, 2010 respectively; the Final Public Meetings for those projects were November 9 and 10, 2011 for Hwy 2 and Odessa, and December 7 and 13, 2011 for Unity Road and Taylor Kidd. For all intents and purposes, those four projects could have been considered as one major project by SunEdison. Splitting them could have been a strategic move that gave the proponent better chances of getting the projects approved, at the expense of public engagement. A larger planning strategy that did not allow all these 
meetings to happen at the same time may have yielded a better public response to engagement efforts.

As current practice demonstrates that two meetings is the norm, Guideline 5, which suggests taking advantage of more opportunities for public input to feed into design, stands as is. Suggestions on how to apply this guideline can be found in Chapter 4.

\subsubsection{The engagement mechanism(s)}

The REA regulation's mandate for public meetings led to all project proponents taking a similar approach. All the public meetings were held in an open house format, with display boards around the room and attendees coming and leaving as they pleased. Project representatives were available to discuss the information presented, to answer questions, and to solicit feedback. When asked about the effectiveness of this approach, interviewees agreed that open houses were necessary and worked as intended. They were reasonable venues for presenting all the project information required under the REA regulation to the public. However, the effectiveness of these open houses depended on having project representatives in attendance who could answer questions from the public, and ideally, could claim ownership and responsibility for decisions. Interviewee \#7 stated that in his experience, some proponents were not good at anticipating questions they might get about the project.

Interviewees also agreed that open houses should be supplemented with other methods for engaging the public. Interviewee \#7 suggested a question-and-answer session which allows a more public forum for community members to ask questions and raise concerns. 
Residents would be able to hear from their neighbours; perhaps a question would be asked that they were afraid to ask themselves. Because the proponent's answers would be on public record, they would be held accountable for any promises that they make. Another supplementary engagement mechanism brought up by multiple interviewees was a door-to-door campaign, like the one run by Ernestown. Interviewees credited its success to having a local project representative who could discuss the project outside of the formal open house setting. Interviewee \#4 referred to this local champion as a "mover and shaker" individual, who could drum up support for the project.

The open house as a standard engagement practice confirms the suggestion in Guideline 6 that the focus of engagement is on information provision. Supplementary mechanisms put the proponent (and engineer) in more of a listening and responding role, which as the interviewees suggested, is just as important as the open houses.

\subsubsection{The integration of public input into design}

The summary tables found in each consultation report and replicated in Section 6.1 are meant to demonstrate that the proponent answered all questions, addressed all concerns, and incorporated public input into the project as much as possible. The variance in the content and length of the tables between reports indicates that some proponents handled this better than others.

For the five $10 \mathrm{MW}$ solar projects, with exception of Unity Road, the tables seemed quite short and covered only a few categories of possible concerns. While this may have been driven by the low attendance at public meetings, this also gives the impression that the 
engagement (or the report) was not thorough. For example, with Taylor Kidd, the possibility that the only comment was from an attendee asking to see an aerial photo of the project site seems rather low.

By contrast, for Sol-Luce, Ernestown, and Amherst Island, these summary tables were quite long and were likely the basis for the FAQ documents posted later in the engagement process. The 'response' column in the tables indicates that the proponents were not equally responsive. Windlectric (for Amherst Island) appeared to fall victim to the information-deficit approach; the responses are long, detailed answers that sound like they were copied from the technical reports, with little indication that they address any specific questions or concerns received. Ernestown took the opposite approach; their responses are succinct, they offered residents the appropriate resources to address their concerns, and they invited residents to contact them with any follow up questions. Kingston Solar (for Sol-Luce) landed somewhere between those two extremes, providing succinct answers and promising to look further into any suggestions given by community members.

At the policy level, the government (and its agencies) did not set a good example for project proponents, as it did not appear to take stakeholders' input into account. Interviewee \#8 recounted how CanSIA advocated for the government to consult them before updating the prices offered for solar electricity under the FIT program. After compiling information from across the industry and submitting a report with recommendations, CanSIA was ultimately ignored. This lack of responsiveness on the part of the government led to instability in the industry; sales went up and down, 
businesses opened and closed, and employees were hired and let go. In addition, when stakeholders feel that they have no influence on the outcome, they see their participation in engagement processes as futile; Interviewee \#8 eventually left the solar industry working group, saying, “Forget it, I don't have time and the government doesn't listen".

Given the inconsistency in proponents' abilities to demonstrate sincere efforts to consider public input, as well as the government's poor example, Guideline 7, which suggests making an active effort to integrate public input into design, stands as is.

\subsubsection{The need for new skills}

The consultation reports reveal little about whether engineers have the complementary skillset necessary to engage with the public. Of course, engineers are not the primary focus of the engagement process as they are typically in a consulting role, and thus their performance is not captured in a report. Even if their performance could be recorded, critically assessing their listening, observation, and research skills, or their emotional intelligence and societal awareness, is not an easy task.

Given that the reports are often written and signed off by an engineering consulting firm, one can make a judgement of the engineers' communication skills based on the quality of writing in the reports, as well as the recorded responses to public comments and concerns. The reports feature a technical style of writing, as expected, but they could benefit more from (better use of) non-text methods of displaying information, such as charts and tables. These would be particularly useful when reporting on the statistics for the public meetings. For the most part, the responses to public concerns and comments 
are satisfactory, but in some cases, the response was overly lengthy and technical, or the response was "refer to this technical report". Neither of these cases is ideal because the public is directed to a response which they may not understand or care to read. These critiques are not meant to say that engineers have poor communication skills, but that they could improve on making their work more accessible to the general public. Even though the project application is submitted to a government department, the ultimate audience of public engagement (and the resulting reports) is the public.

Part of the current evolution in engineering education includes helping students to develop the necessary skills for public engagement. Professional development is also moving in this direction; although, having a portal that shows all the relevant courses available would help to facilitate the education process. Since education and life-long learning is always a work in progress, Guideline 8 stands as is.

\subsection{THE GUIDELINES}

Below are the guidelines from Chapter 4, refined to consider the discussion just presented. None of the guidelines were scrapped or overhauled, but most of them were elaborated to clarify their application. Recall that these guidelines are directed to engineers looking or needing to incorporate public engagement into their design processes for renewable energy projects.

These guidelines are meant to be just guidelines; they do not tell you what to do, but rather prepare you to approach public engagement with a mindset prepared to undertake the work required and appreciative of the importance of engagement. 
1. Treat legislated public engagement requirements like the Code of Ethics; you must comply with the law, but if circumstances require you to go above and beyond, then you should do so. In fact, conducting an effective public engagement process likely requires going above and beyond legislated requirements.

2. You may not be directly responsible for public engagement, but you have a role in the process. This applies to you whether you are part of the project or not, and both inside and outside of a formal project process.

3. Apply the principles from the Code of Ethics to public engagement; not only are they necessary for the engineering profession, they are also fundamental to effective engagement processes. Of course, they must be practised, not simply professed.

4. You may be used to focusing solely on the end result, but shift your focus to the process; focusing on the process will almost certainly improve the overall outcome.

5. Public input can feed into every stage of design, from problem definition to implementation. Take advantage of these multiple opportunities.

6. You may not get to choose the engagement mechanism(s), but chances are you will be providing information to members of the public. Ideally, this is supplemented with other engagement mechanisms where you are in a listening and responding role. 
7. Make an active effort to integrate public input into your design by addressing concerns and considering suggestions, so long as doing so does not undermine your professional obligation to public safety, health, and welfare. Be sure to justify any decisions made and report back to the public.

8. Your formal engineering education may not have prepared you for public engagement; take advantage of professional development opportunities and pair them with practical experience. 


\section{Closing notes}

This chapter is where the interdisciplinary research is brought back to the individual disciplines. This research has implications for renewable energy projects, for policymakers, and for the engineering profession.

\subsection{Implications for renewable energy projects}

This research clearly shows that current public engagement processes for renewable energy projects are inadequate. The two-meeting approach is minimal and, without supplementary engagement mechanisms, provides little opportunity for candid discussion of the project. The focus is very much on information provision and avoiding major opposition movements. The public does not seem very engaged, but those who participate often feel that they are unheard and have little influence on the outcome.

Public engagement processes need to be more flexible and adaptable. They need to provide more opportunities for the proponent and the public to come together to discuss the project, both one-on-one and in a group setting. They need to balance information provision with listening to participants and responding to their questions and concerns. While more flexible engagement processes will likely take more time and energy, the resulting fairer process is worth the effort. Ernestown had the best public engagement process in this case study; proponents could learn much from their example. 


\subsection{Implications for policymakers}

This research is timely as the federal and some provincial governments are currently overhauling their environmental assessment and energy regulatory processes. This overhaul includes developing new requirements for the public engagement processes associated with energy and infrastructure projects.

This research demonstrates that current policies around public engagement processes for renewable energy projects are too prescriptive. The REA regulation's two-meeting mandate results in an inflexible process that does not adapt to the specific circumstances surrounding a project. This results in proponents focusing on completing the requirements rather than conducting an effective and meaningful engagement process.

Policies need to allow for more flexibility in the public engagement process, but of course have some constraints to maintain industry predictability. Policymakers will have to develop new criteria for assessing whether an engagement process is complete and satisfactory. The policies may have to be supplemented by programs that financially or capitally support proponents who do not have the resources to undertake thorough engagement, particularly in the early stages of project development.

As engineers try to better consider public engagement in engineering design, policymakers can try to better consider engineering design in new policies. Although directed to engineers, the guidelines presented in Section 7.3 can help policymakers better integrate technical experts within larger policy processes. If policymakers know that engineers are using public engagement as an input to their design processes (and how 
that is being done), they can support engineers by designing policies to leverage public engagement to improve design processes. Alternatively, policymakers may have to incentivize engineers to better consider public engagement (by following the guidelines). New criteria for assessing and approving projects and their associated engagement processes could be a useful policy instrument here.

Policymakers should keep in mind that the policy development process is also a public engagement process. If they expect project proponents to meaningfully engage the public, then they should set the example for proponents to follow. They should meet early and often with stakeholders to discuss the policy in question; they should listen to stakeholders' questions and comments; they should address concerns and consider suggestions, justify their decisions and report back to the public.

\subsection{Implications for the engineering profession}

This thesis aimed to make public engagement more tractable for engineers, who may see the whole engagement process as not their responsibility and outside their comfort zone. As this research shows, engineers have a role in public engagement, but are not necessarily prepared to take on that role.

Engineers understand public engagement better than they think. The engineering design cycle has parallels to the policy cycle. The Code of Ethics contains the same principles fundamental to effective public engagement processes. Ethical considerations in consulting apply to public engagement. The evolution of engineering design towards human-centred design specifically aims to better engage the public. Explicitly drawing 
these links for engineers (and policymakers) to see is only possible through an interdisciplinary lens, such as that used in this thesis.

From here, the engineering profession has some work to do. Professional engineering bodies such as Engineers Canada (through the CEAB), PEO, and OSPE can help to facilitate this work. Currently, public engagement does not factor into the technical design of a renewable energy project as much as it could or should. Guideline 5 (in Chapter 4) shows how public input can feed into every stage of design. Changing the way engineers think about design, with a focus on engaging the public, can make the public engagement and engineering design processes more cohesive. As demonstrated, prioritizing public engagement in engineering design significantly changes how engineering design is conducted, and thus how engineering design should be taught.

In addition, engineers can work on developing the complementary skillset necessary to engage the public within the context of design. As described earlier, engineering educators (post-secondary and continuing education) have already started to make progress in this area. The ability to communicate technical information to generalist audiences is crucial in this respect. Being able to listen, to observe, and to learn from others is necessary for public input to be reflected in design. The ability to be empathetic, humble, patient, and open minded is essential for building relationships and partnerships with the public. Developing these skills is probably easier earlier in one's career, but now is not too late.

The guidelines presented in Section 7.3 are a best attempt at distilling everything this thesis covers into eight actionable points relevant to the engineering profession. Adopting 
these guidelines will surely amplify engineers' contributions to engagement processes as well as the public's contributions to the design of renewable energy projects. Conversely, not considering these guidelines will only reinforce the status quo, which this research has clearly shown to be inadequate. These guidelines are a step towards making engagement processes more effective, leading to renewable energy projects that are more meaningful to the communities in which they are situated. 


\section{References}

AMEC Environment \& Infrastructure. (2012, September). Sol-Luce Kingston Solar PV Energy Project - Consultation Report. Retrieved September 18, 2019, from https://www.samsungrenewableenergy.ca/our-projects/kingston/

Andrews, G. C., Shaw, P., \& McPhee, J. (2019). Canadian Professional Engineering and Geoscience: Practice and Ethics, Sixth Edition. Toronto: Nelson Education Ltd.

Annable, K. (2012, April 19). Green bins versus raccoons: Round 2. Retrieved from National Post: https://nationalpost.com/posted-toronto/green-bins-versus$\% \mathrm{C} 2 \%$ ADraccoons-round-2

Arnstein, S. R. (1969). A Ladder of Citizen Participation. Journal of the American Institute of Planners, 35(4), 216-224. doi:10.1080/01944366908977225

ASCE. (2019, July 13). Policy Statement 139 - Public Involvement in the Decision Making Process. Retrieved from https://www.asce.org/issues-andadvocacy/public-policy/policy-statement-139---public-involvement-in-thedecision-making-process/

ASME. (2016, March 31). Clearing the Air over Cookstoves. Retrieved from Demand: ASME Global Development Review: https://demandasme.org/clearing-the-airover-cookstoves/

Atman, C. J., Adams, R. S., Cardella, M. E., Turns, J., Mostborg, S., \& Saleem, J. (2007). Engineering Design Processes: A Comparison of Students and Expert Practitioners. Journal of Engineering Education, 96, 359-379. doi:10.1002/j.2168-9830.2007.tb00945.x

Bakx, K., \& Seskus, T. (2018, August 31). Don't dig Trans Mountain's grave just yet. Retrieved from CBC News: https:/www.cbc.ca/news/business/tmx-oilpatchcourt-ruling-construction-1.4804894

Barnett, J., Burningham, K., Walker, G., \& Cass, N. (2012). Imagined publics and engagement around renewable energy technologies in the UK. Public Understanding of Science, 21(1), 36-50. doi:10.1177/0963662510365663

Bell, D., Gray, T., \& Haggett, C. (2005). The 'Social Gap' in Wind Farm Siting Decisions: Explanations and Policy Responses. Environmental Politics, 14(4), 460-477. doi:10.1080/09644010500175833

Bidwell, D. (2013). The role of values in public beliefs and attitudes towards commercial wind energy. Energy Policy, 58, 189-199. doi:10.1016/j.enpol.2013.03.010 
Bielefeldt, A. R., \& Lima, M. (2019). Service-Learning and Civic Engagement as the Basis for Engineering Design Education. In N. M. Hassan (Ed.), Engineering Design and Innovation Methods. IntechOpen. doi:10.5772/intechopen.83699

Blackwell, R. (2016, October 27). Canadian arm of SunEdison files for bankruptcy protection. Retrieved from The Globe and Mail:

https://www.theglobeandmail.com/report-on-business/industry-news/energy-andresources/canadian-arm-of-sunedison-files-for-bankruptcyprotection/article32561733/

Burke, R. D., Parrish, K., \& El Asmar, M. (2018). Environmental Product Declarations: Use in the Architectural and Engineering Design Process to Support Sustainable Construction. Journal of Construction Engineering and Management, 144(5), 04018026. doi:10.1061/(asce)co.1943-7862.0001481

Burningham, K. (2000). Using the Language of NIMBY: A topic for research, not an activity for researchers. Local Environment, 5(1), 55-67. doi:10.1080/135498300113264

CanWEA. (2019). Wind Energy in Ontario. Retrieved from https://canwea.ca/windenergy/ontario-market-profile/

Cardenas, M. P. (2013). A Community-Engagement-Based Design Project in Introductory Environmental Engineering. Proceedings 120th ASEE Annual Conference \& Exposition, (p. 6381). Atlanta.

Carlisle, J. E., Kane, S. L., Solan, D., \& Joe, J. C. (2014). Support for solar energy: Examining sense of place and utility-scale development in California. Energy Research and Social Science, 3, 124-130. doi:10.1016/j.erss.2014.07.006

Cash, P., Hicks, B., \& Culley, S. (2015). Activity Theory as a means for multi-scale analysis of the engineering design process: A protocol study of design in practice. Design Studies, 38, 1-32. doi:10.1016/j.destud.2015.02.001

Cass, N., \& Walker, G. (2009). Emotion and rationality: The characterisation and evaluation of opposition to renewable energy projects. Emotion, Space and Society, 2, 62-69. doi:10.1016/j.emospa.2009.05.006

CEAA. (2008). Public Participation Guide: A Guide for Meaningful Public Participation in Environmental Assessments under the Canadian Environmental Assessment Act. Ottawa. Retrieved from https://www.canada.ca/en/environmentalassessment-agency/services/policy-guidance/public-participation-guide.html

Chong, A., Irish, R., \& Foster, J. (2019). Community Finding as Learning: Impacts of a Novel Model for Community Engaged, Project Based Learning in Engineering. 
Proceedings 2019 Canadian Engineering Education Association (CEEAACEG19) Conference, (p. 172). Ottawa.

CSPS. (2019, June). Learning Together for Better Public Engagement. Ottawa.

Cuppen, E., Bosch-Rekveldt, M. G., Pikaar, E., \& Mehos, D. C. (2016). Stakeholder engagement in large-scale energy infrastructure projects: Revealing perspectives using Q methodology. International Journal of Project Management, 34, 13471359. doi:10.1016/j.ijproman.2016.01.003

Devine-Wright, P. (2011). Public engagement with large-scale renewable energy technologies: breaking the cycle of NIMBYism. WIREs Climate Change, 2, 1926. doi:10.1002/wcc.89

Dillon Consulting. (2014, January). Sol-Luce Kingston Solar PV Energy Project Consultation Report Addendum. Retrieved September 23, 2019, from https://www.samsungrenewableenergy.ca/our-projects/kingston/

Downunder Solar Inc. (2019). About Us. Retrieved from http://www.downundersolar.ca/

Earle, J. H. (2005). Graphics Technology, 2nd Ed. Pearson Prentice Hall.

Engineers Canada. (2016, January). Graduate Attributes. Retrieved from https://engineerscanada.ca/sites/default/files/Graduate-Attributes.pdf

Engineers Canada. (2016, September). National guideline on sustainable development and environmental stewardship for professional engineers. Retrieved from https://engineerscanada.ca/publications/national-guideline-on-sustainabledevelopment-and-environmental-stewardship

Engineers Canada. (2016, March). Public Guideline on the code of ethics. Retrieved from https://engineerscanada.ca/publications/public-guideline-on-the-code-of-ethics

Ernestown Windpark Inc. (2012, October). Ernestown Windpark Consultation Report. Retrieved September 18, 2019, from https:/www.ernestownwind.com/documents

Eseonu, C. I., \& Cortes, M. A. (2018). Engineering for Good: A Case of Community Driven Engineering Innovation. Journal of Humanitarian Engineering, 6(1), 1-9. Retrieved from http://jhe.ewb.org.au/index.php/jhe/article/view/110

Expert Panel on the Modernization of the NEB. (2017). Forward, Together-Enabling Canada's Clean, Safe and Secure Energy Future. Ottawa. Retrieved from https://www.nrcan.gc.ca/sites/www.nrcan.gc.ca/files/pdf/NEB-ModernizationReport-EN-WebReady.pdf 
Expert Panel: Review of EA Processes. (2017). Building Common Ground: A New Vision for Impact Assessment in Canada. Ottawa: Canadian Environmental Assessment Agency. Retrieved from https://www.canada.ca/en/services/environment/conservation/assessments/environ mental-reviews/environmental-assessment-processes/building-commonground.html

Fast, S., \& Mabee, W. (2015). Place-making and trust-building: The influence of policy on host community responses to wind farms. Energy Policy, 81, 27-37. doi:10.1016/j.enpol.2015.02.008

Fast, S., Mabee, W., Baxter, J., Christidis, T., Driver, L., Hill, S., . . Tomkow, M. (2016). Lessons learned from Ontario wind energy disputes. Nature Energy, 1(2), 15028. doi:10.1038/nenergy.2015.28

Fisher, J., \& Brown, K. (2009). Wind energy on the Isle of Lewis: implications for deliberative planning. Environment and Planning A, 41, 2516-2536. doi:10.1068/a41129

Friendly Fires. (2019). Friendly Fires Merges with Renewable Energy of Plum Hollow. Retrieved from https://friendlyfires.ca/about-us/plum-hollow/

Gagnon, B., Leduc, R., \& Savard, L. (2012). From a conventional to a sustainable engineering design process: Different shades of sustainability. Journal of Engineering Design, 23(1), 49-74. doi:10.1080/09544828.2010.516246

Gignac, J. (2018, April 15). U of T students devise strategies to administer naloxone faster. Retrieved from The Toronto Star: https://www.thestar.com/news/gta/2018/04/15/u-of-t-students-devise-strategiesto-administer-naloxone-faster.html

Gilbert, D. J., Held, M. L., Ellzey, J. L., Bailey, W. T., \& Young, L. B. (2015). Teaching 'community engagement' in engineering education for international development: Integration of an interdisciplinary social work curriculum. European Journal of Engineering Education, 40(3), 256-266. doi:10.1080/03043797.2014.944103

Gonnet, S., Henning, G., \& Leone, H. (2007). A model for capturing and representing the engineering design process. Expert Systems with Applications, 33, 881-902. doi:10.1016/j.eswa.2006.07.004

Government of Canada. (2019, May). Discussion Paper on Information Requirements and Time Management Regulatory Proposal. Retrieved from Environmental and Regulatory Reviews: https://www.impactassessmentregulations.ca/Consultationon-the-proposed-Information-Requirements-and-Time-Management-Regulations 
Government of Canada. (2019, June 21). ERR. Retrieved from

https://www.canada.ca/en/services/environment/conservation/assessments/environ mental-reviews.html

Government of Canada. (2019, March 14). Pan-Canadian Framework on Clean Growth and Climate Change. Retrieved from

https://www.canada.ca/en/services/environment/weather/climatechange/pancanadian-framework.html

Government of Canada. (2019, September). Strategic Assessment of Climate Change. Retrieved from https://www.strategicassessmentclimatechange.ca/

Government of Ontario. (2010, October 25). Environmental Assessment Act, R.S.O. 1990, c. E.18. Retrieved from https://www.ontario.ca/laws/statute/90e18

Government of Ontario. (2016, May 1). O. Reg. 359/09: RENEWABLE ENERGY APPROVALS UNDER PART V.0.1 OF THE ACT. Retrieved from https://www.ontario.ca/laws/regulation/090359

Government of Ontario. (2017, July). Renewable Energy Projects. Retrieved from https://www.ontario.ca/data/renewable-energy-projects

Government of Ontario. (2018, April 1). Professional Engineers Act, R.S.O. 1990, c. P.28. Retrieved from https://www.ontario.ca/laws/statute/90p28

Government of Ontario. (2019, January 1). Green Energy Act, 2009, S.O. 2009, c. 12, Sched. A. Retrieved from https://www.ontario.ca/laws/statute/09g12

Gross, C. (2007). Community perspectives of wind energy in Australia: The application of a justice and community fairness framework to increase social acceptance. Energy Policy, 35, 2727-2736.

Harsh, M., Bernstein, M. J., Wetmore, J., Cozzens, S., Woodson, T., \& Castillo, R. (2017). Preparing engineers for the challenges of community engagement.

European Journal of Engineering Education, 42(6), 1154-1173. doi:10.1080/03043797.2016.1270902

Hatch Ltd. (2011, November 30). Draft Consultation Report for Kingston Gardiner Hwy 2 South Solar Energy Project. Retrieved September 18, 2019, from Great Circle Solar Management Corporation: http://greatcirclesolar.ca/rea-5155-8wdh5g

Hill, S. D., \& Knott, J. D. (2010). Too close for comfort: Social controversies surrounding wind farm noise setback policies in Ontario. Renewable Energy Law and Policy Review, 1(2), 153-168. 
IAP2. (2018, November 12). IAP2 Spectrum of Public Participation. Retrieved from https://cdn.ymaws.com/www.iap2.org/resource/resmgr/pillars/Spectrum_8.5x11_ Print.pdf

IESO. (2016, September 29). LRP II and EFW procurements cancelled. Retrieved from http://www.ieso.ca/sector-participants/ieso-news/2016/09/lrp-ii-and-efwprocurements-cancelled

Jami, A. A., \& Walsh, P. R. (2017). From consultation to collaboration: A participatory framework for positive community engagement with wind energy projects in Ontario, Canada. Energy Research and Social Science, 27, 14-24. doi:10.1016/j.erss.2017.02.007

Lapp, S. (2018, December 17). (A. Mallett, C. Merrett, \& N. Moy, Interviewers)

Lindow, K., Woll, R., \& Stark, R. (2012). A Conceptual Framework for Sustainable Engineering Design. In D. A. Dornfeld, \& B. S. Linke (Eds.), Leveraging Technology for a Sustainable World (pp. 197-202). Berlin, Germany: Springer. doi:10.1007/978-3-642-29069-5_34

Mabee, W. E., Mannion, J., \& Carpenter, T. (2012). Comparing the feed-in tariff incentives for renewable electricity in Ontario and Germany. Energy Policy, 40(1), 480-489. doi:10.1016/j.enpol.2011.10.052

McDivitt, P. (2016). The Information Deficit Model is Dead. Now What? Evaluating New Strategies for Communicating Anthropogenic Climate Change in the Context of Contemporary American Politics, Economy, and Culture. Masters Thesis. Boulder, Colorado.

McRobert, D., Tennent-Riddell, \& Walker, C. (2016). Ontario's Green Economy and Green Energy Act: Why a Well-Intentioned Law is Mired in Controversy and Opposed by Rural Communities. Renewable Energy Law and Policy Review, $7(2), 91-112$.

Militello, L. G., Dominguez, C. O., Lintern, G., \& Klein, G. (2010). The Role of Cognitive Systems Engineering in the Systems Engineering Design Process. Systems Engineering, 13, 261-273. doi:10.1002/sys.20147

Mitchell, M., \& Do, L. (2019, April 17). First-year students engineer solutions to complex city challenges. Retrieved from University of Toronto Engineering News: https://news.engineering.utoronto.ca/first-year-students-engineer-solutionsto-complex-city-challenges/

Morrissey, B. (2015, April 21). The importance of stakeholder and community engagement in engineering projects. Retrieved July 8, 2019, from Engineers 
Journal: http://www.engineersjournal.ie/2015/04/21/importance-stakeholdercommunity-engagement-engineering-projects/

Mulvihill, P., Winfield, M., \& Etcheverry, J. (2013). Strategic Environmental Assessment and Advanced Renewable Energy in Ontario: Moving Forward or Blowing in the Wind? Journal of Environmental Assessment Policy and Management, 15(2), 1340006. doi:10.1142/S1464333213400061

North American Solar Stores. (2017). Renewable Energy of Plum Hollow Inc. Retrieved from https://www.northamericansolarstores.com/kingston-ontario-solar/

NRCan. (2018, September 12). Renewable Energy Facts. Retrieved from https://www.nrcan.gc.ca/energy/facts/renewable-energy/20069

NRCan. (2018). The Atlas of Canada - Clean Energy Resources and Projects (CERP). Retrieved from https://atlas.gc.ca/cerp-rpep/en/

Ontario Ministry of Energy. (2017, October 26). 2017 Long-Term Energy Plan: Delivering fairness and choice. Retrieved from https://www.ontario.ca/document/2017-long-term-energy-plan

Ontario Ministry of Energy. (2019, May 9). Renewable energy development in Ontario: A guide for municipalities. Retrieved from https://www.ontario.ca/document/renewable-energy-development-ontario-guidemunicipalities

Ontario MOE. (2013). Technical Guide to Renewable Energy Approvals. Retrieved from https://www.ontario.ca/document/technical-guide-renewable-energy-approvals-0

Ontario MOE. (2017, March 10). Renewable Energy Approvals. Retrieved from https://www.ontario.ca/page/renewable-energy-approvals

O'Reilly, C. J., Göransson, P., Funazaki, A., Suzuki, T., Edlund, S., Gunnarsson, C., . . . Potting, J. (2016). Life cycle energy optimisation: A proposed methodology for integrating environmental considerations early in the vehicle engineering design process. Journal of Cleaner Production, 135, 750-759. doi:10.1016/j.jclepro.2016.06.163

OSPE. (2012, March 14). Wind and the Electrical Grid - Mitigating the Rise in Electricity Rates and Greenhouse Gas Emissions. Retrieved from https://www.ospe.on.ca/public/documents/advocacy/2012-wind-electrical-grid.pdf

OSPE. (2016, September 30). Ontario's cancellation of \$3.8 billion in additional renewable energy projects could have been avoided if government heeded the advice of engineers. Retrieved from Society Notes: 
https://blog.ospe.on.ca/advocacy/ontario-cancels-plans-sign-3-8-billion-contractsrenewable-energy-heeding-advice-engineers/

OSPE. (2016, September 12). Two Sides of the Same Coin. Retrieved from https://blog.ospe.on.ca/advocacy/peo-ospe-two-sides-coin/

OSPE. (2017, June 29). Ontario Wasted More Than \$1 Billion Worth of Clean Energy in 2016. Retrieved from https://blog.ospe.on.ca/featured/ontario-wasted-more-than1-billion-worth-of-clean-energy-in-2016-enough-to-power-760000-homes/

OSPE. (2019). About Us. Retrieved from https://www.ospe.on.ca/about

Pal, L. (2014). Beyond Policy Analysis: Public Issue Management in Turbulent Times, 5th Edition. Nelson Higher Education.

PEO. (2012, July). GLP Note 4.1 - The Green Energy Act. Retrieved from http://www.peo.on.ca/index.php/ci_id/26742/la_id/1.htm

PEO. (2017, August). Professional Engineering Practice Guideline. Retrieved from http://www.peo.on.ca/index.php/ci_id/22127/la_id/1.htm

PEO. (2018). About PEO. Retrieved from http://www.peo.on.ca/index.php?ci_id=1792\&la_id=1

Quantum Renewable Energy Inc. (2019). About Quantum Renewable Energy. Retrieved from https://quantumenergy.ca/about-quantum-energy/

Robinson, J. (2019). Keynote Presentation: Normalizing Sustainability - from behaviour change to metamorphosis. International Sustainability Transitions Conference. Ottawa.

Rosen, M. A. (2012). Engineering Sustainability: A Technical Approach to Sustainability. Sustainability, 4, 2270-2292. doi:10.3390/su4092270

Rowe, G., \& Frewer, L. J. (2005). A Typology of Public Engagement Mechanisms. Science, Technology, \& Human Valules, 30(2), 251-290. doi:10.1177/0162243904271724

Samsung Renewable Energy Inc. (2018). Kingston. Retrieved from https://www.samsungrenewableenergy.ca/our-projects/kingston/

Simis, M. J., Madden, H., Cacciatore, M. A., \& Yeo, S. K. (2016). The lure of rationality: Why does the deficit model persist in science communication? Public Understanding of Science, 25(4), 400-414. doi:10.1177/0963662516629749 
SolarShare. (2019). Wintergreen. Retrieved from https://www.solarbonds.ca/allprojects/Wintergreen

Songsore, E., \& Buzzelli, M. (2016). Ontario's experience of wind energy development as seen through the lens of human health and environmental justice. International Journal of Environmental Research and Public Health, 13(7), 1-18. doi:10.3390/ijerph13070684

St. Lawrence College. (2019). Energy Systems Engineering Technician. Retrieved from https://www.stlawrencecollege.ca/programs-and-courses/fulltime/programs/a_m/energy-systems-engineering-technician/kingston/

Stantec. (2017). Amherst Island WInd Project. Retrieved from http://amherstislandwindproject.com/site_main/

Stantec Consulting Ltd. (2013, April). Amherst Island Wind Energy Project Consultation Report. Retrieved September 18, 2019, from http://amherstislandwindproject.com/site_main/index.php/publicinformation/final-renewable-energy-approval-technical-documents/

Stokes, L. C. (2013). The politics of renewable energy policies: The case of feed-in tariffs in Ontario, Canada. Energy Policy, 56, 490-500. doi:10.1016/j.enpol.2013.01.009

Stott, N. W., Schultz, W. W., Brei, D., Hoffman, D. M., \& Markus, G. (2000). ProCEED: A program for civic engagement in engineering design. ASEE Annual Conference Proceedings, (p. 5.502).

Suldovsky, B. (2017). The Information Deficit Model and Climate Change Communication. Oxford Research Encyclopedia of Climate Science. doi:10.1093/acrefore/9780190228620.013.301

SunEdison Canada. (2012, February 1). Kingston Gardiner TS Odessa Solar Energy Project - Consultation Report. Retrieved September 18, 2019, from Great Circle Solar Management Corporation: http://greatcirclesolar.ca/rea-22948wjhd3

SunEdison Canada. (2012, February 17). Kingston Gardiner TS Unity Road Solar Energy Project - Consultation Report. Retrieved September 18, 2019, from Great Circle Solar Management Corporation: http://greatcirclesolar.ca/rea-84388xnq31

SunEdison Canada. (2012, February 23). Napanee TS Taylor Kidd Solar Energy Project Consultation Report. Retrieved September 18, 2019, from Great Circle Solar Management Corporation: http://greatcirclesolar.ca/rea-00178ygjjm

SunEdison Canada. (2012, May 17). SunE Westbrook Solar Farm - Consultation Report. Retrieved September 18, 2019, from Great Cirle Solar Management Corporation: http://greatcirclesolar.ca/rea-876892qljt 
SunEdison Canada. (2012, May 17). SunE Westbrook Solar Farm - Executive Summary. Retrieved September 18, 2019, from Great Circle Solar Management Corporation: http://greatcirclesolar.ca/rea-876892qljt

SWITCH. (2019). About Us. Retrieved from http://www.switchontario.ca/about-us

The Canadian Press. (2016, November 22). Ontario advises other provinces to avoid its 'mistake' and keep an eye on hydro bills as coal phased out. Retrieved from Financial Post: https://business.financialpost.com/commodities/energy/ontarioadvises-other-provinces-to-avoid-its-mistake-and-keep-an-eye-on-hydro-bills-ascoal-phased-out

The Canadian Press. (2018, July 13). Ontario government cancels 758 renewable energy contracts, says it will save millions. Retrieved from CBC News: https://www.cbc.ca/news/canada/toronto/758-renewable-energy-cancelled1.4746293

TransAlta. (2018). Wolfe Island. Retrieved from https://www.transalta.com/facilities/plants-operation/wolfe-island/

Walker, C., \& Baxter, J. (2017). Procedural justice in Canadian wind energy development: A comparison of community-based and technocratic siting processes. Energy Research and Social Science, 29, 160-169. doi:10.1016/j.erss.2017.05.016

Walker, G., Cass, N., Burningham, K., \& Barnett, J. (2010). Renewable energy and sociotechnical change: Imagined subjectivities of 'the public' and their implications. Environment and Planning A, 42, 931-947. doi:10.1068/a41400

Wallen, M. R., \& Pandit, A. S. (2009). Encouraging undergraduate engineering students towards civic engagement. European Journal of Engineering Education, 34(2), 141-148. doi:10.1080/03043790902829299

WCED. (1987). Our common future. Oxford University Press.

Weisbrod, G., \& Kroll, E. (2018). Idea-configuration-evaluation (ICE): development and demonstration of a new prescriptive model of the conceptual engineering design process based on parameter analysis and $\mathrm{C}-\mathrm{K}$ theory. Research in Engineering Design, 29, 203-225. doi:10.1007/s00163-017-0263-6

Wesoff, E. (2011, June 2). Flash: SunEdison to Acquire PV Developer Axio Power. Retrieved from Greentech Media:

https://www.greentechmedia.com/articles/read/flash-sunedison-to-acquire-pvdeveloper-axio-power 
WGC. (2019). Wintergreen Renewable Energy Co-op. Retrieved from https://www.wintergreencoop.com/home/

Yatchew, A., \& Baziliauskas, A. (2011). Ontario feed-in-tariff programs. Energy Policy, 39(7), 3885-3893. doi:10.1016/j.enpol.2011.01.033 


\section{Appendices}

\section{A. Consultation Events and Dates}

\begin{tabular}{|c|c|c|c|}
\hline Date & Project & Activity & Venue \\
\hline 2010-05-29 & Ernestown & $\begin{array}{l}\text { Notice of Proposal and Public } \\
\text { Meeting }\end{array}$ & Kingston Whig Standard \\
\hline 2010-05-31 & Ernestown & $\begin{array}{l}\text { Notice of Proposal and Public } \\
\text { Meeting }\end{array}$ & Kingston Whig Standard \\
\hline 2010-06-03 & Ernestown & $\begin{array}{l}\text { Notice of Proposal and Public } \\
\text { Meeting }\end{array}$ & Kingston EMC \\
\hline 2010-06-10 & Ernestown & $\begin{array}{l}\text { Notice of Proposal and Public } \\
\text { Meeting }\end{array}$ & Kingston EMC \\
\hline 2010-06-14 & Ernestown & $\begin{array}{l}\text { Notice of Proposal and Public } \\
\text { Meeting }\end{array}$ & Mailed to identified landowners \\
\hline 2010-06-29 & Ernestown & First Public Meeting & Amherstview Community Hall \\
\hline 2010-06-30 & Ernestown & Second Public Meeting & $\begin{array}{l}\text { INVISTA Centre, } 1385 \\
\text { Gardiners Road, Kingston, ON }\end{array}$ \\
\hline 2010-07-19 & Hwy 2 South & $\begin{array}{l}\text { Notice of Proposal to Engage in a } \\
\text { Renewable Energy Project and First } \\
\text { Public Meeting }\end{array}$ & Mailed to identified landowners \\
\hline 2010-07-19 & Odessa & $\begin{array}{l}\text { Notice of Project Commencement } \\
\text { and First Public Meeting }\end{array}$ & Mailed to identified landowners \\
\hline $2010-07-27$ & Taylor Kidd & $\begin{array}{l}\text { Notice of Project Commencement } \\
\text { and First Public Meeting }\end{array}$ & Mailed to identified landowners \\
\hline $2010-07-27$ & Unity Road & $\begin{array}{l}\text { Notice of Project Commencement } \\
\text { and First Public Meeting }\end{array}$ & Mailed to identified landowners \\
\hline 2010-07-31 & Hwy 2 South & $\begin{array}{l}\text { Notice of Proposal to Engage in a } \\
\text { Renewable Energy Project and First } \\
\text { Public Meeting }\end{array}$ & Kingston Whig Standard \\
\hline 2010-07-31 & Odessa & $\begin{array}{l}\text { Notice of Project Commencement } \\
\text { and First Public Meeting }\end{array}$ & Kingston Whig Standard \\
\hline 2010-07-31 & Taylor Kidd & $\begin{array}{l}\text { Notice of Project Commencement } \\
\text { and First Public Meeting }\end{array}$ & Kingston Whig Standard \\
\hline $2010-07-31$ & Unity Road & $\begin{array}{l}\text { Notice of Project Commencement } \\
\text { and First Public Meeting }\end{array}$ & Kingston This Week \\
\hline 2010-08-05 & Hwy 2 South & $\begin{array}{l}\text { Notice of Proposal to Engage in a } \\
\text { Renewable Energy Project and First } \\
\text { Public Meeting }\end{array}$ & Kingston This Week \\
\hline 2010-08-05 & Odessa & $\begin{array}{l}\text { Notice of Project Commencement } \\
\text { and First Public Meeting }\end{array}$ & Kingston This Week \\
\hline 2010-08-05 & Taylor Kidd & $\begin{array}{l}\text { Notice of Project Commencement } \\
\text { and First Public Meeting }\end{array}$ & Kingston This Week \\
\hline 2010-08-05 & Unity Road & $\begin{array}{l}\text { Notice of Project Commencement } \\
\text { and First Public Meeting }\end{array}$ & Kingston Whig Standard \\
\hline 2010-08-07 & Hwy 2 South & $\begin{array}{l}\text { Notice of Proposal to Engage in a } \\
\text { Renewable Energy Project and First } \\
\text { Public Meeting }\end{array}$ & Kingston Whig Standard \\
\hline
\end{tabular}




\begin{tabular}{|c|c|c|c|}
\hline Date & Project & Activity & Venue \\
\hline 2010-08-07 & Odessa & $\begin{array}{l}\text { Notice of Project Commencement } \\
\text { and First Public Meeting }\end{array}$ & Kingston Whig Standard \\
\hline $2010-08-07$ & Taylor Kidd & $\begin{array}{l}\text { Notice of Project Commencement } \\
\text { and First Public Meeting }\end{array}$ & Kingston Whig Standard \\
\hline 2010-08-07 & Unity Road & $\begin{array}{l}\text { Notice of Project Commencement } \\
\text { and First Public Meeting }\end{array}$ & Kingston This Week \\
\hline 2010-08-12 & Hwy 2 South & $\begin{array}{l}\text { Notice of Proposal to Engage in a } \\
\text { Renewable Energy Project and First } \\
\text { Public Meeting }\end{array}$ & Kingston This Week \\
\hline $2010-08-12$ & Odessa & $\begin{array}{l}\text { Notice of Project Commencement } \\
\text { and First Public Meeting }\end{array}$ & Kingston This Week \\
\hline 2010-08-12 & Taylor Kidd & $\begin{array}{l}\text { Notice of Project Commencement } \\
\text { and First Public Meeting }\end{array}$ & Kingston This Week \\
\hline $2010-08-12$ & Unity Road & $\begin{array}{l}\text { Notice of Project Commencement } \\
\text { and First Public Meeting }\end{array}$ & Kingston Whig Standard \\
\hline 2010-09-07 & Odessa & First Public Meeting & $\begin{array}{l}\text { Odessa Fairgrounds, } 231 \text { Main } \\
\text { Street, Odessa, ON }\end{array}$ \\
\hline 2010-09-08 & Taylor Kidd & First Public Meeting & $\begin{array}{l}\text { Odessa Fairgrounds, } 231 \text { Main } \\
\text { Street, Odessa, ON }\end{array}$ \\
\hline 2010-09-09 & Hwy 2 South & First Public Meeting & $\begin{array}{l}\text { Odessa Fairgrounds, } 231 \text { Main } \\
\text { Street, Odessa, ON }\end{array}$ \\
\hline 2010-09-14 & Unity Road & First Public Meeting & $\begin{array}{l}\text { Glenburnie United Church, } 1028 \\
\text { Unity Road, Glenburnie, ON }\end{array}$ \\
\hline 2011-07-25 & Sol-Luce & $\begin{array}{l}\text { Notice of Proposal to Engage in a } \\
\text { Renewable Energy Project and First } \\
\text { Public Meeting }\end{array}$ & Kingston Whig Standard \\
\hline $2011-07-25$ & Sol-Luce & $\begin{array}{l}\text { Notice of Proposal to Engage in a } \\
\text { Renewable Energy Project and First } \\
\text { Public Meeting }\end{array}$ & Mailed to identified landowners \\
\hline 2011-08-04 & Sol-Luce & $\begin{array}{l}\text { Notice of Proposal to Engage in a } \\
\text { Renewable Energy Project and First } \\
\text { Public Meeting }\end{array}$ & Kingston EMC \\
\hline 2011-08-17 & Westbrook & $\begin{array}{l}\text { Notice of Project Commencement } \\
\text { and First Public Meeting }\end{array}$ & Kingston Whig Standard \\
\hline 2011-08-17 & Westbrook & $\begin{array}{l}\text { Notice of Project Commencement } \\
\text { and First Public Meeting }\end{array}$ & Mailed to identified landowners \\
\hline 2011-08-30 & Sol-Luce & First Public Meeting & $\begin{array}{l}\text { Odessa Fairgrounds, } 231 \text { Main } \\
\text { Street, Odessa, ON }\end{array}$ \\
\hline $2011-08-31$ & Sol-Luce & First Public Meeting & $\begin{array}{l}\text { INVISTA Centre, } 1385 \\
\text { Gardiners Road, Kingston, ON }\end{array}$ \\
\hline 2011-09-07 & Hwy 2 South & Notice of Final Public Meeting & Mailed to identified landowners \\
\hline 2011-09-09 & Hwy 2 South & Notice of Final Public Meeting & Kingston Whig Standard \\
\hline 2011-09-09 & Odessa & Notice of Final Public Meeting & Kingston Whig Standard \\
\hline 2011-09-10 & Hwy 2 South & $\begin{array}{l}\text { Draft REA Reports available for } \\
\text { public review }\end{array}$ & Multiple \\
\hline 2011-09-10 & Odessa & $\begin{array}{l}\text { Draft REA Reports available for } \\
\text { public review }\end{array}$ & Multiple \\
\hline 2011-09-13 & $\begin{array}{l}\text { Amherst } \\
\text { Island }\end{array}$ & $\begin{array}{l}\text { Notice of Proposal to Engage in a } \\
\text { Renewable Energy Project }\end{array}$ & Mailed to distribution list \\
\hline 2011-09-15 & $\begin{array}{l}\text { Amherst } \\
\text { Island }\end{array}$ & $\begin{array}{l}\text { Notice of Proposal to Engage in a } \\
\text { Renewable Energy Project }\end{array}$ & Kingston Whig Standard \\
\hline
\end{tabular}




\begin{tabular}{|c|c|c|c|}
\hline Date & Project & Activity & Venue \\
\hline 2011-09-15 & $\begin{array}{l}\text { Amherst } \\
\text { Island }\end{array}$ & $\begin{array}{l}\text { Notice of Proposal to Engage in a } \\
\text { Renewable Energy Project }\end{array}$ & Napanee Guide \\
\hline 2011-09-15 & $\begin{array}{l}\text { Amherst } \\
\text { Island }\end{array}$ & $\begin{array}{l}\text { Notice of Proposal to Engage in a } \\
\text { Renewable Energy Project, Draft } \\
\text { Project Description Report }\end{array}$ & Website \\
\hline 2011-09-15 & Westbrook & $\begin{array}{l}\text { Notice of Project Commencement } \\
\text { and First Public Meeting }\end{array}$ & Kingston This Week \\
\hline 2011-09-18 & Odessa & Notice of Final Public Meeting & Mailed to identified landowners \\
\hline 2011-09-19 & Westbrook & First Public Meeting & $\begin{array}{l}\text { INVISTA Centre, } 1385 \\
\text { Gardiners Road, Kingston, ON }\end{array}$ \\
\hline 2011-09-22 & $\begin{array}{l}\text { Amherst } \\
\text { Island }\end{array}$ & $\begin{array}{l}\text { Notice of Proposal to Engage in a } \\
\text { Renewable Energy Project }\end{array}$ & Kingston Whig Standard \\
\hline 2011-09-22 & $\begin{array}{l}\text { Amherst } \\
\text { Island }\end{array}$ & $\begin{array}{l}\text { Notice of Proposal to Engage in a } \\
\text { Renewable Energy Project }\end{array}$ & Napanee Guide \\
\hline 2011-10-03 & Unity Road & Notice of Final Public Meeting & Mailed to identified landowners \\
\hline 2011-10-05 & Unity Road & Notice of Final Public Meeting & Kingston Whig Standard \\
\hline 2011-10-05 & Unity Road & $\begin{array}{l}\text { Draft REA Reports available for } \\
\text { public review }\end{array}$ & Multiple \\
\hline 2011-10-06 & Taylor Kidd & Notice of Final Public Meeting & Mailed to identified landowners \\
\hline 2011-10-08 & Hwy 2 South & Notice of Final Public Meeting & Kingston Whig Standard \\
\hline 2011-10-08 & Odessa & Notice of Final Public Meeting & Kingston Whig Standard \\
\hline 2011-10-08 & Taylor Kidd & Notice of Final Public Meeting & Kingston Whig Standard \\
\hline 2011-10-12 & Taylor Kidd & $\begin{array}{l}\text { Draft REA Reports available for } \\
\text { public review }\end{array}$ & Multiple \\
\hline 2011-11-01 & $\begin{array}{l}\text { Amherst } \\
\text { Island }\end{array}$ & Notice of First Public Meeting & Mailed to distribution list \\
\hline 2011-11-01 & $\begin{array}{l}\text { Amherst } \\
\text { Island }\end{array}$ & $\begin{array}{l}\text { Notice of Stage } 2 \text { Archaeological } \\
\text { Assessment Field Work }\end{array}$ & $\begin{array}{l}\text { Placed in Island Residents' } \\
\text { mailboxes }\end{array}$ \\
\hline 2011-11-03 & $\begin{array}{l}\text { Amherst } \\
\text { Island }\end{array}$ & Notice of First Public Meeting & Kingston Whig Standard \\
\hline 2011-11-03 & $\begin{array}{l}\text { Amherst } \\
\text { Island }\end{array}$ & Notice of First Public Meeting & Napanee Guide \\
\hline 2011-11-03 & $\begin{array}{l}\text { Amherst } \\
\text { Island }\end{array}$ & $\begin{array}{l}\text { Notice of First Public Meeting, } \\
\text { revised Draft Project Description } \\
\text { Report }\end{array}$ & Website \\
\hline 2011-11-07 & Unity Road & Notice of Final Public Meeting & Kingston Whig Standard \\
\hline 2011-11-08 & Taylor Kidd & Notice of Final Public Meeting & Kingston Whig Standard \\
\hline 2011-11-09 & Hwy 2 South & Final Public Meeting & $\begin{array}{l}\text { Odessa Fairgrounds, } 231 \text { Main } \\
\text { Street, Odessa, ON }\end{array}$ \\
\hline 2011-11-05 & $\begin{array}{l}\text { Amherst } \\
\text { Island }\end{array}$ & Notice of First Public Meeting & Kingston Whig Standard \\
\hline 2011-11-10 & Odessa & Final Public Meeting & $\begin{array}{l}\text { South Stormont Community } \\
\text { Hall, } 2 \text { Mille Roches Road }\end{array}$ \\
\hline 2011-11-30 & Hwy 2 South & Consultation Report Published & Website \\
\hline 2011-11-10 & $\begin{array}{l}\text { Amherst } \\
\text { Island }\end{array}$ & Notice of First Public Meeting & Napanee Guide \\
\hline
\end{tabular}




\begin{tabular}{|c|c|c|c|}
\hline Date & Project & Activity & Venue \\
\hline 2011-12-06 & $\begin{array}{l}\text { Amherst } \\
\text { Island }\end{array}$ & First Public Meeting & $\begin{array}{l}\text { Amherst Island Public School, } \\
5955 \text { Front Road, Stella, ON } \\
\text { (island) }\end{array}$ \\
\hline 2011-12-07 & Unity Road & Final Public Meeting & $\begin{array}{l}\text { Glenburnie United Church, } 1028 \\
\text { Unity Road, Glenburnie, ON }\end{array}$ \\
\hline 2011-12-13 & Taylor Kidd & Final Public Meeting & $\begin{array}{l}\text { Odessa Fairgrounds, } 231 \text { Main } \\
\text { Street, Odessa, ON }\end{array}$ \\
\hline $2011-12-20$ & Sol-Luce & Project Newsletter \#1 & Mailed to identified landowners \\
\hline 2012-01-05 & Ernestown & $\begin{array}{l}\text { Odessa and District Lions Club } \\
\text { January Monthly Meeting }\end{array}$ & \\
\hline 2012-01-20 & Ernestown & $\begin{array}{l}\text { Greater Kingston Chamber of } \\
\text { Commerce new members } \\
\text { introduction event }\end{array}$ & \\
\hline 2012-01-28 & Ernestown & $\begin{array}{l}\text { Odessa and District Lions Club } \\
\text { Pancake Breakfast }\end{array}$ & Odessa Fairgrounds \\
\hline $2012-01-28$ & Ernestown & Sustainable Kingston Forum & \\
\hline 2011-12-07 & $\begin{array}{l}\text { Amherst } \\
\text { Island }\end{array}$ & First Public Meeting & $\begin{array}{l}\text { St. John's Memorial Hall, } 216 \\
\text { Church Street (County Road 7), } \\
\text { Bath, ON (mainland) }\end{array}$ \\
\hline 2012-02-01 & Odessa & Consultation Report Published & Website \\
\hline 2012-02-01 & $\begin{array}{l}\text { Amherst } \\
\text { Island }\end{array}$ & Notice of Draft Site Plan & Mailed to distribution list \\
\hline 2012-02-02 & $\begin{array}{l}\text { Amherst } \\
\text { Island }\end{array}$ & Notice of Draft Site Plan & Kingston Whig Standard \\
\hline 2012-02-02 & $\begin{array}{l}\text { Amherst } \\
\text { Island }\end{array}$ & Notice of Draft Site Plan & Napanee Guide \\
\hline 2012-02-06 & Ernestown & $\begin{array}{l}\text { Helen Henderson Care Centre } \\
\text { presentation to residents }\end{array}$ & \\
\hline 2012-02-13 & Ernestown & $\begin{array}{l}\text { Helen Henderson Care Centre } \\
\text { presentation to residents }\end{array}$ & \\
\hline 2012-02-17 & Unity Road & Consultation Report Published & Website \\
\hline 2012-02-23 & Taylor Kidd & Consultation Report Published & Website \\
\hline $2012-02-25$ & Ernestown & $\begin{array}{l}\text { Greater Kingston Chamber of } \\
\text { Commerce Annual Member's Mixer }\end{array}$ & \\
\hline $2012-02-25$ & Ernestown & $\begin{array}{l}\text { Trade Roots, organized by St. } \\
\text { Lawrence College }\end{array}$ & \\
\hline 2012-03-01 & Westbrook & Notice of Final Public Meeting & Kingston This Week \\
\hline 2012-03-01 & Westbrook & Notice of Final Public Meeting & Mailed to identified landowners \\
\hline 2012-03-01 & Westbrook & $\begin{array}{l}\text { Draft REA Reports available for } \\
\text { public review }\end{array}$ & Multiple \\
\hline 2012-03-03 & Westbrook & Notice of Final Public Meeting & Kingston Whig Standard \\
\hline 2012-03-08 & Ernestown & Green Energy Symposium & \\
\hline 2012-03-18 & Ernestown & Green Profit Conference & \\
\hline $2012-03-28$ & Ernestown & $\begin{array}{l}\text { Napanee Chamber of Commerce } \\
\text { Monthly Networking Meeting }\end{array}$ & \\
\hline 2012-04-07 & Sol-Luce & $\begin{array}{l}\text { Invitation to Interim Community } \\
\text { Session }\end{array}$ & Kingston Whig Standard \\
\hline
\end{tabular}




\begin{tabular}{|c|c|c|c|}
\hline Date & Project & Activity & Venue \\
\hline 2012-04-12 & Sol-Luce & $\begin{array}{l}\text { Invitation to Interim Community } \\
\text { Session }\end{array}$ & Kingston EMC \\
\hline 2012-04-14 & Sol-Luce & $\begin{array}{l}\text { Invitation to Interim Community } \\
\text { Session }\end{array}$ & Kingston Whig Standard \\
\hline 2012-04-17 & Sol-Luce & Interim Community Session & $\begin{array}{l}\text { INVISTA Centre, } 1385 \\
\text { Gardiners Road, Kingston, ON }\end{array}$ \\
\hline 2012-04-19 & Westbrook & Notice of Final Public Meeting & Kingston This Week \\
\hline 2012-04-21 & Westbrook & Notice of Final Public Meeting & Kingston Whig Standard \\
\hline 2012-05-03 & Westbrook & Final Public Meeting & $\begin{array}{l}\text { INVISTA Centre, } 1385 \\
\text { Gardiners Road, Kingston, ON }\end{array}$ \\
\hline $2012-05-12$ & Ernestown & $\begin{array}{l}\text { United Way Success by } 6 \text { Wolfe } \\
\text { Island Wind Turbine Tour }\end{array}$ & \\
\hline $2012-05-17$ & Westbrook & Consultation Report Published & Website \\
\hline 2012-06-13 & Sol-Luce & Notice of Final Public Meeting & Kingston Whig Standard \\
\hline 2012-06-13 & Sol-Luce & Notice of Final Public Meeting & Kingston EMC \\
\hline 2012-06-13 & Sol-Luce & $\begin{array}{l}\text { Draft REA Reports available for } \\
\text { public review }\end{array}$ & Multiple \\
\hline 2012-06-14 & Sol-Luce & Notice of Final Public Meeting & Mailed to identified landowners \\
\hline 2012-06-15 & Sol-Luce & Project Newsletter \#2 & Mailed to identified landowners \\
\hline 2012-06-17 & Ernestown & $\begin{array}{l}\text { Odessa Antique and Collectible Car } \\
\text { Show }\end{array}$ & \\
\hline 2012-06-21 & Sol-Luce & Notice of Final Public Meeting & Kingston EMC \\
\hline 2012-06-18 & Ernestown & $\begin{array}{l}\text { Draft REA Reports available for } \\
\text { public review }\end{array}$ & Multiple \\
\hline 2012-06-30 & Ernestown & Bath 1812 Bicentennial Celebration & \\
\hline 2012-07-14 & Ernestown & Odessa Fair & \\
\hline 2012-07-17 & Ernestown & $\begin{array}{l}\text { Notice of Proposal and Public } \\
\text { Meeting }\end{array}$ & $\begin{array}{l}\text { Mailed to identified landowners } \\
\text { within } 550 \mathrm{~m}\end{array}$ \\
\hline 2012-07-18 & Ernestown & $\begin{array}{l}\text { Notice of Proposal and Public } \\
\text { Meeting }\end{array}$ & $\begin{array}{l}\text { Mailed to identified landowners } \\
\text { within } 3 \mathrm{~km}\end{array}$ \\
\hline 2012-07-18 & Ernestown & $\begin{array}{l}\text { Notice of Proposal and Public } \\
\text { Meeting }\end{array}$ & Kingston Whig Standard \\
\hline 2012-07-19 & Ernestown & $\begin{array}{l}\text { Notice of Proposal and Public } \\
\text { Meeting }\end{array}$ & Kingston Whig Standard \\
\hline 2012-07-19 & Ernestown & $\begin{array}{l}\text { Notice of Proposal and Public } \\
\text { Meeting }\end{array}$ & Napanee Beaver \\
\hline 2012-07-19 & Ernestown & $\begin{array}{l}\text { Notice of Proposal and Public } \\
\text { Meeting }\end{array}$ & Kingston This Week \\
\hline 2012-08-01 & Sol-Luce & Notice of Final Public Meeting & Kingston Whig Standard \\
\hline 2012-08-01 & Sol-Luce & Notice of Final Public Meeting & Kingston EMC \\
\hline $2012-08-15$ & Sol-Luce & Final Public Meeting & $\begin{array}{l}\text { INVISTA Centre, } 1385 \\
\text { Gardiners Road, Kingston, ON }\end{array}$ \\
\hline 2012-08-16 & Sol-Luce & Final Public Meeting & $\begin{array}{l}\text { Odessa Fairgrounds, } 231 \text { Main } \\
\text { Street, Odessa, ON }\end{array}$ \\
\hline 2012-02-02 & $\begin{array}{l}\text { Amherst } \\
\text { Island }\end{array}$ & $\begin{array}{l}\text { Notice of Draft Site Plan, Draft Site } \\
\text { Plan }\end{array}$ & Website \\
\hline 2012-04-01 & $\begin{array}{l}\text { Amherst } \\
\text { Island }\end{array}$ & $\begin{array}{l}\text { Notice of Stage } 2 \text { Archaeological } \\
\text { Assessment Field Work }\end{array}$ & $\begin{array}{l}\text { Placed in Island Residents' } \\
\text { mailboxes }\end{array}$ \\
\hline
\end{tabular}




\begin{tabular}{|c|c|c|c|}
\hline Date & Project & Activity & Venue \\
\hline $2012-08-22$ & $\begin{array}{l}\text { Amherst } \\
\text { Island }\end{array}$ & $\begin{array}{l}\text { Notice of Revised Draft Site Plan } \\
\text { and Revised Study Area }\end{array}$ & Mailed to distribution list \\
\hline 2012-08-23 & $\begin{array}{l}\text { Amherst } \\
\text { Island }\end{array}$ & $\begin{array}{l}\text { Notice of Revised Draft Site Plan } \\
\text { and Revised Study Area }\end{array}$ & Kingston Whig Standard \\
\hline 2012-07-19 & Ernestown & $\begin{array}{l}\text { Notice of Proposal and Public } \\
\text { Meeting }\end{array}$ & Kingston EMC \\
\hline $2012-08-23$ & Ernestown & Coffee and Pie Meetings & Jiffy Grill (Odessa) \\
\hline 2012-09-01 & Sol-Luce & Consultation Report Published & Website \\
\hline $2012-08-24$ & Ernestown & Coffee and Pie Meetings & Coffee Time Plus (Amherstview) \\
\hline 2012-09-11 & Ernestown & Third Public Meeting & Amherstview Community Hall \\
\hline 2012-09-18 & Ernestown & Final Public Meeting & $\begin{array}{l}\text { Odessa Fairgrounds, } 231 \text { Main } \\
\text { Street, Odessa, ON }\end{array}$ \\
\hline 2012-08-23 & $\begin{array}{l}\text { Amherst } \\
\text { Island }\end{array}$ & $\begin{array}{l}\text { Notice of Revised Draft Site Plan } \\
\text { and Revised Study Area }\end{array}$ & Napanee Guide \\
\hline $2012-08-23$ & $\begin{array}{l}\text { Amherst } \\
\text { Island }\end{array}$ & $\begin{array}{l}\text { Notice of Revised Draft Site Plan } \\
\text { and Revised Study Area, Revised } \\
\text { Draft Site Plan, Revised Draft } \\
\text { Project Description Report }\end{array}$ & Website \\
\hline $2012-12-21$ & $\begin{array}{l}\text { Amherst } \\
\text { Island }\end{array}$ & Notice of Final Public Meeting & Mailed to distribution list \\
\hline $2012-12-26$ & $\begin{array}{l}\text { Amherst } \\
\text { Island }\end{array}$ & Notice of Final Public Meeting & Website \\
\hline $2012-12-27$ & $\begin{array}{l}\text { Amherst } \\
\text { Island }\end{array}$ & Notice of Final Public Meeting & Kingston Whig Standard \\
\hline $2012-12-27$ & $\begin{array}{l}\text { Amherst } \\
\text { Island }\end{array}$ & $\begin{array}{l}\text { Draft REA Reports available for } \\
\text { public review }\end{array}$ & Multiple \\
\hline 2013-01-03 & $\begin{array}{l}\text { Amherst } \\
\text { Island }\end{array}$ & Notice of Final Public Meeting & Kingston Whig Standard \\
\hline 2013-01-10 & $\begin{array}{l}\text { Amherst } \\
\text { Island }\end{array}$ & Notice of Final Public Meeting & Kingston Whig Standard \\
\hline 2013-01-10 & $\begin{array}{l}\text { Amherst } \\
\text { Island }\end{array}$ & Notice of Final Public Meeting & Napanee Guide \\
\hline 2013-01-17 & $\begin{array}{l}\text { Amherst } \\
\text { Island }\end{array}$ & Notice of Final Public Meeting & Napanee Guide \\
\hline 2013-01-29 & $\begin{array}{l}\text { Amherst } \\
\text { Island }\end{array}$ & $\begin{array}{l}\text { Municipal Community Town Hall } \\
\text { Meeting }\end{array}$ & Loyalist Township \\
\hline 2013-03-05 & $\begin{array}{l}\text { Amherst } \\
\text { Island }\end{array}$ & Final Public Meeting & $\begin{array}{l}\text { Amherst Island Public School, } \\
5955 \text { Front Road, Stella, ON } \\
\text { (island) }\end{array}$ \\
\hline 2012-10-01 & Ernestown & Consultation Report Published & Website \\
\hline 2013-03-06 & $\begin{array}{l}\text { Amherst } \\
\text { Island }\end{array}$ & Final Public Meeting & $\begin{array}{l}\text { St. John's Memorial Hall, } 216 \\
\text { Church Street (County Road 7), } \\
\text { Bath, ON (mainland) }\end{array}$ \\
\hline 2013-04-01 & $\begin{array}{l}\text { Amherst } \\
\text { Island }\end{array}$ & Consultation Report Published & Website \\
\hline
\end{tabular}




\section{B. Interview Questions}

Each interview consists of approximately 15 questions, divided into three sections. The full list of sample questions is provided below; the number of questions as well as the questions themselves are tailored for each interviewee.

The first section seeks to understand the interviewee's background in renewable energy in the Kingston area. This section consists of four questions:

- Could you please tell me / us a little about the work that you and your team do? What brought you (your company) to work on renewable energy projects?

- What is your (team's) experience with renewable energy projects?

- What is your (team's) experience with renewable energy development and operation in Kingston?

- What is your (team's) experience with the public engagement process associated with renewable energy projects?

The second section asks about the various renewable energy stakeholders in the Kingston area, and the interviewee's knowledge of and relationships with them. In addition, it explores their understanding of and thoughts regarding current public engagement practices. This section consists of the following questions:

- Who do you consider an important stakeholder when it comes to renewable energy development and operations in Kingston? Why are they important? 
- How would you characterize your relationships with the various stakeholders? How do they differ between stakeholders?

- Having identified your stakeholders, how would you plan and execute an engagement strategy? What would be your role in an engagement strategy?

- What engagement methods do you use? In your experience have some been preferable over others, and if so, why?

- How extensive would you say your engagement is? Is it enough / too much / too little? If you wish you could do more, what are some constraints that you face?

- Why do you engage the public (or why do you think public engagement is important)?

- What is the desired outcome from engagement? How close have you gotten to achieving your desired outcome?

- Have you had particular instances where engagement went really well or really poorly? What contributed to that?

- Do you think the engagement process can be improved, and if so, how?

The final section gives the interviewee an opportunity to reflect on their earlier responses, and consists of the following two questions:

- What do you think are some of the biggest advantages and disadvantages of renewable energy?

- Is there anything else you would like to add? 


\section{List of potential interviewees}

The following is a list of all the stakeholders who were contacted to request an interview, identified by role and affiliation. Names are not provided to protect their privacy.

- Project Manager, SolarShare

- Engineering consultant and former professor, Energy Systems Engineering Technician program, St. Lawrence College

- Community Investment and Marketing Manager, SolarShare

- Technical Consultant for renewable energy cooperatives

- Associate Dean and Director of the School of Policy Studies, Queen's University

- Former postdoctoral fellow, Institute for Energy and Environmental Policy, Queen's University

- Deputy General Manager, Samsung Renewable Energy Inc.

- Former Manager, Communications, Government, and Public Relations, Samsung Renewable Energy Inc.

- Site Manager, Amherst Island Wind Project, Windlectric Inc.

- Communications and Community Relations Manager, Ernestown Windpark

- Great Circle Solar Management Corporation

- Former Director of Planning and Development, City of Kingston

- Mayor, City of Kingston

- Former Director of Planning and Development Services, Loyalist Township

- Member of Provincial Parliament, Kingston and the Islands 
- Member of Parliament, Kingston and the Islands

- Former Member of Parliament, Kingston and the Islands

- Member of Provincial Parliament, Lanark-Frontenac-Kingston

- Member of Parliament, Lanark-Frontenac-Kingston

- Member of Parliament, Hastings - Lennox and Addington

- Chairman and President, Director of Education and Research, SWITCH

- Vice Chairman, Director of Education and Research, SWITCH

- Treasurer, Director of Government and Utilities, SWITCH

- Director of Government and Utilities, SWITCH

- Director of Government and Utilities, SWITCH

- Director of Private Businesses and Residents, SWITCH

- Director of Private Businesses and Residents, SWITCH

- Owner and Operator, Quantum Renewable Energy

- Owner and Operator, Downunder Solar 